DOE/RL-93-35

Revision 0

UC-630

\title{
Feasibility Study Report for the 200-BP-1 Operable Unit
}

\author{
Date Published \\ June 1993
}

\section{DISCLAIMER}

This report was prepared as an account of work sponsored by an agency of the United States Government. Neither the United States Government nor any agency thereof, nor any of their employees, makes any warranty, express or implied, or assumes any legal liability or responsibility for the accuracy, completeness, or usefulness of any information, apparatus, product, or process disclosed, or represents that its use would not infringe privately owned rights. Reference herein to any specific commercial product, process, or service by trade name, trademark, manufacturer, or otherwise does not necessarily constitute or imply its endorsement, recommendation, or favoring by the United States Government or any agency thereof. The views and opinions of authors expressed herein do not necessarily state or reflect those of the United States Government or any agency thereof.

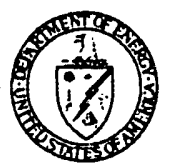

United States

Department of Energy

P. Box 550

Richland, Washington 99352

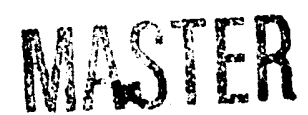

DISTRIBUTION OF THIS DOCUMENT IS UNLIMITED

Approved for Public Release

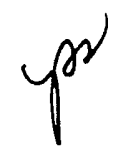




\section{EXECUTIVE SUMMARY}

This feasibility study (FS) examines a range of alternatives and provides recommendations for selecting a preferred alternative for remediating contamination at the 200-BP-1 operable unit. The 200-BP-1 operable unit is located in the center of the Hanford Site along the northern boundary of the 200 East Area. The 241-BY Tank Farm is located immediately to the south of the operable unit.

200-BP-1 is a source operable unit with contaminated soils associated primarily with nine inactive cribs (known as the 216-B cribs). These cribs were used for disposal of lowlevel radioactive liquid waste from $U$ Plant uranium recovery operations, and waste storage tank condensate from the adjacent 241-BY Tank Farm. The cribs used for disposal of U Plant waste were in operation from 1955-1965, and the cribs used for disposal of tank condensate were in operation from 1965-1975. In addition to the cribs, four unplanned releases of radioactive materials have occurred within the operable unit. Contaminated surface soils associated with the unplanned releases have been consolidated over the cribs and covered with clean soil to reduce contaminant migration and exposure.

Discharge of wastes to the cribs has resulted in soil and groundwater contamination. The groundwater is being addressed as part of the 200 East Aggregate Area groundwater operable unit. Contaminated soils at the site can be categorized by the types of contaminants, their distribution in the soil column, and the risk posed by the various potential exposure pathways. Below the clean soil cover, the near surface soils contain low-levels of contamination with cesium-137, radium-226, strontium-90, thorium-22, and uranium. The lifetime incremental cancer risk associated with these soils if they were exposed at the surface is $9 \times 10^{-5}$.

The majority of the high activity contaminated soils are located between about 5-15 $\mathrm{m}$ (15-50 ft) below ground surface. The most significant contaminants in this zone include strontium-90, cesium-137, plutonium-238 and $239+240$, and uranium. Most of the radioactivity is attributable to strontium-90 and cesium-137. These radionuclides have relatively short half-lives (29-30 yr, respectively) and are highly immobile in the soils. These soils, if exposed at the ground surface through human or biotic intrusion pose unacceptable risk ( $>10^{-2}$ lifetime incremental cancer risk). However, due to the relatively short half-lives and immobility of strontium-90 and cesium-137, they do not pose a risk to groundwater. The plutonium isotopes are highly immobile, however plutonium $239+240$ are extremely long lived (half-life $>10,000 \mathrm{yr}$ ). Uranium is relatively mobile and extremely long-lived (half-life in excess of 100 million yr) and poses the most significant future risk for ground water contamination from the operable unit.

Contaminants of concern present in soils below $15 \mathrm{~m}(50 \mathrm{ft})$ include nitrate, cobalt60 , technetium-99 and total uranium. Nitrate, cobalt-60 and technetium-99 are highly mobile and reached groundwater very soon after being discharged to the cribs. The peak groundwater concentrations associated with these contaminants are located more than a mile downgradient of the operable unit. Concentrations currently entering groundwater from the soils at 200-BP-1 are declining and only nitrate is in excess of drinking water standards. Concentrations of cobalt -60 and technetium- 99 entering groundwater from the 
contaminated soils are below both current and proposed drinking water standards, however they exceed Washington State Model Tosics Control Act (MTCA) Cleanup Regulations Method B standards.

The nrimary contaminant of concern below $15 \mathrm{~m}(50 \mathrm{ft})$ is uranium. Due to it's relatively high mobility, uranium has migrated to extensive depths in the soil column beneath the cribs and is likely impacting groundwater at low concentrations. Vadose zone modeling indicates that, if no action is taken to remediate the operable unit, uranium will reach the groundwater at concentrations that exceed the proposed drinking water standard $(30 \mathrm{pCi} / \mathrm{L})$ in about 700 years.

Remedial action objectives have been developed based on the location of the 200-BP1 operable unit, and the risk posed by site contaminants through the relevant exposure pathways. These remedial action objectives are as follows:

- Limit human receptor exposure to near surface and subsurface high-activity soils to maintain a risk in the range of $10^{-4}$ to $10^{-6}$.

- Limit biotic intrusion into high-activity contaminated soils that could result in exposing contaminants at the surface.

- Limit future impacts to groundwater by taking measures which minimize infiltration and downward migration of contaminants (primarily uranium), such that ARARs are not exceeded.

- Consider the proximity and potential remedial actions at the adjacent 241-BY Tank Farm in evaluation of alternatives and remedy selection for 200-BP-1.

Based on these remedial action objectives, a range of potential remedial technologies were evaluated and combined to form 10 alternatives for detailed analysis. The range of alternatives includes: No Action with monitoring; Institutional Controls; three barrier alternatives; four alternatives that involve excavation of the high-activity soils with and without treatment; and one in-situ treatment alternative.

A detailed analysis of these alternatives was conducted for compliance with the seven evaluation criteria required by Comprehensive Environmental Response, Compensation and Liability Act (CERCLA) and the National Oil and Hazardous Substances Contingency Plan (NCP). The most significant aspects of the evaluation criteria in terms of remedy selection include the following:

- Long-term effectiveness -- how effective and reliable the alternative is at meeting remedial action objectives to limit residual risk of surface exposure to high activity soils, and in limiting future groundwater contamination due to uranium; 
- Short-term effectiveness -- the potential for radiation exposure of workers involved in remedial activities for alternatives that require excavation and treatment or drilling into the contaminated soils;

- Implementability -- the need for development of specialized equipment for robotics, remote handling, shielding, and contaminant control facilities associated with the excavation and treatment alternatives; and

- Cost -- Estimated costs for the alternatives cover a very wide range (\$1.1 million - $\$ 268$ million). The barrier alternatives would all cost less than $\$ 10$ million, while the next least expensive alternative (in-situ fixation) would costs $\$ 54$ million and the least expensive alternative that includes excavation would cost $\$ 81$ million.

A comparative analysis was conducted to evaluate the ability of the alternatives to meet the criteria. The comparative analysis was conducted by first determining relative scores for each of the alternatives against the individual criteria. The relative scores were then normalized on a 0 to 10 preference scale, with 10 being the most preferred. The criteria were then weighted in terms of importance. Finally, composite scores were calculated by multiplying the criteria weight by the alternative score and summing for all criteria.

A multi-attribute decision analysis computer program was used to assist in conducting the comparative analysis. This program allows for rapid interactive input and analysis, provides sensitivity analysis of the criteria weights to the results, and provides graphical display of the output for presentation of the results.

The results of the comparative analysis indicate that the low-permeability barriers (with Institutional Controls and components that prevent biointrusion) score the highest. The Hanford Barrier scored highest, just slightly higher than the modified RCRA Barrier. Following these two barriers, the next highest scoring alternative is Institutional Controls. The remaining alternatives all score significantly lower. The sensitivity analysis indicates that the Hanford Barrier scores highest across a wide range of criteria weights.

Both the Hanford and RCRA Barriers meet remedial action objectives by providing protection from intrusion and exposure to the near-surface, high-activity soils and by limiting infiltration and migration of uranium. Vadose zone modeling indicates that, with infiltration rates of $0.01 \mathrm{~cm}$ assumed through the barriers, uranium will not reach groundwater in excess of proposed drinking water standards for more than $10,000 \mathrm{yr}$.

This is the first complete FS for contaminated soils associated with use of cribs for disposal of radioactive wastes in the 200 Area of the Hanford Site and provides information that can be used to accelerate remedy selection elsewhere. There are numerous similar contaminated sites in the 200 Area. In accordance with the Hanford Site past practice strategy, the results of the RI and FS at the 200-BP-1 operable unit can be used to identify analogous facilities which pose similar risks for installation of barriers. Sites such as cribs and trenches elsewhere in the 200 Area that received similar wastes, but 
received similar wastes, but that are not located adjacent to facilities such as 241-BY Tank Farms, should be evaluated to determine if they are suitable for accelerated Records of Decision (RODs) for installation of barriers.

While a low-permeability barrier is recommended as the ultimate remedy for the 200-BP-1 operable unit, installation of the barrier should be delayed until the remedial action for the adjacent 241-BY Tank Farm is selected. When a remedy is selected for the 241-BY Tank Farm, installation of the barrier at 200-BP-1 should be coordinated with those activities. Delay of the barrier installation does not pose any unnecessary risk to human health or the environment and will ensure cost-effectiveness and consistency with overall remedial measures for this portion of the Hanford Site. Therefore, the recommended alternative for the 200-BP-1 operable unit is to maintain institutional controls and monitoring, followed by installation of a low-permeability barrier closely coordinated with 241-BY Tank Farm remediation. 


\section{LIST OF ACRONYMS}

\begin{tabular}{|c|c|}
\hline ALARA & as low as reasonably achievable \\
\hline AMSL & above mean sea level \\
\hline ARAR & applicable or relevant and appropriate requirement \\
\hline CERCLA & $\begin{array}{l}\text { Comprehensive Environmental Response, Compensation and } \\
\text { Liability Act of } 1980\end{array}$ \\
\hline CFR & Code of Federal Regulations \\
\hline CWA & $\begin{array}{l}\text { Clean Water Act } \\
\text { derived concentration guide }\end{array}$ \\
\hline DCG & $\begin{array}{l}\text { derived concentration guide } \\
\text { U. S. Department of Health, Education and Welfare }\end{array}$ \\
\hline DHEW & U. S. Department of Health, Education and Welfare \\
\hline DNR & Washington State Department of Natural Resources \\
\hline DOE & U.S. Department of Energy \\
\hline Ecology & Washington State Department of Ecology \\
\hline EDMC & Environmental Data Management Center \\
\hline EPA & U.S. Environmental Protection Agency \\
\hline ERA & expedited response action \\
\hline ERDA & United States Energy Research and Development Administration \\
\hline ERSDF & Environmental Restoration Storage and Disposal Facility \\
\hline FDM & Fugitive Dust Model \\
\hline FS & feasibility study \\
\hline GRA & general response actions \\
\hline HFSUWG & Hanford Future Site Uses Working Group \\
\hline $\mathrm{HI}$ & Hazard Index \\
\hline HMS & Hanford Meteorological Station \\
\hline HPDE & high-density polyethylene \\
\hline $\mathrm{HQ}$ & hazard quotient \\
\hline HSBRAM & Hanford Site Baseline Risk Assessment Methodology \\
\hline IAREC & $\begin{array}{l}\text { Washington State University Irrigated Agriculture Research and Extension } \\
\text { Center }\end{array}$ \\
\hline ISV & in-situ vitrification \\
\hline LICR & lifetime incremental cancer risk \\
\hline MCL & maximum contaminant level \\
\hline MCLG & maximum contaminant level goals \\
\hline MTCA & Model Toxics Control Act \\
\hline MTR & minimum technology requirements \\
\hline $\mathrm{NCP}$ & National Oil and Hazardous Substances Contingency Plan \\
\hline NEPA & National Environmental Policy Act \\
\hline NPL & National Priorities List \\
\hline NRC & Nuclear Regulatory Commission \\
\hline NRDA & Natural Resource Damage Assessment \\
\hline PQL & practical quantification limits \\
\hline QC & Quality Control \\
\hline RAGS & Risk Assessment Guidance for Superfund \\
\hline RAO & remedial action objective \\
\hline RCRA & Resource Conservation and Recovery Act \\
\hline RCW & Revised Code of Washington (State) \\
\hline $\mathrm{RfD}$ & reference dose \\
\hline RI & remedial investigation \\
\hline RL & Richland Field Office \\
\hline ROD & Record of Decision \\
\hline
\end{tabular}


DOE/RL-93-35, Rev. 0

\section{LIST OF ACRONYMS (Cont.)}

$\begin{array}{ll}\text { SAR } & \text { Safety Analysis Report } \\ \text { SDWA } & \text { Safe Drinking Water Act } \\ \text { SMCL } & \begin{array}{l}\text { secondary max } \\ \text { to be considered }\end{array} \\ \text { TBC } & \text { transuranic waste } \\ \text { TRU } & \text { United States Fish and Wildlife Service } \\ \text { USFWS } & \text { United States Geological Survey } \\ \text { USGS } & \text { United States Weather Bureau } \\ \text { USWB } & \text { ultra violet } \\ \text { UV } & \text { volatile organic compound } \\ \text { VOC } & \text { Washington Administrative Code } \\ \text { WAC } & \text { Washington Department of Wildlife } \\ \text { WDOW } & \text { Westinghouse Hanford Company } \\ \text { WHC } & \text { Wemp } \\ \text { WIPP } & \text { Waste Isolation Pilot Plant }\end{array}$




\section{CONTENTS}

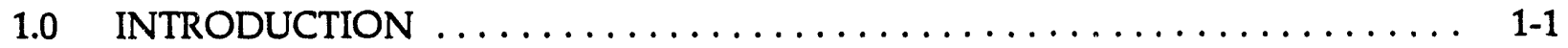

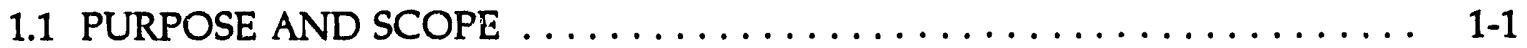

1.2 OVERVIEW OF THE FEASIBILITY STUDY PROCESS $\ldots \ldots \ldots \ldots \ldots \ldots \ldots 1-2$

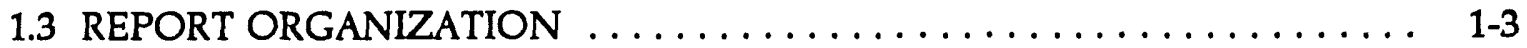

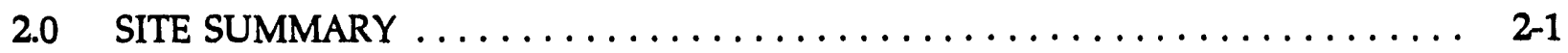

2.1 OPERABLE UNIT DESCRIPTION $\ldots \ldots \ldots \ldots \ldots \ldots \ldots \ldots \ldots \ldots \ldots \ldots$ 2-1

2.1 .1 Location ............................ 2-1

2.1.2 Identification and History of Waste Units $\ldots \ldots \ldots \ldots \ldots \ldots \ldots . \ldots .2-2$

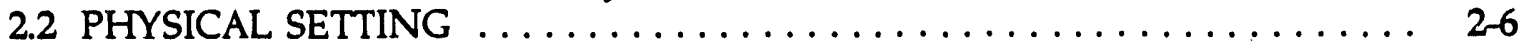

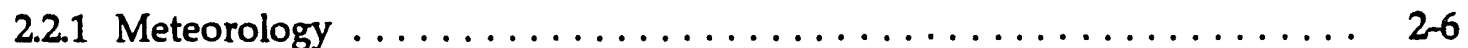

2.2.2 Surface Water Hydrology . . . . . . . . . . . . . . . 2-9

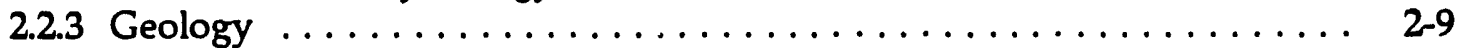

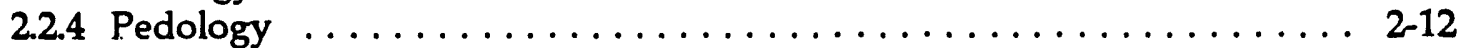

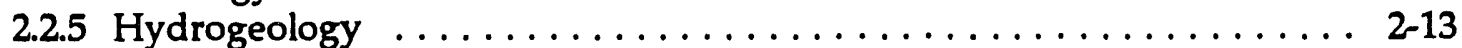

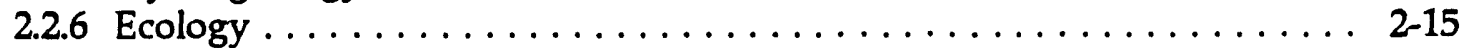

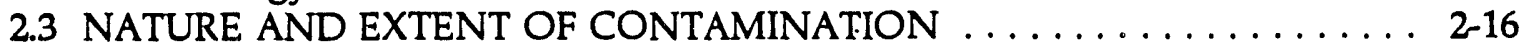

2.4 CONTAMINANT FATE AND TRANSPORT $\ldots \ldots \ldots \ldots \ldots \ldots \ldots \ldots . \ldots \ldots$

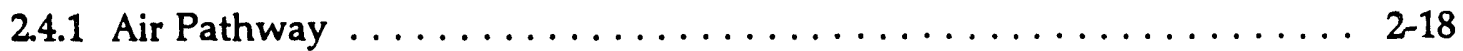

2.4.2 Surface Water Pathway ..................... 2-19

2.4.3 Subsurface Water Pathways . . . . . . . . . . . . . . . 2-20

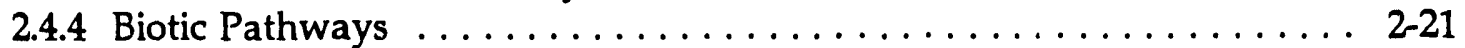

2.5 SUMMARY OF BASELINE RISK ASSESSMENT $\ldots \ldots \ldots \ldots \ldots \ldots \ldots \ldots$

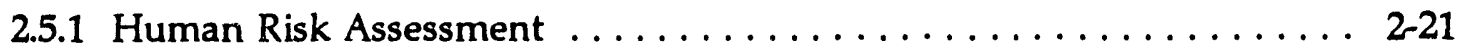

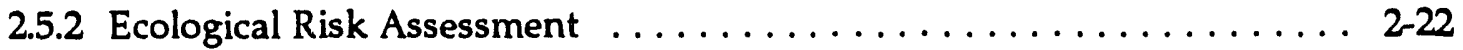

3.0 REMEDIAL ACTION OBJECTIVES AND GENERAL RESPONSE ACTIONS .... 3-1

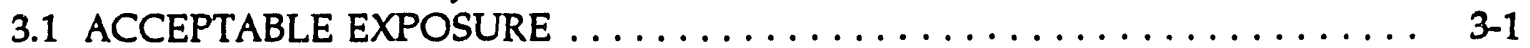

3.1.1 Potential Applicable or Relevant and Appropriate

Requirements ........................ 3-1

3.1.2 Acceptable Risk-Based Exposure Concentrations . . . . . . . . . . . 3-9

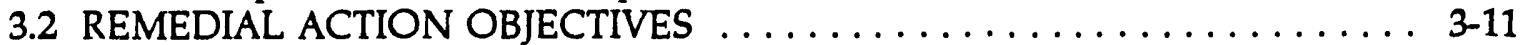

3.3 GENERAL RESPONSE ACTIONS $\ldots \ldots \ldots \ldots \ldots \ldots \ldots \ldots \ldots \ldots \ldots$ 3-14

3.4 AREAS AND VOLUME OF CONTAMINANTS $\ldots \ldots \ldots \ldots \ldots \ldots \ldots \ldots$ 3-16

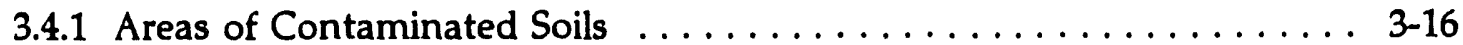

3.4.2 Volumes of Contaminated Soils . . . . . . . . . . . . . 3-17

4.0 IDENTIFICATION AND SCREENING OF REMEDIAL
TECHNOLOGIES AND PROCESS OPTIONS $\ldots \ldots \ldots \ldots \ldots \ldots \ldots \ldots \ldots \ldots \ldots, \ldots, 1$

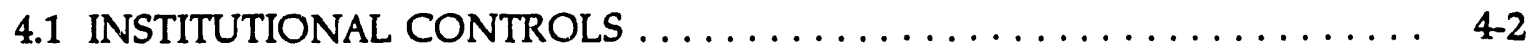

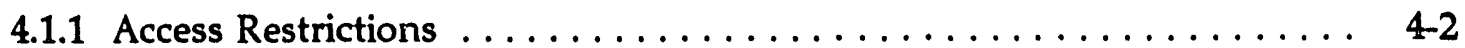

4.1.2 Warning Markers ......................... 4-3

4.1.3 Land Use Restrictions $\ldots \ldots \ldots \ldots \ldots \ldots \ldots \ldots \ldots \ldots$ 4-3

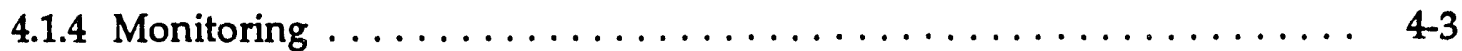

4.2 REMOVAL (EXCAVATION) $\ldots \ldots \ldots \ldots \ldots \ldots \ldots \ldots \ldots \ldots \ldots \ldots$

4.3 IN-SITU CONTAINMENT $\ldots \ldots \ldots \ldots \ldots \ldots \ldots \ldots \ldots \ldots \ldots \ldots \ldots \ldots \ldots$

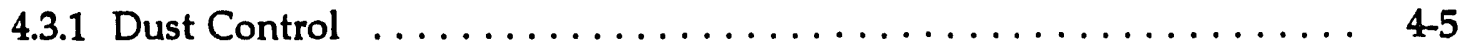

4.3.2 Surface Water Management ................... 4-5 
4.3.4 Vertical Barriers ......................... 4-10

4.3.5 Horizontal Subsurface Barriers . . . . . . . . . . . . . . . 4-11

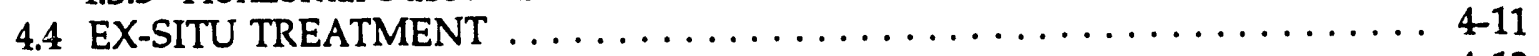

4.4.1 Dry Soil Sieving $\ldots \ldots \ldots \ldots \ldots \ldots \ldots \ldots \ldots \ldots \ldots \ldots \ldots$ 4-12

4.4.2 Physical Soil Washing (Aqueous Physical

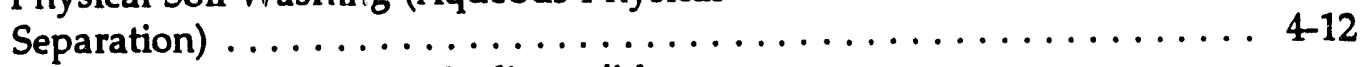

4.4.3 Chemical Soil Washing (Radionuclide

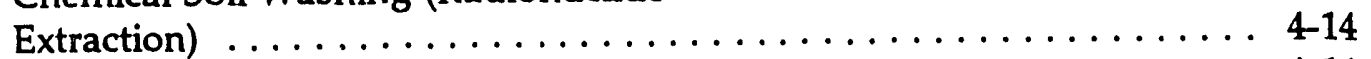

4.4.4 Fixation (Chemical Stabilization) $\ldots \ldots \ldots \ldots \ldots \ldots \ldots \ldots \ldots \ldots$ 4-14

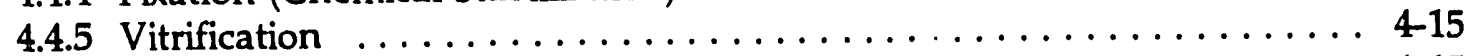

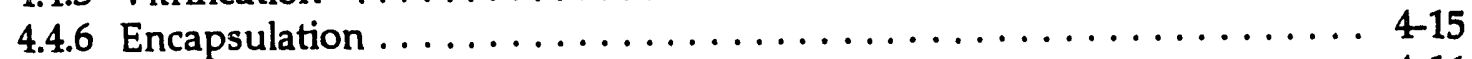

4.4.7 Biological Treatment . . . . . . . . . . . . . . . . . . . 4-16

4.4.8 Thermal Treatment . . . . . . . . . . . . . . . . . . . . 4-16

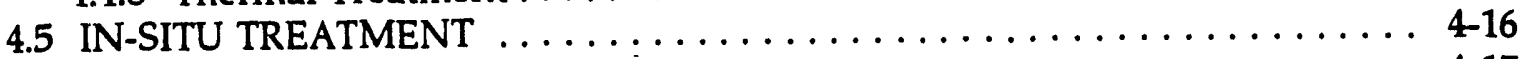

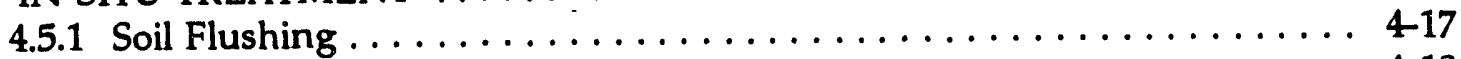

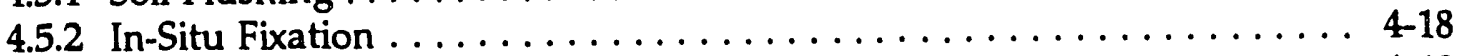

4.5 .3 In-Situ Vitrification $\ldots \ldots \ldots \ldots \ldots \ldots \ldots \ldots \ldots \ldots \ldots \ldots \ldots \ldots$

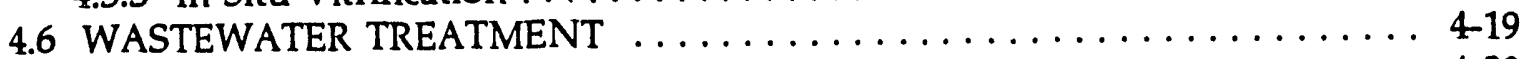

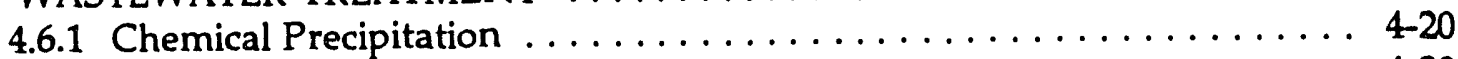

4.6 .2 Ion Exchange ........................... 4-20

4.6 .3 Reverse Osmosis ........................... 4 20

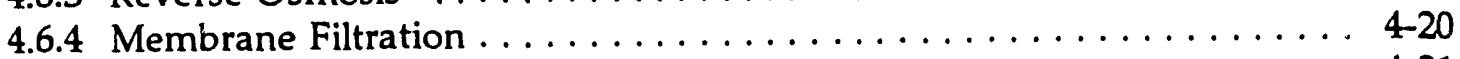

4.6 .5 Gravity Separation ........................ 4-21

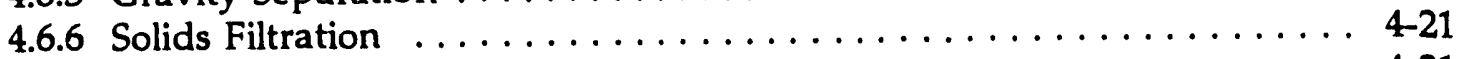

4.6 .7 Dewatering ............................ 4-21

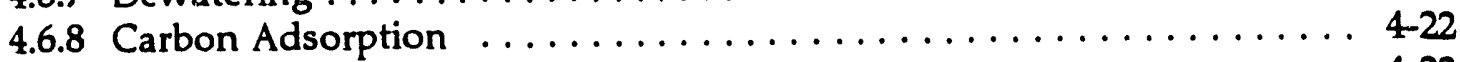

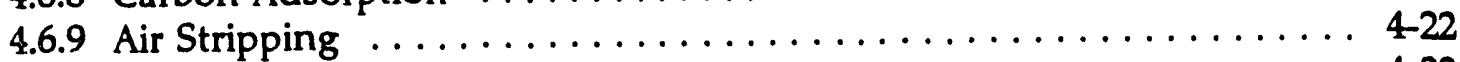

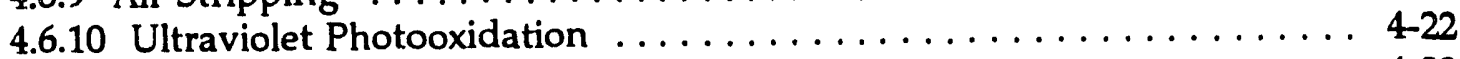

4.6.11 Biological Treatment . . . . . . . . . . . . . . . . . . . 4-22

4.7 DISPOSAL ............................. 4-22

4.7.1 Engineered Landfill within Hanford Site (Environmental
Restoration Storage \& Disposal Facility [ERSDF]) . . . . . . . . . 4-23

4.7.2 Engineered Landfill at the $200-\mathrm{BP}-1$ Operable
Unit Site $\ldots \ldots \ldots \ldots \ldots \ldots \ldots \ldots \ldots \ldots \ldots \ldots \ldots \ldots \ldots \ldots \ldots \ldots \ldots \ldots \ldots$
4.23

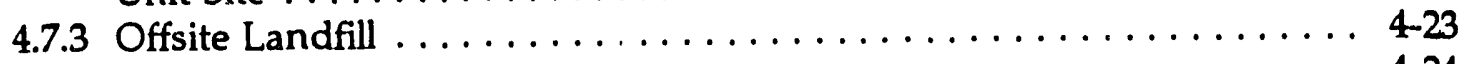

4.7.4 Geologic Repository . . . . . . . . . . . . . . . . . . 4-24

4.8 SUMMARY OF TECHNOLOGY SCREENING ... . . . . . . . . . 4-24

5.0 ASSEMBLY AND SCREENING OF REMEDIATION ALTERNATIVES . . . . . . 5-1

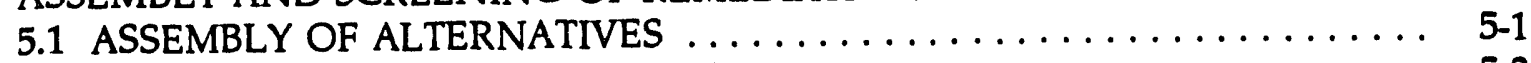

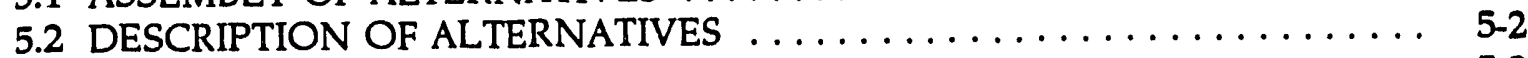

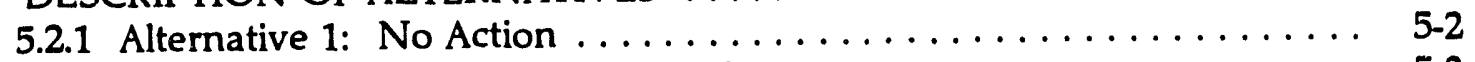

5.2.2 Alternative 2: Institutional Controls $\ldots \ldots \ldots \ldots \ldots \ldots \ldots \ldots \ldots \ldots$ 5-3

5.2.3 Alternative 3: Biointrusion Barrier ................. $5-4$

5.2.4 Alternative 4: Modified RCRA Barrier . . . . . . . . . . . . . $5-5$ 
5.2.5 Alternative 5: Hanford Barrier . . . . . . . . . . . . . . .

5.2.6 Alternative 6: Excavation and Soil Washing of Most Contaminated Soil with a RCRA Barrier . . . . . . . . . . . . . . . . . .

5.2.7 Alternative 7: Excavation and Soil Washing of All Contaminated Soil ...................................

5.2.8 Alternative 8: Excavation and Soil Washing of Most Contaminated Soil with Vitrification and a RCRA Barrier .................

5.2.9 Alternative 9: Excavation and Fixation of Most Contaminated Soil ...

5.2.10 Alternative 10: Excavation and Fixation of Most Contaminated

Soil with a RCRA Barrier . . . . . . . . . . . . . . . . . . . 5-11

5.2.11 Alternative 11: Excavation and Fixation of All Contaminated Soil ... . 5-11

5.2.12 Alternative 12: Excavation and Vitrification of Most Contaminated

Soil ............................... 5-12

5.2.13 Alternative 13: Excavation and Vitrification of Most Contaminated

Soil with a RCRA Barrier . . . . . . . . . . . . . . . . . . 5-13

5.2.14 Alternative 14: Excavation and Vitrification of All Contaminated

Soil ................................. 5-13

5.2.15 Alternative 15: Excavation and Disposal of Most Contaminated

Soil with a RCRA Barrier . . . . . . . . . . . . . . . . . . . 5-14

5.2.16 Alternative 16: Excavation and Disposal of All Contaminated Soil ... 5-15

5.2.17 Alternative 17: In-situ Fixation of Most Contaminated Soil . . . . . . . 5-15

5.2.18 Alternative 18: In-situ Fixation of Most Contaminated Soil with a RCRA Barrier ....................... 5-16

5.2.19 Alternative 19: In-situ Fixation of All Contaminated Soil . . . . . . . 5 5-16

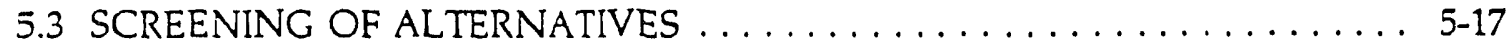

5.3 .1 No Action and Institutional Controls . . . . . . . . . . . . 5-18

5.3.2 Barrier Alternatives . . . . . . . . . . . . . . . . . . . 5-18

5.3.3 Alternatives Requiring Excavation .................... 5-18

5.3.4 Effectiveness Evaluation With and Without Barriers ........... 5- 5-19

5.3 .5 Cost-Effectiveness Evaluation .................... 5-19

5.4 SUMMARY OF RETAINED ALTERNATIVES $\ldots \ldots \ldots \ldots \ldots \ldots \ldots \ldots .5-20$

6.0 DEVELOPMENT AND EVALUATION OF REMEDIATION ALTERNATIVES . . $6-1$

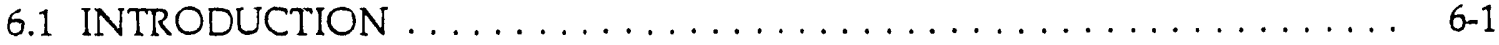

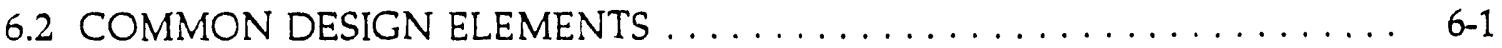

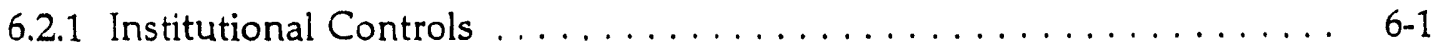

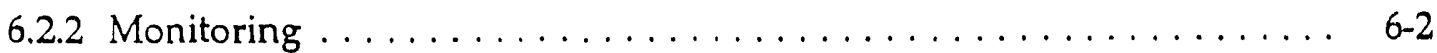

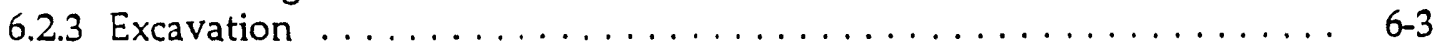

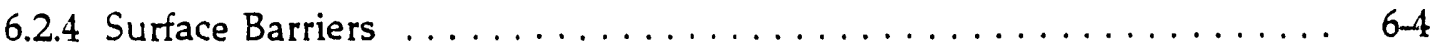

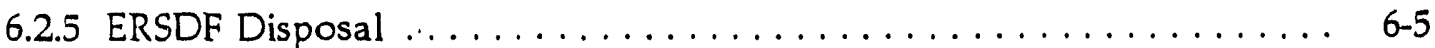

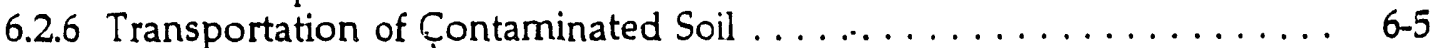

6.2.7 Surface Water Management ........................ . 6-6

6.2 .8 Wastewater Treatment ....................... 6-6

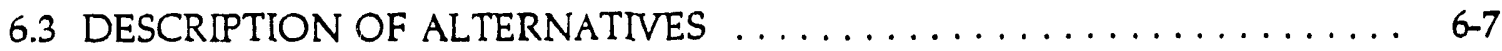

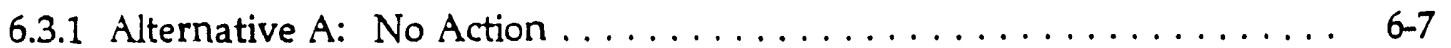

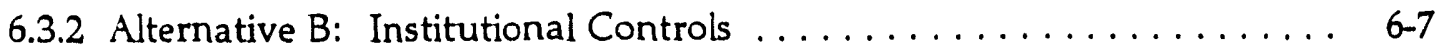

6.3 .3 Alternative $C$ : Biointrusion Barrier . . . . . . . . . . . . . . . 6-7

6.3.4 Alternative D: RCRA Barrier .................... 6.8

6.3 .5 Alternative $E$ : Hanford Barrier . . . . . . . . . . . . . 6-9 


\section{CONTENTS (Cont)}

6.3.6 Alternative F: Soil Washing ..................... 6-10

6.3.7 Alternative G: Excavation and Soil Washing with Vitrification . . . . . . 6-12

6.3.8 Alternative $\mathrm{H}$ : Excavation and Fixation ............... 6-13

6.3.9 Alternative I: Excavation and ERSDF Disposal . . . . . . . . . . . 6-14

6.3.10 Alternative J: In-Situ Fixation . . . . . . . . . . . . . . 6-15

6.4 EVALUATION OF REMEDIATION ALIERNATIVES ........... 6-16

6.4.1 Common Evaluation Elements .................... 6-17

6.4.2 Detailed Evaluation of Alternatives ................. 6-27

7.0 COMPARATIVE EVALUATION OF ALTERNATIVES $\ldots \ldots \ldots \ldots \ldots \ldots \ldots .7-1$

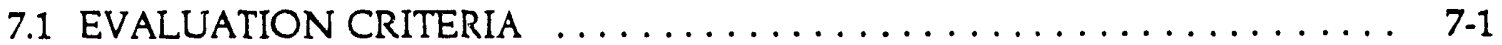

7.1.1 Overall Protection of Human Health and the Environment ... . . . 7-2

7.1.2 Compliance with ARARs .................... 7 -2

7.1.3 Long-term Effectiveness and Permanence .............. $7-2$

7.1.4 Reduction of Toxicity, Mobility, and Volume through

Treatment ......................... 7-3

7.1.5 Short-term Effectiveness . . . . . . . . . . . . . . . . . $7-4$

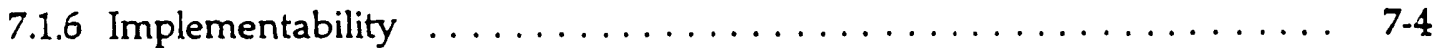

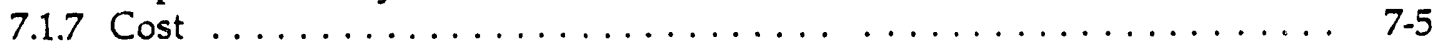

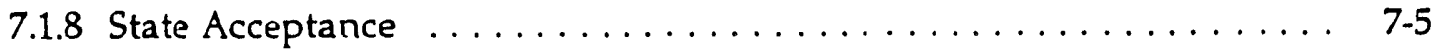

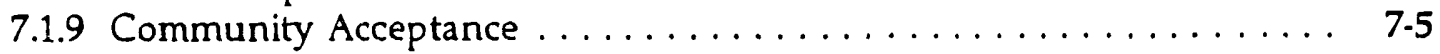

7.2 METHODOLOGY ............................ $7-6$

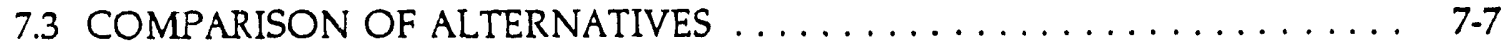

7.3.1 Long-term effectiveness and permanence $\ldots \ldots \ldots \ldots \ldots \ldots \ldots$ 7-7

7.3.2 Reduction of Toxicity, Mobility, and Volume through

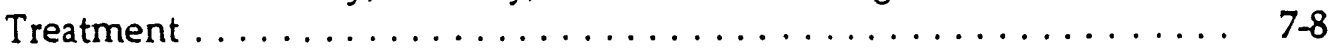

7.3.3 Short-term Effectiveness . . . . . . . . . . . . . . . . . 7.8

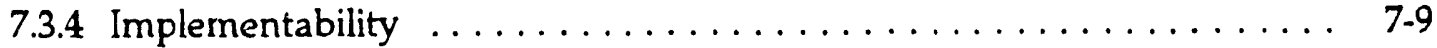

7.3 .5 Cost . . . . . . . . . . . . . . . . . . . . . . 7-10

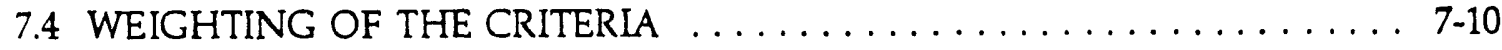

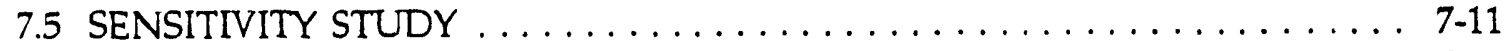

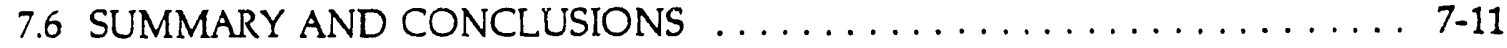

8.0 REFERENCES $\ldots \ldots \ldots \ldots \ldots \ldots \ldots \ldots \ldots \ldots \ldots \ldots \ldots \ldots \ldots \ldots \ldots \ldots \ldots \ldots \ldots$

\section{APPENDIXES:}

A - Cost Estimates for Remediation Alternatives

B - Unit Costs Derivations for Remediation 
DOE/RL-93-35, Rev. 0

CONTENTS (Cont)

\section{FIGURES:}

1-1 Location of 200-BP-1 Operable Unit in 200 East Area . . . . . . . . . . . 1F-1

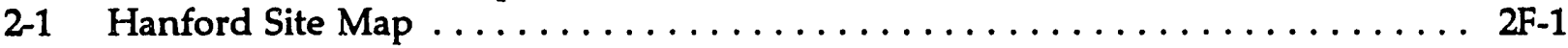

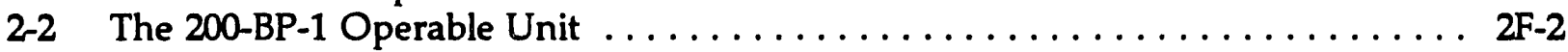

2-3 Topography of the 200-BP-1 Operable Unit $\ldots \ldots \ldots \ldots \ldots \ldots \ldots \ldots \ldots$

2-4 Interim Stabilization Zones within the UN-216-E-89

Unplanned Release . . . . . . . . . . . . . . . . . . . $2 F-4$

2-5 Total Monthly Evapotranspiration Near the 300 Area $\ldots \ldots \ldots \ldots \ldots \ldots \ldots$. . . . . .

$2-6$ Borehole Location Map . . . . . . . . . . . . . . . . . . . . 2F-6

2-7 Generalized Stratigraphic Column of the 200-BP-1 Operable Unit . . . . . . . 2F-7

2-8a 200-BP-1 Operable Unit Map Cross Section Locations . . . . . . . . . . . . 2F-8a

2-8b Explanation of Symbols Used in Geologic Cross-Sections . . . . . . . . . . . 2F-8b

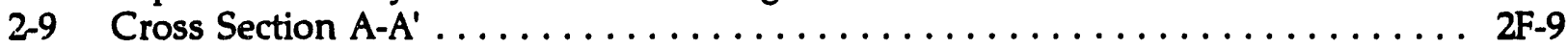

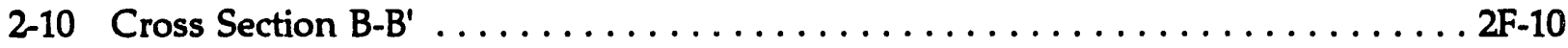

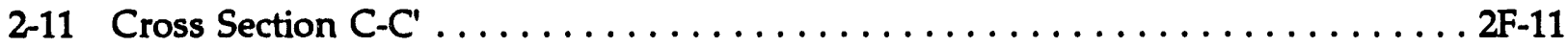

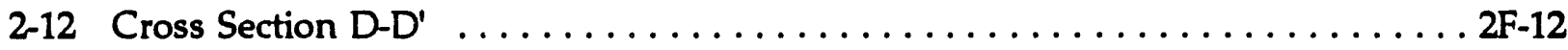

2-13 Geologic Fence Diagram for the 200-BP-1 Operable Unit . . . . . . . . . 2F-13

2-14 Typical Crib Cross Section ard Contaminant Distribution . . . . . . . . . 2F-14

6-1 50-Foot-Deep Excavation Layout . . . . . . . . . . . . . . . . . . .

6-2 Effective Barrier Areas . . . . . . . . . . . . . . . . . . . . . .

6-3 Process Flow Diagram Wastewater Management System . . . . . . . . . . . 6F-3

6-4 Biointrusion Barrier, Cross Section ...................... $6 \mathrm{~F}-4$

6-5 Modified RCRA Subtitle C Barrier, Cross Section . . . . . . . . . . . . . 6F-5

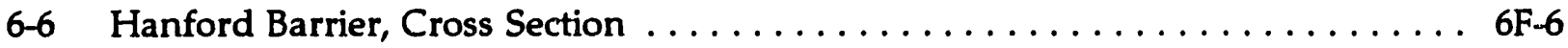

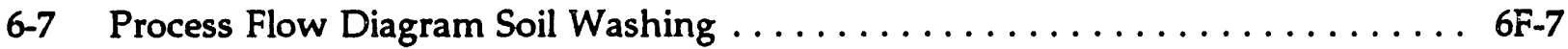

6-8 Block Flow Diagram Plasma Arc Vitrification . . . . . . . . . . . . . 6F-8

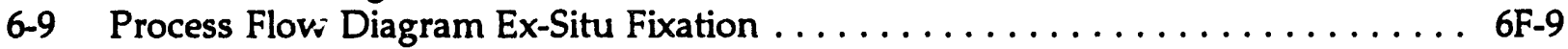

6-10 In-Situ Fixation Process Fiow Diagram . . . . . . . . . . . . . . . 6 F-10

6-11 Total Uranium Concentration in Groundwater $-1 \mathrm{~cm} / \mathrm{yr}$ Infiltration $\ldots \ldots \ldots 6 \mathrm{~F}-11$

6-12 Total Uranium Concentration in Groundwater $-0.1 \mathrm{~cm} / \mathrm{yr}$

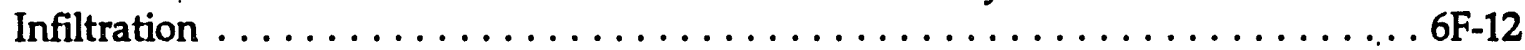

6-13 Total Uranium Concentration in Groundwater $-0.01 \mathrm{~cm} / \mathrm{yr}$

Infiltration . . . . . . . . . . . . . . . . . . . . . . . . 6 F-13

6-14 Total Uranium Concentration in Groundwater $-10 \mathrm{~cm} / \mathrm{yr}$

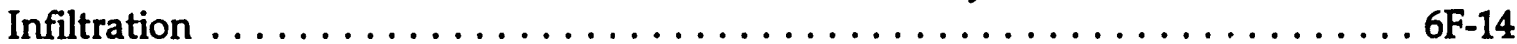

6-15 Total Uranium Concentration in Groundwater - 50-Foot-Deep

Excavation . . . . . . . . . . . . . . . . . . . . . . . . .

6-16 Total Uranium Concentration in Groundwater - 100-Foot-Deep

Excavation ............................... . . . . . . . .

6-17 Total Uranium Concentration in Groundwater - 150-Foot-Deep

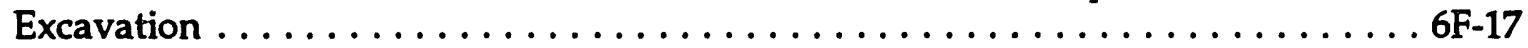

6-18 Total Uranium Concentration in Groundwater-Comparison . . . . . . . . 6F-18

7-1 Value Function for Total Worker Radiation Exposure ............. 7F-1

7-2 Value Function for Expected Number of Worker Fatalities from Accidents . . . . 7F-2

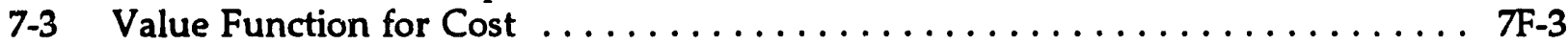

$7-4$ Composite Scores for Hypothetical Weighting of Criteria $\ldots \ldots \ldots \ldots \ldots$ F 4 


\section{CONTENTS (Cont)}

FIGURES (cont):

7-5 Sensitivity of Composite Scores to Weighting of Long Term Effectiveness .............................. FF-5

7-6 Sensitivity of Composite Scores to Weighting of Short Term Effectiveness ................................

7-7 Sensitivity of Composite Scores to Weighting of Implementability $\ldots \ldots \ldots \ldots$. . . .

7-8 Sensitivity of Composite Scores to Weighting of Treatment $\ldots \ldots \ldots \ldots \ldots \ldots$ F -8

7-9 Sensitivity of Composite Scores to Weighting of Cost $\ldots \ldots \ldots \ldots \ldots \ldots$ 7F-9

\section{TABLES:}

3-1 Identification of Federal ARARs at the 200-BP-1 Operable Unit . . . . . . . . 3T-1

3-2 Identification of State ARARs at the 200-BP-1 Operable Unit . . . . . . . . . 3T-2

3-3 Preliminary Chemical-Specific ARARs for the 200-BP-1 Operable Unit

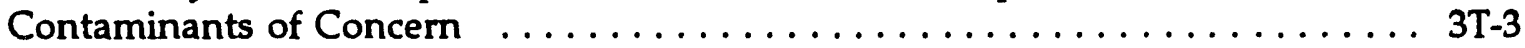

3-4 Summary of Remedial Action Objectives and General Response Actions . . . . . 3T-4

3-5 Soil and Groundwater Concentrations at the $10^{-6}$ Risk Level for thie 200-BP-1 Operable Unit . . . . . . . . . . . . . . . . . . . . . .

4-1 Identification and Screening of Technologies and Process Options . . . . . . . . 4T-1

5-1 Summary of Remediation Alternatives and Screening . . . . . . . . . . . 5T-1

6-1 Remediation Alternatives Retained for Detailed Evaluation . . . . . . . . . . . 6T-1

7-1 Alternative Scores for Long Term Effectiveness and Permanence . . . . . . . . TT-1

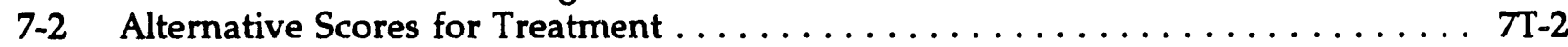

7-3 Alternative Scores for Short-Term Effectiveness $\ldots \ldots \ldots \ldots \ldots \ldots \ldots \ldots$ TT-3

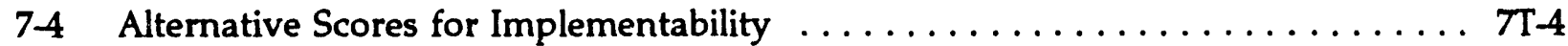

7-5 Alternative Cost ..........................

7-6 Criteria Weights; Normalized Preference Scores, and Composite Scores for

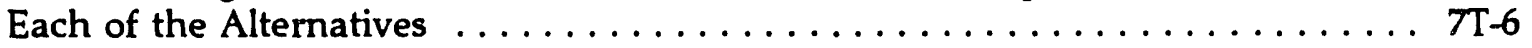




\subsection{INTRODUCTION}

The U.S. Department of Energy (DOE) Hanford Site, in Washington State, is organized into numerically designated operational areas including the 100, 200, 300, 400, 600, and 1100 Areas. The U.S. Environmental Protection Agency (EPA) in November 1989 included the 200 Area (as well as the 100, 300, and 1100 Areas) of the Hanford Site on the National Priority List (NPL) under the Comprehensive Environmental Response, Compensation and Liability Act of 1980 (CERCLA). The 200 Area is divided into eight waste area groups largely corresponding to the major processing plants (e.g., B-Plant). Each waste area group is further subdivided into one or more operable units based on waste disposal information, location, facility type, and other site characteristics. The 200-BP-1 operable unit is one specific site located within the 200 East Area (Figure 1-1).

Inclusion on the NPL initiated the remedial investigation and feasibility study (RI/FS) process for characterizing the nature and extent of contamination, assessing risks to human health and the environment, and evaluating remedial alternatives for the 200-BP-1 operable unit. These efforts are being addressed through the Hanford Federal Facility Agreement and Consent Order (Ecology et al. 1989) which was negotiated and approved by the DOE, the EPA, and the State of Washington Department of Ecology (Ecology) in May 1989. This agreement, known as the Tri-Party Agreement, governs all CERCLA efforts at the Hanford Site. In March of 1990, an RL/FS work plan (DOE-RL 1990a) for the 200-BP-1 operable unit was issued by DOE-Richland Field Office (DOE-RL). The work plan initiated the first phase of site characterization activities associated with the 200-BP-1 operable unit. Draft A of the Phase I Remedial Investigation Report (Phase I RI) has been prepared and is currently in the review process (DOE-RL, 1993). This document is the Decisional Draft Feasibility Study report (FS) for the 200-BP-1 operable unit, and represents the next step in the RI/FS process.

\subsection{PURPOSE AND SCOPE}

The purpose of the 200-BP-1 operable unit FS is to use data collected during the Phase I RI to develop and analyze remedial alternatives. The FS alternative analysis will, in turn, be used by Tri-Party Agreement signatories to make a risk management-based selection of remedies for the releases of hazardous substances that have occurred at the 200-BP-1 operable unit.

In accordance with the Tri-Party Agreement, the 200-BP-1 operable unit RI and FS were conducted in a concurrent, interactively phased manner. Data collected and evaluated during the RI provide information needed to develop and analyze remedial alternatives presented in the FS. Several agreements were reached between the Tri-Party Agreement signatories prior during the FS process. A proposal was made by the EPA on September 9, 1992 to adopt EPA's streamlined approach for an accelerated Record of Decision (ROD) for the 200-BP-1 operable unit.

To accomplish this, groundwater beneath the operable unit was removed from the scope of work and assigned to the 200 East Aggregate Area operable unit, simplifying the 200-BP-1 operable unit to a soils/source control operable unit. Separate Phase I, II, and III FS reports were combined into a single FS report, based on the consensus that a Phase II 
RI would not be required. While the FS considers all relevant technologies for remediating contamination at the operable unit, a presumptive remedy consisting of a barrier to prevent biological intrusion and minimize infiltration was assumed as a standard for evaluation of alternatives identified by the FS process. At the same time, a plan to implement a prototype Hanford Barrier over Crib 216-B-57 was proposed by the EPA and accepted by the DOE and Ecology.

In a series meetings, the Tri-Party Agreement signatories also agreed on the following points:

- completion of the prototype Hanford Barrier, to be constructed on Crib 216-B-57, was not needed for the FS process, and construction and testing information would not be available in time for inclusion in the barrier alternatives section of the FS report

- a listing of technology classes and technologies was adopted to provide the investigators with the minimum technologies expected to be considered by the regulatory agencies for inclusion in the FS

- an accelerated FS schedule was adopted to provide a Record of Decision by January 1994.

- the agreements and schedule were incorporated into TPA Change Package M-15-92-5

The goal of the FS report is to document the development of screening and analysis of remedial alternatives to allow DOE-RL, EPA, and Ecology (the primary data users and decision makers) to assess the ability of various remedial alternatives to mitigate threats to human health and the environment from hazardous substances found in the soils at the 200-BP-1 operable unit. A separate FS for remediation of contaminated groundwater beneath the 200-BP-1 operable unit will be included in the groundwater aggregate area FS being conducted for the 200 East Area. This report is consistent with the statutory requirements of CERCLA, the regulatory requirements of the NCP, and the Tri-Party Agreement.

\subsection{OVERVIEW OF THE FEASIBILITY STUDY PROCESS}

The methodology used in this FS report follows a step-by-step evaluation process as specified in EPA's document "Guidance for Conducting Remedial Investigations and Feasibility Studies Under CERCLA", Interim Final, dated October 1988. For explanatory purposes, the FS may be viewed as occurring in three phases: 1) the identification and screening of potentially applicable technologies and process options; 2 ) the development and screening of alternatives from among applicable technologies; and 3) the detailed analysis of alternatives to support selection of a preferred remedy for the operable unit. In practice, the delineation between phases is not so distinct, and the development of the phases is somewhat iterative. 
Development of alternatives begins with development of remedial actions objectives (RAOs) to establish goals for clean-up of the site. The RAOs specify contaminants and media of interest, potential exposure pathways, and preliminary remediation goals based on chemical-specific applicable or relevant and appropriate requirements (ARARs) and site specific risk-related factors. The next step is to develop general response actions (GRAs) for each medium of interest defining containment, treatment, excavation or other actions that may satisfy the RAOs. Volumes and areas of media to which GRAs might be applied are then developed, followed by identification of technologies that might achieve the GRAs and meet the RAOs. Screening of the list of possible technologies to eliminate those that cannot be implemented at the site completes the activities of the first phase of the FS.

The second phase of the FS consists of assembling the remaining technologies and evaluating process options to select a representative process for each technology type retained for consideration. In practice, the evaluation and selection of representative process options can be part of the technology screening and can be included in Phase I activities, as was done in this report. The representative technologies are then assembled into alternatives representing a range of treatment and containment combinations that meet RAOs for the media of concern at the site. Those alternatives that are developed and considered to be appropriate are refined and screened on the basis of a general evaluation of effectiveness, implementability and cost, to reduce the number of alternatives that will be analyzed in detail.

During the final phase of the FS, alternatives brought through the screening process are further refined and analyzed in detail with respect to evaluation criteria established in the National Oil \& Hazardous Substances Contingency Plan (NCP) in 40 CFR 300.430. These include: overall protection of human health and the environment; compliance with ARARs; short term effectiveness; long term effectiveness and performance; reduction of toxicity, mobility and volume through treatment; implementability; and cost. Two additional criteria are evaluated during the preparation of the ROD and following public review and comment. These are State and community acceptance. The detailed analysis is conducted so that decision-makers are provided with sufficient information to compare alternatives with respect to the evaluation criteria and to select an appropriate remedy. The FS provides a comparative analysis of alternatives and a recommendation for a preferred alternative for consideration by decision-makers in selecting a remedial alternative for the site.

In addition to the phased screening and analysis procedures prescribed by the NCP, CERCLA and the Clean Water Act (CWA) provide that natural resource trustees may assess damages to natural resources resulting from a discharge or release of a hazardous substance and may seek to recover those damages. According to the NCP, the lead agency shall make available information and documentation that can assist the respective trustees in the determination of actual or potential damages. To date, a Natural Resources Damage Assessment (NRDA) has not been conducted for the 200-BP-1 operable unit.

\subsection{REPORT ORGANIZATION}

The 200-BP-1 operable unit FS report is organized in a format similar to that recommended in EPA (1988a). In addition to this introduction, the FS report consists of the following 8 chapters with appendices. Chapters 2 through 4 comprise the Phase I FS. The 
Phase II FS is incorporated into Chapter 5. The Phase III FS is contained in Chapters 6 and 7. Details of chapter contents are outlined below:

- Chapter 2.0, Site Summary, includes a detailed description of the operable unit, its history of operations, characterization of waste units, and summaries of the physical setting, nature and extent of contamination, and the areas and volumes of contamination found at the operable unit.

- Chapter 3.0, Remedial Action Objectives, includes a summary of the baseline risk assessment completed for the Phase I RI, identification of potential ARARs, and development of remedial action objectives.

- Chapter 4.0, Identification and Screening of Remediation Technologies, includes identification of potential technology classes, technologies, and process options which are then screened for applicability at the operable unit.

- Chapter 5.0, Assembly and Screening of Remediation Alternatives, assembles representative technologies into alternatives to meet remedial action objectives. The alternatives are then screened using CERCLA criteria.

- Chapter 6.0, Detailed Analysis of Alternatives, provides a description of evaluation criteria and the detailed evaluation of each of the remaining alternatives against these criteria.

- Chapter 7.0, Comparative Analysis of Alternatives, includes a final comparison of alternatives using decision analysis tools to provide guidance to decision-makers regarding use of the FS results.

- Chapter 8.0, References, provides a list of documents cited within the body of the FS report. 


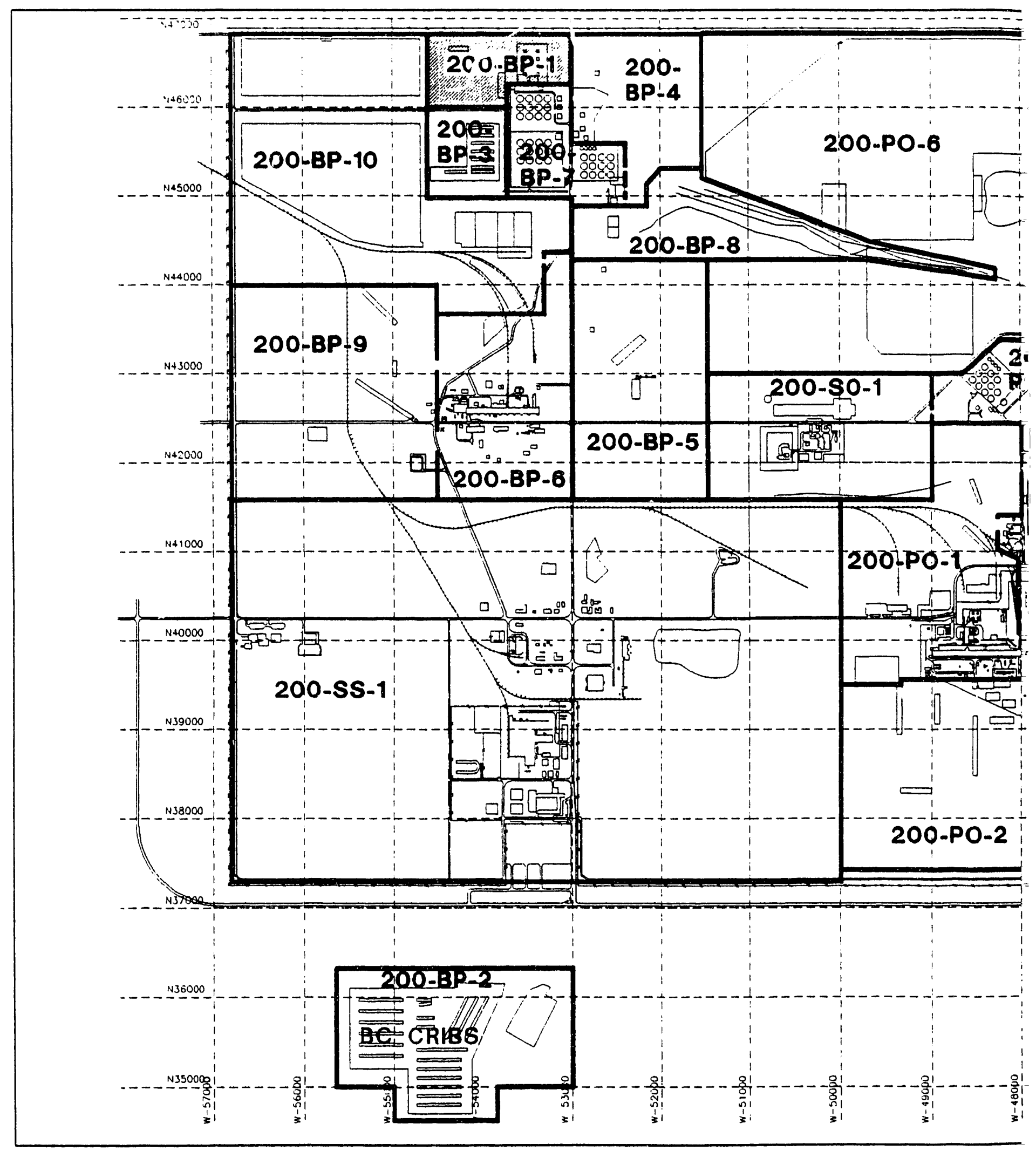




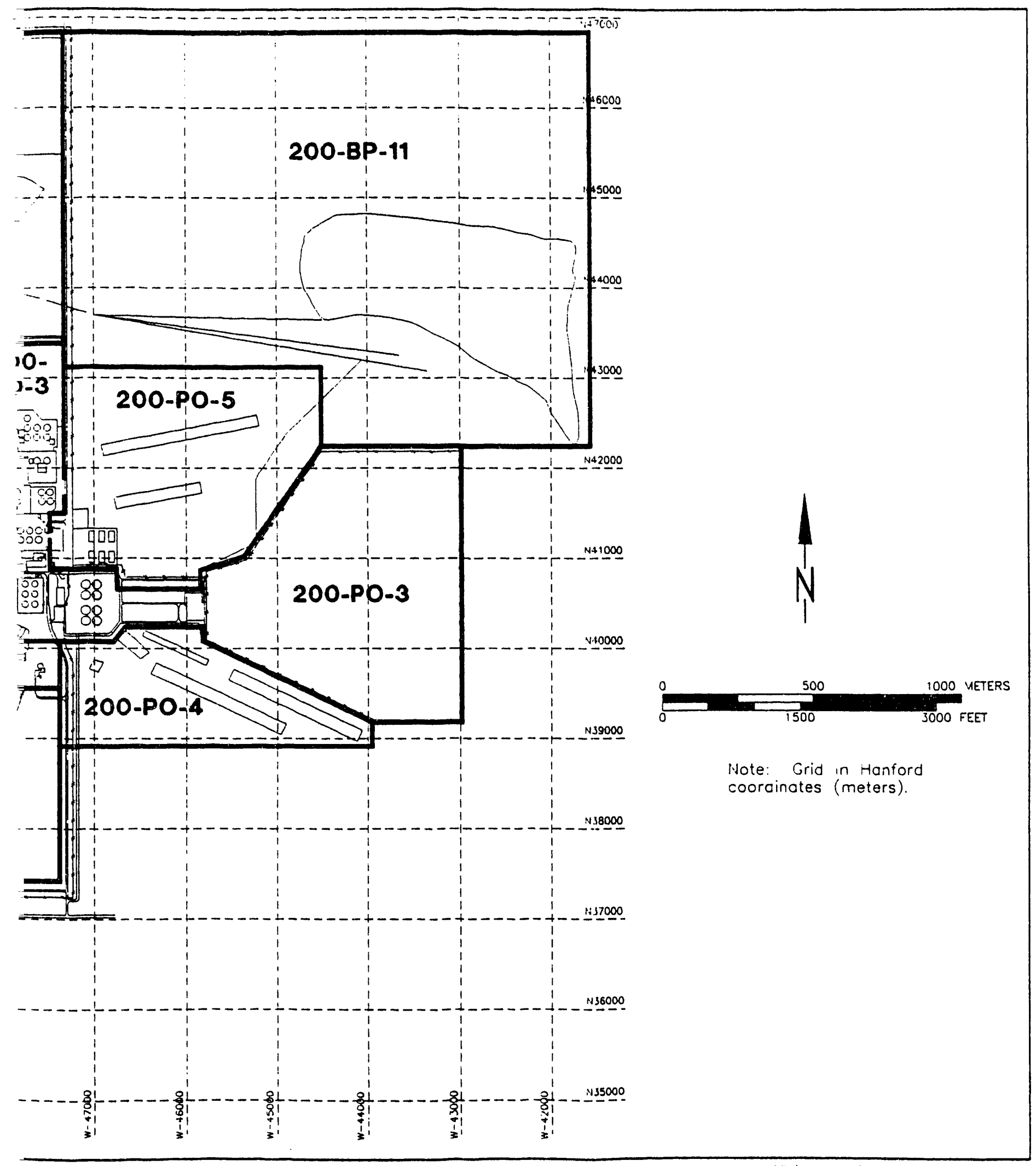

Figure 1-1. Location of 200. BP-1 Operable Unit in 200 East Area. 


\subsection{SITE SUMMARY}

A summary of the site characterization derived from the 200-BP-1 operable unit Phase I RI (DOE-RL 1993) is presented in this chapter. The summary includes a description of the operable unit with a brief history of operations, the physical setting of the site, the nature and extent of contamination, and estimates of the areas and volumes of contaminants in the operable unit soils.

\subsection{OPERABLE UNIT DESCRIPTION}

\subsubsection{Location}

The Hanford Site is a $1,450 \mathrm{~km}^{2}\left(560 \mathrm{mi}^{2}\right)$ tract of land located along the Columbia River in southeastern Washington and covers portions of Benton, Grant, Franklin, and Adams Counties (Figure 2-1). The Hanford Site is located approximately $280 \mathrm{~km}$ (174 mi) southeast of Seattle and $210 \mathrm{~km}(130 \mathrm{mi})$ southwest of Spokane.

The 200 Area was designated an NPL site by EPA in November, 1989. The 200 Area NPL site is divided into eight waste area groups largely corresponding to the major processing plants (e.g., B Plant). Each waste area group is further subdivided into one or more operable units based on waste disposal information, location, facility type and other site characteristics. The 200-BP-1 operable unit is one of the 11 operable units within the B-Plant waste area group (Figure 1-1). The 200-BP-1 operable unit waste disposal activities were associated with the management of waste from the U-Plant uranium reclamation operations and waste storage condensate from the adjacent 241-BY tank farm (Figure 2-2).

The 200-BP-1 operable unit is located in the approximate center of the Hanford Site, along the northern boundary of the 200 East Area. A site plan of the 200-BP-1 operable unit is shown in Figure 2-2. Topography of the operable unit is shown in Figure 2-3. The 200-BP-1 operable unit is bordered by operable units 200-BP-4 to the east, 200-BP-7 and 200BP-3 to the south, and 200-BP-10 to the west. The 600 Area, which includes all areas at the Hanford Site not located in other designated areas (i.e., 100, 200, 300, 400, and 1100 Areas), borders the 200-BP-1 operable unit to the north.

The 200-BP-1 operable unit is located within the southeast quadrant of Section 34 of Township 13 North and Range 26 East and encompasses a total area of approximately 10 ha $(25 \mathrm{ac})$. The majority of the waste management units within the 200-BP-1 operable unit ale concentrated in a $1.6 \mathrm{ha}(4 \mathrm{ac})$ region at the eastern end of the 200-BP-1 operable unit (Figure 2-2). The operable unit is bounded within the Washington State plane (NAD 83) north/south coordinates of N42012.2 m (N137800 ft) and N41920.7 m (N137500 ft) and east/west coordinates of E174756.1 $\mathrm{m}(\mathrm{E} 573200 \mathrm{ft})$ and E174939.0 m (E573800 ft).

Contamination in groundwater beneath the 200-BP-1 operable unit is being addressed in a separate groundwater operable unit, as part of the 200 Aggregate Area FS per Tri-Party Agreement change request M-92-15. 


\subsubsection{Identification and History of Waste Units}

This section presents a review of the sources and the known and suspected contaminants which have been associated with the waste management units at the 200-BP1 operable unit, either through disposal activities, or through unplanned releases. Included is historic information about waste generating processes in the 200-BP-1 operable unit vicinity and waste management practices at each waste management unit.

Since 1943, the Hanford Site has been used for reactor operations, reprocessing of spent fuel, and management of radioactive waste. The historical mission was plutonium production for defense purposes; plutonium was produced in reactors located in the 100 Area via the irradiation of uranium fuel, and subsequently separated from the other constituents in the irradiated fuel at the separations plants located in the 200 East and West Areas. In recent years, the mission at the Hanford Site has changed from production of special nuclear materials to waste management and environmental restoration.

2.1.2.1 Waste Units. The 200-BP-1 uperable unit includes nine inactive cribs (known as the 216-B cribs) and four unplanned releases (UNs) (Figure 2-2). The cribs within the 200-BP-1 operable unit, except 216-B-61, received liquid, mixed waste from two sources: low-level liquid waste from the $U$ Plant uranium reclamation operations, and waste storage tank condensate from the adjacent 241-BY Tank Farm. A tenth crib (216-B-61) was constructed, but there is no evidence that it was ever used or received any wastes (DOE-RL 1990a). Soils samples taken during the Phase I RI indicate that crib 216-B-61 does not currently have any detectable contamination (DOE-RL 1993).

The disposal cribs were designed to receive, disperse and infiltrate liquid waste effluents underground. Waste effluents were diverted to the cribs via the flush tank and underground pipe and were discharged through pipe perforations and sumps to a gravel bed. The gravel infiltration zones are generally located about 3.4 to $6.1 \mathrm{~m}$ (11 to $20 \mathrm{ft}$ ) belov: ground surface. While the exact concentrations and quantities of radionuclides and contarninants of concern discharged to the cribs is uncertain, records indicate that cribs $216-B-43$ through -49 received an estimated $33,840,000 \mathrm{~L}(8,940,000 \mathrm{gl})$ of tributyl phosphate (TBP) process (described below) supernatant waste over their operational life (1955-65), and cribs $216-\mathrm{B}-50$ and -57 received an estimated $139,200,000 \mathrm{~L}(36,780,000 \mathrm{gl})$ of in-tank solidification condensate while they were in operation from 1965-74.

During the time period when the $216-B-43$ to -49 cribs were in use, the concept of "specific retention disposal" was employed at various liquid waste disposal facilities in the separations area. This type of disposal was used for "intermediate-level" wastes, including TBP supernatant and other types of radioactive wastes, which were generally not considered disposable by conventional cribbing techniques because of appreciable concentrations of radioisotopes. The term referred to that volume of water which could be disposed to the soil and be held against the force of gravity by the surface tension characteristics of the soil surfaces and pores. In practice, it represented the volume of liquid which could be discharged to a pit without leakage to the groundwater. The practice differed from conventional cribbing techniques in that discharge volumes were limited to the specific retention volumes of the soils, based on their moisture retention capacity. 
While specific retention disposal was employed at some cribs in the separations area, the 216-B-43 through -49 cribs were apparently not operated in this manner, based upon information presented in Haney and Honstead (1958). In general, the quantities disposed at each crit exceeded the cribs' calculated specific retention capacity. For cribs 216-B-43 through 216-B-49, the volumes disposed of exceeded calculated retention capacities by from one and two times; however, at cribs 216-B-50 and 216-B-57, which received the greatest volumes of liquid waste, the disposal volumes were approximately 15 and 45 times the caiculated retention capacities, respectively.

Rather than operating the cribs as specific retention disposal facilities, the amount of TBP supernatant waste discharged to any one of the 216-B-43 through $216-B-49$ cribs was theoretically linuited by the resulting concentration of any "critical nuclide" in the underlying groundwater 'Thomas et al. 1956). A critical nuclide was defined as a radioactive isotope with a half-life greater than 3 years. Discharge to a crib was permitted until the concentration of such a nuclide in a groundwater sample collected from an adjacent well was found to exceed one-tenth the nuclide's maximum permissible drinking: water concentration. For example, the maximum permissible drinking water concentration for cobalt-60 during this period was $400,000 \mathrm{pCi} / \mathrm{L}$. The corresponding maximum groundwater concentration was, therefore, $40,000 \mathrm{pCi} / \mathrm{L}$. However, cobalt- 60 was found exceeding this discharge limit in a monitoring well installed adjacent to the cribs by a factor of more than 100 in early 1956 (Thomas et al. 1956), thereby indicating that the operational plan to control crib discharges did not function as intended in limiting impacts to the underlying groundwater. The "time lag" between disposal of the TBP supernatant waste and the appearance of the radionuclides in the groundwater was apparently not accounted for.

Cribs $216-B-43$ through -49 received tributyl phosphate (TBP) supernatant waste generated in the TBP process, which occurred in the 221-U building. The TBP process was used for the recovery of uranium metal from wastes generated in the bismuth phosphate $\left(\mathrm{BiPO}_{4}\right)$ process in the B-Plant. Before implementing the TBP process, this waste had been stored at the 241-BY tank farm.

From 1952 to 1958, waste stored within the 241-BY tanks was transferred to the U Plant for uranium recovery. The sludge was dissolved in nitric acid, and then the uranium was extracted using TBP in a normal paraffin diluent. The TBP process wastes contained fission products, sulfate, and phosphate ions in aqueous nitric acid solution. The acid solution was made alkaline for transfer and storage in 241-BY Tank Farm. The TBP process wastes in the $241-B Y$ tanks were treated with potassium ferrocyanide $\left[\mathrm{K}_{4} \mathrm{Fe}(\mathrm{CN})_{6}\right]$ as a cesium scavenger. The supernatant was decanted to cribs $216-\mathrm{B}-43$ through -49 (Anderson and Mudd 1979). Chemical and radioactive constituents known and/or suspected to be present in the decanted supernatant included the following (DOE-RL 1992a and Stenner et al. 1988):

$\begin{array}{ll}\text { ferrocyanide } & \text { cesium-137 } \\ \text { nitrate } & \text { ruthenium-106 } \\ \text { phosphate } & \text { strontium-90 } \\ \text { sodium } & \text { plutonium } \\ \text { sulfate } & \text { gross alpha } \\ \text { tributyl phosphate } & \text { gross beta } \\ \text { paraffin hydrocarbons } & \text { uranium }\end{array}$




$$
\begin{aligned}
& \text { tritium (H-3) } \\
& \text { cobalt- } 60 \\
& \text { technetium-99 }
\end{aligned}
$$

Cribs $216-\mathrm{B}-50$ and -57 received ITS condensates that were high-volume, low-level wastes. These waste streams were apparently considered suitable for disposal by the conventional cribbing techniques employed during the time they were in use. Waste sent to cribs $216-\mathrm{B}-50$ and -57 consisted of storage tank condensate from the in-tank solidification units nos. 1 and 2 (ITS nos. 1 and 2), respectively. In-tank solidification was accomplished by in-tank heating. Both units were located in the 241-BY tank farm. The ITS no. 1 unit start-up occurred on March 19, 1965, and the ITS no. 2 unit started up on February 17, 1968. On August 24, 1971, the ITS no. 1 unit was converted from an evaporator to a cooler for ITS no. 2. Evaporates were collected and condensed. Condensate was discharged to either the $216-B-50$ or the $216-B-57$ crib. The $216-B-50$ crib has similar concentrations of contaminants as cribs $216-B-43$ through -49 . It is therefore probable that this crib received additional wastes other than just ITS effluent.

Chemical and radioactive constituents known and/or suspected to be present in the storage tank condensate included the following (DOE-RL 1992a and Stenner et al. 1988):

$\begin{array}{ll}\text { ammonium carbonate } & \text { cesium-137 } \\ \text { ammonium nitrate } & \text { ruthenium-106 } \\ \text { nitrate } & \text { strontium-90 } \\ \text { sodium } & \text { plutonium } \\ & \text { gross alpha } \\ & \text { gross beta } \\ & \text { uranium } \\ & \text { tritium }(\mathrm{H}-3) \\ & \text { cobalt-60 } \\ & \text { technetium-99 }\end{array}$

The $216-\mathrm{B}-61$ crib was constructed to receive ITS no. 1 unit condensate, but there is no documentation that it received any process wastes. Soil samples collected during the Phase I RI show no detectable contamination at the 216-B-61 crib (DOE-RL 1993).

2.1.2.2 Unplanned Releases. Four unplanned releases have been identified (Figure 2-2) within the 200-BP-1 operable unit. These unplanned releases have been designated as the following waste units:

$$
\begin{array}{ll}
\text { - } & \text { UN-200-E-9 } \\
\text { - } & \text { UN-200-E-63 } \\
\text { - } & \text { UN-200-E-89 } \\
& \text { UN-200-E-110. }
\end{array}
$$

Available information regarding the details of these UNs is provided in Appendix H, of the Phase I RI Report (DOE-RL 1993).

UN-200-E-63 was an unplanned mixed waste release, and is described as tumbleweeds becoming contaminated by uptake of radionuclides from the $B C$ crib and trench in the 200-BP-2 operable unit. This vegetation was then uprooted and blown 
around, contaminating the surrounding ground surface. The contaminated vegetation was removed and a weed control program was initiated to control future growth of tumbleweeds.

Waste unit UN-200-E-9 involved approximately $41,600 \mathrm{~L}(11,000 \mathrm{gl})$ of TBP supernatant waste which leaked onto the ground from the 216-B crib flush tank. The spill occurred in an area directly north of the flush tank. Most of the wastes were removed to a

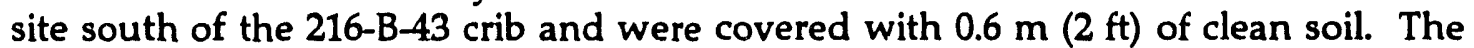
contamination left near the flush tank was covered with $3 \mathrm{~m}(10 \mathrm{ft})$ of clean soil (DOE-RL 1992a).

Surface radiological conditions at the UN-200-E-89 area were documented in a series of surveillance reports identified in Hayward (1992). The reports identified soil surface radiation readings that exceeded allowable levels, and the lack of an adequate surface barrier to prevent migration. This unplanned release was originally named UN-216-E-17 which has been changed to UN-200-E-89. The interim stabilization action was undertaken to correct the deficiencies identified in these reports and bring the site into compliance with WHC-CM-7-5, Part L, "Inactive Radioactive Waste Sites" (WHC 1988a). The source of the contamination was suspected to be the manhole and risers near the $216-\mathrm{B}$ cribs, and the BX/BY tank farms (Hayward 1992).

Waste unit UN-200-E-89 was bounded on the east by Baltimore Avenue, on the north by 12 th Street, and on the south by the BY tank farm (Figure 2-2). The majority of the unplanned release (approximately 4.3 ha [10.6 ac]) was within the 200-BP-1 operable unit. The remainder (approximately 0.85 ha [2.1 ac]) was within the 200-BP-7 operable unit to the south (Hayward 1992).

Interim stabilization actions consisted of a combination of scraping and replacement of surface contaminated soils followed by covering (stabilization) with clean soil and rock, and covering (stabilization) of soils in-place. The UN-200-E-89 area was divided into 7 zones based on the treatment they would receive for the interim stabilization. Scraping occurred to depths of up to $15 \mathrm{~cm}$ (6 in.) over much of the UN-200-E-89 area. Scraped soils were placed either in the low area in the center of $216-B-43$ through -50 or over the surface of 216-B-57. Once the consolidation was complete, the crib areas were stabilized with approximately 46 to $61 \mathrm{~cm}$ (18 to 24 in.) of clean soil. Figure $2-4$ depicts the zones within the UN-200-E- 89 area and treatment received. Additional detailed information of the UN200-E-89 interim stabilization activities are included in Hayward (1992).

Waste unit UN-200-E-110 involved the release of first-cycle waste from the 112-BY tank in the 241-BY tank farm that impacted an area of approximately $2,300 \mathrm{~m}^{2}\left(25,000 \mathrm{ft}^{2}\right)$ around the 112-BY pit. It is possible, although currently unknown, that the release flowed into the 200-BP-1 operable unit. No information was obtained on the quantity of the release or whether remedial action was taken at the time of the release. The interim stabilization actions described above were conducted prior to RI field activities. They involved identification and stabilization of all surface contaminated soils within the operable unit, including any possible surface contamination resulting from UN-200-E-110.

2.1.2.3 Interaction with Other Operable Units. Some contamination in 200-BP-1 may be a result of activities conducted on adjacent operable units. The 200-BP-1 operable unit is bordered by operable units 200-BP-4 to the east, 200-BP-7 and 200-BP-3 to the south, and 
the 200-BP-10 operable unit to the west. The 600 Area, which includes all areas at the Hanford Site not located in the other designated areas (i.e., 100, 200,300,400, and 1100), borders the operable unit to the north.

The waste disposal cribs and waste storage tanks in adjacent operable units received or contain many of the same constituents as the cribs in the 200-BP-1 operable unit. Cribs in adjacent operable units were designed for underground infiltration of waste water effluents. Leaks, have occurred from single-shell storage tanks in 200-BP-7 operable unit, resulting in release of wastes containing higher concentrations of radionuclides than were normally disposed of in the cribs (WHC 1988).

The proxirnity of the 241-BY tank farm in the 200-BP-7 operable unit located south and east of the 2/30-BP-1 operable unit has signif icant impacts on several of the remedial alternatives considered in this FS. This is due tc the proximity of this tank farm to the cribs, the high level of hazard associated with single-shell tank wastes, and the uncertainty regarding final remedial actions at the 200-BP-7 operable unit. These implications are discussed in more detail as they affect implementability of remedial alternatives in Chapter 6 of this FS.

The proximity and nature of contaminants at adjacent operable units also affect the groundwater beneath the 200-BP-1 operable unit. Most of the adjacent operable units are hydraulically upgradient of the 200-BP-1 operable unit and may be contributing to groundwater contaminatior, in the area. Therefore, remedial actions taken for the contaminated groundwater beneath and near 200-BP-1 must be coordinated to provide remediation of contamination emanating from the other operable units as well as the contribution from the scuurces within 200-BP-1. For this reason, groundwater was removed from the 200-BP-1 operable unit and combined into a 200 East Aggregate Area feasibility study for restoration activities.

In addition to the operable units immediately adjacent to the 200-BP-1 operable unit, other major potential contaminant sources include B-pond effluent infiltration to groundwater, reverse well $216-B-5$, and possible stack emission fallout associated wit'n processing plants in the 200 East Area.

\subsection{PHYSICAL SETTING}

A detailed description: of the regional and local aspects of the 200-BP-1 operable unit physical characteristics is provided in Chapter 3 of the Phase I RI (DOE-RL 1993). The following summary focuses on the major issues related to the meteorology, surface hydrology, geology, soils, hydrogeology and ecology.

\subsubsection{Meteorology}

This section presents an interpretation of meteorological datz. for the Hanford Site and the 200-BP-1 operable unit. The data has been collected primarily at the Hanford Meteorologic Station (HMS), which is located between the 200 East and 200 West Areas of the Hanford Site, approximately $8 \mathrm{~km}(5 \mathrm{mi})$ to the west of the $200-\mathrm{BP}-1$ operable unit. 
Data from the HMS are assumed to be representative of the general climatic conditions of the region, and of the 200-BP-1 operable unit.

A large compilation and summary of HMS data for the period from 1946 to 1980 , and of additional data from other nearby stations for the period 1912 to 1943 , was conducted by Stone et al. (1983). The discussion which follows, unless otherwise noted, is based on this compilation.

2.2.1.1 Precipitation. The Cascade Range is located approximately $130 \mathrm{~km}(80 \mathrm{mi})$ west of the Hanford Site and has an average crest elevation of about $1,800 \mathrm{~m}(6,000 \mathrm{ft}) \mathrm{AMSL}$. This mountain range creates a rain shadow that limits the average total annual precipitation at the HMS to about $16 \mathrm{~cm}$ (6.3 in.). The total annual precipitation (98 percentile) ranges from 8 to $28 \mathrm{~cm}$ ( 3 to 11 in.). The three months November through January generally contribute approximately $42 \%$ of this total, while the three months July through September contribute only $12 \%$. January is the wettest month with an average of $2.3 \mathrm{~cm}(0.9$ in.) while July is the driest month with an average of only $0.4 \mathrm{~cm}(0.15 \mathrm{in}$.$) . Precipitation intensity is greatest in$ the summer months. This seasonal intensity peak coincides with the thunderstorm season.

Rain is the usual form of precipitation at the HMS, but snowfall regularly occurs during winter, and hail storms, though infrequent, may occur during the summer thunderstorm season. Approximately $38 \%$ of all precipitation during the months of December through February is in the form of snow. However, in only one winter in four does an accumulation in excess of $15 \mathrm{~cm}(6 \mathrm{in}$.) occur. The average annual snowfall is 33 cm (13 in.). Complete snowmelt generally occurs within a month of a snowstorm.

2.2.1.2 Temperature and Humidity. The summer months at the Hanford Site are typically hot and dry, and winters are moderately cold. July is the warmest month of the year with an average temperature of $24.7^{\circ} \mathrm{C}\left(76.4^{\circ} \mathrm{F}\right)$, and January is the coolest month with an average temperature of $-1.5^{\circ} \mathrm{C}\left(29.3^{\circ} \mathrm{F}\right)$. Average high temperatures in the summer are $37^{\circ} \mathrm{C}\left(99^{\circ} \mathrm{F}\right)$ and average lows in winter are $-5^{\circ} \mathrm{C}\left(23^{\circ} \mathrm{F}\right)$. Annual high temperatures are normally recorded in July and the annual lows normally occur in January. Historical extreme temperature readings of $46^{\circ} \mathrm{C}\left(115^{\circ} \mathrm{F}\right)$ and $-29^{\circ} \mathrm{C}\left(-20^{\circ} \mathrm{F}\right)$ have been recorded.

The diurnal temperature range is substantial, due to low humidity. During summer months, when the average relative humidity is 30 to $40 \%$, the diumal temperature range is greatest, on the order of $15^{\circ} \mathrm{C}\left(27^{\circ} \mathrm{F}\right)$. In winter, with relative humidity ranging from 60 to $80 \%$, the diurnal temperature range is reduced to about $8^{\circ} \mathrm{C}\left(14^{\circ} \mathrm{F}\right)$ (DOE-RL 1990b).

The annual average relative humidity at the HMS is $54 \%$, with maxima during the winter months (averaging about $75 \%$ ) and minimum average relative humidity during the summer (about 35\%) (Stone et al. 1983).

2.2.1.3 Wind. Wind directions at the HMS varies over 360 degrees, with a prevailing wind direction from west-northwest to northwest for every month of the year (average of $31.6 \%$ of the time). Secondary maxima occur for southwesterly winds. The months of June and July have the highest percentage of winds from the WNW and NW (38 and 37\%, respectively). October has the lowest percentage $(25 \%)$ from those directions.

Elsewhere on the Hanford Site, the preclominant wind direction may differ from those at HMS. Mountain ridges and river vaileys locally influence wind direction, 
particularly along the Columbia River where predominant wind directions parallel the river. There is also a strong diurnal effect observed from March through August, when wind speeds tend to increase 7 to $10 \mathrm{~km} / \mathrm{h}(4$ to $6 \mathrm{mph})$ during the afternoon and evening hours (DOE-RL 1990b).

Monthly average wind speeds are generally lowest during the winter months, averaging 10 to $12 \mathrm{~km} / \mathrm{h}$ (6 to $7 \mathrm{mph}$ ), and highest during the summer, averaging 15 to $17 \mathrm{~km} / \mathrm{h}$ (9 to $10 \mathrm{mph})$. The highest monthly average wind speeds occur in June $(15.3 \mathrm{~km} / \mathrm{h}$ [9.2 mph]) and the lowest monthly average wind speeds occur in November and December (10.2 km/h [6.1 mph]).

At the HMS, the strongest winds observed, with speeds up to $130 \mathrm{~km} / \mathrm{h}(80 \mathrm{mph})$, generally are southwesterly. Most hourly wind speeds greater than $50 \mathrm{~km} / \mathrm{h}(31 \mathrm{mph})$ are from the south-southwest to west-southrest and occur at the highest frequency from March through May (Hulstrom 1992).

Wind-blown dust accompanies strong winds on the Hanford Site. Blowing dust originating from the site itself has been observed at wind speeds greater than $32 \mathrm{~km} / \mathrm{h}(20$ $\mathrm{mph})$. Dust entrained elsewhere and transported to the Hanford Site has been observed for lower wind speeds of $7 \mathrm{~km} / \mathrm{h}$ (4 mph) (DOE-RL 1990b). Observations of blowing dust may occur with any wind direction, however, the strongest winds at the HMS are from the southwest and therefore there are more cases of blowing dust from that direction. Dust transported to the Hanford Site from elsewhere is most often associated with winds from the north and northeast.

2.2.1.4 Evapotranspiration. Pan evaporation data was obtained from the Washington State University Cooperative Extension for Prosser, Washington located approximately $40 \mathrm{~km}(25$ mi) southwest of the 200 East Area. Monthly rates of pan evaporation at the Washington State University Irrigated Agriculture Research and Extension Center (IAREC) average from about 8 to $25 \mathrm{~cm}$ ( 3 to $10 \mathrm{in}$.). These averages are based upon data collected over the period 1924 to 1988 for the months April through October. Total pan evaporation over the April through, October period averaged about $127 \mathrm{~cm}$ (50 in.). This seasonal component represents approximately $80 \%$ of the total annual pan evaporation.

Free surface evaporation (or potential evaporation) is expected to equal approximately $70 \%$ of the pan evaporation for the Hanford Site vicinity, or about $109 \mathrm{~cm}$ (43 in.) (Weather Bureau 1966). Free water surface evaporation is of interest because it closely represents the potential evaporation from adequately watered surfaces, such as vegetation and soil, and the evaporation from a surface body of water.

A monitoring program was conducted for the Hanford Site beginning in the late 1970 s to study groundwater recharge and measure parameters that affect recharge rates. Rockhold et al. (1990) reported on water balance data that was collected as part of this program from three sites in 1988 and 1989. The sites included the 300 Area buried waste test facility and grass site, and the 200 East Area closed-bottom lysimeter. While evapotranspiration was not specifically reported for the 200 East Area site, it was reported that measured water contents in the soil implied that significant recharge had not occurred within the lysimeter. 
For the 300 Area buried waste test facility, evaporation and transpiration were determined to be about $14.3 \mathrm{~cm}(5.6 \mathrm{in}$.) for a bare surface and $19.9 \mathrm{~cm}(7.8 \mathrm{in}$.$) for a$ vegetated surface, using measurements of changes in water storage, drainage, and precipitation. Precipitation during this period was approximately $18 \mathrm{~cm}(7.1 \mathrm{in}$.). Drainage was about $4 \mathrm{~cm}(1.6 \mathrm{in}$.) from the bare surface and $1 \mathrm{~cm}(0.4 \mathrm{in}$.) from the vegetated surface. The excess of evapotranspiration and drainage over precipitation was compensated for by a reduction in soil moisture.

Figure 2-5 presents a plot of monthly evapotranspiration totals for the north (bare) and south (vegetated) weighing lysimeters at the buried waste test facility during the period December 1987 to August 1990. Figure 2-5 illustrates the large seasonal and annual variations in evapotranspiration and the large differences that can occur as a result of vegetation.

\subsubsection{Surface Water Hydrology}

There are no perennial or ephemeral streams in the 200 East Area or adjacent land, as the topography is relatively flat and the precipitation, combined with high evapotranspiration, provides little water to generate runoff. Surface drainage from the 200-BP-1 operable unit is primarily to the north. West Lake, located approximately $2.8 \mathrm{~km}$ $(1.7 \mathrm{mi})$ north of the 200 East Area, is the nearest surface water body to the 200-BP-1 operable unit. The pond, with a surface area of approximately 4 ha $(10 \mathrm{ac})$ and a depth of approximately $1 \mathrm{~m}(3 \mathrm{ft})$, is located in a topographic depression where it intersects the surface of the water table. As such, the lake constitutes a surface representation of the water table. The source of recharge to the lake is groundwater which is locally mounded as a result of 200 Areas operations. The Columbia River, an important regional surface water resource, is located to the north and east of the 200-BP-1 operable unit. At its closest approach to the operable unit, the river is located approximately $20 \mathrm{~km}(12 \mathrm{mi})$ to the northwest.

\subsubsection{Geology}

2.2.3.1 Stratigraphy. The operable unit is underlain by massive basalt flows that form a regional bedrock, and by the overlying assemblage of sedimentary deposits. The geologic units of interest in the vicinity of the 200-BP-1 operable unit include, from oldest to youngest: (1) the Pomona Member of the Saddle Mountains Basalt, (2) the Rattlesnake Ridge interbed of the Ellensburg Formation, (3) the Elephant Mountain Member of the Saddle Mountains Basalt, (4) the Ringold Formation, (5) the Hanford formation, and (6) the Holocene surficial deposits. Borehole locations are shown on Figure 2-6. A generalized stratigraphic column of the geologic units below the 200-BP-1 operable unit is shown on Figure 2-7. Cross sections are shown on Figures 2-8 through 2-12; a fence diagram is shown on Figure 2-13.

The lower of the two basalts, the Pomona Member, varies in thickness from approximately $50 \mathrm{~m}(164 \mathrm{ft})$ throughout much of the study area to $0 \mathrm{~m}(0 \mathrm{ft})$ along the axis of the Umtanum Ridge-Gable Mountain anticline (in the Gable Gap area) where the unit has been completely eroded by floodwater erosion. Overlying the Pomona Member is the Rattlesnake Ridge interbed, a sedimentary deposit which varies in thickness from over $25 \mathrm{~m}$ 
$(82 \mathrm{ft})$ in the southwest portion of the 200 East Area to $0 \mathrm{~m}(0 \mathrm{ft})$ in the Gable Gap Area where the unit has been completely removed by erosion. The interbed consists of air fall and fluvially-reworked fine-grained siliciclastic material, and arkosic sands.

The uppermost basalt in the immediate vicinity of the 200-BP-1 operable unit is the Elephant Mountain Basalt Member of the Saddle Mountains Basalt Formation. The Elephant Mountain Member thickens from approximately $21 \mathrm{~m}$ ( $69 \mathrm{ft}$ ) in the northwestern portion of the study area to over $30 \mathrm{~m}(98 \mathrm{ft})$ in the south. As with other units in the area, the buried surface of the Elephant Mountain Member has been eroded to varying degrees by floodwater erosion. North of the 200-BP-1 operable unit, in the Gable Gap Area, the unit has been completely removed, exposing underlying deposits to the unconsolidated sediments of the Hanford formation. The total depth and extent of erosion in the Gable Gap Area and the geologic materials which are exposed are uncertain. In addition, an erosional "window", which may be continuous with the erosional feature in the Gap Area, is apparently present in the vicinity of two boreholes (699-53-55 and 699-55-55) north of the 200-BP-1 operable unit. Within this erosional "window", the unconsolidated sediments of the Hanford formation are in direct contact with the Rattlesnake Ridge interbed.

Overlying the bedrock is the Ringold Formation, a mixed deposit of fluvial sands and gravels, lacustrine muds and overbank deposits. The formation is present only in the southern portion of the study area and is generally absent from the area immediately beneath the 200-BP-1 operable unit and to the north where the sediments of the Hanford formation directly overlie basalt or sedimentary interbeds in the basalt.

Above the Ringold Formation is the Hanford formation, a variable mixture of boulders, cobbles, pebbles, sands and silts of glaciofluvial origin. The deposit is continuous over all of the study area except for Gable Mountain where basalt is exposed. Generally, the Hanford formation overlies basalt where the Ringold Formation is not present and overlies the Ringold Formation elsewhere. In the study area, the formation has been subdivided into three primary stratigraphic sequences: an upper gravel, a middle sand and a lower gravel. The total thickness of the Hanford formation in the study area varies from approximately 50 to $100 \mathrm{~m}$ (164 to $328 \mathrm{ft}$ ).

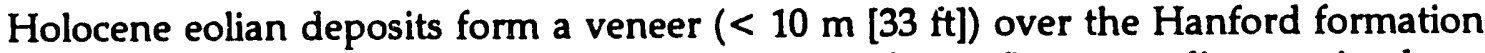
in the area of the operable unit. These deposits consist of very-fine-to-medium-grained sands or silty sands that were originally derived from the Hanford formation.

2.2.3.2 Vadose Zone Characterization. The vadose zone is the region above the water table in which the fluid pressures of the sediments are negative with respect to local atmospheric pressure. It occurs between the ground surface and the water table, and is the zone through which natural and man-made recharge waters may flow to the water table. This section will address vadose zone sediments which occur at depths greater than $4.6 \mathrm{~m}(15 \mathrm{ft})$. Vadose zone sediments above $4.6 \mathrm{~m}(15 \mathrm{ft})$ are discussed in Section 2.2.4.

In the vicinity of the 200 East Area, the vadose zone encompasses units of the Hanford formation and the Ringold Formation (Lindsey et al. 1992). Beneath the 200-BP-1 operable unit, however, the vadose zone consists of the interlayered sandy gravel, gravely sand, and silty sandy gravel of the Hanford formation only. The Ringold Formation, because of erosion which occurred during cataclysmic flooding, has been removed from the immediate vicinity of the 200-BP-1 operable unit and the areas to the north. 
The total thickness of the vadose zone in the study area varies from approximately

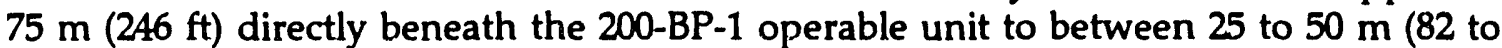
$164 \mathrm{ft}$ ) in the Gable Mountain/Gable Butte area. Except for localized areas where basalt bedrock occurs above the water table, all portions of the vadose zone in the area surrounding 200-BP-1 are comprised of the Hanford formation.

Beneath the 200-BP-1 operable unit, the vadose zone is comprised of three primary lithologic units: the Hanford upper gravel, the Hanford sand, and the Hanford lower gravel. The water table occurs within sediments of the lower gravel. Based on information collected from two boreholes drilled in the immediate vicinity of the cribs (299-E33-40 and -38), the lower gravel unit is approximately 14 to $20 \mathrm{~m} \mathrm{(46} \mathrm{to}$

$66 \mathrm{ft}$ ) in thickness directly beneath the 216-B cribs. The sand unit is the thickest of the three lithologies and varies from approximately 30 to $41 \mathrm{~m}$ (98 to $134 \mathrm{ft})$ in thickness while the upper gravel sequence ranges from approximately 5 to $14 \mathrm{~m}$ (16 to $46 \mathrm{ft}$ ) in thickness beneath the cribs. The upper gravel and the sand generally thicken from south to north beneath the crib area while the lower gravel thins.

In addition to the three main stratigraphic units of the Hanford Formation, several relatively continuous silt layers were revealed during the recent drilling (Hoffman et al. 1992). The most significant of these is a thin silt horizon identified at a depth of approximately $58 \mathrm{~m}(190 \mathrm{ft})$ which appears to be relatively continuous beneath the 200-BP-1 operable unit and crib area (Figure 2-13). Beneath the 200-BP-1 operable unit, the layer is continuous between boreholes 299-E33-40, 299-E33-38, 299-E33-31, 299-E33-32, 299-E33-41, 299-E33-34, and 299-E33-30. The unit was also detected in deep vadose zone drilling boreholes 299-E33-296, 299-E33-302 and 299-E33-304 that were drilled directly through cribs $216-B-43,216-B-49$, and 216-B-57, respectively. The unit was apparently not detected in boreholes 299-E33-12 and 299-E33-39, located directly east of the 200-BP-1 operable unit.

The silt horizon at a depth of about $58 \mathrm{~m}(190 \mathrm{ft})$ is the only fine-grained layer observed beneath the 200-BP-1 operable unit which is interpreted to be continuous beneath the entire crib area (Figure 2-13). The thickness of the zone beneath the 200-BP-1 operable unit varies from approximately 0.1 to $1.5 \mathrm{~m}(0.5$ to $5 \mathrm{ft})$. Directly beneath the cribs, the zone

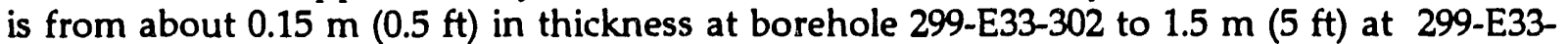
40. The dip of the silt horizon, based on the observed elevations in boreholes 299-E33-30, 299-E33-34, 299-E33-38 and 299-E33-40, is gentle and generally is toward the north at about 1 degree.

Samples collected during the Phase I RI were predominantly sands and gravels with only a few examples of fine-grained material. The fines contents of the soils were generally low, typically less than $10 \%$. In boreholes 299-E33-38 and -40 , a fine grained layer was identified at depths of 58 and $59 \mathrm{~m}$ (190 and $194 \mathrm{ft}$ ), respectively. The fines contents of the two samples were 87 and $23 \%$ by weight, respectively. This layer is felt to be continuous beneath the crib area, as discussed above.

Although a variety of methods have been developed to directly measure unsaturated hydraulic conductivity, these are often costly and difficult to implement. An alternative to direct measurements is the use of theoretical approaches that predict unsaturated hydraulic conductivity relationships from measured soil water retention data. As such, under Task 4 of the 200-BP-1 operable unit work plan (DOE-RL 1990a) and other 200 area RCRA and CERCLA projects, water retention measurements (for both wetting and 
drying) were made on 60 unsaturated zone samples collected from 13 boreholes located throughout the 200 East Area, three of which are located in the 200-BP-1 operable unit (299E33-38, -40 and-307). The water retention data were used in conjunction with the theoretical approach of van Genuchten et al. (1991) to define the unsaturated hydraulic conductivity vs. soil moisture content relationship for each sample. The theoretical basis of this approach and results, as well as all retention curves and hydraulic conductivity vs. matric potential curves, are summarized in Connelly et al. (1992). Detailed presentations of the work are provided in Smoot et al. (1989) and Bergeron et al. (1987).

For the Hanford gravels, a total of fifteen soil moisture retention curves were measured, including eight curves for samples from the 200-BP-1 operable unit boreholes 299-E33-307, 299-E33-38, and -40. The functional relationships, which are presented in Connelly et al. (1992), exhibit strong non-linear characteristics, i.e., for a small change in volumetric moisture content, the hydraulic conductivity change can be several orders of magnitude. The total range of unsaturated hydraulic conductivities calculated for the Hanford gravels was from approximately $10^{-2}$ to $10^{-20} \mathrm{~cm} / \mathrm{s}\left(10^{1}\right.$ to $\left.10^{-17} \mathrm{ft} / \mathrm{d}\right)$. Saturated hydraulic conductivities ranged from approximately $10^{-6}$ to $10^{-3} \mathrm{~cm} / \mathrm{s}\left(10^{-3}\right.$ to $\left.10^{0} \mathrm{ft} / \mathrm{d}\right)$. The low hydraulic conductivity value was measured in a sample of sandy clay collected at $57.9 \mathrm{~m} \mathrm{(190} \mathrm{ft)} \mathrm{depth} \mathrm{from} \mathrm{borehole} \mathrm{299-E33-38.} \mathrm{The} \mathrm{high} \mathrm{value} \mathrm{was} \mathrm{measured} \mathrm{in} \mathrm{a} \mathrm{sandy}$ gravel collected from borehole $699-42-41 \mathrm{~B}$. These results indicate a high degree of variability within the Hanford gravels with respect to their hydraulic properties.

A total of 41 samples were evaluated for the Hanford formation sand sequence of which three were collected from the 200-BP-1 operable unit (from borehole 299-E33-38). As with the gravels, the degree of non-linearity is high. The range of unsaturated hydraulic conductivities was similar to that exhibited for the graveis. Saturated hydraulic conductivities ranged from approximately $10^{-5}$ to $10^{-2} \mathrm{~cm} / \mathrm{s}\left(10^{-2}\right.$ to $\left.10^{1} \mathrm{ft} / \mathrm{d}\right)$, indicating a high degree of variability as with the gravels.

The results of the unsaturated hydraulic conductivity measurements indicate that both saturated and unsaturated hydraulic conductivity can vary by several orders of magnitude within a lithologic unit. As discussed in Connelly et al. (1992), it is necessary to evaluate sample collection and textural description when selecting moisture characteristic curves. Typically, the choice of a water retention curve is made by examining water retention curves along with the particle size analyses to distinguish lithologies with significantly different soil textures and hydraulic conductivities.

Additional saturated hydraulic conductivity data is included in Hoffman (1992) where the results of physical soils testing performed under Tasks 2, 4, and 6 of the 200-BP-1 operable unit work plan are presented. Hydraulic conductivities presented include the results of vertical hydraulic conductivity measurements. Results range from $10^{-2}$ to $10^{-6}$ $\mathrm{cm} / \mathrm{s}\left(10^{1}\right.$ to $\left.10^{-3} \mathrm{ft} / \mathrm{d}\right)$. Most of the values fell in the $10^{-3}$ to $10^{-5} \mathrm{~cm} / \mathrm{s}\left(10^{0}\right.$ to $\left.10^{-2} \mathrm{ft} / \mathrm{d}\right)$ range.

\subsubsection{Pedology}

This section will address the physical characteristics of soils within the upper

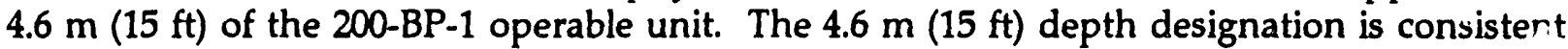
with evaluations of risk presented in the Phase I RI. Results referred to in the discussiol: 
which follows are taken from only those borings completed within the 200-BP-1 operable unit or immediate vicinity.

In a soil survey of the Hanford Site (Hajek 1966), three major soil types were identified in the vicinity of the 200 East Area, each of which is represented in approximately equal areal extent. These include the Ephrata Sandy Loam, the Burbank Loamy Sand, and the Rupert Sand. The Ephrata Sandy Loam and Burbank Loamy Sand appear to be present within the operable unit, although recent field studies were not conducted for confirmation. Surface soils over crib areas are disturbed and represent backfilled materials that are not representative of native surface soils.

The soils of the operable unit vicinity are largely dominated by the characteristics of the parent material from which they are derived. As such, and due to limited weathering and soil formation, the soil characteristics are very similar to the properties of the Hanford formation. The moisture content of the soils is generally low, ranging from approximately 1 to $6 \%$ by weight, with an average of just under $3 \%$. These values indicate that the water content of the soils to be near or at residual levels.

The surficial soil characteristics of the 200-BP-1 operable unit were significantly modified in the UN-200-E-89 interim stabilization effort. An approximately 4-ha (10-ac) area

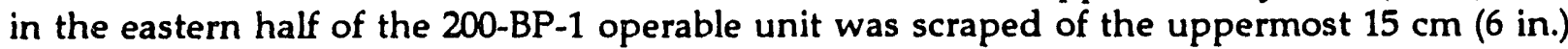
of soil to reduce the level of surface soil radiation. This soil was collected, consolidated, and re-placed atop the $216-B-43$ through -50 cribs and then covered with approximately 46 to $61 \mathrm{~cm}$ (18 to $24 \mathrm{in}$.) of clean soil. Other areas within the 200-BP-1 operable unit (Figure 2-3) were also covered with clean soil (15 to $30 \mathrm{~cm}$ [6 to 12 in.]) to facilitate drilling during the Phase I RI activities. Areas outside the 200-BP-1 operable unit, specifically the steep embankments on the east and north sides of the BY tank farm were stabilized with large cobble and pit run soil (Hayward 1992). Due to this disturbance, as well as additional surface disturbances which have likely occurred in the past due to general construction activities, the in-place surficial soils probably do not have the same properties as the undisturbed major soil types. The Task 2, 4, and 6 drilling for the 200-BP-1 work plan, however, was undertaken after the UN-200-E-89 interim stabilization work. The samples collected and tests performed are, therefore, representative of the current, in-place soil conditions.

Soil samples collected during the Phase I RI activities were tested for moisture content, porosity, dry bulk density, and grain size. These soil characteristics varied with depth. The $0-4.6 \mathrm{~m}(0-15 \mathrm{ft})$ interval of soils in the immediate area of the cribs have an average moisture content of $2.75 \%$ by weight, with a porosity value of $35 \%$, and a dry bulk density of $1.69 \mathrm{~g} / \mathrm{cm}^{3}\left(105 \mathrm{lb} / \mathrm{ft}^{3}\right)$. The $0-4.6 \mathrm{~m}(0-15 \mathrm{ft})$ interval has been affected by the sludge disposed to the 200-BP-1 operable unit. These soils are composed of approximately $70 \%$ gravel, $20 \%$ sand, and $10 \%$ silt (or fines) by weight (Hoffman 1992, and Hoffman et al. 1992).

\subsubsection{Hydrogeology}

There are two primary hydrostratigraphic units of interest in the vicinity of the 200BP-1 operable unit. These include a highly conductive, upper unconfined aquifer which occurs within sediments of the Hanford and Ringold Formations, and a deeper, more 
moderately conductive confined aquifer which occurs in sediments of the Rattlesnake Ridge interbed. Directly beneath the operable unit and to the north, the Ringold Formation is absent, due to erosion from catastrophic flooding. Directly beneath the 200-BP-1 operable unit and immediately to the north (downgradient), the uppermost aquifer is generally very ihin, ranging from only about 1 to $5.5 \mathrm{~m} \mathrm{(3} \mathrm{to} 18 \mathrm{ft}$ ) in thickness. The Ringold formation is abient due to erosion from catastrophic flooding. Further to the north (in the Gable Gap Are. 1 and in the erosional "window" feature), the aquifer thickens to approximately 20 to 30 $\mathrm{m}$ (60 to $98 \mathrm{ft}$ ). The vadose zone varies in thickness across the study area from approximately $75 \mathrm{~m}(246 \mathrm{ft})$ directly beneath the operable unit to between 25 to $50 \mathrm{~m} \mathrm{(82}$ to $164 \mathrm{ft}$ ) in the Gable Gap area. In the study area, except for localized areas, all portions of the vadose zone are comprised of sediments of the Hanford formation.

On the Hanford Site, groundwater flow in the unconfined aquifer is primarily from the recharge areas, principally small ephemeral streams located around the western periphery of the Pasco Basin, to the discharge zones located along the Columbia River. Superimposed on this predominantly west to east groundwater flow pattern is an artificial pattern of flow which has arisen from the waste disposal activities associated with Hanford Site operations. In the separations area, disposal activities at B-Pond have resulted in the creation of a water table mound located beneath the eastern portion of the 200 East Area. Groundwater flows radially outward from this mound. In the 200-BP-1 operable unit study area, groundwater in the unconfined aquifer flows under the influence of this mound towards the Gable Gap area to the north.

The uppermost regionally confined aquifer is the Rattlesnake Ridge aquifer. The Elephant Mountain Basalt Member acts as a confining layer separating the Rattlesnake Ridge from the uppermost aquifer except for in areas where the basalt has been removed by erosion. As with the uppermost aquifer, the predominant flow direction is primarily from west to east. The groundwater mound which has developed in the unconfined aquifer, however, has lead to the creation of a localized disturbance to this general pattern. The creation of the water table mound has resulted in the establishment of downward hydraulic gradients between the uppermost and confined aquifers, and has lead to a radial pattern of flow beneath B-Pond in the Rattlesnake Ridge aquifer. North and west of the 200 East Area, flow in the Rattlesnake Ridge aquifer is apparently towards the Gable Gap Area. Potentiometric data suggests that once reaching the Gap Area, discharge from the Rattlesnake Ridge aquifer is to the uppermost aquifer. Groundwater of the unconfined aquifer then flows generally to the east where it discharges to the Columbia River.

Currently, the downward gradients between the two aquifers are confined to the immediate vicinity of the B-Pond. In the past, however, the area characterized by downward gradients is expected to have been significantly larger in areal extent. In conjunction with erosional features and possibly joint/fracture systems, the introduction of contaminants to the Rattlesnake Ridge confined aquifer occurred. There are at least one, and possibly two, erosional features where direct aquifer communication has occurred in the past. Currently however, except for the B-Pond area, gradients between the two aquifers are generally upward throughout the study area. 


\subsubsection{Ecology}

Access to the entire Hanford Site has been administratively controlled since 1943. Access to most of the 200 Areas, including the 200-BP-1 operable unit, is further restricted in addition to the general Hanford Site administrative controls. Although DOE is expected to retain control of the Hanford Site for the foreseeable future, a Hanford Future Site Uses Working Group (HFSUWG) is laying out land use alternatives for DOE to consider when it develops an environmental impact statement for the Hanford Site. The final report of the HFSUWG recommends "some type of government presence or oversight of the area should be assumed for the foreseeable future due to the anticipated level of residual contamination in the 200 Areas" (HFSUWG 1992). The report recommends six future use options for the 200 Areas, all of which include a buffer zone around the Areas, and assume that the 250 Areas remain as managed waste storage and disposal facilities.

Since 1944, there has been no agricultural activity or resident human population on the Hanford Site. Based on 1980 census data, approximately 110 people live within $17 \mathrm{~km}$ $(10 \mathrm{mi})$ of the 200 East Area. The nearest resident is at least $12 \mathrm{~km}(7 \mathrm{mi})$ away rrom the 200-BP-1 operable unit as this is the approximate distance to the nearest Hanford Site boundary. The working population for all 200 Areas shifts is approximately 2,400 .

The Columbia River, which is located approximately $12 \mathrm{~km}(7 \mathrm{mi})$ from the 200-BP-1 operable unit at its closest approach, is the most significant surface-water body in the region and is used as a source of drinking water, industrial process water, crop irrigation, and for a variety of recreational activities, including fishing, hunting, boating, water skiing, and swimming. Downgradient groundwater in the immediate vicinity of the 200-BP-1 operable unit is not used for either drinking or irrigation. The nearest drinking water supply wells are those that serve the 400 Area, approximately $13 \mathrm{~km}(8 \mathrm{mi})$ to the southeast of the operable unit.

The 200-BP-1 operable unit is located on the 200 Areas plateau. Habitat within the undisturbed areas of the 200 Areas plateau consist primarily of the big sagebrush/Sandberg's bluegrass community that dominates most of the Hanford Site. Because of the operational disturbances which have taken place in the operable unit, however, the majority of the plants occurring in the 200-BP-1 operable unit are invader species. In the nonradiation areas the major vegetation includes rabbitbrush, Sandberg's bluegrass, Russian thistle and cheatgrass. In the radiation zone plant species include revegetated wheatgrass and thickspike used to stabilize soil of two cribs. The major plants around the cribs are cheatgrass, Sandberg's bluegrass, Russian thistle and rabbitbrush. No endangered or threatened plant species were observed in the operable unit.

The most abundant fauna in the region include the western meadowlark, Great Basin pocket mouse, deer mouse, Townsend's ground squirrel, Black-tailed jackrabbit, mule deer, coyote, badger, and various raptor and insect species. The ferruginous hawk, Swainson's hawk, loggerhead shrike, and long-billed curlew are candidate species for inclusion on the Federal threatened or endangered species list. Candidates for state listing are the burrowing owl, sage sparrow, sage thrasher, and long-billed curlew. With regards to mammals, two species of concern are Merriam's shrew, a candidate for listing by Washington State, and the Pacific western big-eared bat, a candidate for federal protection. The northern grasshopper mouse is a State monitor listed species. None of these candidate species were observed on the 200-BP-1 operable unit, however, they are commonly 
associated with the big sagebrush/Sandberg's bluegrass habitat of the 200 Area plateau. The striped whipsnake is a State candidate listed reptile. There are no Federal- or Stateclassified threatened, endangered or candidate species among the insects of the Hanford Site.

\subsection{NATURE AND EXTENT OF CONTAMINATION}

The Phase I RI report (DOE-RL 1993) uses a step-wise screening process that defines the extent of contamination associated with the waste management units within 200-BP-1 operable unit. In this screening process, chemical constituents detected in soil and groundwater samples were compared to levels observed in sample blanks, established background concentrations, and to calculated risk-based screening levels with the goal of identifying those compounds that constitute actual contamination and potentially pose risk to human health and the environment. The compounds that were defined in this process were designated contaminants of potential concern and were used in the baseline risk assessment. All compounds which were eliminated by the screening process were dropped from further consideration in the Phase I RI and have not been considered in the FS. This subsection will summarize the chemical and contaminant characteristics of concern for the operable unit which resulted from the baseline risk assessment.

Risk-based screening was conducted for soil and groundwater. For soils, the screening was performed separately for two different zones. The first zone, near surface soils, is defined as soil between the ground surface and $4.6 \mathrm{~m}(15 \mathrm{ft})$. This zone consists of stabilized surface soils, trench backfill and the top 0.3 to $1.2 \mathrm{~m}$ ( 1 to $4 \mathrm{ft}$ ) of crib infiltration

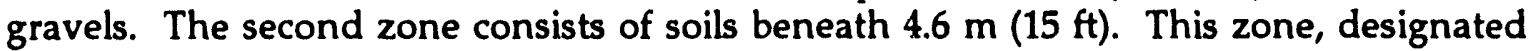
subsurface infiltration gravels/soils, includes the remainder of the crib infiltration gravels (approximately $1.5 \mathrm{~m}[5 \mathrm{ft}]$ ) and underlying natural materials. The $4.6 \mathrm{~m}$ (15 ft) cut-off is based on guidelines presented in the Washington State Model Toxics Control Act (MTCA) Cleanup Regulations, and also represents a demarcation in contaminant concentration since

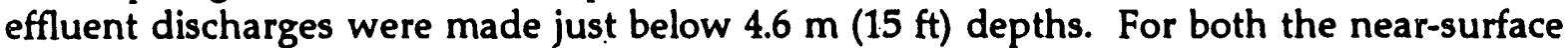
soils and subsurface infiltration gravels/soils, three soil exposure pathways are used in calculating preliminary risk-based benchmark concentrations: soil ingestion, air inhalation (including inhalation of fugitive dust) and external exposure to radioactivity. For groundwater, the only exposure pathway evaluated is groundwater ingestion. A typical crib cross section showing the general distribution of contaminants is included on Figure 2-14.

For near surface soils, the identified contaminants of concern include the following:

- cesium-137, radium-226, and thorium-228.

For subsurface infiltration gravels/soils, the identified contaminants of concern include the following:

- $\quad$ cesium-137, cobalt-60, plutonium-239 and -240 , radium-226, strontium90 , technetium-99, thorium-228, and total uranium.

The type of radionuclide contamination detected within the 200-BP-1 operable unit near surface soils is similar within the nine cribs. Cesium-137, radium-226, and thorium-228 
were detected in each of the cribs. Total uranium was detected in cribs 216-B-44, 216-B-46, $216-B-47,216-B-48,216-B-50$ and $216-B-57$. All the contaminants are distributed fairly evenly with respect to depth, with no obvious horizons of increased radionuclide contamination.

The radionuclide contamination concentrations detected within the 200-BP-1 operable unit subsurface infiltration gravels/soils $(>4.6 \mathrm{~m}[>15 \mathrm{ft}])$, are much higher than those detected in the surface soils. Cobalt -60 , and plutonium $239+240$ which were not detected in the near surface soils, are found consistently in the sub-surface infiltration gravels and underlying native soils. The specific contaminants detected in each of the cribs are somewhat variable, only plutonium-238 and -239 , and strontium-90, are found consistently in each of the cribs.

Crib 57 has significantly lower concentrations of strontium-90 and cesium-137. This is consistent with historical records that show cribs 216-B-57 and 216-B-50 received evaporative condensate as opposed to actual liquid waste. However, the contamination in crib 216-B-50 is consistent with cribs $216-B-43-49$ and may, in fact, have received supernatant decant liquid waste from the BY tank farm.

The largest detected concentrations of radionuclides are between (4.6-9.1 m [15-30 ft]) below the ground surface, although contamination was detected up to $71.9 \mathrm{~m}$ $(236 \mathrm{ft}$ ) below the surface. For strontium-90, cesium-137, plutonium $239+240$, and total uranium, maximum concentrations are consistently between $4.9-7.9 \mathrm{~m}(16-26 \mathrm{ft})$ and mostly between $5.4-6.7 \mathrm{~m} \mathrm{(18-22} \mathrm{ft})$. The concentration of these radionuclides at the bottom of the cribs is consistent with their relative immobility (high partitioning with soil relative to water Fheses) and may also indicate that these radionuclides were discharged to the cribs as a suspended flocculent within the supernatant effluent.

The data and the contrasts between the near surface and subsurface gravels/soils are consistent with the crib construction and waste disposal methods utilized. Based on information from the sample drilling operation, the top and bottom of the cribs (engineered infiltration gravels) are generally from 3.4-6.1 m (11-20 ft) below ground surface, respectively. The waste discharge pipes were designed to discharge effluent below the top of the crib gravels and infiltrate through approximately $1.8 \mathrm{~m}(6 \mathrm{ft})$ of gravels before reaching presumably in-situ soil at the crib bottom. Samples were generally taken of the soil/gravel and gravel/soil interface zones, respectively, for each crib. All the samples taken in the soil/gravel interface at the top of the cribs (typically $2.7-4 \mathrm{~m}[9-13 \mathrm{ft}]$ ) show much less contamination than samples taken at the gravel/soil interface at the bottom of the crib. The few samples taken at $4.6 \mathrm{~m}$ (15 ft) (the cutoff between near surface and subsurface zones for this report ), contain significantly lower levels of radionuclides than samples in the same crib taken a few feet deeper.

Results of the soil sampling and spectral gamma-ray logging indicate that contamination is generally confined to the area beneath the cribs and that significant lateral waste migration due to perched groundwater conditions does not appear to have occurred. The precise lateral extent of contam: ation away from the cribs, however, is not precisely known, but is thought to be less than 100 feet (DOE-RL 1993). Exploration coring currently underway at 216-B-57 may provide additional information regarding the lateral spread of contaminants at this crib. 
Extensive contamination of groundwater in the 200-BP-1 operable unit study area has occurred due to Hanford Site operations. This contamination is likely the result of multiple sources located throughout the 200 East and West Areas. While still in exceedance of regulatory standards, levels which are currently present in groundwater are, for most radioisotope constituents, one or more orders of magnitude less than concentrations which occurred in the early years of Hanford operations.

Contaminant plumes were identified throughout the study area for gross beta, total cyanide, cobalt- 60 , nitrate, technetium- 99 , and tritium at concentrations exceeding background levels, risk-based screening concentrations, or other regulatory criteria. For the other contaminants of potential concern in groundwater, the extent of contamination tends to be confined to localized areas and/or is characterized by relatively lower concentrations. Generally, the plumes are centered at well 699-50-53a where maximum contaminant levels are consistently observed. Well $699-55-57$ is also characterized by relatively high concentrations as compared to other monitoring wells throughout the study area.

Currently, the 200-BP-1 operable unit sources are contributing technetium-99, nitrate, cobalt -60 , and possibly uranium to the underlying unconfined aquifer. These are the only contaminants of concern currently impacting groundwater from the 200-BP-1 source operable unit.

\subsection{CONTAMINANT FATE AND TRANSPORT}

A transport analysis of the contaminants of potential concern identified above was included in the Phase I RI. The purpose of the analysis was to evaluate the behavior of each contaminant of potential concern in the environmental media in which it is transported, specifically to provide estimates of the contaminant concentrations at points of potential receptor exposure. Air, surface water, subsurface water, and biotic exposure pathways were evaluated. Although the subsurface water pathway includes both an unsaturated and a saturated pathway, transport in the saturated pathway was not addressed since groundwater is not a part of the operable unit. The groundwater pathway will be addressed in the 200 East Aggregate Groundwater Study.

Potentially operative contaminant transport pathways were evaluated for the Phase I RI (DOE-RL 1993), taking preliminary toxicity screening results into account. The results are summarized in the following sections.

\subsubsection{Air Pathway}

There are three possible release mechanisms by which soil contaminants can enter the atmosphere: radioactive decay, volatilization, and emission of fugitive dust.

Radioactive decay is a possible release mechanism when the daughter product is a gas, and can apply to Ra-226, decaying to Rn-222, and Th-228, decaying eventually to Rn-220.

Volatilization most often occurs when an organic liquid passes into the vapor state, and is a possible release mechanism for only one potential contaminant of concern, PCB. Emission of fugitive dust acts as a release mechanism for contaminants which adsorb onto soil particles, and hence is applicable to all of the potential contaminants of concern. 
2.4.1.1 Air Emissions. Air emissions of Rn-222 and Rn-220 from the near surface and subsurface infiltration gravels/soils were evaluated in the Phase I RI. These radioisotopes are gaseous decay products of Ra-226, and Th-228, respectively. Because of the relatively long half-life of Ra-226, and the small quantities of both Th-228 and Ra-226 present in the crib soils, radioactive decay is not considered a significant airborne release mechanism for this operable unit (DOE-RL 1993).

2.4.1.2 Volatile Emissions. Volatile emissions of PCBs from the subsurface infiltration gravels/soils were also considered in the Phase I RI. Because of the low vapor pressures and high soil adsorption constants characteristic of PCBs, as well as the low PCB concentrations measured, the volatilization release mechanism is not considered to be significant at this operable unit (DOE-RL 1993). PCBs were determined not to be contaminants of concern in the Phase I RI Baseline Risk Assessment.

2.4.1.3 Fugitive Dust Emissions. Fugitive dust emission and subsequent atmospheric transport was modeled using EPA's Fugitive Dust Model (FDM) (Winges 1991). 'The FDM is a computer code which analytically solves a commonly used air dispersion equation. The model was used to calculate concentrations of fugitive dust and the resulting fallout which will characterize the study area in the year 2018 (2018 represents the earliest year for which alternative land uses may occur at the Hanford Site). It was assumed in the model simulations that the current protective clean soil cover (from the interim stabilization activities) is not maintained in the future and that the contaminated near surface soils are exposed and accessible to wind erosion. Furthermore, a major disturbance of the crib infiltration gravel materials is assumed to potentially occur, such as excavation, thereby exposing these soils directly to wind erosion. These assumptions were made to provide a full spectrum of future scenarios for the baseline risk assessment, and are felt to provide a strong conservative bias to the modeling results.

The results of the modeling for the contaminants of concern indicate that airborne particulate matter is transported and deposited over an elliptically shaped area which extends principally to the southeast from the operable unit, and reaches the approximate vicinity of the B-Pond at its furthest downwind extent. Concentrations of airborne dust vary from about 1 to $1 \times 10^{-6} \mu \mathrm{g} / \mathrm{m}^{3}$. Based on these estimates of airborne particulate concentrations and appropriate decay factors, the projected soil concentrations resulting from contaminants originating from the 200-BP-1 operable unit were calculated. Soil concentrations, mixing factors, assumed dust layer thickness, and other parameters were then used as input parameters to the RESRAD code (Argonne 1992) to compute dose-based results which were then converted to risk-based results using EPA risk factors. Estimated exposures resulting from fugitive dust deposition result in a life incremental cancer risk of less than $10^{-6}$ (DOE-RL 1993).

\subsubsection{Surface Water Pathway}

This pathway includes surface water transport resulting from run-off from storm events and deposition of airborne fugitive dust on nearby surface water bodies with subsequent transport. After consideration of the potential for run-off and review of the results of the fugitive dust modeling, the potential for transport by the surface water pathway was considered to be insignificant in the Phase I RI report (DOE-RL 1993). 


\subsubsection{Subsurface Water Pathways}

The unsaturated or vadose zone consists of all soil between the ground surface and the water table. The saturated zone lies beneath the water table of unconfined aquifers, or the sonfining layer of confined aquifers. The physics describing movement of water in the saturated and ursaturated zones are different, so the two zones are frequently separated into different pathways.

2.4.3.1 Saturated Pathway. By definition, this operable unit does not include the saturated pathway. A portion of the saturated zone was, however, incorporated into the unsaturated pathway. The unsaturated pathway modeled lies between the bottom of the cribs and the bottom of the unconfined aquifer directly beneath the cribs. Inclusion of the saturated zone in the unsaturiced pathway was necessary to determine which of the potential contaminants of concern reach the water table at unacceptable concentrations. Although the 200-BP-1 operable unit is a source operable unit, the prediction of future potential impacts to the underlying unconfined aquifer is needed to formulate remedial action objectives and evaluate appropriate source control measures.

2.4.3.2 Unsaturated Pathway Modeling. Contaminant migration through the vadose zone, due to historical crib operation and subsequent infiltration of meteoric water, was modeled using a finite difference computer code (PORFLO-3) (Runchal, et al 1992). The modeling objective was to identify potential future impacts to the unconfined aquifer.

Several scenarios with different infiltration rates were modeled using PORFLO-3. Simulations were run with an unrealistically high infiltration rate of $22.5 \mathrm{~cm} / \mathrm{yr}, 10 \mathrm{~cm} / \mathrm{yr}$, and at a more realistic natural infiltration rate of $1.0 \mathrm{~cm} / \mathrm{yr}$. Each simulation was run until either the contaminant reached the water table directly below the operable unit at a concentration of $1 \mathrm{pCi} / \mathrm{L}$, or the simulations indicated that it was unlikely that the contaminant would reach the "Nater tabie at these concentiations. In general, those contaminants which were both immobile and short-lived never reached the water table at unacceptable levels. These included Cs-137 and $\mathrm{S}_{\mathrm{r}}-90$ which were bound in the upper $23 \mathrm{~m}$ $(75 \mathrm{ft})$ at the time discharge to the cribs ceased. Radioactive decay following cessation of discharge prevented either contaminant from reaching the water table, even under extreme infiltration rates of $22.5 \mathrm{~cm} / \mathrm{yr}$ simulated in the model.

Migration of Co-60 to the water table was shown to occur rapidly with concentrations in the saturated zone reaching maximum values soon after crib operations began. Because of its short half-life, however, within 100 years the concentration of Co-60 in the groundwater was reduced to less than $1 \mathrm{pCi} / L$. The modeling results indicate that the most mobile constituents, Tc- 99 and nitrate, reached the aquifer at maximum concentration shortly after cessation of discharge to the cribs. Residual Tc-99 and nitrate are currently impacting the groundwater at concentrations of about $400-700 \mathrm{pC} / \mathrm{L}$ and $10-20 \mathrm{mg} / \mathrm{L}$, respectively.

Of the compounds modeled, potential future impacts to groundwater were confined to plutonium and uranium. Aithough plutonium has a distribution coefficient similar to that of Cs-137, it also has an extremely long half-life thereby allowing it to reach the water table in an estimated 9,500 yr. Diffusion is the dominant transport mechanism for plutonium. Although the maximum concentration of plutonium in groundwater was not modeled, it is expected to be significant $(>100 \mathrm{pCi} / \mathrm{L})$ in tens-of-thousands of years. Total $U$ 
is shown reaching the water table by about $15 \mathrm{yr}$ after the start of crib operations. The maximum concentration of total uranium in the saturated zone could exceed $3,000 \mathrm{pCi} / \mathrm{L}$ approximately $4,500 \mathrm{yr}$ in the future. Detailed modeling results are evaluated and presented graphically in Chapter 6.

The unsaturated pathway modeling predicts potential future impacts to the surface of the aquifer directly beneath the cribs. These estimates illustrate contaminant concentrations at the top of the aquifer and not at the boundary of the operable unit. As a result, the estimated travel times are conservatively short in that they do not account for the time required to migrate laterally to the operable unit boundary. Up to three or four times the estimated vertical travel time may be required before contaminants substantially impact groundwater at the operable unit boundary (see Chapter 6).

\subsubsection{Biotic Pathways}

Terrestrial biological transport of cesium-137, radium-226, strontium-90, thorium-228, and total uranium from near surface soils to Swainson's hawk, loggerhead shrike, and burrowing owl were considered in the Phase I RI. Two generalized contaminant transport pathways for the species of concern were considered. The first model assumed that the exposure mechanism for the birds was ingestion of the Great Basin pocket mouse, while in the second model the bird's diet consisted entirely of insects. Within each type of prey, estimated contaminant concentrations attributable to the operable unit were estimated for the near surface soil contaminants of potential concern. The estimated tissue concentrations were carried forward for use in the ecological risk assessment. Due to the lack of species-specific concentration data, conservative simplifying assumptions and surrogate uptake factors were necessar; in the biological transport pathway evaluation.

\subsection{SUMMARY OF BASELINE RISK ASSESSMENT}

\subsubsection{Human Risk Assessment}

The human health baseline risk assessment evaluates the risks posed by contaminants in the 200-BP-1 operable unit under four exposure scenarios (industrial, residential, recreational, and agricultural) and three locations (operable unit, Hanford Site, off Hanford Site). These evaluations are performed for current conditions as well as for several future conditions. Evaluation of the future conditions is divided into three possibilities:

- the clean soil cover is maintained and undisturbed

- the near surface soils are exposed and/or excavated

- the infiltration gravels/soils are exposed and deposited on the ground surface.

Non-radioactive contaminants were evaluated for both non-carcinogenic and carcinogenic effects, as appropriate. Radioactive contaminants were evaluated only for their carcinogenic potential. No systemic toxic effects are expected to occur as a result of exposure to contaminants at the operabie unit under any scenario; the largest estimated 
hazard quotient $(\mathrm{HQ})$ is 0.007 . The remaining summary of the human health assessment focuses on estimates of cancer risk.

Evaluation of the current scenario recognizes that a clean soil cover exists at the operable unit and that access to the unit is limited. For both crib groupings (cribs 216-B-43 through -50 and crib $216-B-57$ ), the estimated cancer risks under the current scenario is less than $1 \times 10^{-6}$.

Although future land use of the 200 Area is assumed to be limited to industrial activities based on recommendations from the Hanford Future Site Uses Working Group (HFSUWG 1992), for the purposes of this human health baseline risk assessment, radiological controls are assumed to be nonexistent for the future industrial scenarios. Even without restricting access to the operable unit, this risk assessment indicates that a cancer risk of $10^{-6}$ is exceeded only under the future industrial scenario for receptors on the operable unit, and only if near surface soils or infiltration gravels/soils are uncovered, permitting direct contact with contaminants.

Assuming near surface soils are exposed, the risk for operable unit receptors is $9 \times 10^{-5}$ for cribs $216-\mathrm{B}-43$ through -50 , and $2 \times 10^{-5}$ for crib $216-\mathrm{B}-57$. Risk estimates associated with excavation of infiltration gravels/soils (which are approximately $4.6 \mathrm{~m} \mathrm{[15} \mathrm{ft}]$ below ground surface) for operable unit receptors exceed $10^{-2}$ for both crib groupings. Because risk estimates made using a linear dose-response equation become increasingly inaccurate as they approach a value of $1, \mathrm{LICR}$ values that exceed $1 \times 10^{-2}$ are reported as $>10^{-2}$.

Risk estimates for receptors on the Hanford Site (excluding the 200 Area) and off the Hanford Site are less than $1 \times 10^{-6}$ under all future conditions. This is the case even with the assumption that infiltration gravels/soils are deposited on the surface and contribute exposures resulting from fugitive dust emissions and deposition of cesium-137 and strontium-90.

The risk estimates for future conditions do not consider the probability that the clean soil cover will be absent or present in the year 2018, or that future operable unit workers will excavate the near surface soils or infiltration gravels/soils. In addition, because this is a deterministic risk assessment, the uncertainty associated with all risk estimates cannot be quantified. In order to compensate for the uncertainty associated with input parameters, estimates used to characterize these parameters are often conservatively biased. As a result, the risk estimates provided in this assessment represent a set of assumptions which, as a whole, is extremely unlikely. Use of a more realistic set of assumptions is likely to yield significantly lower risk estimates.

\subsubsection{Ecological Risk Assessment}

The baseline ecological risk assessment evaluates the impact of near surface soil contaminants on six indicator species (Great Basin Pocket mouse, Jack rabbit, Swainson's hawk, loggerhead shrike, burrowing owl, and coyote). No data have been obtained to provide concentrations of contaminants in biological media within the operable unit; therefore, biological uptake of contaminants by indicator species is estimated by combining soil concentrations, bioconcentration factors, gastro-intestinal absorption efficiencies, biological half-lives, and food intake rates. Inhalation and soil ingestion pathways were not 
evaluated. External exposure to wildlife from radioactive contaminants has been shown to be a minor contributor to dose and was not evaluated.

The scological assessment is based on the assumption that a clean soil cover does not exist, and that no controls exist to prevent access to the operable unit by the indicator species. In addition, it is assumed that ecological conditions on the unit (e.g., vegetation and food supply) are identical to the natural habitat of these species. Such conditions do not currently exist, and, given the assumption of permanent industrial land use in the 200 Area, the presence of indicator species on the operable unit could be controlled indefinitely.

The frequency of exposure of a receptor to contaminants was determined by estimating the proportion of the site area to the receptor's home range. For organisms whose home range is smaller than the operable unit, it is assumed that $100 \%$ of their diet consists of contaminated foodstuffs. The $95 \%$ UCLs of the mean soil concentrations are used as the exposure concentrations for modeling and dose calculations.

Contaminant intakes are calculated in units of $\mathrm{mg} / \mathrm{kg}$ - $\mathrm{d}$ for non-radioactive contaminants, and rad/d for radionuclides. These intakes are divided by benchmark intakes to yield (unitless) hazard indices. The benchmark intake level for radioactive contaminants is $0.2 \mathrm{rad} / \mathrm{d}(20 \%$ of the $1 \mathrm{rad} / \mathrm{d}$ dose rate at which slight effects of radiation become apparent in important population maintenance attributes). A hazard index (HI) value greater than 1 indicates that a benchmark intake value may be exceeded, potentially resulting in an adverse impact on the ecological receptor population.

For the six key receptors evaluated, $\mathrm{HI}$ values range from 0.001 to 16 for radioactive contaminants. The potentially impacted receptors $(\mathrm{HI}>1)$ are the Pocket mouse, jack rabbit, loggerhead shrike, and burrowing owl. This assessment indicates that these receptors could be adversely impacted by near surface soil contaminants on the operable unit if exposure to these soils is allowed to occur. Uncertainty associated with the results of the ecological assessment are extremely high because of the limited number of exposure pathways evaluated, and the conservative assumptions made in the evaluation of the food chain pathway. 


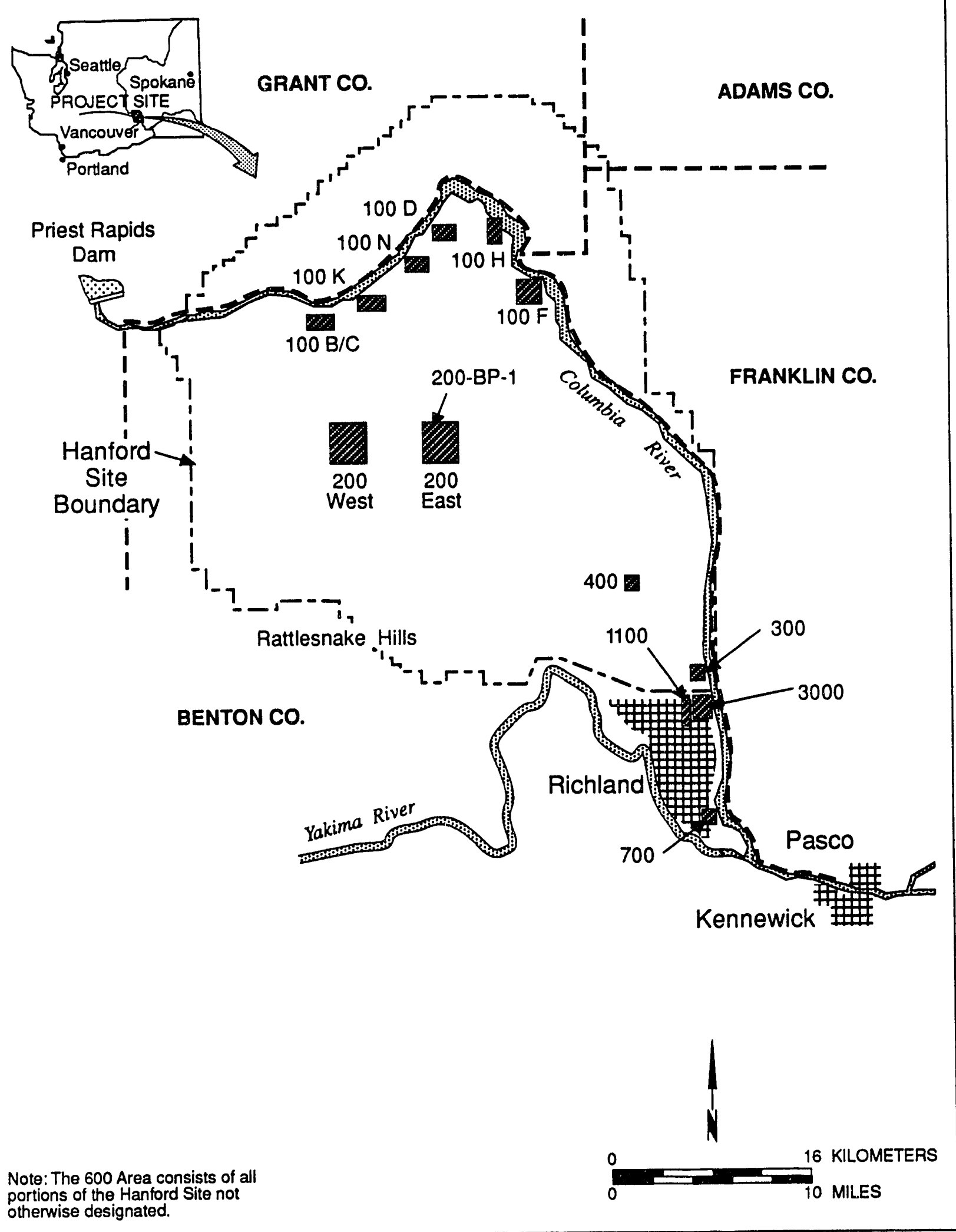

$9031216 / 44968 / 4-23-93$

Figure 2-1. Hanford Site Map. 
DOE/RL-93-35, Rev. 0

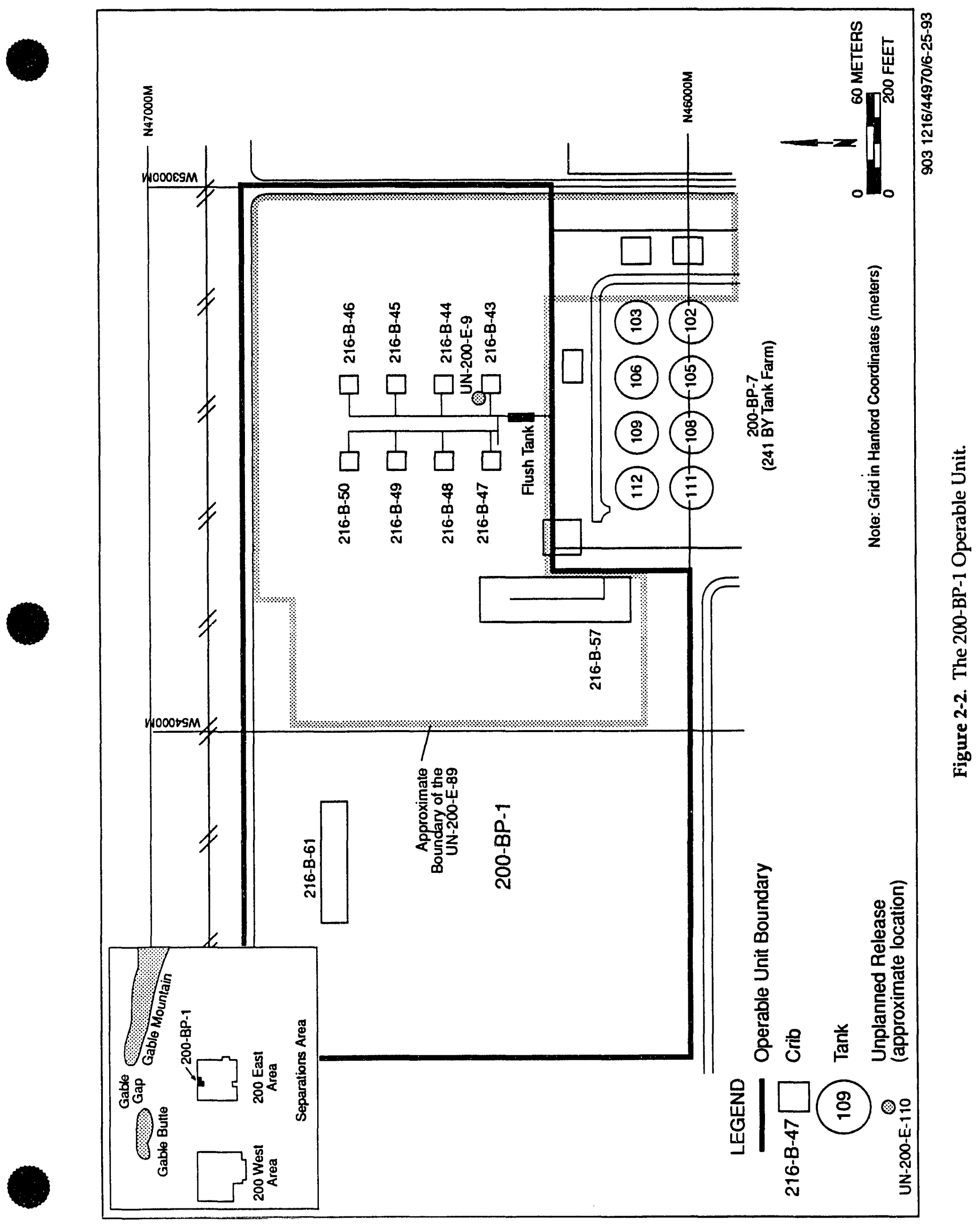




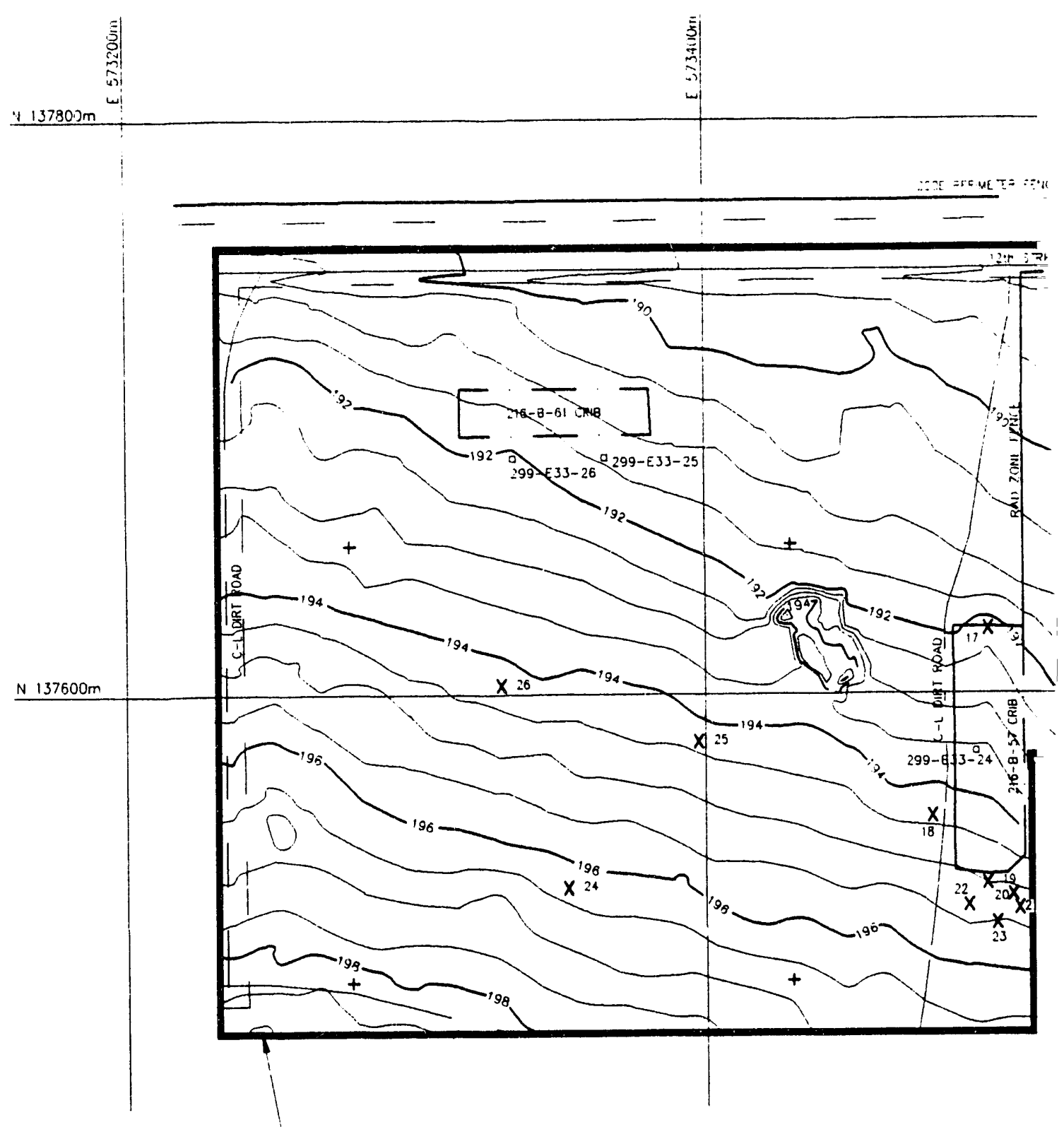

ZOO-BP-I OPE PABLE UNIT GOUNDAPY 

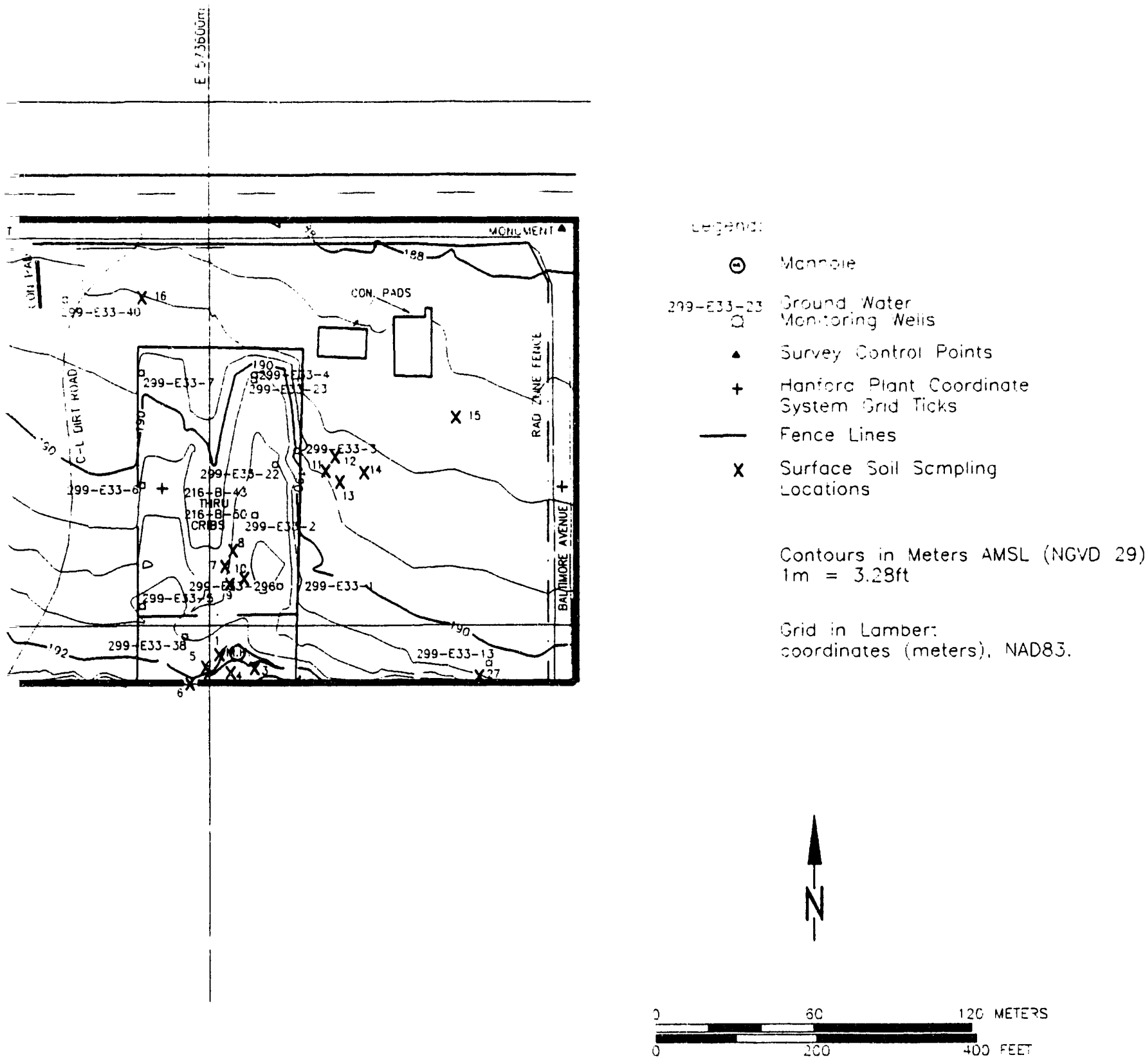

'WORK! $9031216 \backslash 31919 \quad 6-22-93 \quad 20.04$

Figure 2-3. Topography of the 200-BP-1 Operable Unit. 


\section{Before Interim Stabilization}
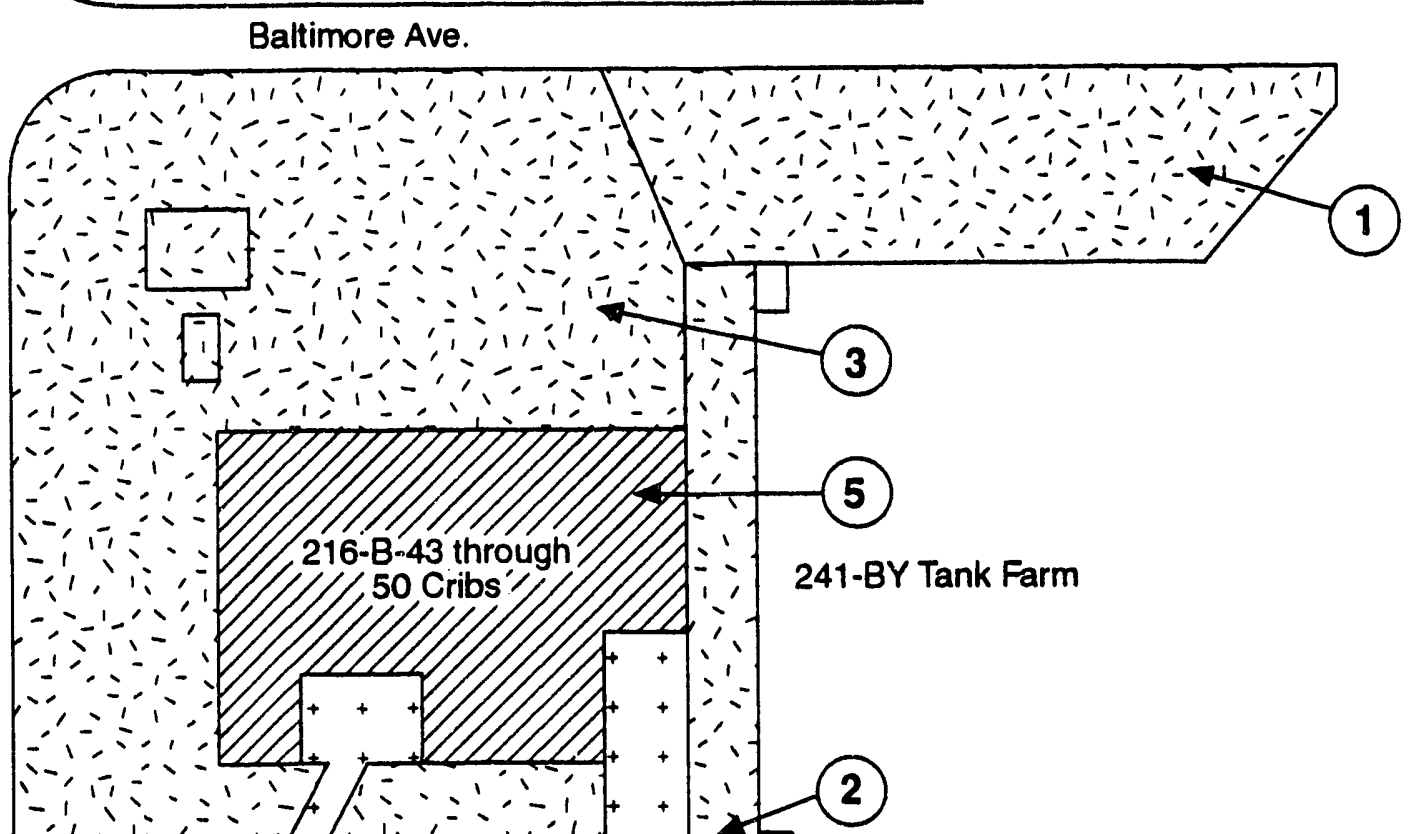

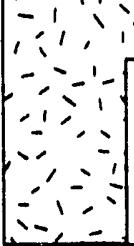

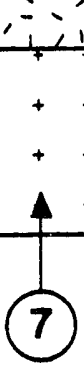

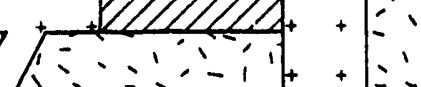

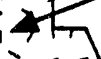

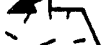

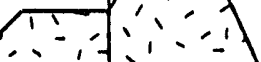

1

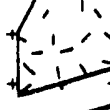

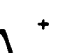

$\because, 1-\because=$

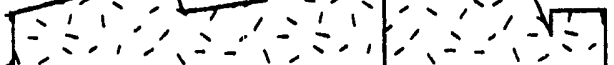

216-B-57 Crib"

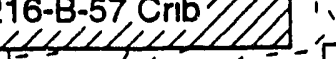

6

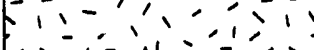

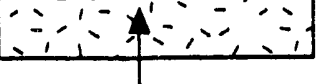

(4) 
After Interim Stabilization

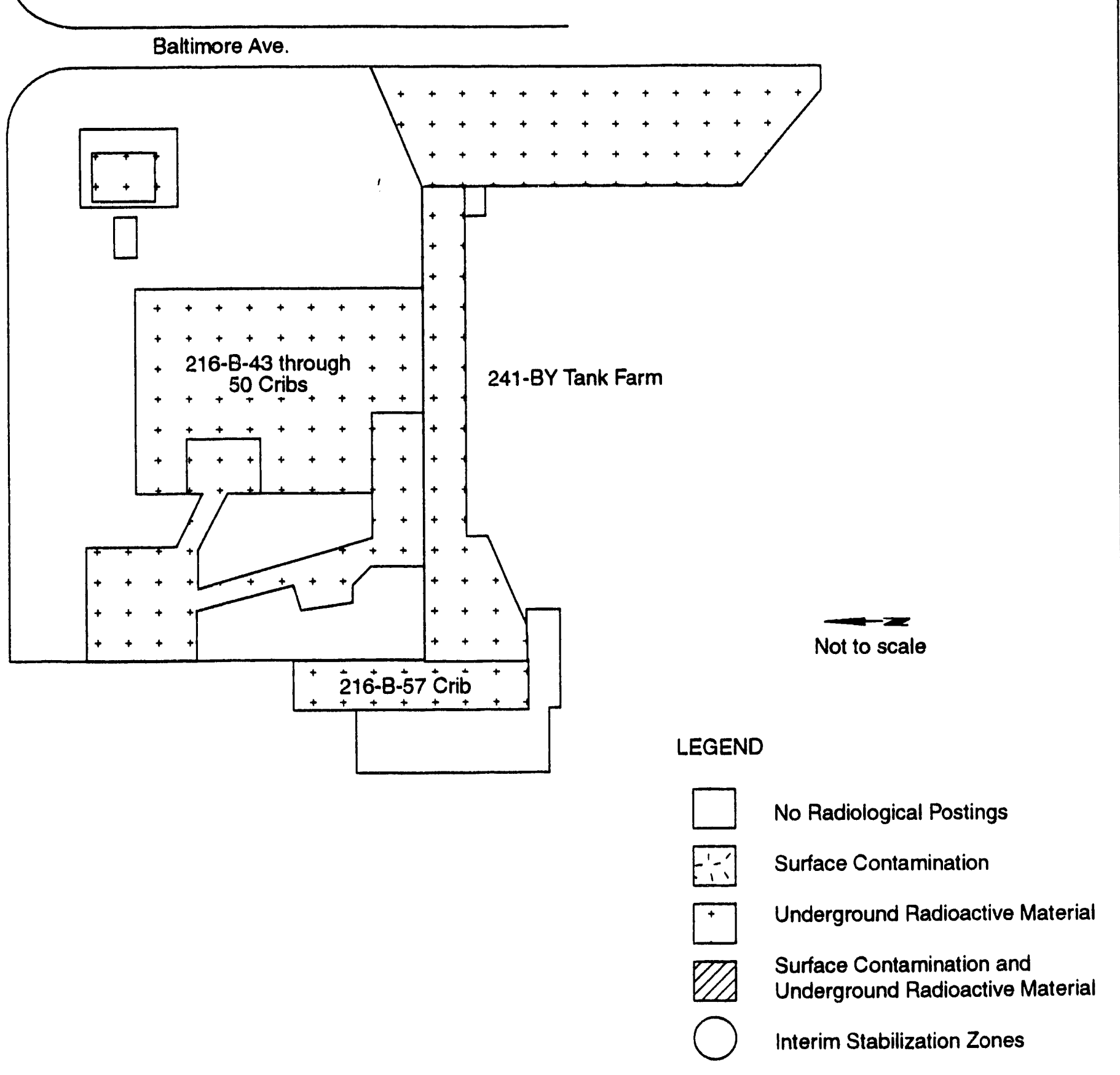

903 1216/44969/6-23-93

Figure 2-4. Interim Stabilization Zones within the UN-216-E-89

Unplanned Release. 
DOE/RL-93-35, Rev. 0

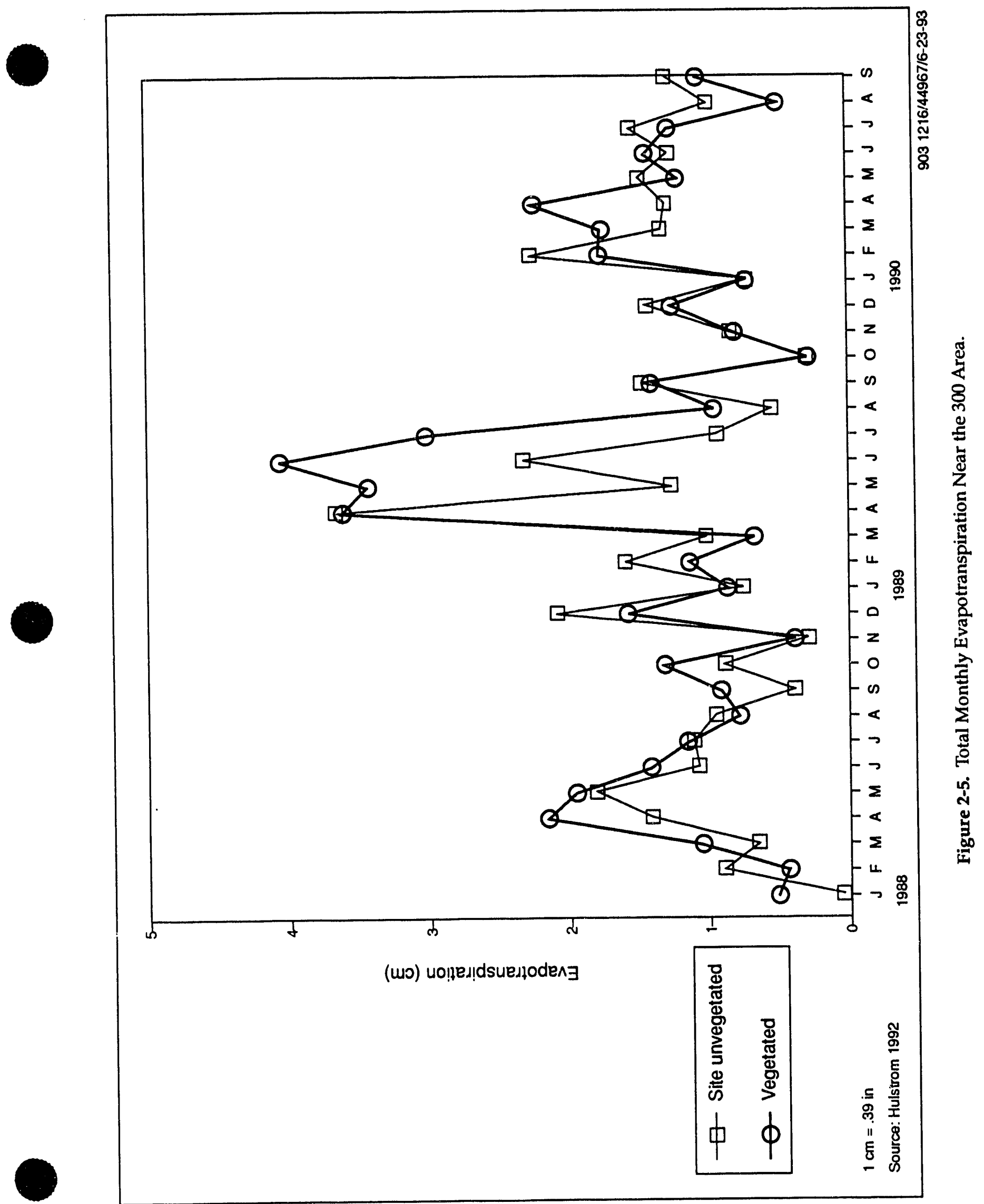


DOE/RL-93-35, Rev. 0




DOE/RL-93-35, Rev. 0

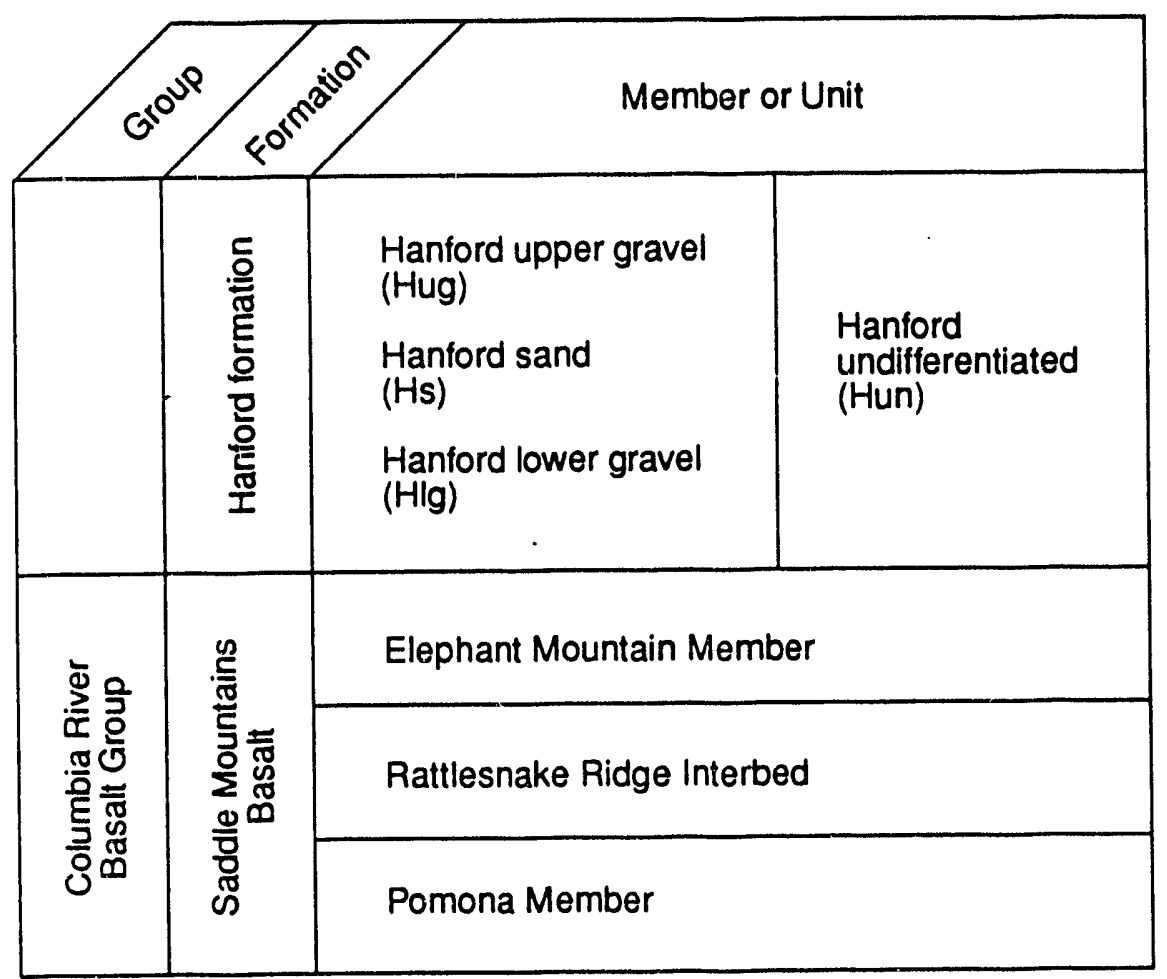

Figure 2-7. Generalized Stratigraphic Column of the 200-BP-1 Operable Unit. 


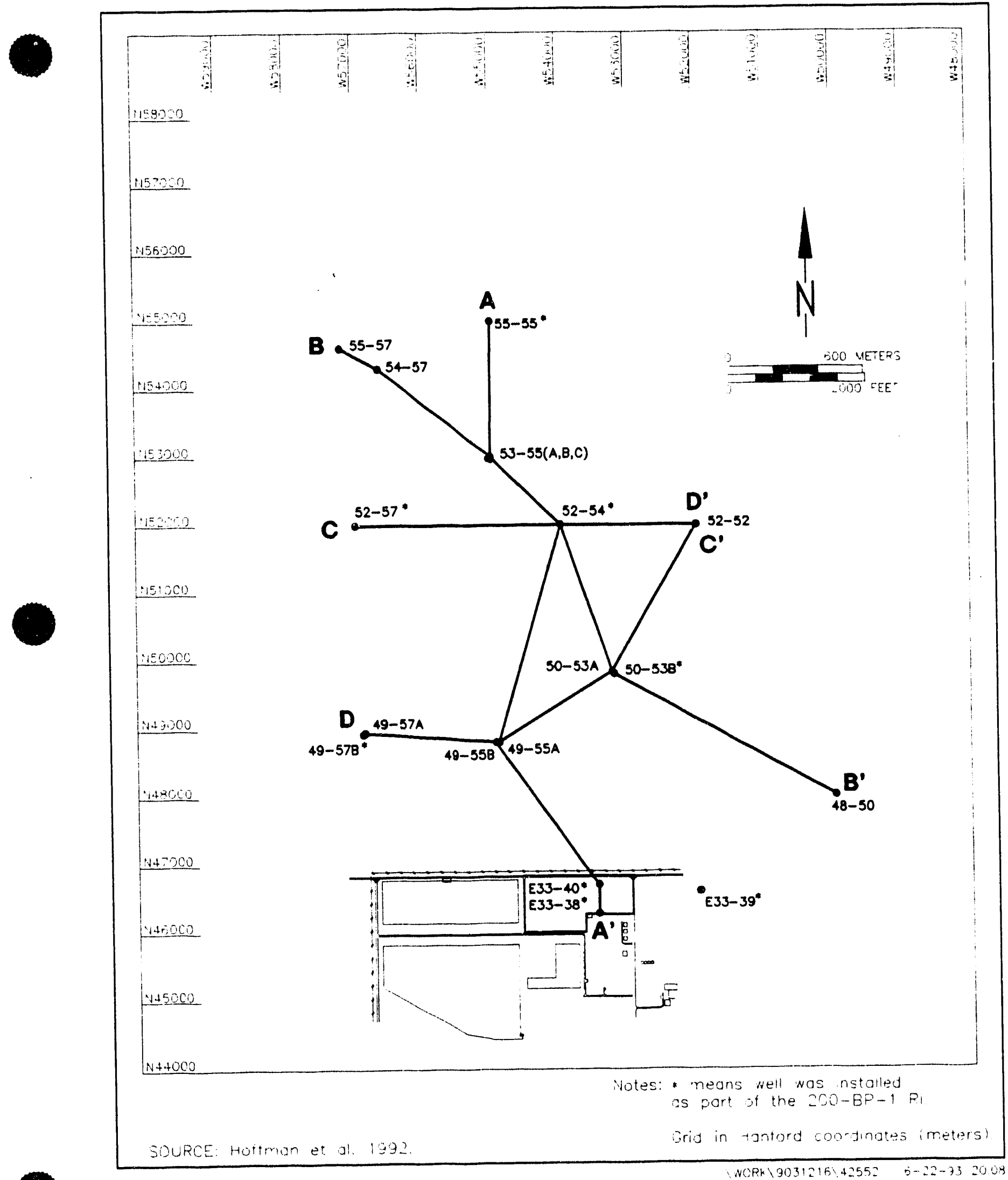

Figure 2-8a. 200-BP-1 Operable Linit Map Cross Section Locations. 


\section{Explanation of Symbols}

Srair Size Bos. injicares

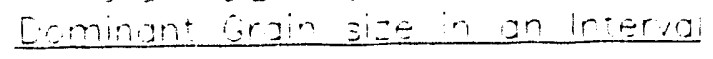

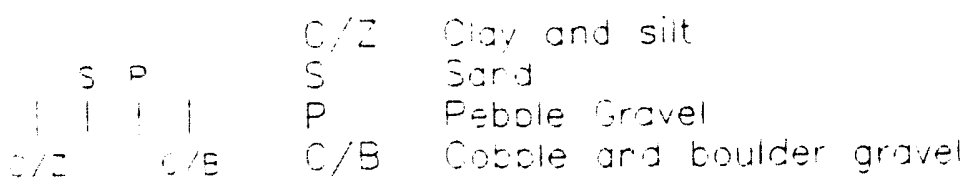

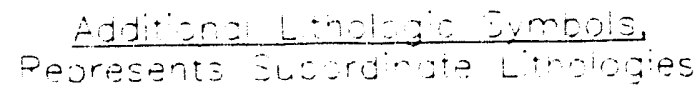

$$
\begin{aligned}
& \text { - - rar righ } \\
& \sim \sim \text { Eitrich } \\
& \text { Earis } \\
& \because \because \because: \text { Eab-i, to cotbiv } \\
& \therefore: \therefore \text { Eudicery } \\
& \therefore \because \equiv \text { Esint }
\end{aligned}
$$

\section{Sther Syme:15}

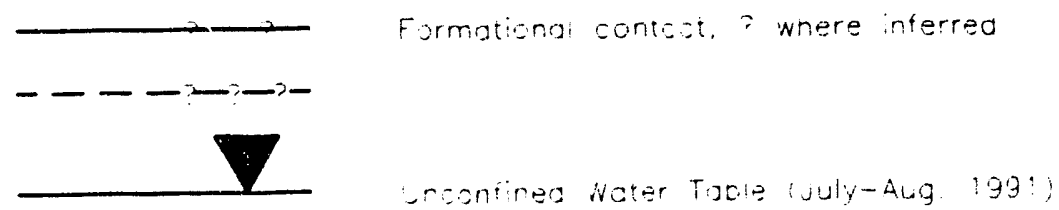

\section{Eiratigrapnic Atereviatons}

$$
\begin{aligned}
& \text { Hun -- Undifferentiotej Houforj formction } \\
& \text { Hug - Loder arjul sequence. Hanford formction } \\
& \text { Hs .. Sona, Secuence, tonford formation } \\
& \text { - a - Liwer aravel cezuence, Hanfora formation }
\end{aligned}
$$

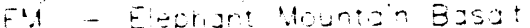

$$
\begin{aligned}
& \text { Ea - Pottlesnake Pldge nterced } \\
& \text { - - Pomono Basait }
\end{aligned}
$$

Sours: totton et a tog.

Figure 2-8b. Explanation of Symbols Used in Geologic Cross-Sections.

$$
z=-3 b
$$




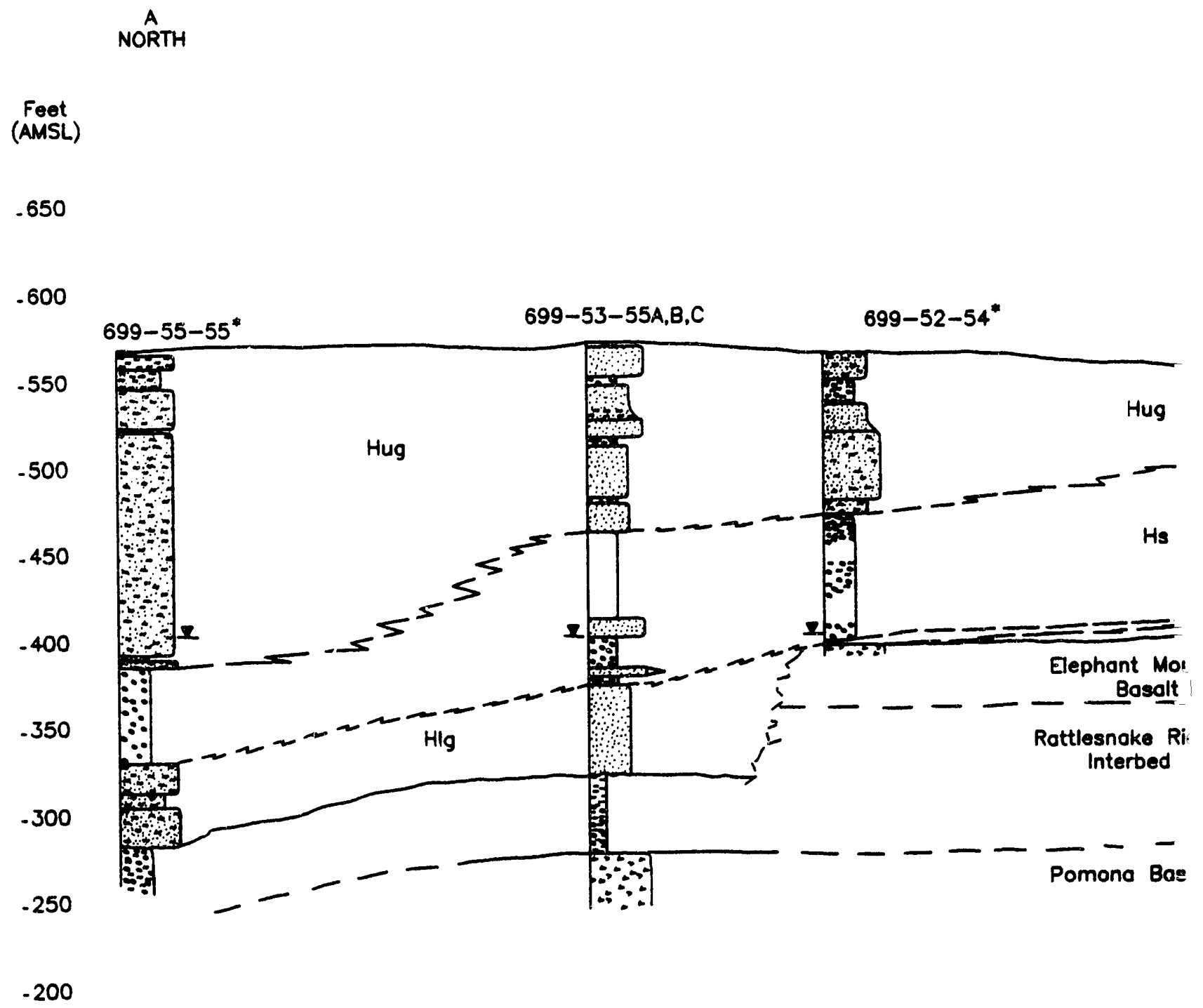

Grain Size Scale

(indicates dominant litholeax)

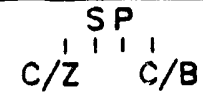




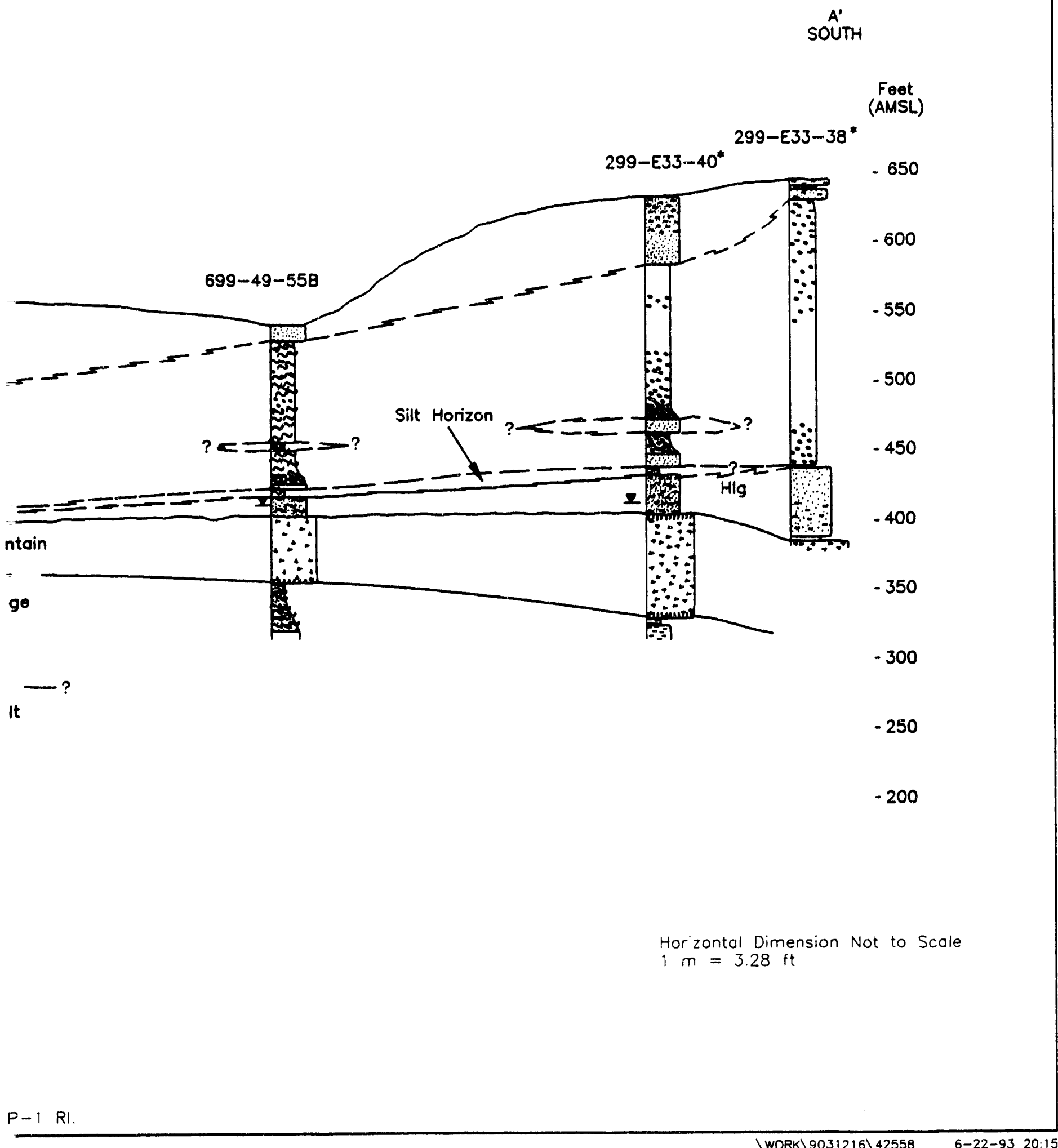

Figure 2-9. Cross Section A-A'. 


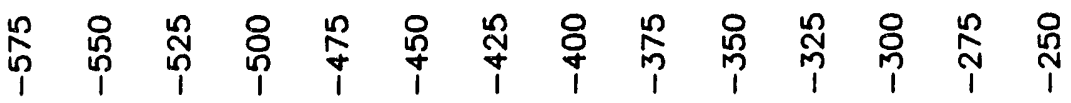

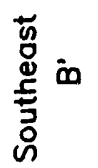

1

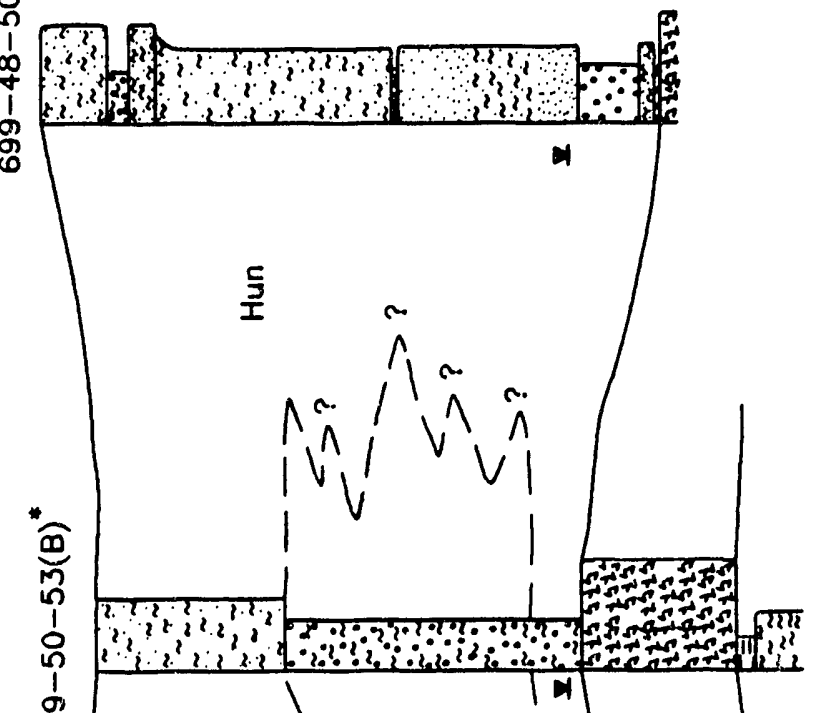

$\frac{2}{0}$

(n)
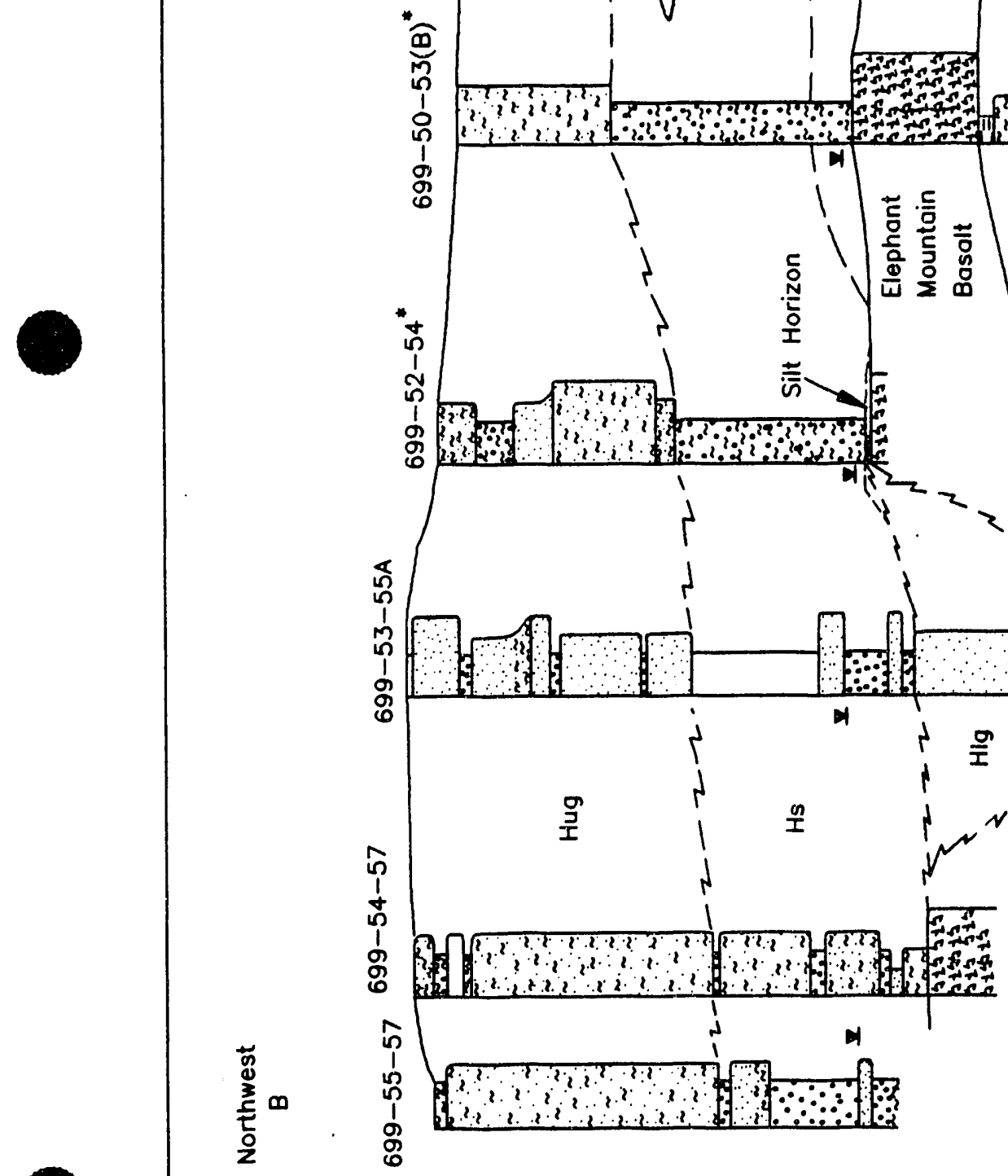

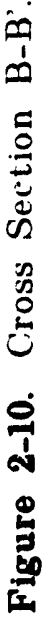




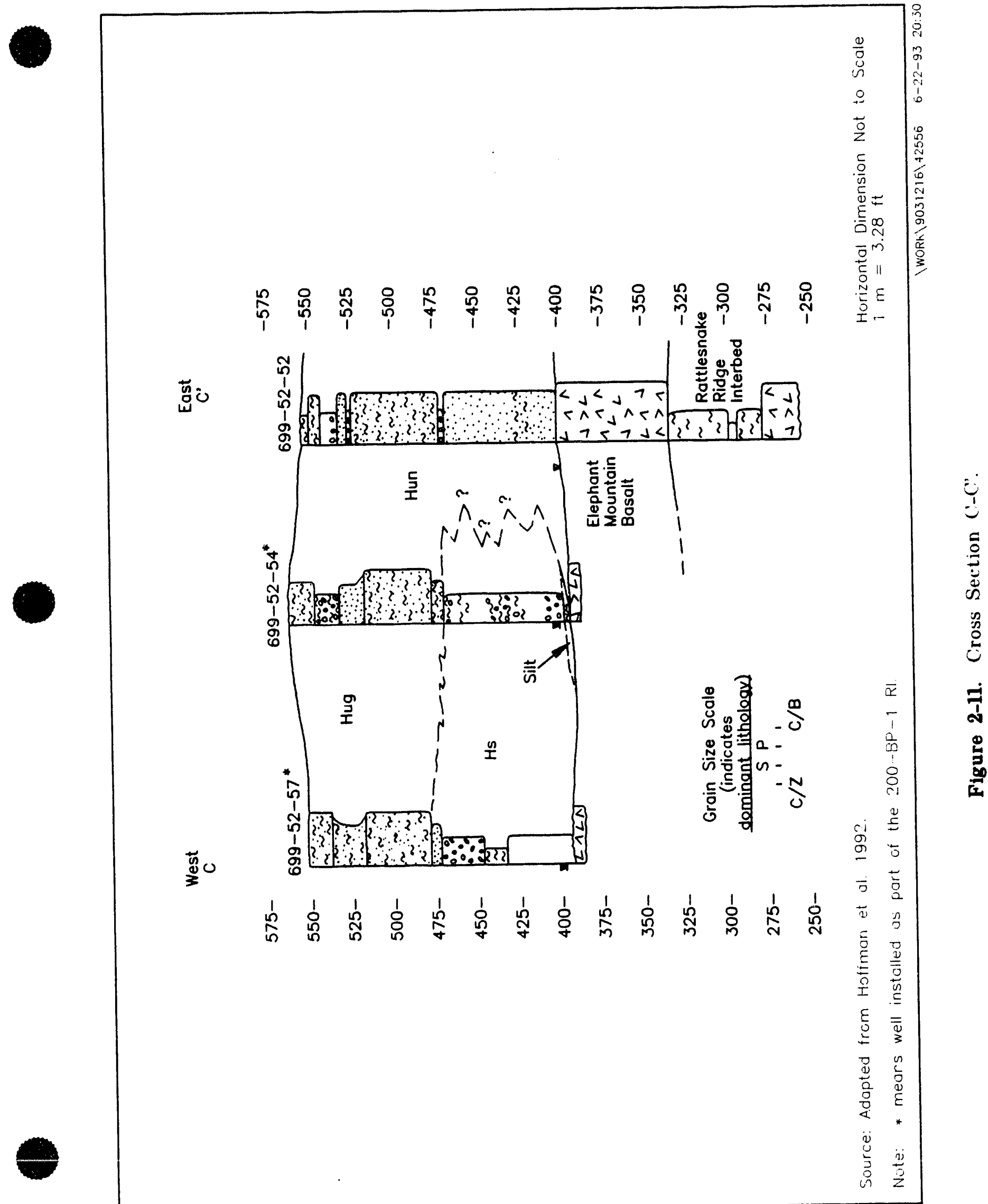




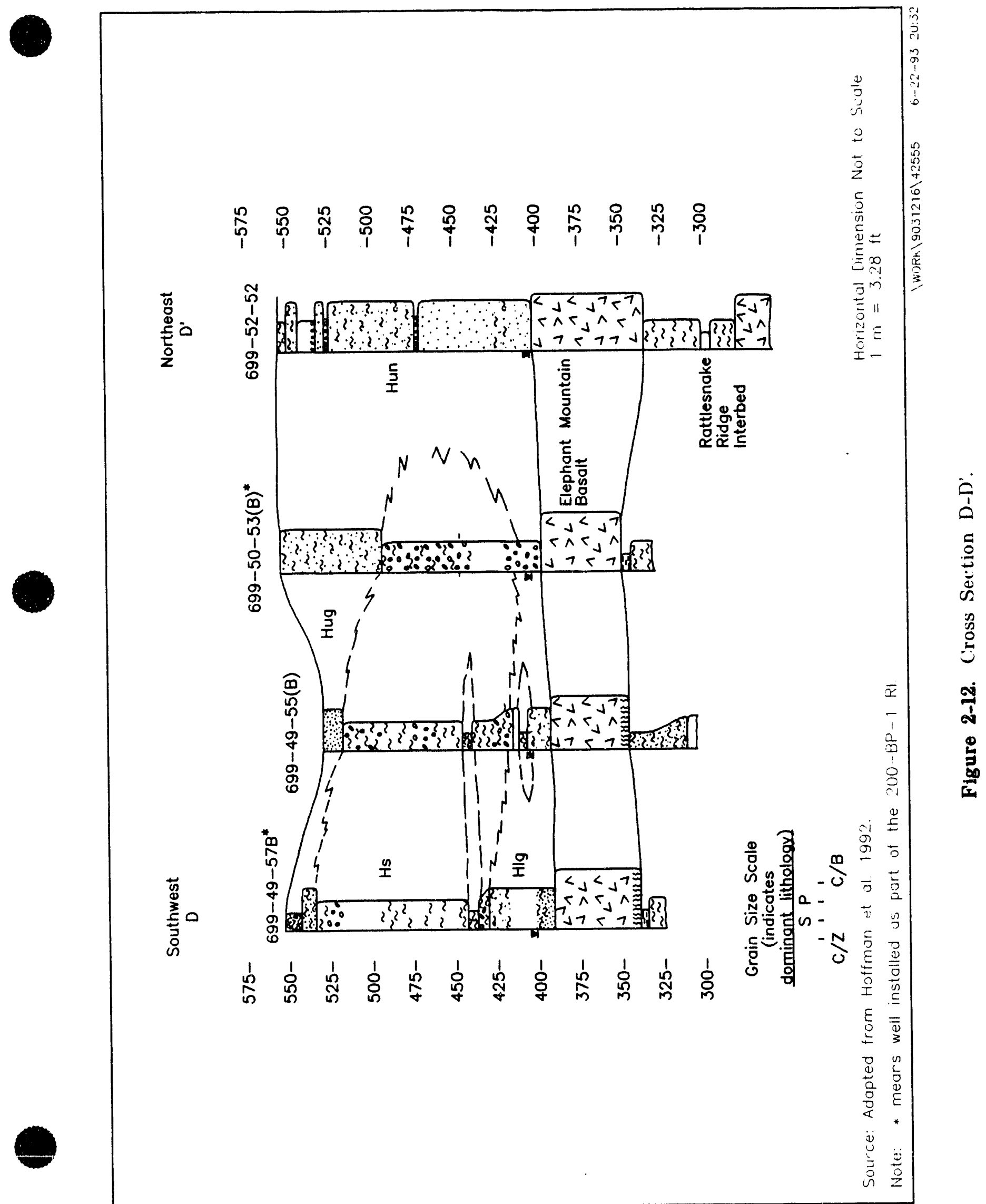




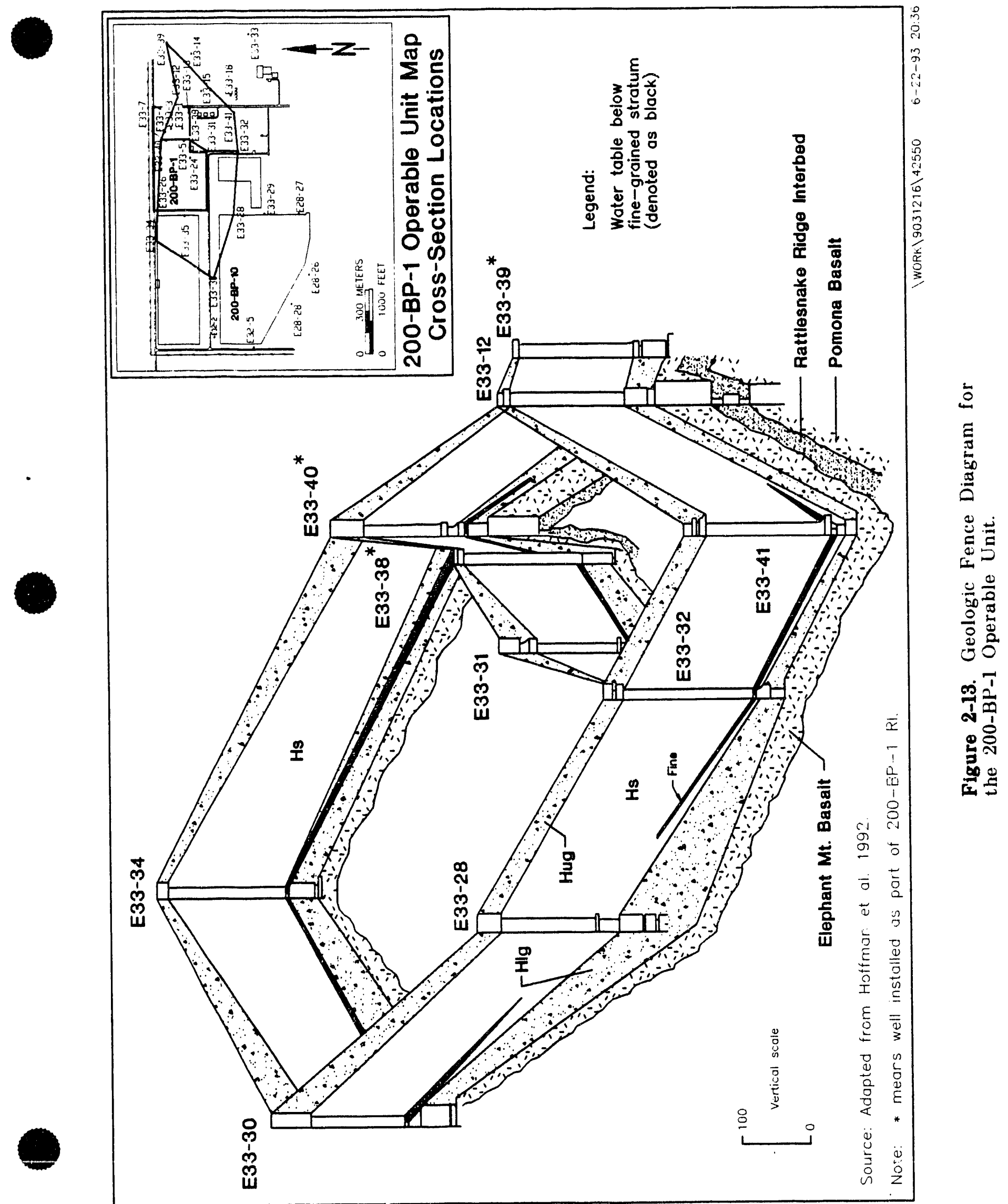


DOE/RL-93-35, Rev. 0

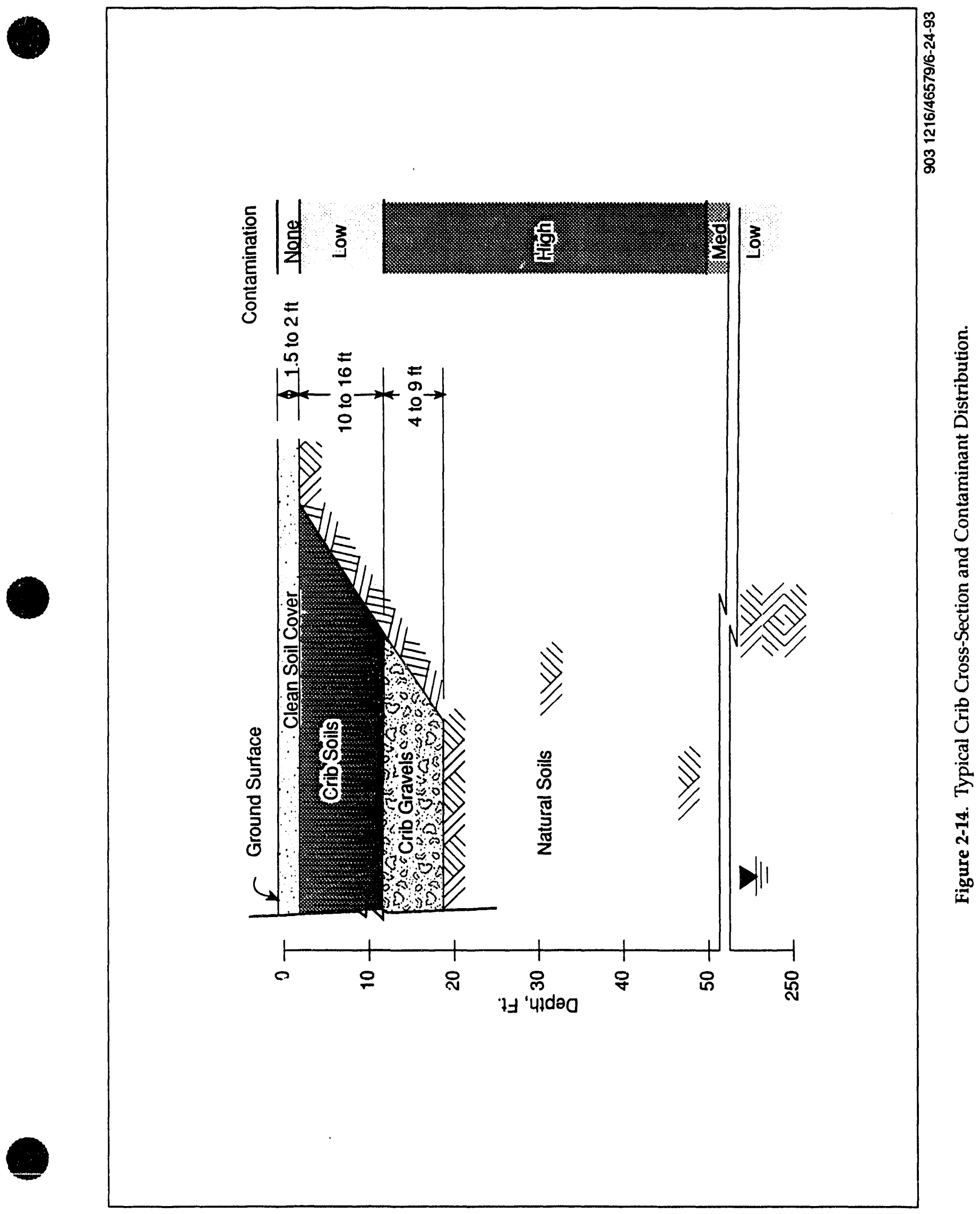




\subsection{REMEDIAL ACTION OBJECTIVES AND GENERAL RESPONSE ACTIONS}

Remedial action objectives (RAOs) for the feasibility study are developed in this chapter. They provide the foundation for the FS, and the basis for identification and screening of remedial technologies presented in Chapter 4. Remedial action objectives are operable unit-specific goals for protecting human health and the environment. For the 200-BP-1 soils operable unit, RAOs are based on the findings of the Phase I RI and on the statutory requirements of CERCLA, the NCP and the Tri-Party Agreement. The development of RAOs is founded on the baseline risk assessment and chemical-specific ARARs, and are specific for the contaminants of concern and exposure pathways identified for the site. Using this information, allowable exposures for each contaminant (or group of contaminants) and for each pathway are defined in Section 3.1. RAOs are then formulated in Section 3.2, specifying the goals for protecting human health and the environment based on allowable exposures. General response actions (GRAs) are formulated to satisfy the RAOs in Section 3.3. Finally, the areas and volumes of contaminated soils to be impacted by each GRA are estimated in Section 3.4.

\subsection{ACCEPTABLE EXPOSURE}

As specified in the NCP in 40 CFR 300.430 (e)(2)(i), remediation goals for the 200-BP-1 operable unit are based on establishing acceptable exposure levels that are protective of human health and the environment by considering chemical-specific and location-specific ARARs and risk-based exposure concentrations.

The NCP states that acceptable exposure levels will be based on ARARs, where they are available and are sufficiently protective. For known or suspected carcinogens where ARARs are not available, acceptable exposure levels are concentration levels that represent an excess upper bound lifetime cancer risk to an individual of between $10^{-4}$ and $10^{-6}$. The $10^{-6}$ risk level is to be used as the point of departure for determining remediation goals for alternatives when ARARs are not available or are not sufficiently protective, because of multiple contaminants or multiple pathways of exposure. The NCP specifies that in cases involving multiple contaminants or pathways, where attainment of chemical-specific ARARs will result in cumulative cancer risk in excess of $10^{-4}$, the cleanup level should be established using risk-based criteria.

Potential chemical-specific, location-specific and action-specific ARARs are discussed in Section 3.1.1. Acceptable risk-based exposure concentrations are discussed in Section 3.1.2.

\subsubsection{Potential Applicable or Relevant and Appropriate Requirements}

This section consists of a review of potential federal and state applicable or relevant and appropriate requirements (ARARs) which may be pertinent to the remedial actions which are considered in the FS. Identification and refinement of ARARs is an ongoing process which occurs throughout all phases of the RI/FS. The review of ARARs included herein is an update of the preliminary ARAR identification which was presented in the 
Phase I RI. The ARAR development process is based on CERCLA guidance (EPA 1988a and EPA 1988b).

Section 121 (d) of CERCLA, as amended establishes cleanup standards for remedial actions. This section requires in part that, any applicable or relevant and appropriate standard, requirement, criteria or limitation under any federal environmental law, or any more stringent state requirement promulgated pursuant to a state environmental statute, be met for any hazardous substance, pollutant, or contaminant remaining on-site.

A requirement for Superfund compliance at a hazardous substance cleanup site may be either "applicable" or "relevant and appropriate", but not both. Identification of ARARs must be done on a site-specific basis and involves a two-part analysis: first, a determination is made whether a given requirement is applicable; then if it is not applicable, a determination is made whether it is nevertheless both relevant and appropriate. The EPA guidance also includes To-Be-Considered (TBC) materials which are advisories and nonpromulgated guidance issued by federal or state governments that are non-statutory requirements evaluated along with ARARs as part of the risk assessment used to establish protective cleanup limits.

The EPA may waive ARARs and select a remedial action that does not attain the same level of cleanup as identified by ARARs. Section 121 (d)(4) of CERCLA identifies six circumstances where EPA may waive ARARs for on-site remedial actions. The six circumstances are:

- The remedial action selected is only a part of a total remedial action (such as an interim action) and the final remedy will attain the ARAR upon its completion.

- Compliance with the ARAR will result in a greater risk to human health and the environment than alternative options.

- Compliance with the ARAR is technically impracticable from an engineering perspective.

- An alternative remedial action will attain an equivalent standard of performance through the use of another method or approach.

- The ARAR is a state requirement that the state has not consistently applied (or demonstrated the intent to apply consistently) in similar circumstances.

- In the case of Section 104, Superfund-financed remedial actions, compliance with the ARAR will not provide a balance between protecting human health and the environment and the availability of Superfund money for response at other facilities.

The different types of requirements that CERCLA actions may have to comply with are identified as chemical-specific, location-specific and action-specific ARARS. The following definitions are excerpts from EPA guidance in CERCLA Compliance with Other 
Laws Manual: Interim Final (EPA 1988b). However, some requirements may not fall neatly into the classification system.

Chemical-specific requirements are usually health-or risk-based numerical values or methodologies which, when applied to site-specific conditions, result in the establishment of numerical values. These numbers establish the acceptable amount or concentration of a chemical that can be found in, or discharged to the ambient environment.

Location-specific requirements are restrictions placed on the concentration of hazardous substances or the conduct of activities because they occur in special or sensitive locations or environments.

Action-specific requirements are those that place either technology-based or activitybased requirements on remedial actions at CERCLA sites.

Federal and state regulations along with other guidance were evaluated as potential ARARs and TBC materiais. The laws and regulations evaluated a potentially applicable or relevant and appropriate requirements for the 200-BP-1 operable unit are summarized in Tables 3-1 and 3-2. Significant requirements are discussed in the following sections.

3.1.1.1 Chemical-Specific ARARs. Chemical-specific ARARs may be federal, state regulations and other guidance that identify acceptable health or risk based contaminant levels for different media known to be contaminated.

3.1.1.1.1 Federal Chemical-Specific ARARs. Federal chemical-specific requirements, criteria, or guidance for the contaminants of concern at the 200-BP-1 operable unit are listed in Table 3-1. Regulatory limits for contaminants of concern, established by these regulations are presented in Table 3-3.

National Primary Drinking Water Regulations. The National Primary Drinking Water Regulations (40 CFR 141) promulgated under the Safe Drinking Water Act (SDWA) establish maximum contaminant level goals (MCLGs) and maximum contaminant levels (MCLs) for community drinking water systems. MCLs and MCLGs have been established for a large number of both non-radioactive contaminants and radionuclides. Because there are no drinking water systems affected by the 200-BP-1 operable unit, the regulations are not applicable. However, the regulations would be relevant and appropriate requirements to the 200-BP-1 operable unit if affected portions of the Hanford Site converts to other land uses, and the groundwater in the area is considered a potential source of drinking water. Section $300.430(e)(2)(i)(B)$ of the NCP states that remedial actions for ground or surface water that are current or potential sources of drinking water shall attain standards established under the SDWA, where the MCL or MCLG is relevant and appropriate to the circumstances of the release. Although groundwater affected by the 200-BP-1 operable unit is not currently used for drinking, it could be used in the future if the site is released from institutional controls. There is also potential for discharge of contaminated groundwater to the Columbia River which is used for drinking water. Remedial alternatives for the $200-\mathrm{BP}-1$ cribs and contaminated soils need to evaluate actions to prevent migration of contaminants from soils to groundwater at concentrations that cause the groundwater to exceed MCLGs and MCLs. Drinking water MCLGs and MCLs for radionuclide contaminants of concern are listed in Table 3-3. Nitrate was reported in the Phase I RI as 
the only non-radioactive contaminant of concern (DOE-RL 1993). The MCL and MCLG for nitrate are both set at $45 \mathrm{mg} /$.

National Secondary Drinking Water Regulations. The National Secondary Drinking Water Regulations control contaminants in drinking water that primarily affect aesthetic qualities of the water that relate to public acceptance. These regulations are not applicable nor relevant and appropriate to the 200-BP-1 operable unit since they are not federally enforceable. However, under Washington State regulations (173-340-720(2)(9)(ii)) they are a potential ARAR because State regulations specify secondary maximum contaminant levels (SMCLs) as enforceable standards. Secondary maximum contaminant levels have not been established for operable unit contaminants of concern.

National Emission Standards for Hazardous Air Pollutants. EPA standards for radionuclides from facilities owned and operated by DOE under 40 CFR 61.90, National Emission Standards for Hazardous Air Pollutants are potentially applicable since radionuclides are present in operable unit soils and there is potential for airborne release.

Environmental Radiation Protection Standards for the Management and Disposal of Spent Nuclear Fuel, High-Level and Transuranic Radioactive Waste. A performance standard of 1,000 years is currently required in the Environmental Radiation Protection Standards for the Management and Disposal of Spent Nuclear Fuel, High-Level, and Transuranic Radioactive Waste (40 CFR 191). Groundwater protection standards established under the regulation specify that disposal systems provide a reasonable expectation that for 1,000 years after disposal, the system shall not cause the radionuclide concentrations averaged over any portion of a special source of groundwater to exceed the levels presented in Table 3-3. However, the proposed rule published on February 10, 1993 (58 FR 7924) proposes that disposal systems shall be designed so that for $10,000 \mathrm{yr}$ of undisturbed performance after disposal shall not cause the levels of radioactivity to exceed the limits specified in 40 CFR 141, as they exist on the date the implementing agency determines compliance. Under the proposed rule, disposal methods would be required to limit radiation exposure to an individual to no more than 15 mrems per year.

The requirements of 40 CFR 191 are not potentially applicable requirements to the 200-BP-1 operable unit because the contaminated soils do not meet the definition of waste subject to the regulation. However, the long-term performance standards of 58 FR 7924 are potentially relevant and appropriate because of the long-lived radionuclide uranium that could impact groundwater within the 10,000 year time frame. Vadose zone modeling indicates that plutonium will not impact groundwater within this time frame. Table 3-3 summarizes the maximum allowable exposure to members of the public that may result from activities conducted at these facilities.

Health and Environmental Protection Standards for Uranium and Thorium Mill Tailings. Requirements of 40 CFR 192, Health and Environmental Protection Standards for Uranium and Thorium Mill Tailings are potentially relevant and appropriate requirements to the operable unit since they establish maximum acceptable cleanup levels for Ra-226, 228 and gross alpha radioactivity, which are contaminants of the 200-BP-1 operable unit. The standard states that remedial actions intended to stabilize the site be designed to be effective for up to 1,000 years, to an extent reasonably achievable, and in any case, no less than $\mathbf{2 0 0}$ years. This is a design standard and monitoring after disposal is not required to 
demonstrate compliance. The requirements are not applicable since the facility is not associated with uranium or thorium milling.

Standards for Protection Against Radiation. The NRC Standards for Protection Against Radiation found in 10 CFR 20 are relevant and appropriate to the operable unit since the regulation establishes standards for protection against radiation hazards that may result from occupational exposure or discharges to air and water. The standard is not applicable because it only applies to operations licensed by the Nuclear Regulatory Commission. The concentration limits for radionuclides in airborne and liquid effluent discharged to unrestricted areas established under the standard are summarized in Table 3-3.

DOE Order 5400.5 Radiation Protection of the Public and Environment. Radiation protection and radioactive waste management requirements issued under the Atomic Energy Act are implemented at DOE facilities as DOE orders. Under CERCLA these standards are TBC for activities conducted at the 200-BP-1 operable unit since they are not formally promulgated regulations. However, compliance with DOE Orders is required at Hanford. DOE Order 5400.5, Radiation Protection of the Public and Environment, includes derived concentration guides (DCGs) for radioactively contaminated liquid discharges to surface waters, aquifers, soil, and sanitary sewage systems. The order incorporates most of the same control and cleanup provisions of EPA's 40 CFR 192 and provides factors used to estimate external and internal doses received from exposure to radiation, as well as expanded requirements and guidance on environmental monitoring.

The DOE Order applies the "As Low As is Reasonably Achievable" (ALARA) process to radiation protection. The ALARA process is not a dose-based limit, but a process that has the objective of reducing exposures as far below applicable limits as practicable, while taking into account social, economic, technical, practical and public policy considerations. The ALARA process includes procedures for evaluating alternative operations and other factors to reduce radiation exposures.

Radiological protection requirements are established for residual radioactive material and cleanup of residual materials. The basic public dose limit is $100 \mathrm{mrem}$ effective dose equivalent per year in excess of natural occurring background. Additional guidelines for residual radioactive material in soils for radium and thorium are set at the levels issued under 40 CFR 192. Airborne radon decay product levels within habitable structures are set at 0.002 Working Levels, the same as promulgated under 40 CFR 192. The level of gamma radiation in any habitable structure shall not exceed $20 \mathrm{uR} / \mathrm{h}$ above background and residual concentrations of radionuclides in air and water are set at the DCGs or as required by applicable state and federal law. Long-term management guidelines for uranium, thorium and their decay products include:

- $\quad$ Control and stabilization features designed to provide to the extent possible an effective life of $1,000 \mathrm{yr}$, but no less than $200 \mathrm{yr}$.

- $\quad$ Rn-222 emanation limited to less than $20 \mathrm{pCi} / \mathrm{m}^{2} / \mathrm{s}$ and prevent increase in $\mathrm{Rn}-22$ concentrations at any point at or outside the boundary by more than $0.5 \mathrm{pCi}$. 
- Groundwater protection in accordance with legally applicable federal and state standards

DOE Order 5400.5 identifies circumstances where supplemental limits or exceptions to the standards may be implemented. Situations identified by DOE that may warrant use of a supplemental standard include situations where remedial action would pose a clear and present risk to workers or members of the public using reasonable measures to reduce or avoid the risk. Supplemental standards may also be issued where the costs for remedial actions for contaminated soils is unreasonably high relative to the long-term benefits and where residual material does not pose a clear present risk after taking necessary control measures. The likelihood that persons will not erect buildings or spend long periods on the property should be evaluated in considering the site risk.

The DOE published proposed rule, Radiation Protection of the Public and the Environment (10 CFR 834), in the March 23, 1993 Federal Register (58 FR 16268), which promulgates the standards presently found in DOE Order 5400.5. The proposed rule retains the substantive portions of the DOE Order and differs from the existing Order in format, enhanced emphasis on the ALARA process, and changes the usage of DCGs. The proposed rule identifies DCGs not as "acceptable" discharge limits, but to be used as reference values for estimating potential dose and determining compliance with the requirements of the proposed rule. Where residual radioactive materials remain, the proposed rule states that various disposal modes should address impacts beyond the 1,000 year time period identified in the existing DOE Order.

3.1.1.1.2 State of Washington Chemical-Specific ARARs. CERCLA 121(d) requires that, in addition to satisfying Federal ARARs, any state standard, requirement, criterion, or limitation that is more stringent must also be met. State requirements must be legally enforceable regulations or statutes, identified in a timely manner, and be of general applicability to all circumstances covered by the requirement. Table 3-2 identifies preliminary chemical-specific Washington State ARARs for the 200-BP-1 operable unit. Tables 3-3 and 3-4 present regulatory limits for operable unit contaminants of concern.

Model Toxics Control Act Cleanup Regulation. Regulations under Chapter 173-340 WAC, which implement requirements of the Model Toxics Control Act (MTCA) are potentially applicable to the 200-BP-1 operable unit. These regulations establish administrative processes and standards to identify, investigate and cleanup facilities where hazardous substances have been released. The state regulations have the potential to be stricter than federal standards. For example, MTCA specifies secondary drinking water MCLs as applicable requirements. Secondary MCLs are nonenforceable standards under 40 CFR 143 and are based on non-human health-based goals relating to qualities of taste and odor.

The MTCA regulations establish three basic methods for determining cleanup levels for soils, as set forth in WAC 173-340-700. These include Method A - Tables, Method B standard method, and Method C - Conditional method. The MTCA regulations specify procedures for establishing levels that are protective of human health and the environment based on reasonable maximum exposure assuming either a residential site use (WAC 173340-740) or industrial site use (WAC 173-340-745). Section 740 establishes standards under all three methods and Section 745 uses only Methods $A$ and $C$. 
Method A is generally used for routine cleanups with relatively few contaminants. Standards for Method A cleanups are established based on other federal or state ARARs, including those deveiupad:

- at a $10^{-6}$ risk-level, based on residential site use in WAC 173-340-740,

- at a $10^{-5}$ risk level, based on industrial site use in WAC 173-340-745,

- based on natural background concentrations, or

- $\quad$ based on practical quantification limits (PQLs).

Since the cleanup at the 200-BP-1 operable unit cannot be considered routine and most of the contaminants are not included in Tables 1 or 3, Method A cleanup standards are not appropriate for use.

Method $B$ is the standard method for determining cleanup levels and assumes a residential site use. Method $B$ levels for soil are determined using federal or state ARARs or are based on risk equations specified in WAC 173-340-740. For individual carcinogens, the cleanup levels are based on the upper bound of the excess lifetime cancer risk of one in one million $\left(1 \times 10^{-6}\right)$. Total excess cancer risk under Method $B$ for multiple substances and pathways cannot exceed one in one hundred thousand $\left(1 \times 10^{-5}\right)$. Residential use of the 200-BP-1 operable unit is not a likely scenario either currently or in the future; therefore, Method B is not considered to be an appropriate requirement. Method B soil clean up levels for radicactive contaminants of concern are, however, shown in Table 3-3 for comparison purposes. Method B clean up level for nitrate is set at $1.28 \times 10^{5} \mathrm{mg} / \mathrm{kg}$.

Method C industrial cleanup levels are appropriate for use at the 200-BP-1 operable unit. Method $C$ cleanup levels are used where: Method $A$ or $B$ cleanup levels are below area background concentrations; cleanup to Method A or B levels has the potential for creating greater overall threat to human health and the environment than Method $C$; cleanup to Method A or B is not technically possible; or the site meets the definition of an industrial site. Method $C$ cleanups must comply with other federal or state ARARs, must use all practical levels of treatment and must incorporate institutional controls as specified in WAC 173-340-740. Risk-based equations for Meth $\mathrm{d} C$ cleanup levels for soil are specified in WAC 173-340-74C ior residential and WAC 173-340-745 for industrial exposure assumptions. Total excess cancer risk for Method $C$ cannot exceed 1 in one hundred thousand $\left(1 \times 10^{-5}\right)$. Method $C$ industrial cleanup levels are most appropriate for use at the 200-BP-1 operable unit based on current and projected future land use. An industrial land use with institutional controls is currently planned for the 200 Areas, which also includes a buffer zone (HFSUWG 1992). Method C soil clean up levels for radionuclides are shown in Table 3-3. The Method C soil clean-up level for nitrate is $5.12 \times 10^{5} \mathrm{mg} / \mathrm{kg}$.

All three MTCA methods for determining cleanup levels require minimum compliance with other federal or state ARARs, and consideration of cross-media contamination. For example, soil cleanup standards may be based on protection of groundwater. The regulations specify soil cleanup to levels equal to or less than one hundred times the groundwater cleanup levels established in accordance with WAC 173$340-720$, unless it can be demonstrated that a higher soil concentration is protective of groundwater at the site. Vadose zone fate and transport modeling has been used at the 
200-BP-1 operable unit to determine the potential of hazardous substances in the soil to impact groundwater, rather than the arbitrary 100 times the groundwater cleanup level. Groundwater cleanup levels based on WAC 173-340-720 Methods B and C for radionuclides are included in Table 3-3 for comparison with the results of the vadose zone fate and transport modeling. Method $B$ and $C$ cleanup levels for nitrate are $26 \mathrm{mg} / \mathrm{l}$ and $45 \mathrm{mg} /$, respectively.

The point of compliance for soil cleanup based on protection of groundwater and for cleanup levels based on human exposure via direct contact are defined under MTCA. The point of compliance is defined as the point or points throughout the site where cleanup levels are established in accordance with the cleanup requirements for groundwater and soil specified in Sections 173-340-720 through 750. The point of compliance for soil cleanup levels based on the protection of groundwater are to be achieved in all soils throughout the site. For soil cleanup levels based on human exposure via direct contact, soil cleanup levels are established for the upper fifteen feet, from the ground surface to fifteen feet. These depths represent the extent that could be excavated or disturbed as a result of site development. For alternatives that involve containment of hazardous substances, cleanup levels typically will not meet points of compliance established for groundwater protection or human exposure via direct contact. In these case ., compliance monitoring and other requirements identified in 173-340-360 (8) may be required to ensure long term integrity of the containment system.

Department of Health Radiation Protection Standards. Radiation Protection Standards were developed pursuant to the Atomic Energy Act of 1954, as amended. The standards set maximum allowable annual radiation doses in restricted and unrestricted areas, set maximum dose levels that minors may receive in restricted areas and establish acceptable concentration limits in effluent released to unrestricted areas. Radiation protection standards contained in Chapters 220 through 255 of WAC 246 are not specifically applicable to the operable unit, however, they are relevant and appropriate because they address similar contaminants and establish standards for acceptable levels of exposure.

3.1.1.2 Location-Specific ARARs. Location-specific ARARs at the 200-BP-1 operable unit are restrictions placed on the concentration of hazardous substances or the conduct of activities at the site based solely on site characteristics of the 200-BP-1 operable unit.

3.1.1.2.1 Federal Location-Specific ARARs. Federal location-specific requirements that were evaluated are summarized in Table 3-1.

The National Historic Preservation Act. The National Historic Preservation Act of 1966 is not an ARAR since no facilities located in the operable unit are listed or considered for inclusion on the National Register of Historic Places.

The Archeological and Historic Preservation Act. The Archeological and Historic Preservation Act is also not currently an ARAR since no archaeologic or historic sites have been identified at the operable unit. This act is similar to the National Historic Preservation Act but differs in that it mandates only protection of historic or archaeologic data and not the actual archaeologic or historical site. 
The Endangered Species Act. The Endangered Species Act of 1973 is not an ARAR since no endangered or threatened species or habitat was identified in the operable unit during ecological surveys of the Hanford Site.

Fish and Wildlife Coordination Act. Requirements under the Fish and Wildlife Coordination Acts are not an ARAR to remedial actions at the site since remedial actions are not expected to involve loss of habitat.

The Wild and Scenic River Act. The Wild and Scenic River Act is not an ARAR since the Columbia River is not currently included in the national system of wild and scenic rivers. The Columbia River has been nominated for inclusion on the list and remedial alternatives proposed for the site should consider migration of contaminants from soils to groundwater and potential impacts to the river. This will be reevaluated as a potential ARAR in the 200 Area Aggregate Management Study for groundwater.

\subsection{State Location-Specific ARARs. State of Washington Department of} Game procedures for compliance with the Washington State Environmental Policy Act are not an ARAR since threatened, endangered or sensitive wildlife or habitat have not been identified at the operable unit. The act requires that management plans be developed if threatened, endangered, or sensitive wildlife or habilat are affected by remedial actions at the site.

3.1.1.3 Action Specific ARARs. Action-Specific ARARs are presented in Tables 3-1 and 3-2 and will be refined once general response actions have been formulated and alternative formulation and screening have been completed. This will allow the ARARs to be identified in an effective and efficient manner. Action-specific ARARs are presented and evaluated with the detailed analysis of alternatives in Chapter 6.

\subsubsection{Acceptable Risk-Based Exposure Concentrations}

3.1.2.1 Present Exposure Conditions. Under present conditions all of the contaminants of concern in the soils operable unit exist below ground surface from depths of 3 to 230 feet. As presented in the baseline risk assessment, the total Life Incremental Cancer Risk (LICR) on the operable unit with the soil cover in place for cribs $216-\mathrm{B}-43$ through 50 is $4 \times 10^{-7}$ and the LICR from crib $216-\mathrm{B}-57$ is $1 \times 10^{-7}$. These levels are below MCLs and MTCA standards for the contaminants, taken individually and in combination, and are below all other ARAR limits identified in Section 3.1.1 above. Under current conditions, there are no exposure pathways for any of the contaminants of concern that exceed a $1 \times 10^{-6}$ risk based allowable exposure level based on LICR.

Vadose zone transport of contaminants was discussed in Chapter 5 of the Phase I RI report (DOE-RL, 1993). To achieve source control for the soils operable unit, the contaminants that are reaching groundwater above ARARs or risk-based concentrations are contaminants of concern. Under present conditions, contaminants currently reaching groundwater beneath the operable unit at, or near, these concentrations include technetium-99 and nitrate.

The highest concentrations of technetium- 99 measured beneath the operable unit correspond to a LICR of $1 \times 10^{-5}$, a level that is below the MCL for technetium-99 but is 
above the State MTCA level for a single radionuclide contaminant. The risk level is, however, within the middle of the range $\left(1 \times 10^{-4}\right.$ to $\left.1 \times 10^{-6}\right)$ acceptable risk promulgated by the NCP as being protective of human health and the environment. The State MTCA not withstanding, a case can be made that the existing $1 \times 10^{-5}$ risk level represents an allowable exposure level.

The concentration of nitrate $\left(\mathrm{NO}_{3}\right)$ beneath the operable unit is above the $\mathrm{MCL}$. However, there are significant concentrations of nitrate up-gradient from the operable unit. The net addition of nitrate to the groundwater from the operable unit as presented in the Phase I RI is $10-20 \mathrm{ug} / \mathrm{l}$, an incremental addition from the operable unit that is below the MCL for nitrate and represents an acceptable exposure from the operable unit.

3.1.2.2 Future Exposure Conditions. Future land use on the operable unit through the year 2117 will be limited to industrial land use only. No residential, recreational, or agricultural uses will be permitted within this time frame. Land use beyond the year 2118 is assumed to remain the same, based on the current policy of using the 200 Areas as permanently controlled waste storage and disposal facilities and on the recommendations from the Hanford Site Future Uses Working Group (HFSUWG 1992).

The baseline risk assessment includes one future exposure scenario that poses lifetime incremental cancer risk in excess of $10^{-6}$. This is a future industrial scenario, with clean cover soils removed and workers exposed to near surface contaminated soils and the infiltration gravels and underlying highly contaminated soils. The pathway that poses the greatest excess risk is external exposure to radionuclides, with ingestion of contaminated soils being less significant. The risk associated with external exposure is $>10^{-2}$, due almost entirely to the high levels of cesium-137. The risk associated with the soil ingestion pathway is about $10^{-2}$ for cribs $216-\mathrm{B}-43$ through -50 , and $8 \times 10^{-5}$ for crib $216-\mathrm{B}-57$. Cesium137 and strontium-90 dominate the risk with the soil ingestion pathway. The risk levels for this scenario are summarized in Tables 6-17 through 6-20 of the 200-BP-1 operable unit Phase I RI report (DOE-RL 1993). The risk assessment identifies the risk to human health and the environment separately for contaminants in cribs $216-\mathrm{B}-43$ through 50 , and in crib 216-B-57. Presented below are the contaminants that exceed the $10^{-6}$ point of departure for soil ingestion and external pathways of exposure under this scenario.

\begin{tabular}{|l|l|l|}
\hline \multicolumn{1}{|c|}{ Location } & Cribs 216-B-43 through 50 & \multicolumn{1}{c|}{ Crib 216-B-57 } \\
\hline Near Surface Soils & $\begin{array}{l}\text { cesium-137 } \\
\text { radium-226 } \\
\text { thorium-228 }\end{array}$ & $\begin{array}{l}\text { cesium-137 } \\
\text { radium-226 } \\
\text { thorium-228 }\end{array}$ \\
\hline $\begin{array}{l}\text { Infiltration } \\
\text { Gravels/Soils }\end{array}$ & $\begin{array}{l}\text { cesium-137 } \\
\text { radium-226 } \\
\text { thorium-228 } \\
\text { cobalt-60 } \\
\text { strontium-90 } \\
\text { plutonium-239 \& 240 } \\
\text { uranium (total) }\end{array}$ & $\begin{array}{l}\text { cesium-137 } \\
\text { radium-226 } \\
\text { thorium-228 }\end{array}$ \\
\hline
\end{tabular}

Future potential exposures from the more slowly migrating contaminants that will eventually reach groundwater must also be considered. Several of the species will decay 
before reaching the groundwater table under the conditions modeled in the Phase I RI. These include cesium-137 and strontium-90. Other species are present in too low of concentrations to pose a risk, or have already reached groundwater (i.e., cobalt-60) in peak concentrations and have already declined below risk-based concentrations or MCLs.

The long-lived radionuclides that will pose a future exposure in excess of ARARs and risk-based limits without remedial action include plutonium -239/240, and total uranium. These species migrate very slowly and are currently concentrated in the 4.6 to 9.2 $\mathrm{m}$ ( 15 to $30 \mathrm{ft}$ ) depth range in cribs $216-\mathrm{B}-43$ through -50 . These contaminants do not pose a risk via the groundwater pathway in crib 216-B-57. The risk assessment conducted for the Phase I RI calculated risk-based limits at the top of the unconfined aquifer directly beneath the cribs. Significantly longer periods of time are expected for contaminants to substantially impact groundwater at the operable unit boundary.

Table 3-4 shows the contaminant concentrations at the $10^{-6}$ risk level for the external and/or ingestion pathways of exposure under the future industrial scenario, and also for groundwater ingestion for plutonium and uranium.

\subsection{REMEDIAL ACTION OBJECTIVES}

Remedial objectives establish site remediation goals by taking specific contaminants, contaminated environmental media, and potential contaminant exposure pathways into account (40 CFR 300.430(e)(2)(i)). Remedial action objectives focus the development, screening, and analysis of remedial alternatives to ensure that they are protective of human health and the environment.

The 200-BP-1 operable unit is a source operable unit, with contaminants contained in the soil matrix or adsorbed to soil particles. Under current conditions, the risk to human health and the environment from the source operable unit is below $1 \times 10^{-6}$ for all pathways combined. Unacceptable risk above this level, requiring remedial actions, occurs under future industrial scenarios for land use at the operable unit.

Groundwater beneath the 200-BP-1 operable unit is included in a separate, groundwater-operable unit, the 200 East Groundwater Aggregate Area. An assessment of environmental risk which is posed by the groundwater pathway, and consideration of remedial objectives aimed at addressing groundwater contamination will be included in the 200 East Groundwater Aggregate Area Study.

The existence of a separate operable unit for groundwater in the 200 East Area leads to questions regarding the allocation (separation) and potential overlap of remedial action objectives between the groundwater- and source-operable units. These questions are related primarily to whether, in spite of the fact that groundwater is not included as a part of the source-operable unit, remedial action objectives for source-operable units should address the issue of potential future impacts to groundwater. There is the opportunity, in the separation of groundwater from the source-operable units, for the establishment of a framework which allows for the efficient coordination of remedial actions between the source- and groundwater-operable units in the separations area. This framework is described below. 
There are numerous sources of contamination which impact groundwater in the $\mathbf{2 0 0}$ East Area. Impacts from these sources will need to be considered in the remedial plan of the 200 East Groundwater Aggregate Study. Impacts from these sources can be addressed in one of the following two ways:

- Groundwater-operable unit studies could include evaluations of impacts to groundwater for each source-operable unit, with the ultirnate remedial solution for groundwater dependent on the completion and integration of these individual source studies.

- The concept of source control can be adopted for the 200 East Area where it is assumed that, by definition, the individual source-operable unit remedial actions will control source migration to groundwater, where this is likely to occur at unacceptable concentrations. In this manner, the remedial objectives of the groundwater-operable unit RI/FS can be focused on addressing the existing groundwater contamination only, thereby decoupling the groundwater-operable unit study from the individual source-operable unit evaluations.

The second of these two alternatives, by eliminating the dependency of the groundwater study on the source studies, will allow the groundwater-operable unit RI/FS to proceed more quickly and efficiently because of the more limited and clearly defined scope. The work which has been performed in this FS, by evaluating the potential for future contaminant migration to the water table, has been completed in this manner.

Therefore, based on the results of the fate and transport analysis and the baseline risk assessment completed in the Phase I RI report (DOE-RL 1993), and within the context of the approach outlined above, recommended remedial action objectives include the following:

- Limit human receptor exposure to near surface and subsurface infiltration gravels/soils to maintain receptor risk in the range of $10^{-4}$ to $10^{-6}$. The results of the risk assessment performed in Chapter 6 of the Phase I RI indicate that, of the various human environmental exposure scenarios which were evaluated, a cancer risk of $10^{-6}$ is exceeded only under the future industrial scenario on the operable unit, and only if near surface soils or infiltration gravels/soils are exposed, permitting direct contact with the contaminants. As long as the current clean soil cover is maintained, or subsurface soils are not disturbed, the risks to human health will remain below a $10^{-6}$ cancer risk level.

- Limit biotic exposures to near surface and subsurface infiltration gravels/soils. The results of the ecological risk assessment indicate that biota could be adversely impacted by near surface soil contaminants on the operable unit if exposure to these soils is allowed to occur. A remedial action objective of the FS, therefore, shall be to include measures which limit such exposures. These measures may largely overlap with and consist of those which will limit human exposures; however, additional measures may also be 
required to address those pathways which are unique to biota. These may include exposures due to the activities of burrowing animals or the systemic uptake by deep rooting plants.

- Limit future impacts to groundwater by taking measures which minimize infiltration and downward migration of contaminated vadose zone pore water, such that ARARs are not exceeded or riskbased concentrations in groundwater remain below the range of $10^{-4}$ to $10^{-6}$. The 200-BP-1 operable unit is currently impacting groundwater with Tc-99, nitrate, cobalt- 60 and possibly uranium. The concentration of Tc-99 is about 400 to $700 \mathrm{pCi} / \mathrm{L}$ in groundwater immediately downgradient of the cribs. This concentration is below the current MCL of $900 \mathrm{pCi} / \mathrm{L}$, and well below the proposed MCL of $3,800 \mathrm{pCi} / \mathrm{L}$. However it is slightly above the MCTA Method C standard of $350 \mathrm{pCi} / \mathrm{L}$ and over an order of magnitude greater than the MCTA Method B standard of $35 \mathrm{pCi} / \mathrm{L}$. The highest concentrations beneath the operable unit correspond to the $1 \times 10^{-5}$ risk level. Nitrate contamination of the aquifer appears to be contributed from the operable unit by 10 to $20 \mathrm{mg} / \mathrm{L}$ over upgradient groundwater. This is less than the current $\mathrm{MCL}$ of $45 \mathrm{mg} / \mathrm{L}$ (as $\mathrm{NO}_{3}$ ), but contributes to groundwater being above the MCL in much of the operable unit. Current $\mathrm{Co}-60$ and uranium impacts to the aquifer are below MCLs and MCTA Method C standards, but exceed MCTA Method B standards.

In the future, the 200-BP-1 operable unit sources will continue to impact the underlying aquifer. Impact from Tc-99, nitrate, and Co-60 will decrease with time, with Co-60 decreasing at a relatively rapid rate due to its short half-life of 5 years. Uranium and plutonium are expected to significantly impact the aquifer in the distant future. Uranium could exceed proposed MCLs ( $30 \mathrm{pCi} / \mathrm{L}$ ) in groundwater in hundreds to possibly even a thousand years depending on infiltration rates and other model assumptions. Plutonium is expected to reach and impact the water table in the tens of thousands of years at levels above the current MCL of $15 \mathrm{pCi} / \mathrm{L}$ and the proposed MCL of $65 \mathrm{pCi} / \mathrm{L}$.

Remedial action objectives for groundwater impact should be consistent with current groundwater use and address future impacts within reasonable time frames. Tc- 99 , nitrate and Co-60 have already impacted the aquifer in much of the study area and are found at much higher concentrations downgradient of the operable unit. The 200 East Aggregate Area Groundwater Study will define remedial action objectives for these plumes and incorporate appropriate measures for the entire 200 East Area. Source control measures do not appear warranted for Tc-99, nitrate and Co-60 since their current impacts from the operable unit are declining with time and are below MCL standards, although they are above certain MTCA standards. 
Remedial action objectives for uranium and plutonium must consider the long time frame required for significant impacts from these contaminants. The appropriate long term performance objectives should be at least 200 to 1,000 years or more based on 40 CFR 192, DOE Order 5400.5, and proposed DOE regulations in 10 CFR 384. Based on these time frames uranium is the only site contaminant for which remedial measures to limit infiltration and migration rates need be considered.

- Take into account impacts of the proximity of the 241-BY tank farm on remedial objectives. Remedial alternatives for the 200-BP-1 operable unit should not be developed without consideration of the adjacent 241-BY tank farm. One of the remedial action objectives for the 200-BP-1 operable unit will be to evaluate remedial alternatives for any potential impacts to, and consistency with, likely alternatives for the adjacent tank farm.

\subsection{GENERAL RESPONSE ACTIONS}

General response actions (GRAs) are broad categories of actions that may be taken at 200-BP-1 to limit exposure of contaminants to humans, the environment, or groundwater via all identified receptor pathways, under future industrial or intrusion scenarios. The response actions are limited to future scenarios due to the low risk posed by the contaminants at the operable under present conditions. Actions taken to address future scenarios include those that must be taken to maintain the current low levels of risk into the future, before, during and after remediation.

The environmental medium of concern at the 200-BP-1 operable unit is contaminated soils, which includes all of the cribs themselves. The piping systems that conveyed effluent discharges to the cribs can be considered part of the cribs and are addressed by the GRAs for soils. Groundwater beneath the operable unit will be addressed in the 200 East Aggregate Area FS. Development of specific actions are based on RAOs to facilitate the selection of technology types and process options and the formulation of alternatives that will subsequently be expected to meet the RAOs.

RAOs may be met in several ways. The preferred method is to destroy (degrade) the contaminants, reducing the concentrations and the associated risks to acceptable levels. Destroying contaminants is usually the most reliable method of ensuring that contaminants do not cause further problems at the site following completion of remedial action. However, contaminants such as radionuclides that are the major contaminants of concern at the 200-BP-1 operable unit cannot be destroyed. For such contaminants, risk may be lessened by containment actions that allow the radionuclides to safely decay over time, away from sensitive receptors, or by treatment actions that reduce the mobility (and hence the opportunities for exposure) and the volume of the radionuclides, or combinations of both.

GRAs for soils at the 200-BP-1 operable unit therefore fall into three categories: No Action/Institutional Actions, Containment Actions, and Excavation/Treatment Actions. Formulation of No Action/Institutional Controls actions are required under CERCLA 
Guidance and the NCP (EPA 1988). For 200-BP-1, this GRA leads directly to the formulation of a No Action alternative and an Institutional Controls alternative for the operable unit. Each of these is introduced and developed in more detail in Chapter 5. Briefly, No Action assumes that any existing institutional controls are discontinued. This forms the baseline alternative against which all of the other alternatives are evaluated. An Institutional Controls alternative assumes that access and use of the operable unit is maintained, so that human and environmental exposures can be broadly controlled. Monitoring of contaminants on the operable unit is also part of this general response action.

Containment actions are the second category of GRAs. Containment prevents exposure to human and environmental receptors by preventing contact with contaminants onsite, and by preventing migration of contaminants offsite. As long as there is no exposure, there is no risk to human health or the environment. Containment actions for 200-BP-1 include surface barrier systems that keep the contaminants in place and reduce migration to groundwater, and placement of contaminants in a controlled disposal facility, such as the Hanford Environmental Restoration Storage and Disposal Facility (ERSDF).

However, because the contaminants still exist within the containment, exposure could occur if the containment, such as a surface barrier or a landfill liner, were to fail. In addition, containment is often imperfect. Surface barriers are never 100 percent efficient at preventing infiltration from entering the soil column, leaving the possibility of migration, over a long period of time, of radionuclides to groundwater in concentrations that exceed RAOs. The risk is not completely eliminated by containment actions. The same possibilities exist for engineered landfill facilities, although in this case the risks $F$ ssed by the contaminants are relocated from the operable unit to the ERSDF.

A third category of GRAs includes treatment and disposal actions. Treatment actions reduce mobility and volume, and secure disposal provides additional containment of treated contaminants. Both sets of actions reduce risk to receptors. At the 200-BP-1 operable unit, treatment actions can be either in-situ or ex-situ. In-situ actions involve treating the contaminants and leaving them in place, away from humans and the environment. Ex-situ actions involve excavation of the contaminants (along with greatly increased worker exposure risk), followed by treatment to accomplish reduction in mobility and in volume, followed by disposal. Disposal, however, can either be back into the excavation, or into the ERSDF, resulting once again in containment of the untreated contaminants.

Finally, GRAs can lead to the formulation of alternatives based on technologies that combine elements from all GRA categories in attempting to meet RAOs. A wide variety of these alternatives is necessary to provide decision makers with enough information to select a preferred alternative based on CERCLA Guidance criteria. This process is presented in Chapters 4, 5, 6, and 7. include:

In summary, the general response actions that meet the remedial action objectives

- $\quad$ No Action/Institutional Controls

- Containment using a surface barrier 
- Excavation followed by containment in a suitable landfill

- In-situ treatment and containment in place

- Excavation followed by Ex-situ treatment and containment, either in a suitable landfill or replacing in the excavation

- Combinations of all of the above.

Table 3-4 contains a summary of the RAO's and applicable GRA's and the corresponding risk-based contaminant levels and exposure pathways for contaminants of concern identified for each of the soil zones beneath the operable unit.

\subsection{AREAS AND VOLUME OF CONTAMINANTS}

Areas and volumes of contaminated media, based on RAOs and GRAs, are required to provide an overall context for the qualitative evaluations performed in Chapters 4 and 5 (Phases I and II) of the feasibility study, and to provide a basis for the more detailed evaluations presented in Chapter 6 (Phase III).

\subsubsection{Areas of Contaminated Soils}

Estimates of ground surface area overlying contaminated soil are needed to evaluate those remediation technologies that are implemented at the ground surface, such as construction of surface barriers. The following assumptions have been made to form a basis for comparison of remedial alternatives:

A buffer zone of $15 \mathrm{~m}(50 \mathrm{ft})$ beyond the edge of the crib at the ground surface will be adequate to (a) extend over any lateral contamination, and (b) prevent surface infiltration from contacting significantly contaminated zones. Wells near the cribs sampled during the Phase I RI indicate the extent of lateral contamination to be no more then 50 feet from the cribs (Well 33-40) (DOE-RL, 1993a). While this assumption may be revised as detailed evaluation of alternatives proceeds, it provides a basis for comparison of competing barrier alternatives. Additional data or modeling may be required to support detailed design following selection of a preferred alternative and issuance of a ROD.

- Crib 216-B-61 will not be remediated. This crib never received waste, and soil testing did not indicate any contamination.

- The underground piping system leading to all cribs, including those pipes leading to $216-\mathrm{B}-61$, will be remediated. The piping system is shown schematically on Figure 2F-2. The extent of contamination in the piping system is unknown; however, the system is not a primary consideration in development of remedial alternatives. Formulation of alternatives will include remediation of the piping system that will 
meet RAOs while resulting in minimal increases in worker risk, equipment contamination, and associated costs (see Chapter 6). While the crib 216-B-61 was never used, operation of valves may have allowed effluent to travel to the point just before entering the crib.

- Contaminated soil from unplanned releases have been consolidated over the 200-BP- 1 cribs and are included in the volume/area estimates for the cribs.

- Contamination from adjacent operable units is not considered. To the extent practical, remediation activities stop at the boundary of the 200-BP-1 operable unit.

- The flush tank at the south end of the area of cribs 216-B-43 through $216-B-50$ is treated as a crib for remediation purposes.

Using these assumptions, the surface area requiring remediation is approximately $15,000 \mathrm{~m}^{2}\left(162,000 \mathrm{ft}^{2}\right)$ for cribs $216-\mathrm{B}-43$ through $216-\mathrm{B}-50$ and $7,000 \mathrm{~m}^{2}\left(76,000 \mathrm{ft}^{2}\right)$ for crib 216-B-57. The total for both areas is approximately $22,000 \mathrm{~m}^{2}\left(238,000 \mathrm{ft}^{2}\right)$.

\subsubsection{Volumes of Contaminated Soils}

Estimates of the volume of contaminated soil are needed to evaluate remedial alternatives such as in-situ stabilization and those treatment processes which involve excavation. Based on available data on the extent of contamination, a conservative set of assumptions has been developed to provide a basis for comparison of remedial alternatives. The previously estimated surface areas were modified using a $6 \mathrm{~m}(20 \mathrm{ft})$ buffer zone and multiplied by the depth of contamination to provide the volume estimates. With this approach, the assumptions previously listed apply to the volume estimate as well. In addition, the following assumptions have been made:

- Technetium-99 is not considered in defining the volume of contaminated soil. Because of its high mobility, this radionuclide has already reached groundwater, whereas the other contaminants of concern have traveled significantly shorter distances. The risk level associated with the highest measured concentrations below the operable unit is $1 \times 10^{-5}$, below the $\mathrm{MCL}$ and within the range of acceptable risk supported by CERCLA guidance, but above the MTCA ARAR standard. Due to its mobility, the majority of the mass of technetium- 99 has already reached groundwater and future vadose zone migration will result in declining concentrations and risk levels in the unconfined aquifer. Volume estimates for potentially feasible alternatives for remediating technetium-99 generally depend on details of the particular technology, and will be developed in the detailed evaluation of alternatives, if appropriate.

- $\quad$ Zones contaminated by nitrate are also not included in the volume estimate. Additional contribution of nitrate to the unconfined aquifer 
beneath the operable unit is about 10 to $20 \mathrm{mg} / \mathrm{L}$, below the MCL and ARARs, and future impact should be declining.

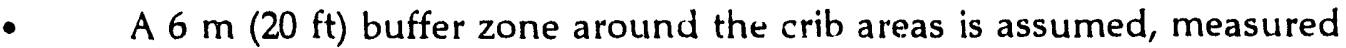
from the edge of the cribs at the ground surface. For excavation alternatives, it is not necessary to prevent lateral migration of

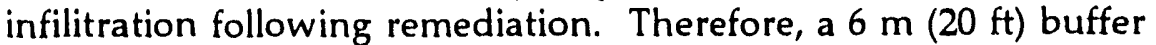
(rather than a $15 \mathrm{~m}$ [50 ft] buffer used for the barrier alternatives) is used to account for uncertainty regarding the lateral distribution of contaminants. The $15 \mathrm{~m}(50 \mathrm{ft})$ buffer zone also provides a uniform basis for comparison of competing excavation and treatment alternatives. This assumption results in an area of contamination of approximately $11,500 \mathrm{~m}^{2}\left(124,200 \mathrm{ft}^{2}\right)$ for cribs $216-\mathrm{B}-43$ through -50 and about $4,100 \mathrm{~m}^{2}\left(44,200 \mathrm{ft}^{2}\right)$ for crib $216-\mathrm{B}-57$. The total for both areas is about $15,600 \mathrm{~m}^{2}\left(168,400 \mathrm{ft}^{2}\right)$.

- The depth of significant contamination requiring remediation for most radionuclides of concern is assumed to be $15 \mathrm{~m}(50 \mathrm{ft})$ for the purpose of providing a basis for detailed analysis. Although contaminants of concern were detected to depths of $72 \mathrm{~m} \mathrm{(236} \mathrm{ft)} \mathrm{the}$ majority of radionuclide concentrations were found at depths of 4.6 to $9.1 \mathrm{~m}$ ( 15 to $30 \mathrm{ft}$ ) below ground surface. The $15 \mathrm{~m}(50 \mathrm{ft})$ assumption should be adequately conservative for cesium-137, strontium-90 and other relatively immobile radionuclides. However, the fate and transport modeling for uranium indicates that with an infiltration rate of $1 \mathrm{~cm} / \mathrm{yr}$, the depth of contamination requiring remediation to prevent exceedance of MCLs in groundwater is greater than $46 \mathrm{~m}(150 \mathrm{ft})$ in cribs $216-\mathrm{B}-43$ through -50 . (Uranium is not a problem from the groundwater pathway at crib 216-B-57.) Because excavation to such depths would be extremely difficult, $15 \mathrm{~m}$ $(50 \mathrm{ft})$ depth is used for volume estimation to provide a basis for evaluation of alternatives. Volume estimates for remediating uranium will be developed in the detailed analysis of alternatives, if appropriate.

Using these assumptions, the volume of contaminated soil beneath the area of cribs $216-B-43$ through $216-B-50$ and crib $216-B-57$ is about $238,000 \mathrm{~m}^{3}\left(312,000 \mathrm{yd}^{3}\right)$. Of this, the upper $3 \mathrm{~m}(10 \mathrm{ft})$ above the infiltration gravels has a volume of $47,000 \mathrm{~m}^{3}\left(62,000 \mathrm{yd}^{3}\right)$, and the soil from the $3-15 \mathrm{~m}(10-50 \mathrm{ft})$ depth has a volume of $191,000 \mathrm{~m}^{3}\left(250,000 \mathrm{yd}^{3}\right)$. These estimates do not include additional, non-contaminated soil which may need to removed for some technologies, for example, during excavation to provide stable slopes. Such additional volumes will be estimated during detailed analysis of the pertinent alternatives. 
DOE/RL-93-35, Rev. 0

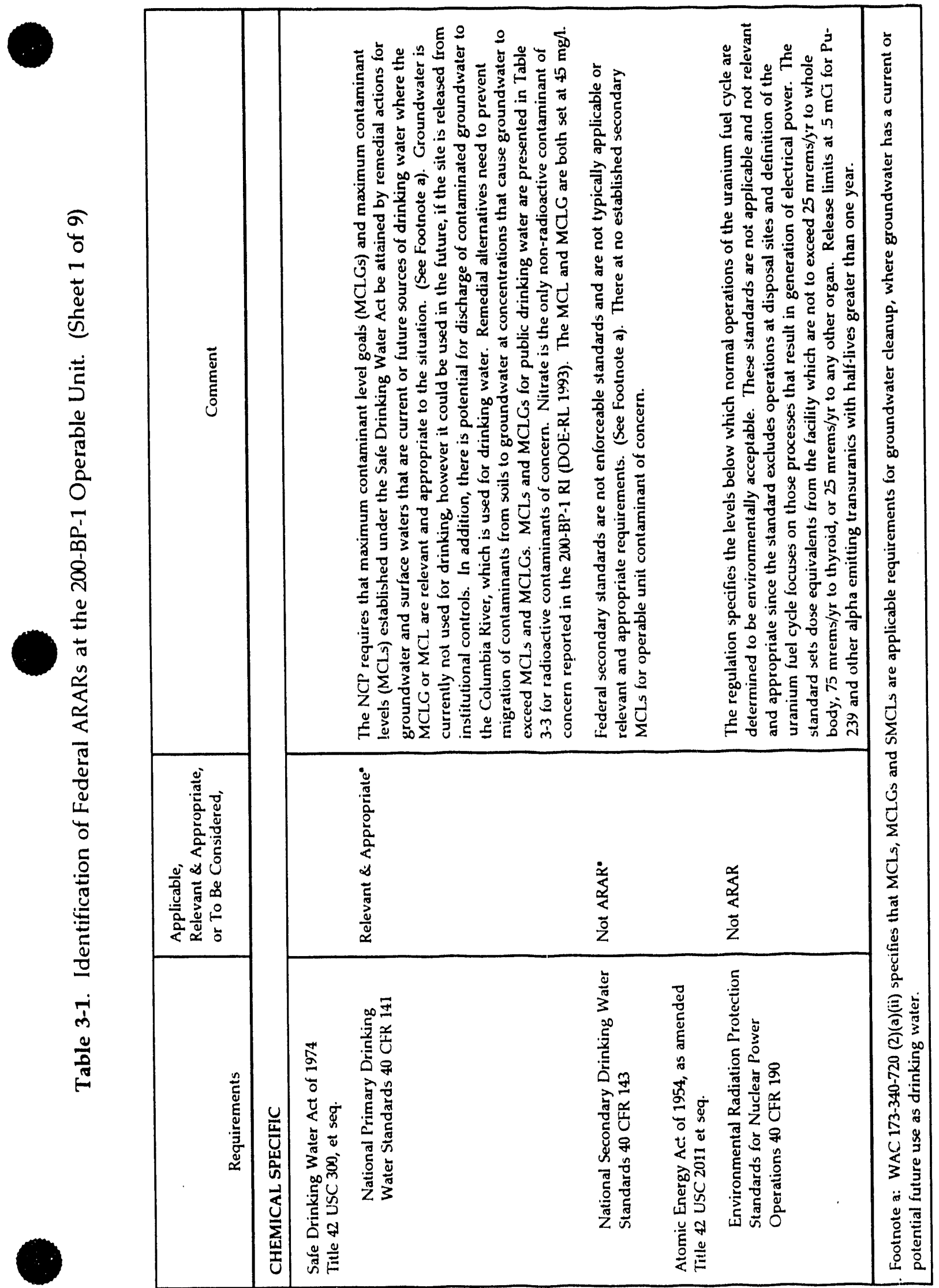


DOE/RL-93-35, Rev. 0

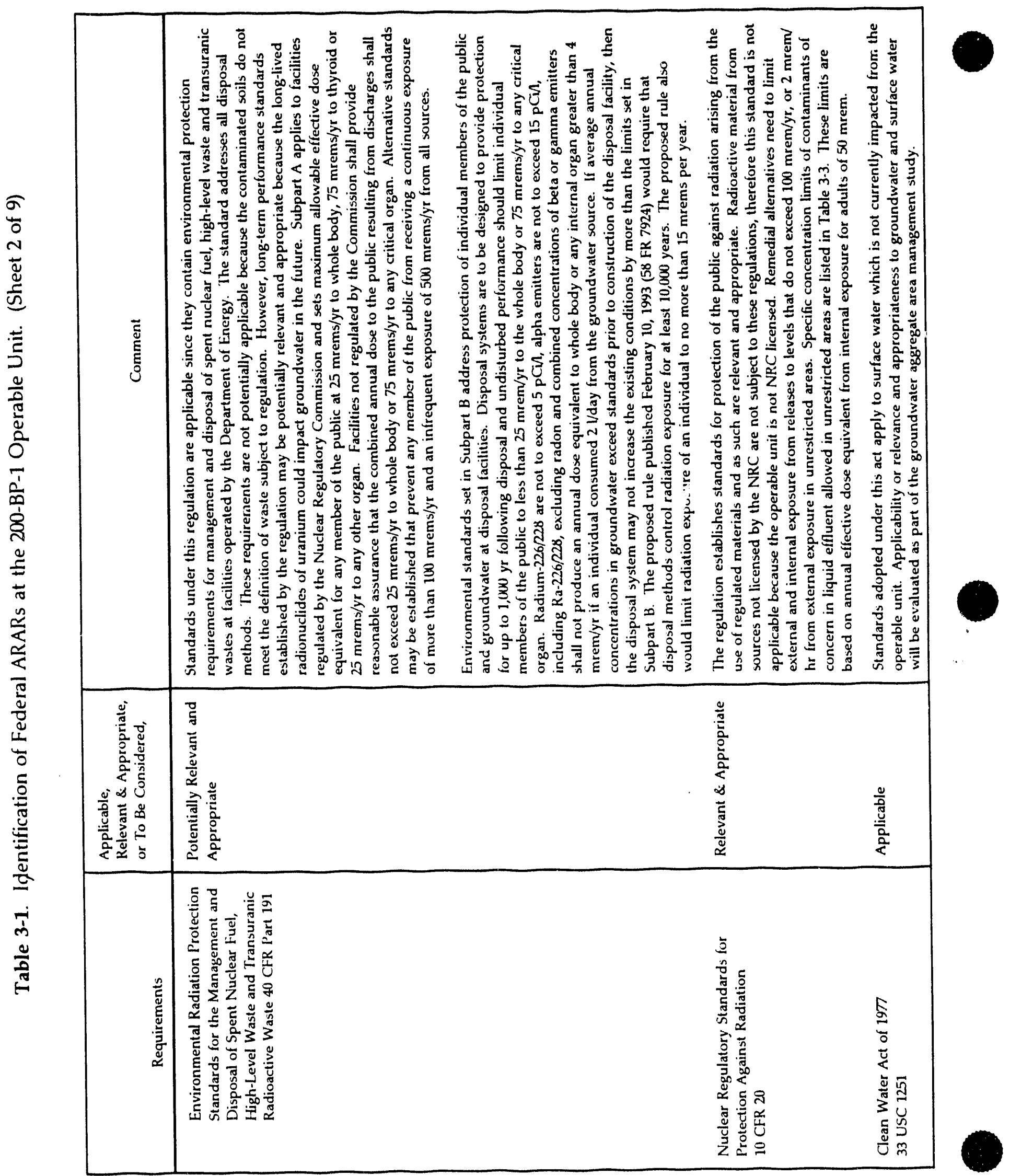


DOE/RL-93-35, Rev. 0

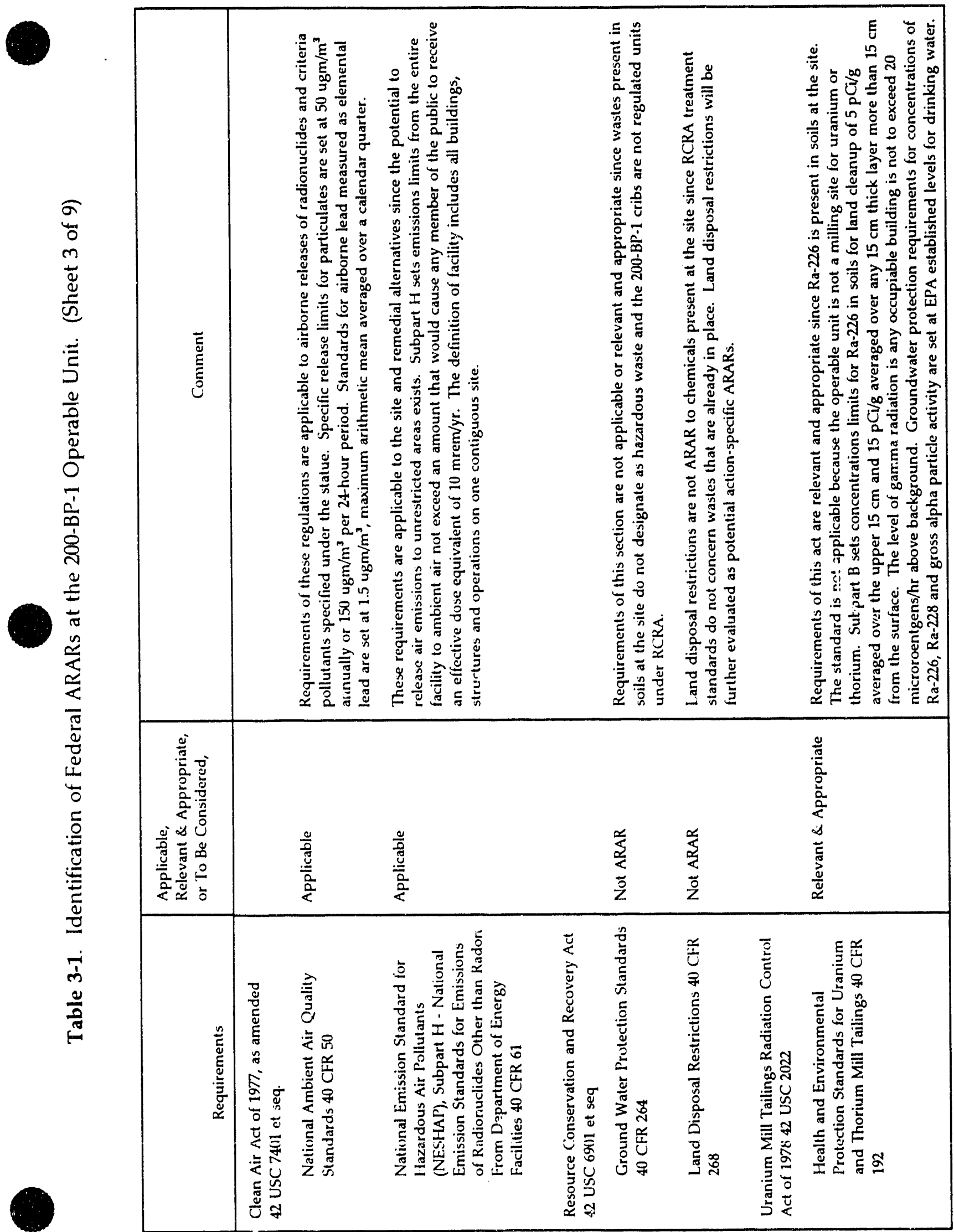




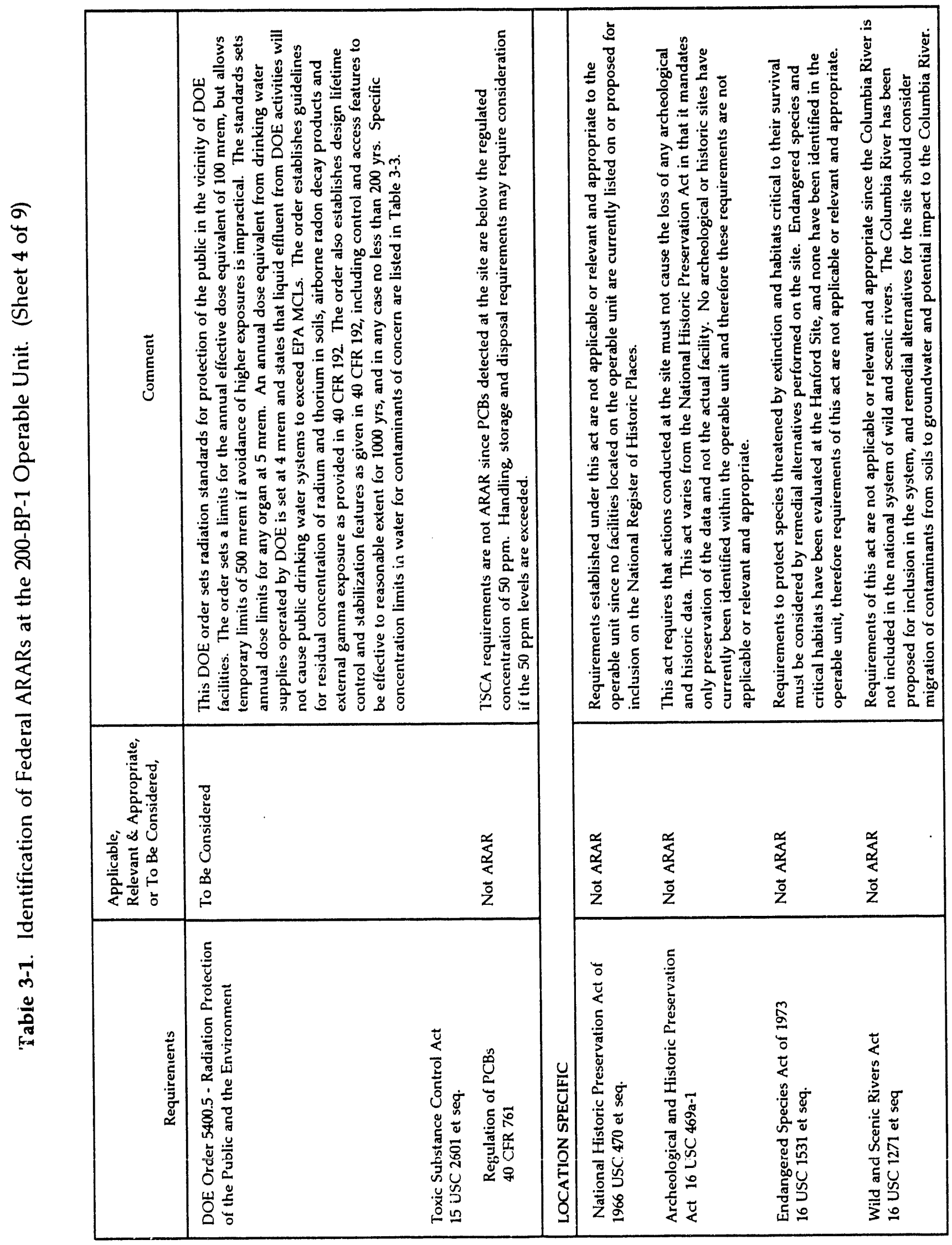


DOE/RL-93-35, Rev. 0




DOE/RL-93-35, Rev. 0

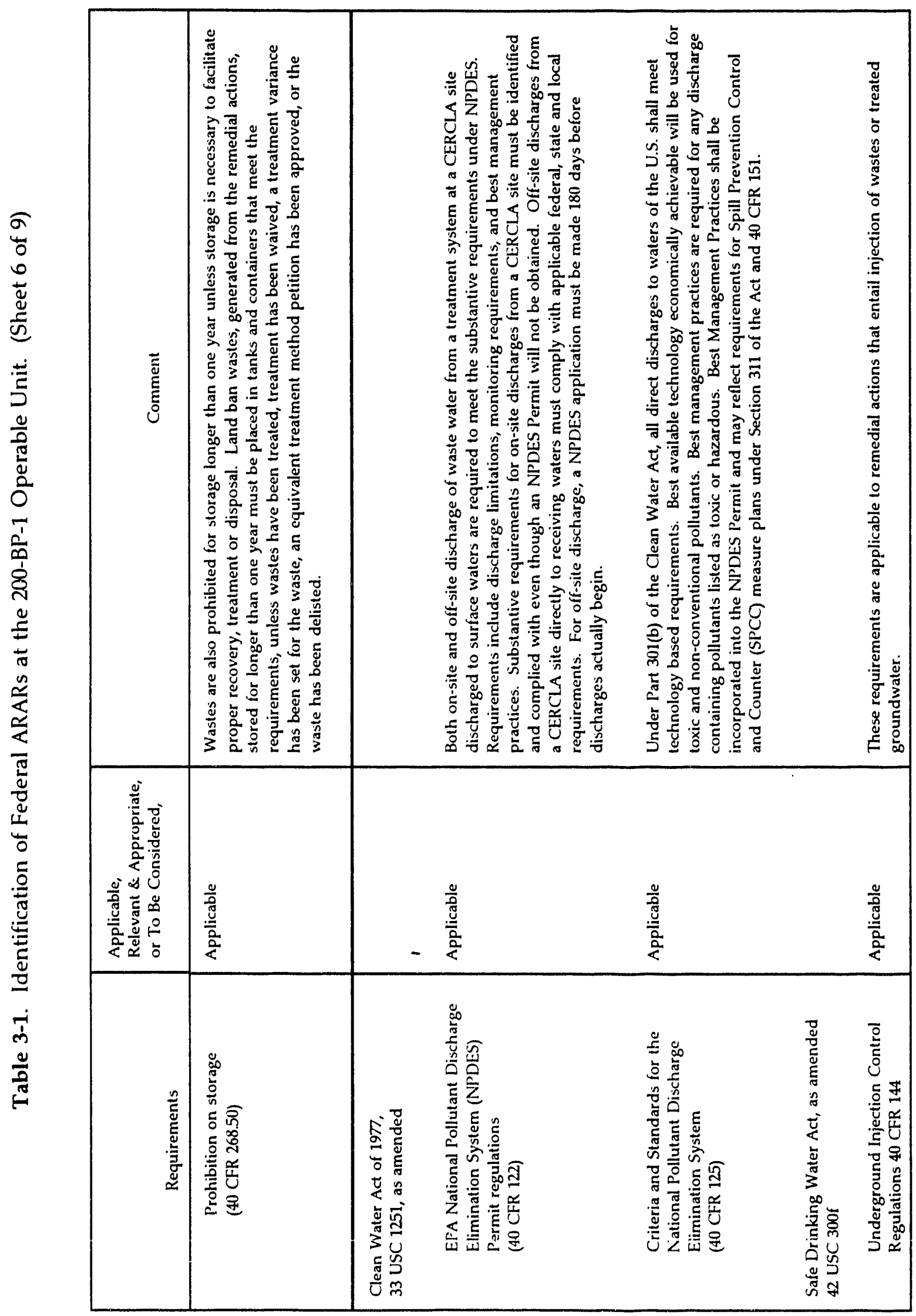


DOE/RL-93-35, Rev. 0

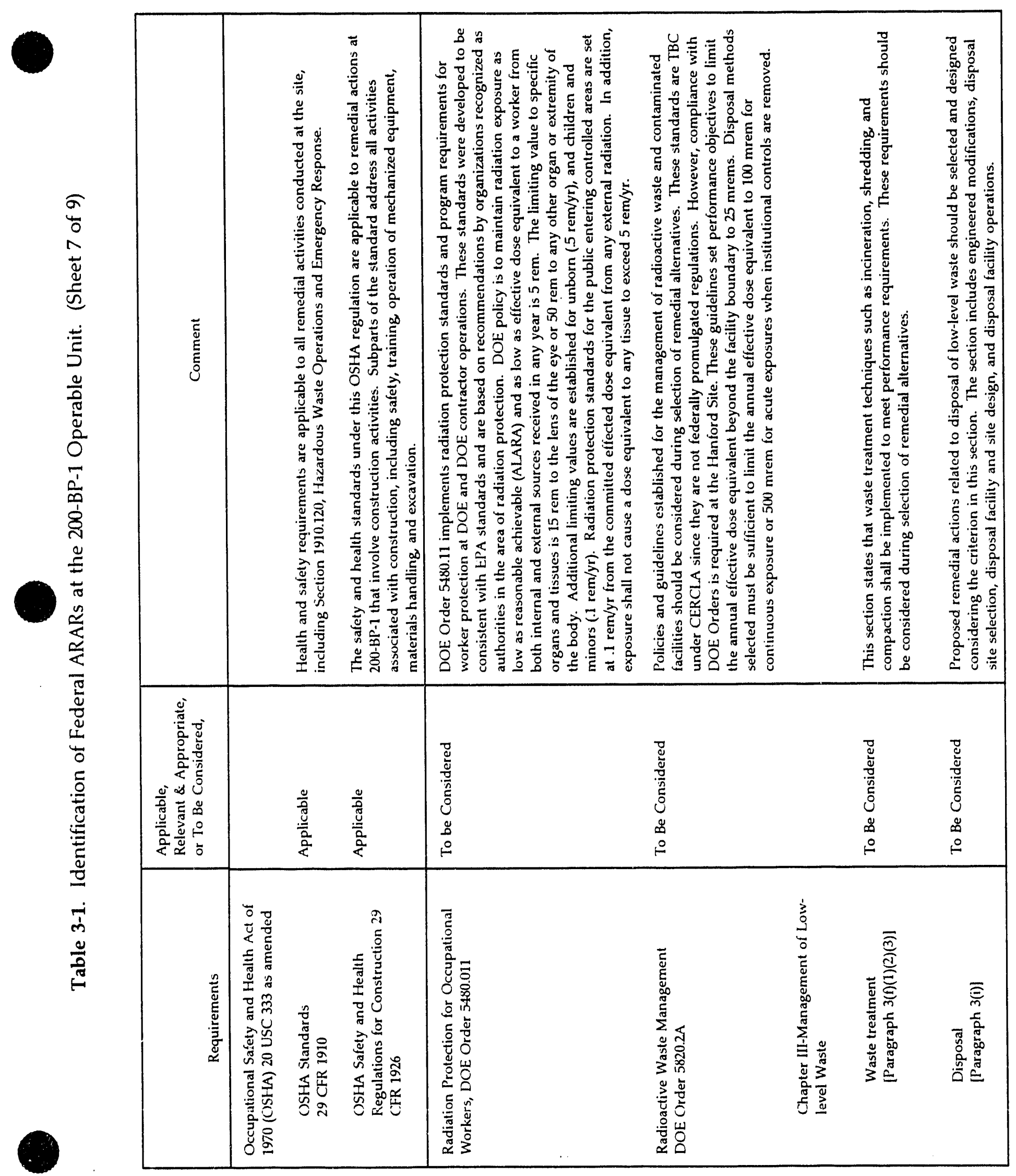


DOE/RL-93-35, Rev. 0

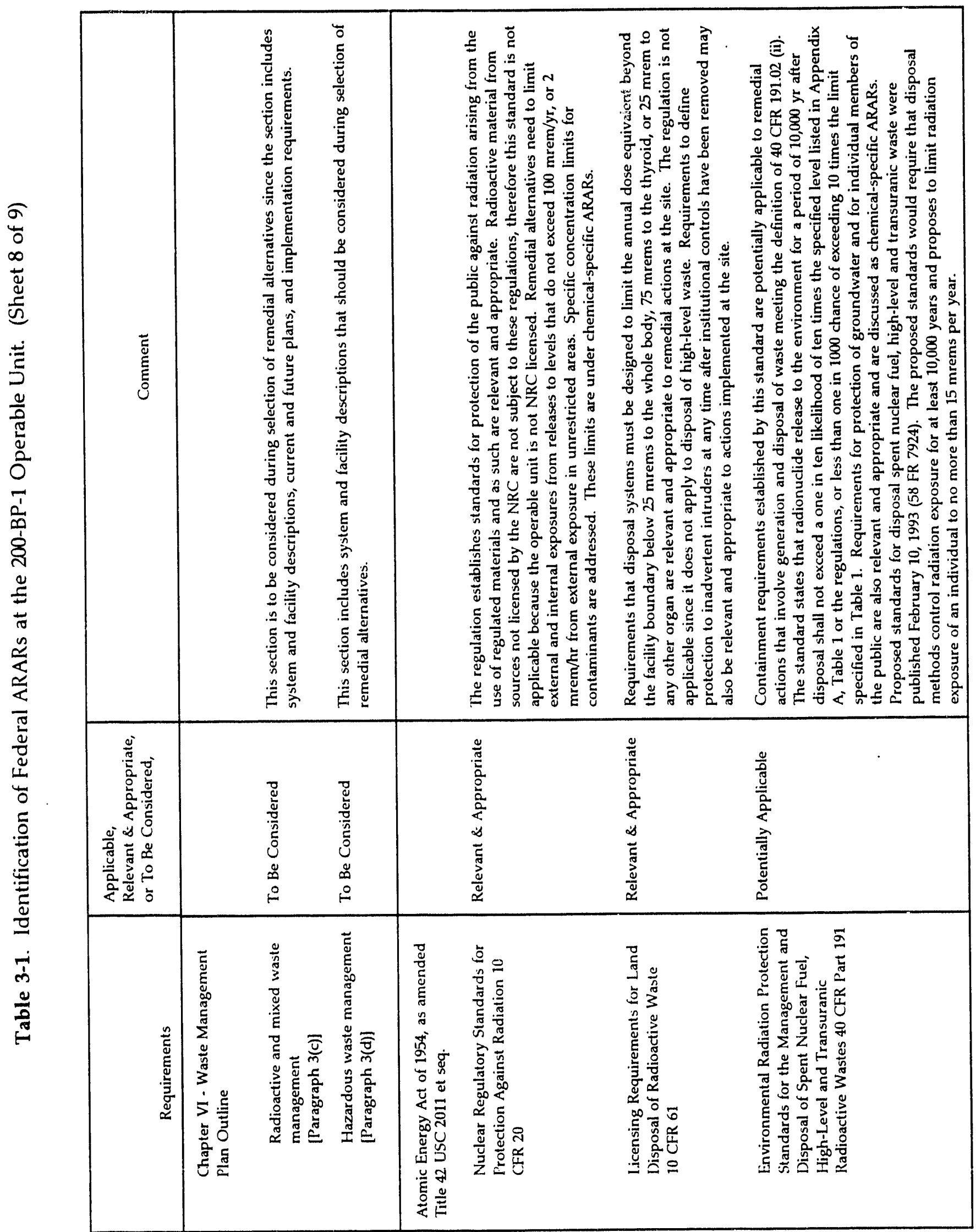


DOE/RL-93-35, Rev. 0

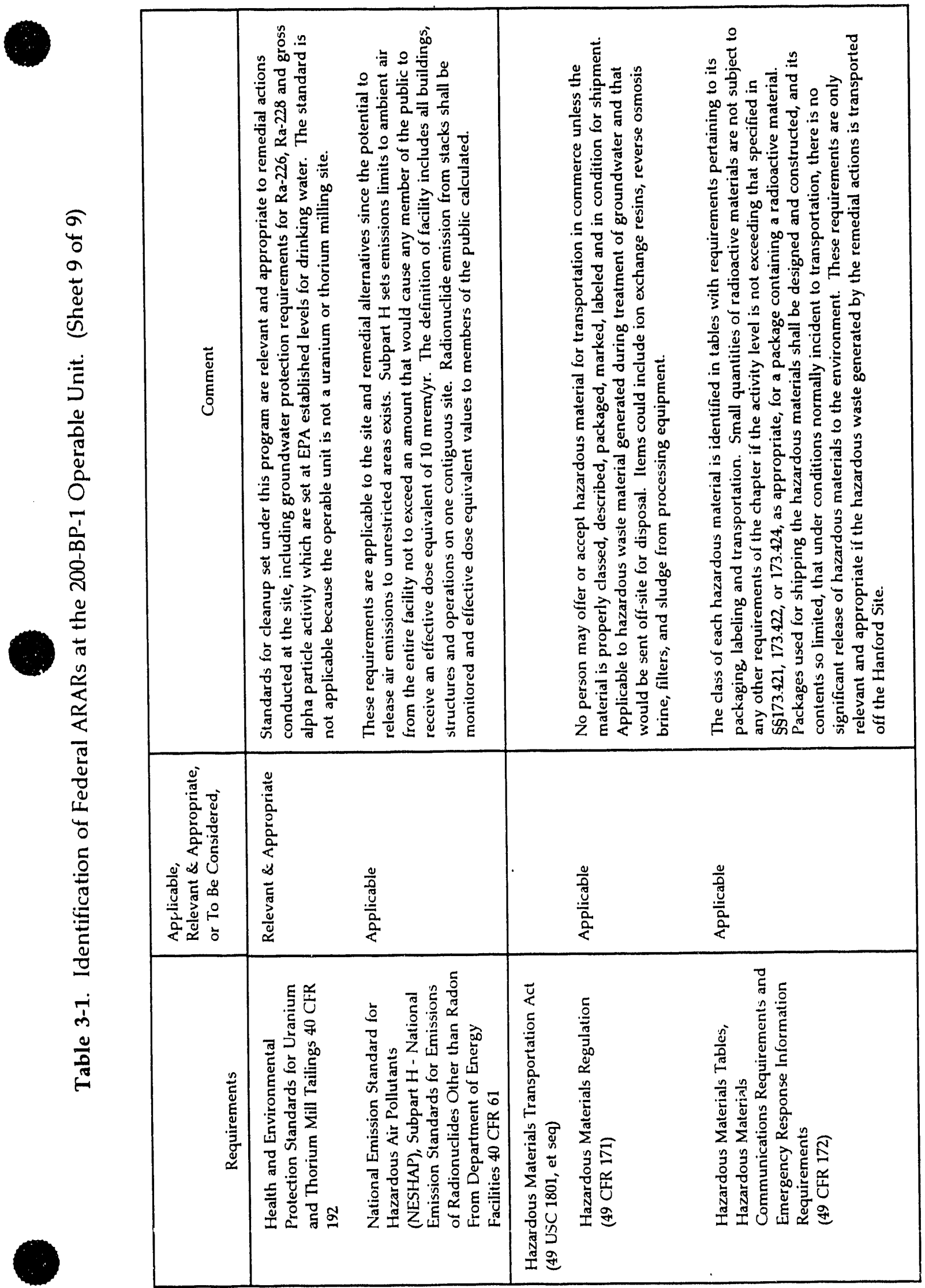


DOE/RL-93-35, Rev. 0

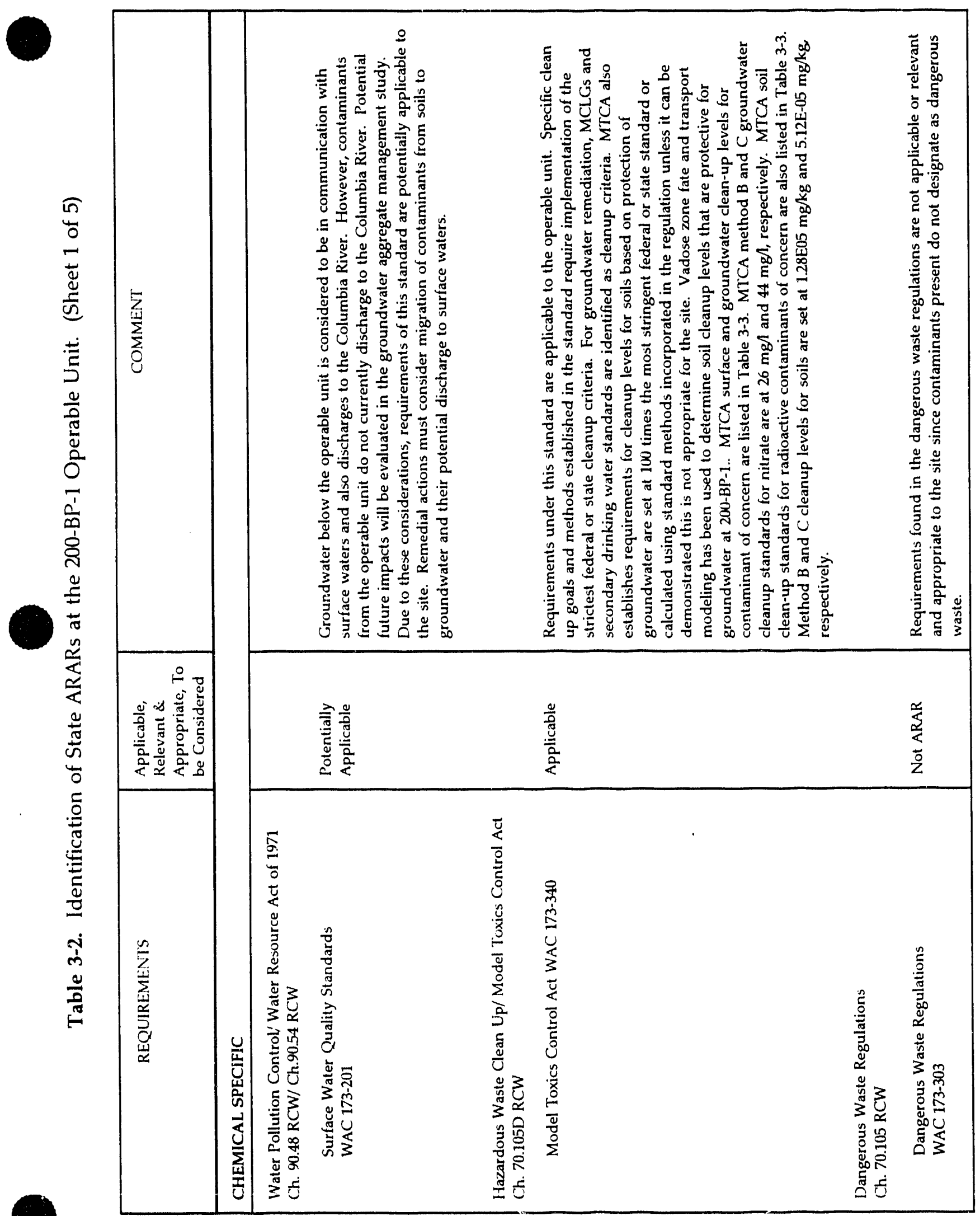


DOE/RL-93-35, Rev. 0

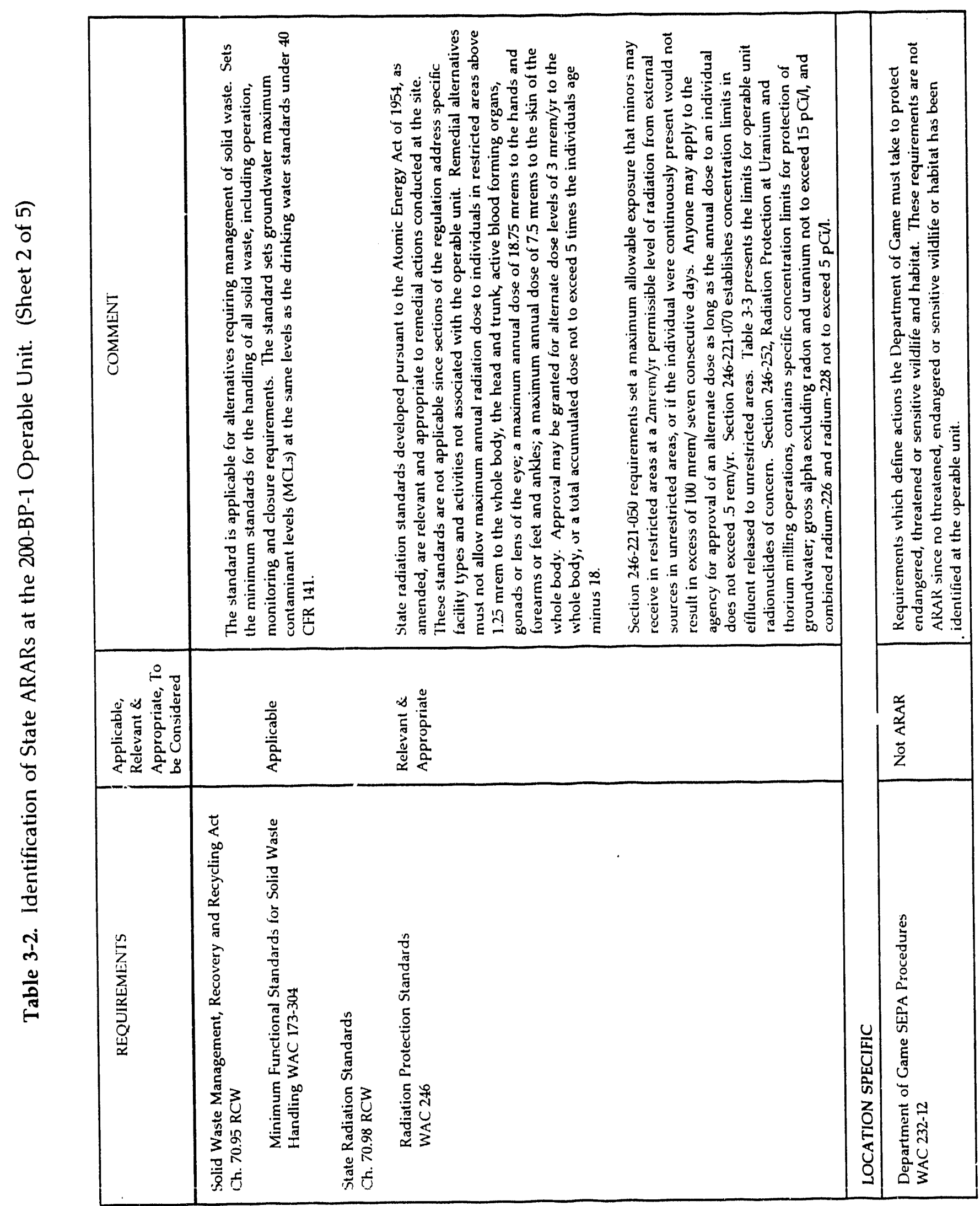


DOE/RL-93-35, Rev. 0

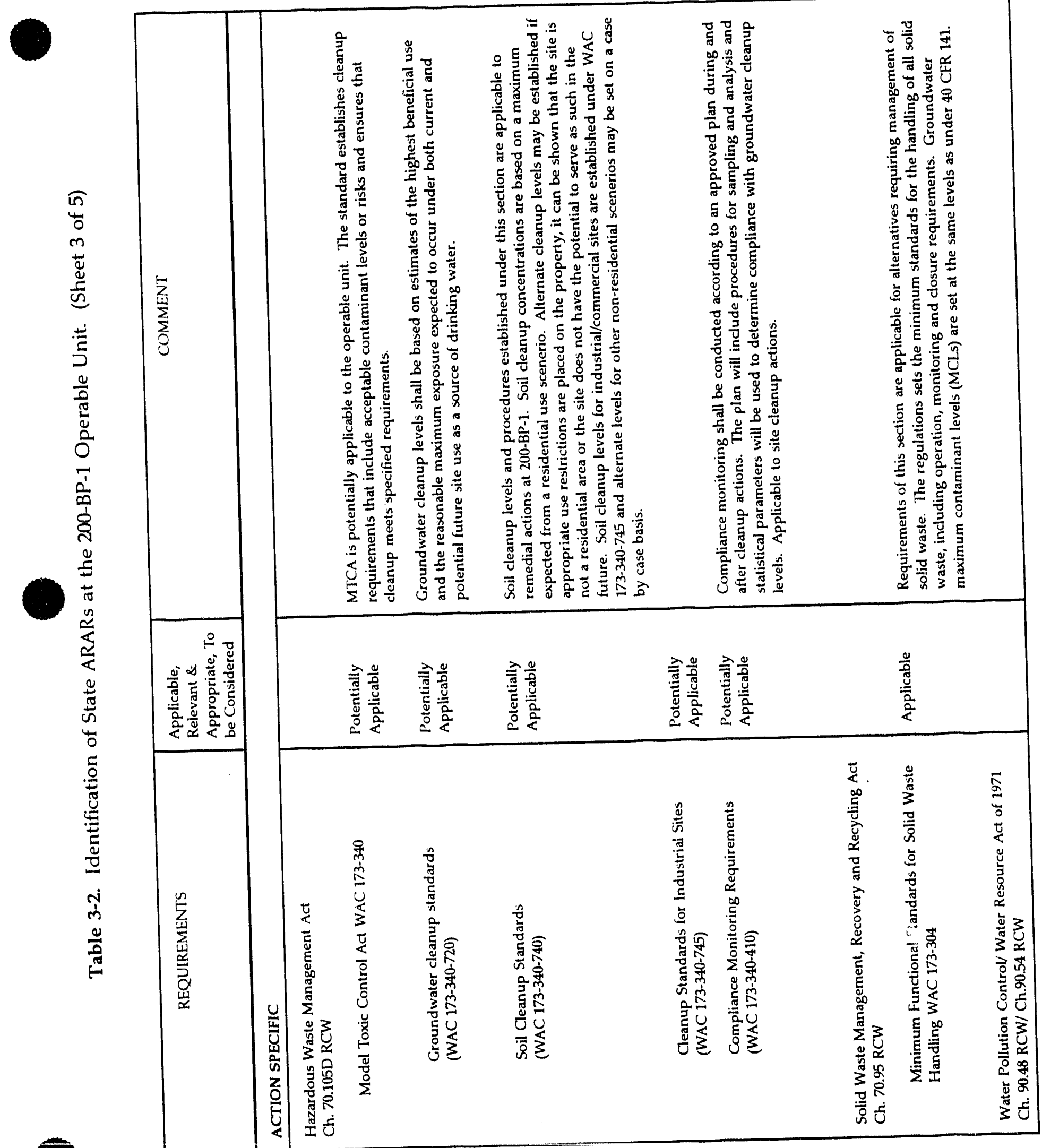


DOE/RL-93-35, Rev. 0

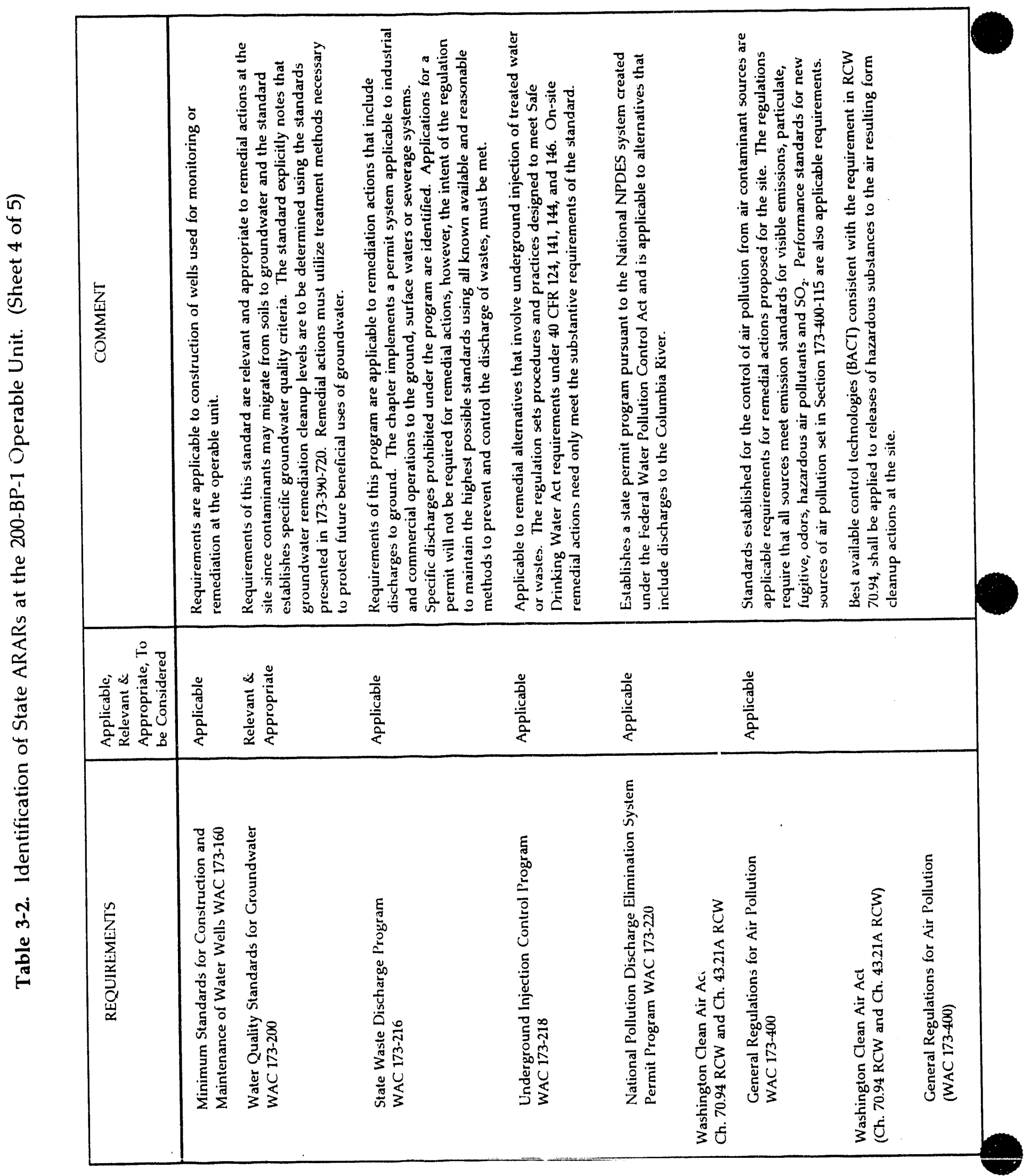


DOE/RL-93-35, Rev. 0

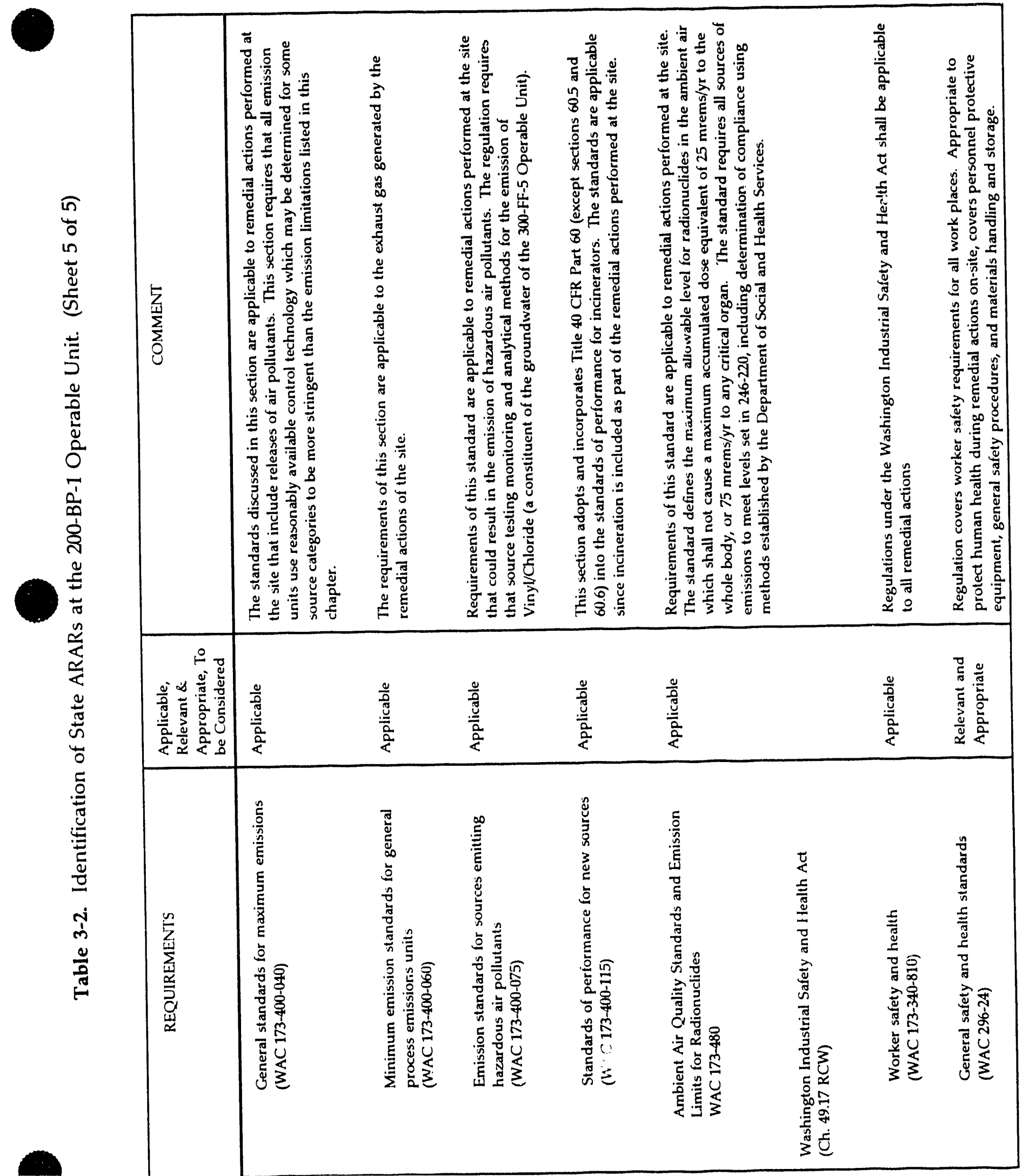


DOE/RL-93-35, Rev. 0

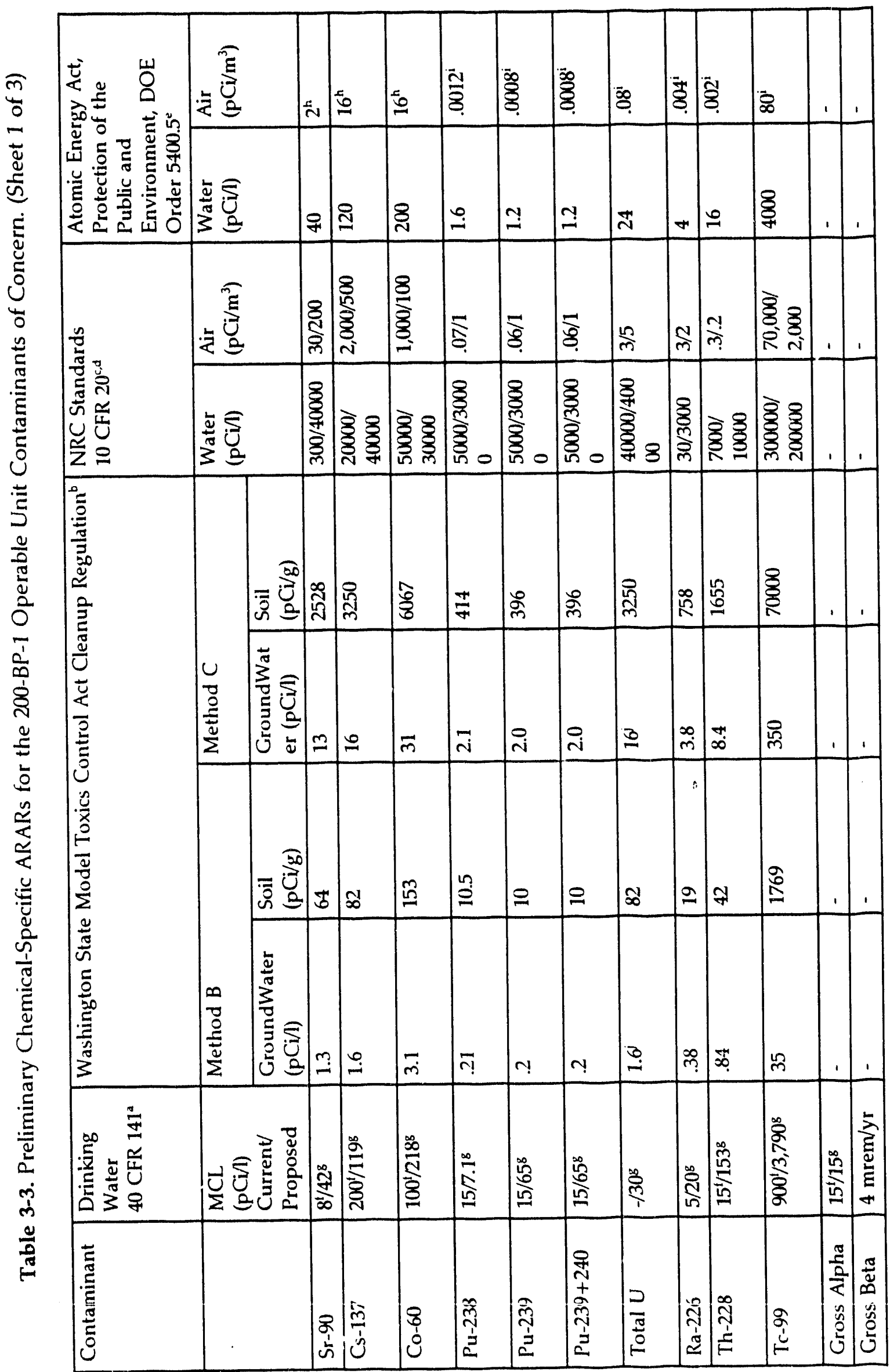


DOE/RL-93-35, Rev. 0

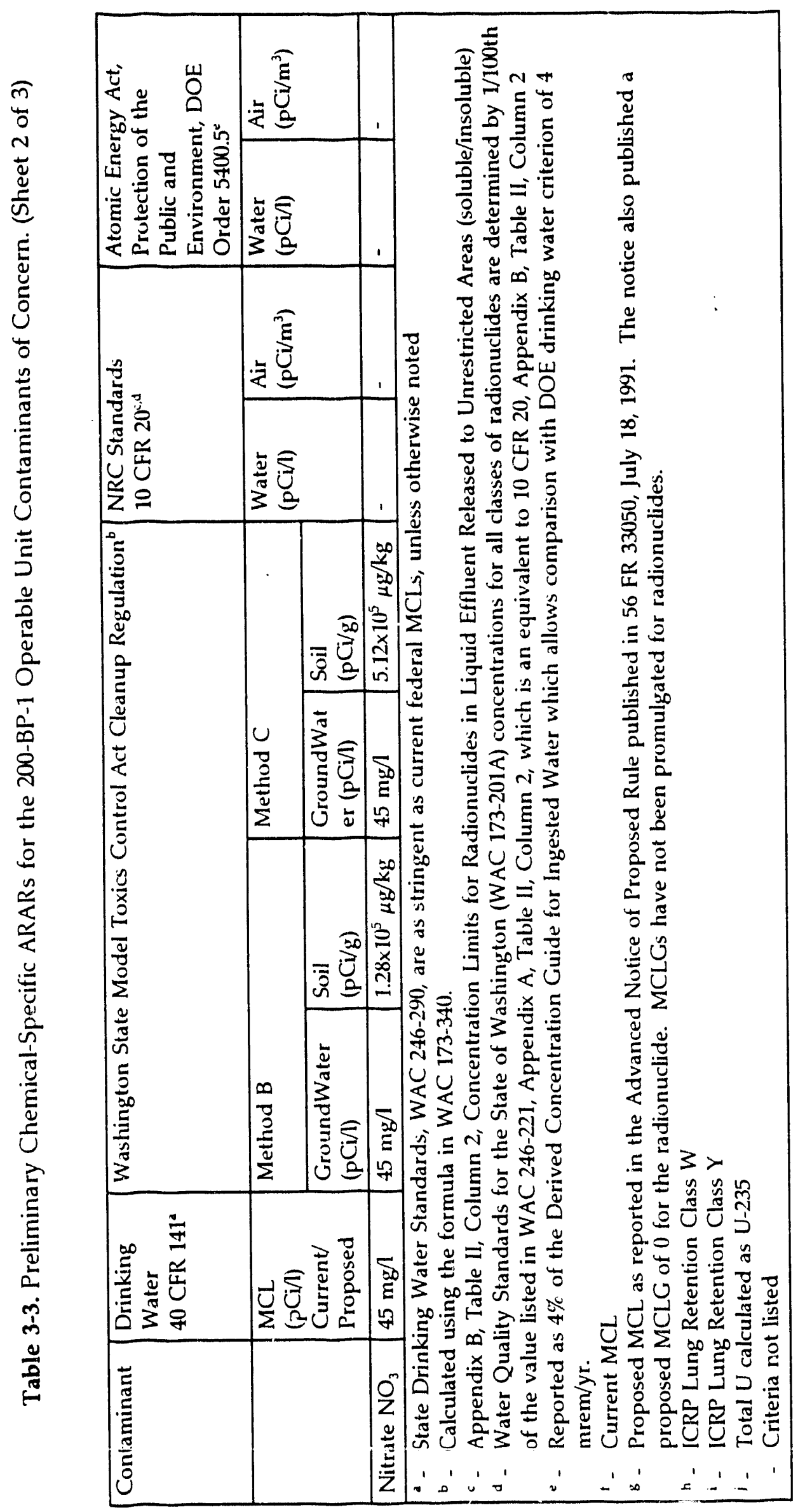


Table 3-3. Preliminary Chemical-Specific ARARS for the 200-BP-1 Operable Unit Contaminants of Concern. (Sheet 3 of 3 )

\section{DOSE RELATED STANDARDS FOR RADIONUCLIDES}

Environmental Standards for the Uranium Fuel Cycle 40 CFR 190

The annual dose equivalent is not to exceed

$25 \mathrm{mrems} / \mathrm{yr}$ to whole body

$75 \mathrm{mrems} / \mathrm{yr}$ to thyroid

$25 \mathrm{mrems} / \mathrm{yr}$ to any other organ

Environmental Radiation Protection Standards for Management and Disposal of Spent Nuclear Fuel, High-Level and Transuranic Radioactive Wastes 40 CFR 191

Subpart A - Facilities regulated by the commission are not to exceed standards set by 40 CFR 190 . Facilities not regulated by the Commission shall provide reasonable assure that the combined annual dose to the public resulting from discharges shall not exceed

$25 \mathrm{mrems} / \mathrm{yr}$ to whole body

$75 \mathrm{mrems} / \mathrm{yr}$ to any critical organ

Alternative standards may be established that prevent any member of the public from receiving continuous exposure of more than $100 \mathrm{mrems} / \mathrm{yr}$ and an infrequent exposure of $500 \mathrm{mrems} / \mathrm{yr}$ from all sources.

Subpart B - Environmental Standards for Disposal sets groundwater protection levels at

Radium-226/228 at $5 \mathrm{pCi} / 1$

Alpha emitters at $15 \mathrm{pCi} /$, including $\mathrm{Ra}-226 / 228$, excluding Radon

Combined concentrations of beta or gamma emitters shall not produce an annual dose equivalent to whole body or any internal organ greater than $4 \mathrm{nrem} / \mathrm{yr}$ if an individual consumed $2 \mathrm{~V} /$ day from the groundwater source

National Emission Standards for Hazardous Air Pollutants 40 CFR 61

Subpart I - National Emission Standards for Radionuclide Emissions from Facilities Licensed by the Nuclear Regulatory Agency and Federal Facilities not Covered by Subpart $\mathrm{H}$

Emission of radionuclides, including iodine, to the ambient air from a facility regulated under this subpart shall not exceed those amounts which cause any member of the public to receive in any year an effective dose equivalent of $10 \mathrm{mrem} / \mathrm{yr}$ 
DOE/RL-93-35, Rev. 0

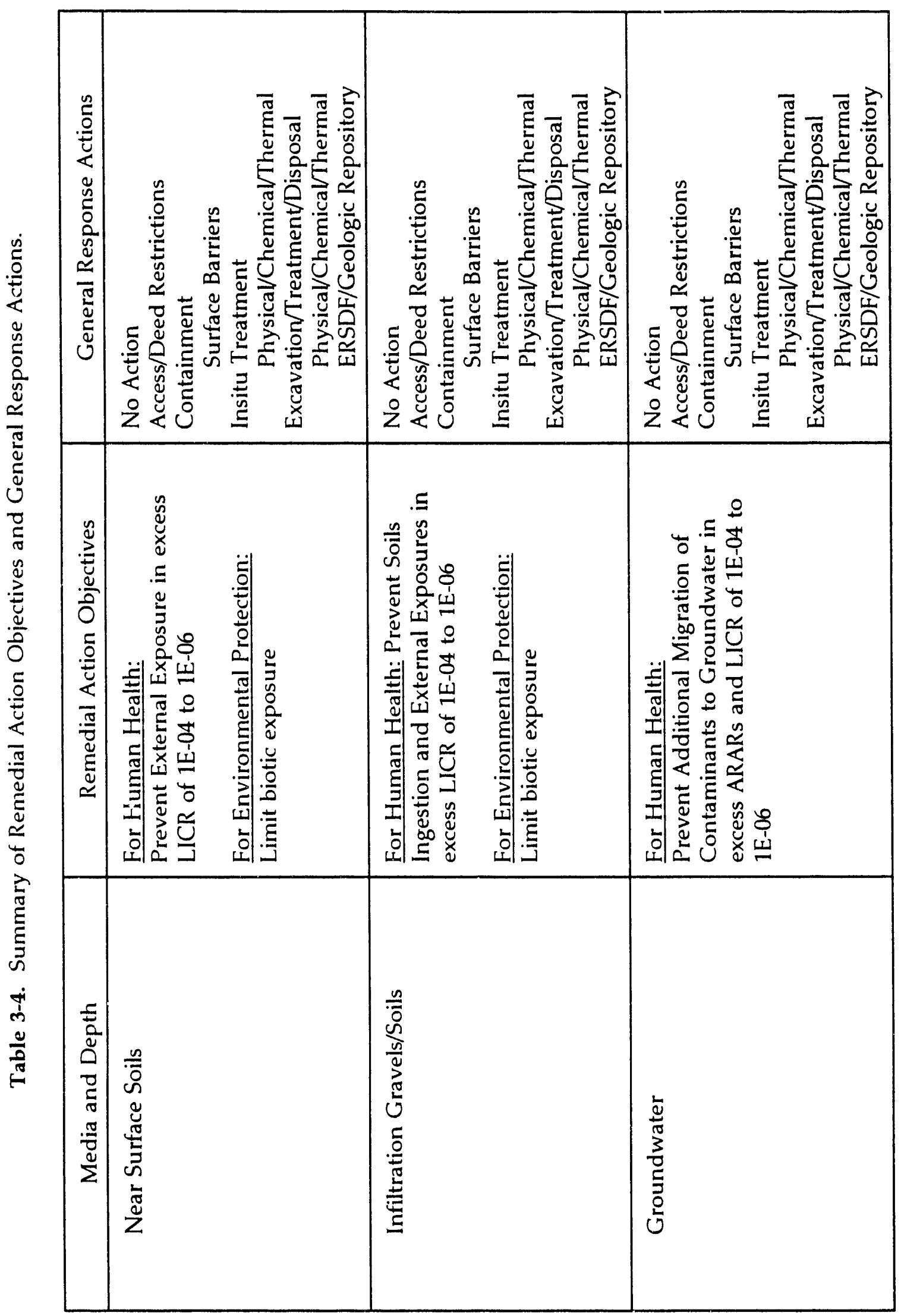


DOE/RL-93-35, Rev. 0

Table 3-5. Soil and Groundwater Concentrations at the $10^{-6}$ Risk Level for the 200-BP-1 Operable Unit ${ }^{a}$.

\begin{tabular}{|c|c|c|c|}
\hline Contaminant & $\begin{array}{l}\text { Soil Ingestion } \\
(\mathrm{pCi} / \mathrm{g})\end{array}$ & $\begin{array}{l}\text { External Exposure } \\
(\mathrm{pCi} / \mathrm{g})\end{array}$ & $\begin{array}{c}\text { Groundwater } \\
\text { Ingestion }(\mathrm{pCi} / \mathrm{l})\end{array}$ \\
\hline Cesium-137 & 244.6 & 0.24 & NA \\
\hline Cobalt-60 & 456.7 & 0.055 & NA \\
\hline Plutonium-239/240 & $29.8 / 29.8$ & $27,647 / 17,407$ & $--/ 0.87$ \\
\hline Radium-226 & 57.1 & 0.078 & NA \\
\hline Strontium $-90^{\mathrm{b}}$ & 190.3 & NA & NA \\
\hline Thorium-228 ${ }^{b}$ & 124.5 & 0.084 & NA \\
\hline Uranium (total) ${ }^{b}$ & 244.6 & 13.1 & 7.1 \\
\hline \multicolumn{4}{|c|}{$\begin{array}{l}\text { aAssumes industrial exposure on the operable unit with contaminated soils exposed. } \\
\text { bIncludes daughter products. } \\
\mathrm{NA}=\text { Not Applicable. }\end{array}$} \\
\hline
\end{tabular}




\subsection{IDENTIFICATION AND SCREENING OF REMEDIAL TECHNOLOGIES AND PROCESS OPTIONS}

In this chapter, technologies are identified that are potentially applicable for remediating contaminated soils at the 200-BP-1 operable unit. A comprehensive list of technologies and process options that are potentially applicable to this operable unit was developed to cover all of the applicable general response actions. The list of technologies was then screened to develop a refined list of potentially feasible technologies that can then be used to develop remediation alternatives for this operable unit. W'astewater treatment technologies are also included in the screening, although they would only be ancillary to other technologies that produce wastewater requiring treatment. These remediation technologies were screened using the following criteria (EPA 1988):

- Effectiveness - The potential effectiveness of the technology to 1) address site-specific conditions, including applicability to the media and contaminants of concern for this operable unit, 2) meet remedial action objectives, 3) minimize human health and environmental impacts during implementation, and 4) provide proven and reliable remediation under site-specific conditions.

- Implementability - The technical and administrative feasibility of implementing a technology at the site. Technical implementability is used to screen technologies or process options that are clearly ineffective or unworkable at the site. Administrative implementability is used to screen based on considerations that include the ability to obtain permits and the availability of workers, equipment, power, disposal services, and supplies.

- Cost - The relative capital costs and the operation and maintenance costs are evaluated for each technology. Cost plays a limited role in the screening of technologies and process options. Cost analysis is made on the basis of engineering judgement on a relative scale of high, medium, or low. At the screening stage, cost is used to reject a technology only if another technology is retained within the same general response action that is at least as effective in meeting remedial action objectives and has a lower cost. Costs are expected to vary more between technologies in different GRA categories than within a category.

The technologies and process options were screened against the criteria in the priority order listed above using the "fatal flaw" approach. This approach was adopted for efficiency, and is based on ranking the criteria in order of importance, as listed above. The ranking is in turn based on CERCLA Guidance (EPA 1988). Once a technology is rejected, based on effectiveness, it is not further evaluated based on implementability or cost. Similarly, if a technology is effective, but not implementable, the technology is rejected; evaluation of cost is not undertaken. For example, a technology that is ineffective for site contaminants or other site conditions is not evaluated against implementability or cost, as further evaluation is unnecessary. This approach streamlined the evaluation of technologies while maintaining the screening methodology required under CERCLA. 
Screening of technologies and process options has been performed in a single step. The key criterion in selecting the screening level (technology class, individual technology, or process option) is whether there is a significant difference between the technologies or process options when evaluated against the screening criteria (effectiveness, implementability, and cost). Technologies and process options that are judged to have significant differences are screened separately, and the retained technologies or process options will be developed into separate remediation alternatives to allow full evaluation and comparison.

Process options retained for any given technology that are screened together (i.e., not evaluated separately) are considered equally suitable (at the screening level of evaluation). Selection of representative process options is performed during the development of alternatives, so that best engineering judgement may be used to select and combine appropriate technologies and process options into cohesive, integrated remediation aiternatives.

The general response actions and potentially applicable technologies and process options considered for remediation of soil at Hanford's 200-BP-1 site are presented in Table 4-1. The technology screening is also summarized in this table. Brief descriptions of the listed technologies and discussions of the screening evaluations a:e provided below. Technologies retained through this screening process are then incorforated into remediation alternatives (Chapter 5).

\subsection{INSTITUTIONAL CONTROLS}

Institutional controls, including monitoring, are usually included as a component of any remedial alternative. Institutional controls for soils prevent or minimize direct exposure to contaminated soil, thereby reducing risk. They do not prevent offsite transport of contaminants via air, surface water, or infiltration into groundwater, and are often ineffective in preventing ecological exposures (e.g., to birds). They also require ongoing maintenance, albeit simple and inexpensive, to remain effective. Institutional controls and monitoring are effective within their limitations, are easily implemented, and are low in cost (and thus very cost-effective). Institutional controls are typically included in any remedy where contaminants will remain after completion of remediation. These controls are therefore retained for further consideration.

\subsubsection{Access Restrictions}

Access restrictions involve preventing access by unauthorized personnel. Risk is minimized by preventing exposure except in cases of trespass. Fencing the site perimeter is the most common means of restricting site access. Security personnel at entrance gates or patrolling can also be used to restrict site access and prevent or discourage trespass. Security personnel are significantly more expensive than other access restriction measures, and are therefore use of security personnel is often limited to the period of active remediation. Long-term use of security would probably be limited to occasional patrols. 


\subsubsection{Warning Markers}

Warning markers would be installed to discourage site trespass by warning potential intruders of the hazards of entering the area. Warning markers have been developed for long-term isolation of radioactive waste at the Hanford site. Markers could include large stone pylons with pictorial and verbal warnings that most people could understand. In addition, ceramic disks with similar information would be buried at the site where they would be encountered by anyone digging there.

\subsubsection{Land Use Restrictions}

Land use restrictions can include zoning and deed restrictions. At present, the Hanford site is not subject to zoning. However, zoning could become relevant under some future uses.

Deed restrictions involve specific limitations on future land use that are incorporated in the deed of ownership to the property. Such restrictions would prevent activities that could cause direct exposure or releases of contaminants. Deed restrictions accompany the deed to the property in a manner that is legally binding and must be transferred to all subsequent owners of the property. The restrictions should include a description of the site and reasons for the limits on future activity. Examples of deeds restriction for the 200-BP-1 operable unit are those that would prohibit residential or agricultural use and prohibit or restrict excavation to maintain the integrity of a surface barrier. Drilling for minerals, water, or other purposes would also be prohibited. Requirements to maintain access restrictions could be included.

\subsubsection{Monitoring}

Under CERCLA, site monitoring is a required component of any site remedy (including "no action"). Short-term monitoring is conducted to ensure that potential risks to human health and the environment are controlled while a site remedy is being implemented. Long-term monitoring is conducted to measure the effectiveness of the remedy and thereby ensure that the remedy continues to be protective of human health and the environment. A monitoring plan will be developed for the selected remedial action. The monitoring performed will depend on the nature of the remedy. Monitoring would include sampling and analysis of air, surface water run-off, and groundwater as appropriate. Monitoring would also include periodic site inspections to determine maintenance needs.

Air monitoring would be used to detect airborne contamination generated during remedial activities, so that appropriate mitigation measures could be taken. Long-term air monitoring is normally not necessary if no contaminated soil remains exposed on the surface following completion of remediation.

Surface water would be monitored for contamination in waters that contact or might have contacted contaminated materials from the site. As with air monitoring, surface water monitoring is normally a short-term measure conducted during remedial activities. It 
would not be necessary if no contaminated soil remains exposed on the surface following completion of remediation. There are no surface water bodies near 200-BP-1.

Groundwater monitoring would consist of establishing a network of groundwater wells (using existing wells where possible) upgradient and downgradient of contaminated soil, and collecting and analyzing water samples from them on a regular basis. For this soil operable unit, groundwater monitoring would be conducted on a long-term basis to determine if the remedy is successful in meeting remedial action objectives (such as prevention of ongoing groundwater contamination from infiltration). The objectives of groundwater monitoring would be combined with objectives for the 200 East Aggregate Area groundwater operable unit to result in an integrated monitoring plan.

\subsection{REMOVAL (EXCAVATION)}

As a general response action, soil removal can include site-wide excavation or selective excavation of highly contaminated soil. Removal does not provide remediation by itself, but must be coupled with subsequent treatment and/or disposal. Soil excavation would expose site workers, and potentially offsite personnel also, to contaminants that are currently unexposed. Excavation would therefore increase potential risk during remediation. The increased short-term risk would need to be offset by a significant decrease in long-term risk for excavation to be justified.

Conventional excavation equipment could be used: a backhoe, bulldozer, or similar equipment could be used for most excavation; a clamshell or dragline could be used for deep excavation. Excavated soil would be staged (placed in temporary storage) or immediately delivered for onsite or offsite treatment and disposal. If transportation outside of the operable unit were required, the soil would be loaded into special shielded containers for hauling. Excavated areas are then usually backfilled, compacted and graded for proper drainage.

For this site, special attention would be required to minimize worker exposure to radioactivity or contact with contaminated soil. This would include personnel protection equipment, modifications to excavation equipment (e.g., shielding), and stringent dust control measures, including working under temporary domes. Remotely operated excavation equipment would be considered.

Although dust control and surface water management are typically used during excavation, particularly stringent measures would be required for this site to minimize offsite exposure to radionuclides in contaminated soil. Excavation is a necessary component of remedial alternatives involving disposal (e.g., landfilling) or ex-situ treatment. This technology is therefore retained as a component of overall site remediation.

\subsection{IN-SITU CONTAINMENT}

In-situ containment is a general response action used to prevent exposure to contaminated material left in place and control migration of contaminants. Common methods of containment are discussed below. 


\subsubsection{Dust Control}

Dust control incorporates any measures to prevent wind dispersion of contaminated material. Several approaches to dust control are available. Materials such as cement, clay, and organic polymers can be sprayed on or mixed with soil to bind the soil matrix. Vegetation can be planted to hold the soil together and reduce wind velocity at the ground surface. Temporary structures (domes) can be used to cover an excavation.

Dust control can be relatively inexpensive and easy to accomplish. Over the short term, it is likely to be effective. However, it is essentially a surficial treatment. It does not prevent humans or animals from directly contacting contaminated soil at the site. Dust controls are not generally effective in preventing offsite migration of contaminants in surface water run-off. More effective dust control measures, such as water sprays or soil-binding additives, are only short-term measures. Binding additives deteriorate relatively quickly. Longer lasting measures, such as vegetation, are much less effective. Where very careful dust control is required, such as excavation of high-activity soil from this site, a temporary building (dome) is sometimes used. This is the most effective, and also the most expensive dust control measure. It is only feasible for covering excavations, treatment plants, or storage areas. It is not feasible during surface barrier construction.

Dust control is not considered effective for permanent remediation of soil. It is retained for consideration in combination with other technologies that involve handling of contaminated soil and generate dust during remediation activities.

\subsubsection{Surface Water Management}

Surface water management involves controlling surface water run-on and run-off at the site. The purpose of these controls is to minimize erosion that can entrain exposed contaminated soil and expose underlying contaminants, and to prevent ponding that could increase the amount of water infiltrating through contaminated soils.

The most common surface water control is grading the ground surface to promote adequate drainage without excessive erosion. In addition, diversion measures, such as berms and ditches, are commonly used to prevent clean surface water from entering a site (run-on) and prevent potentially contaminated surface water from leaving a site (run-off). Potentially contaminated surface water can be collected and treated, if required, prior to discharge. Revegetation can also be used to reduce erosion by stabilizing the soil. Vegetation can be difficult to reestablish in arid climates. However, once established, revegetation requires little or no maintenance.

Surface water controls by themselves are not generally effective as a permanent remedy. These controls may be used as short-term measures, such as during excavation, or as long-term measures as a component of a surface barrier, for example. Routine maintenance is required for continuing effectiveness.

Surface water management is effective, easily implemented and relatively inexpensive, using well-understood, proven design and construction techniques. This technology is therefore retained for use in conjunction with other remediation technologies. 


\subsubsection{Surface Barriers}

Barriers comprise a containment measure that minimizes risk by preventing direct contact with contaminated soil and preventing offsite migration of contaminants in surface water or airborne dust. Where infiltration through contaminated soil is a concern, a lowpermeability barrier is used to minimize the potential for contaminant migration into groundwater by minimizing infiltration of water through the contaminated soil.

Barriers are constructed on the ground surface, over contaminated materials. Barriers may be constructed of a variety of materials such as clay, other types of soils, synthetic membranes, asphalt, and concrete. They may consist of a single layer or be composite barriers with several layers. Barriers provide containment in three primary ways:

- The barrier serves as a physical barrier to prevent humans, other animals, and vegetation from coming in contact with contaminated materials.

- The barrier prevents erosion of contaminated soil by surface water and wind, thereby preventing offsite transport of contaminants via these media.

- If needed, the barrier can have low permeability and thus function as a barrier to infiltration of surface water. Less infiltration will reduce the potential for transport of contaminants from the soil to the groundwater via infiltration.

Barriers can be designed to be compatible with many potential future site uses. Institutional controls (deed restrictions) are often used along with barriers to prevent future site activities that could violate the integrity of the barrier. For example foundation pilings would not be allowed to penetrate an impermeable barrier.

Barriers are a proven, effective technology that is readily implemented using standard design and construction techniques. It is a relatively low cost technology that generally provides high cost effectiveness (i.e., high incremental protection relative to rerridiation cost). However, a wide variety of barrier designs are possible that vary in effectiveness, implementability and cost. The following barrier designs have been evaluated to provide a representative screening:

- Soil

- Asphalt

- Concrete

- Low-permeability clay

- Synthetic membrane with soil cover

- Composite low-permeability barriers

- Modified RCRA design

- Hanford barrier. 
4.3.3.1 Soil Barrier. One or more layers of soil may be used to cover a contaminated site. Native soil is usually used for soil barriers, although it may be amended to improve its properties (e.g., adding gravel to the top layer to protect against wind erosion). A sufficiently thick soil barrier, or one with a layer of coarse soil materials, is effective in preventing humans, other animals, and vegetation from contacting contaminants, yet requires little or no maintenance. For the purposes of this FS, soil barriers differ from composite barriers (discussed below) in that they are composed entirely of soils and are primarily designed for preventing contact with contaminated materials and preventing offsite migration of contaminated materials via surface water or wind erosion.

Soil barriers are typically the most implementable and least costly of the barrier types, and are retained for further consideration. Soil barriers (as defined in this FS) are not specifically designed for low permeability.

WHC has designed a soil cover, utilizing several layers of coarse materials, designed to prevent biointrusion by promoting free drainage. This cover, referred to as a biointrusion barrier, will only be used where infiltration of precipitation is not a concern. The top layers are formed from coarse material the discourage moisture retention, and hence plant growth. They also resist wind erosion and burrowing animals. However, these course layers enhance infiltration, permitting rapid percolation of water away from the plant rooting zone, but directing it downward into the soil column.

4.3.3.2 Asphalt Barrier. Asphalt can be used to provide a single-layer, low-permeability barrier (not counting foundation layers, if required). While effective in the short-term, asphalt requires relatively high maintenance to offset weathering and cracking. Because a relatively thin layer of asphalt is typically used ( 3 to 6 in.), asphalt is easier to breach than thicker barriers. When maintained, asphalt can be an effective barrier against wind erosion, intrusion from burrowing animals and deep rooting plants, and surface water erosion.

A soil barrier is more effective and reliable at preventing direct human and environmental contact for less cost than the asphalt equivalent. Composite barriers are more effective at providing low permeability. Asphalt barriers are therefore not retained. However, an asphalt layer is used in some of the composite barriers.

4.3.3.3 Concrete Barrier. Similar to asphalt, concrete can be used to provide a single-layer barrier. Concrete can have varying permeability, depending on the concrete mixture used. However, concrete is prone to cracking over the long term, and is therefore difficult to maintain as an impermeable barrier. Concrete barriers are relatively effective in preventing wind and surface water erosion. If cracking can be minimized, biointrusion can be minimized. Unfortunately, once cracked, concrete becomes susceptible to intrusion from deep rooting plants and ground nesting insects.

Concrete is very expensive relative to most other barrier materials. A soil barrier prevents direct contact for much less cost. Composite barriers are more effective at providing low permeability. Concrete barriers are therefore not retained.

4.3.3.4 Low-Permeability Clay Barrier. Clay barriers are generally constructed with a layer of low-permeability, high plasticity clays covered by clean native soil for vegetative growth and to prevent the clay from cracking due to freezing. The clay layer may use native or 
imported clay, or may use native soils amended with bentonite or other materials that lower its permeability. With a vegetative soil cover, clay barriers are effective against wind erosion. However, vegetative covers lend themselves to intrusion from burrowing animals, deeply rooting plants and ground nesting insects. Reliability with respect to surface water erosion depends upon the slope, drainage area, and vegetative state of the cover. Once breached, clay barriers are susceptible to wind and water erosion, conditions that are made worse if the clay becomes cracked due to freeze thaw activity or becomes desiccated.

Clay barriers are generally considered effective and reliable. However, at Hanford, the arid climate makes clay subject to desiccation, which can crack the clay and raise its permeability. Clay barriers are not as reliable as composite barriers for long-term, lowpermeability containment, and are therefore not retained.

4.3.3.5 Synthetic Membrane Barriers. Flexible synthetic membranes (e.g., polyvinyl chloride, high density polyethylene [HDPE], and neoprene) are commonly used in landfill liners and covers. Their primary purpose is as a barrier to infiltration of precipitation and surface runoff. A synthetic membrane can provide lower permeability than clay or other soils so long as the membrane does not puncture, tear or deteriorate. A hydraulic barrier relying primarily on a synthetic membrane would have a bedding layer of soil to provide a foundation and protect the membrane during installation. The membrane is then covered with overlying layer soil to protect against damage and exposure to ultraviolet components of sunlight, which can weaken or degrade the membrane.

In this sequence, synthetic membrane barriers are resistant to wind and surface water erosion. The overlying soil cover is usually resistant to deep rooting plants and ground nesting insects. This soil layer often has special design requirements to discourage burrowing animals, however, as many species have teeth of sufficient size to chew through the membrane. Once the overlying cover is breached, the membrane becomes susceptible to a variety of degradation mechanisms.

Synthetic membranes can be very effective initially. However, widespread use began only recently; consequently, long-term effectiveness and reliability of synthetic membranes as impermeable barriers is uncertain. By themselves, the membranes provided little protection against direct contact with contaminated materials; this protection is provided by the overlying soil. Membranes require specialized equipment and careful installation to avoid punctures or latent stresses than cause tearing. Stresses from settling and temperature variation can also tear the membrane. The longevity of the barrier membrane polymers under long-term field conditions is uncertain. Composite barriers (which typically include synthetic membranes) are more reliable. This barrier type is therefore not retained.

4.3.3.6 Low-Permeability Composite Barriers. Composite (multi-media) barriers are designed using multiple layers of different materials to achieve highly effective and reliable, long-term protection of contaminated sites. Low permeability is a key design consideration in these barziers to protect groundwater. The most well-known composite barrier type is the "RCRA barrier", which is a barrier designed to meet the minimum technology requirements (MTRs) specified in 40 CFR 264.310 for hazardous waste landfills. EPA has published guidance for complying with MTRs (EPA 1989a). A RCRA barrier design will typically contain (top to bottom): 
- Vegetative layer - vegetated topsoil and clean fill, typically $0.6 \mathrm{~m} \mathrm{(2 \textrm {ft } )}$ thick, to protect the barrier against damage (e.g., erosion) and provide evapotranspiration to decrease infiltration.

- Drainage layer - either sand $(0.3 \mathrm{~m} \mathrm{[1} \mathrm{ft}]$ thick) or synthetic geonet to divert infiltration away from the covered area.

- Low-permeability liner - typically a synthetic membrane over 0.6 to $0.9 \mathrm{~m}(2$ to $3 \mathrm{ft}$ ) oi compacted clay with a permeability no greater than $1 \times 10^{-9} \mathrm{~m} / \mathrm{s}\left(2.8 \times 10^{-4} \mathrm{ft} /\right.$ day $)$. Use of two liners provides redundant low permeability; the synthetic membrane protects the clay against desiccation, and the clay provides a thick barrier capable of some selfhealing with settling and other geological stresses.

Design and installation of composite barrier requires specialized expertise, and synthetic liners particularly require specialized installation. However, this expertise and equipment are readily available. Composite barriers are more expensive than less sophisticated barriers, but long-term maintenance and monitoring costs can be lower (e.g., compared to asphalt or concrete).

Experience with composite barrier designs in arid climates is limited. In addition, where radioactive contamination is involved, concern over long-term ability of the barriers to maintain their integrity, meeting ARARs for periods of up to 1,000 years, is even greater than for hazardous waste. Consequently, for this operable unit, two composite barrier designs will be considered: a modified RCRA barrier design and the Hanford Barrier.

The modified RCRA barrier will start with a standard RCRA barrier design, and modify it to better suit conditions found at the Hanford site. Modifications include replacing the geosynthetic membrane liner with an asphalt layer with base course to provide improved longevity on the order of hundreds of years. Other modifications include expansion of the typical single component drainage layer to a multiple layer drainage system designed to form a capillary break, and admixture of gravel in a silt matrix as a top layer to maximize evapotranspiration and minimize infiltration under Hanford Site-specific climatic conditions.

The Hanford Barrier is a composite barrier system specifically designed for the Hanford Site. It is intended to provide a high degree of protection and reliability with no maintenance under Hanford Site conditions over time periods up to 1,000 years.

Both the modified RCRA Barrier and the Hanford Barrier have surface layers that have coarse gravel admixed with silty soils. These layers are wind resistant, retain surface water near the surface promoting rapid evapotranspiration, and discourage borrowing animals. Growth of shallow rooted plants is encouraged; subsequent layers are designed to resist biointrusion from deeply rooted plants and burrowing animals. Both the modified RCRA Barrier and Hanford Barrier are retained for further consideration.

In summary, three barrier types are retained for use in developing remedial alternatives: a soil barrier (biointrusion barrier), a modified RCRA barrier, and the Hanford Barrier. 


\subsubsection{Vertical Barriers}

Vertical barriers are intended to minimize lateral tlow of groundwater, preventing or minimizing contaminant migration. For reliable containment, vertical barriers should be keyed into a continuous low-permeability stratum or an artificial horizontal barrier to prevent migration underneath the vertical barrier. Slurry walls, sheet piling, grout curtains, and freeze walls are established technologies for constructing vertical barriers under appropriate site conditions.

Slurry walls are constructed by excavating the native soils and adding admix in a slurry to construct a low-permeability wall. Bentonite and cement/bentonite are common admixes, with cement used where structural strength is required in addition to low permeability. Slurry walls are widely used in site remediation.

A sheet pile wall is constructed by diving interlocking steel sheets into the soil. Sheet piling is primarily used for providing structural containment in excavation. Leaking can occur between individual sheets unless special measures are taken (such as grouting) to seal the seams. Steel piles will eventually deteriorate via rusting. Sheet piling may not be feasible at the 200-BP-1 operable unit because the large gravel and cobbles could prevent driving the piling to the required depth.

A grout curtain is constructed by drilling boreholes and injecting cement or other grout into the boreholes and outward into the surrounding soil. The boreholes are spaced closely enough to obtain overlapping grout zones, forming a continuous wall. Grout injection is more difficult to control than slurry wall construction, and is considered less reliable.

Freeze walls are established technology for short-term containment during dam construction and deep excavation, where technical difficulties can make this expensive technology cost-effective. A freeze wall (cryogenic barrier) is formed by installing pipe using drilling techniques and circulating refrigerant to freeze the water in the surrounding soil. Frozen soil is substantially less permeable than unfrozen soil and possesses more structural strength. Continuous operation of a cryogenic (refrigerant) unit is required to prevent the wall from melting.

Freeze walls for long-term containment are unproven technology. In addition, at this site, the unsaturated soils have insufficient moisture to allow formation of a freeze wall. The cryogenic plant is required to operate indefinitely to maintain the barrier, making it an active barrier in contrast to more permanent and proven passive barriers. This technology is therefore not considered suitable as permanent containment.

For this operable unit, groundwater containment is not a major concern and will be addressed in the 200 East Aggregate Area FS. Infiltration through the soils will move primarily downward. There are no shallow laterally continuous confining layers or zones of greatly reduced hyciraulic conductivity beneath the cribs. Lateral spreading is not a concern at shallow depths where installation of vertical barriers would be feasible. Therefore, vertical barriers are not applicable to soil remediation at this site, and are not retained. 


\subsubsection{Horizontal Subsurface Barriers}

Horizontal subsurface barriers are intended to minimize infiltration of leachate from contaminated soil into the underlying groundwater. In general, horizontal barriers are difficult to implement and, primarily due to difficulties in construction and verification (quality control), have questionable reliability. Grout injection and ground freezing (cryogenic barrier) are two technologies often proposed for creating subsurface horizontal barriers.

Similar to vertical grout walls, grout injection constructs a horizontal barrier by drilling inclined or horizontal boreholes around the contaminated zone. Grout is injected into the boreholes and outward into the surrounding soil. An overlapping pattern of holes should form a continuous grout barrier under the contaminated zone.

However, orout injection to form an low-permeability horizontal barrier is unproven technology thac has not been performed at full scale. Inclined and horizontal drilling is more difficult to accomplish and control than vertical drilling, and requires specialized equipment. The continuity of the completed barrier is difficult to verify, particularly with heterogeneous soils. Consequently, subsurface horizontal grout walls are not considered effective and reliable for this site, and are not retained.

Ground freezing (cryogenic barriers) has been proposed for constructing horizontal barriers. This is the same technology as would be used for vertical barriers (see preceding discussion). This technology is unproven for long-erm containment. At the 200-BP-1 operable unit the unsaturated soils have insufficient moisture to allow formation of a freeze wall. The cryogenic plant is required to operate indefinitely to maintain the barrier, making it an active barrier in contrast to more permanent and proven passive barriers. This technology is therefore not considered suitable as permanent containment.

\subsection{EX-SITU TREATMENT}

This section considers a wide range of technologies for ex-situ treatment following excavation. Treatment is intended to reduce the toxicity, mobility or volume of contaminated material. Many treatment technologies convert contaminants to less toxic forms. Destruction or degradation of organic compounds is possible (e.g., oxidation to carbon dioxide and water) although not always feasible or cost-effective. However, metals and radionuclides cannot be destroyed by treatment. Heavy metal toxicity can be reduced via chemical conversion to a less toxic compound of the metal. Effective toxicity due to radioactivity can be reduced via containment (shielding), but the inherent radioactivity remains. Therefore, treatment for radionuclides focuses on reducing mobility or volume.

Ex-situ treatment technologies provide treatment following excavation. The advantage to treatment ex-situ is greater control of the treatment process, hence greater effectiveness (better treatment results) and greater reliability by assuring that treatment objectives have actually been achieved. However, the benefits of greater control of treatment must be balanced against potential short-term exposure risks due to excavation and handling, and greater costs. 


\subsubsection{Dry Soil Sieving}

Dry soil sieving is an ex-situ physical separation process that is performed without the addition of water. Soil is passed through one or more screens and separated into various size fractions. The concept behind remediation using this technology is that the degree of contamination often increases with decreasing particle size. Therefore, the volume of soil requiring remediation can be reduced by sieving and removing various soil size fractions that meet the cleanup criteria. This technology is inexpensive and easily implemented, although dust control and shielding must be added to conventional implementations to minimize potential worker exposure to radionuclides and to prevent migration of the dust off-site. However, dry sieving is not as effective as wet separation processes (see discussion of physical soil washing), and therefore is not retained.

\subsubsection{Physical Soil Washing (Aqueous Physical Separation)}

The term "soil washing" is used io describe a variety of treatment processes. In particular, there is often semantic confusion between soil washing intended to physically separate soil into clean and contaminated fractions, and soil washing intended to extract contaminants from the soil. For clarity, the term "physical soil washing" is used in this FS to refer to soil washing for physical separation, and "chemical soil washing" to refer to soil washing for contaminant extraction.

Physical soil washing is applicable to any contaminated soil where the contaminants are concen $r$ rated in a particular size fraction. In practice, the majority of radioactive contaminants in soils are often associated with the silt and clay soil fractions (collectively called the fines), with coarser soil (sand and gravel) being relatively clean. If the contaminants on coarser particles is concentrated on the particle surfaces, attrition scrubbing (surface abrasion) can be successful in removing the surface contamination.

Physical soil washing can be effective in providing significant volume reduction. In general, soil washing is feasible under the following conditions:

- contaminants are concentrated in one soil size fraction (typically the fines)

- the contaminated fraction is a small percentage of the soil volume

- the relatively clean soil particles (typically sand and gravel) meet remedial action objectives either as found or after attrition scrubbing.

Physical soil washing is performed using a combination of unit or sations, which can include:

- Screening (wet and dry)

- Gravity separation

- Classification

- Spiral classifiers

- Hydrocyclones (liquid-phase cyclones)

- Attrition scrubbing

- Flotation 
- Dewatering.

Treatment of contaminated washwater is necessary prior to discharge. When contaminant solubilities are low, such as for this site, washwater would be recycled and would not require treatment until final discharge on completion of soil treatment. Because it is a wet process, dust control requirements are greatly reduced compared to dry separation processes.

The unit operations employed in soil washing have been widely used in the mining and mineral processing industries for many years, and the equipment is readily available. Demonstration projects have been conducted as part of EPA's Superfund Innovative Technology Evaluation Program (SITE) (EPA 1989b). Soil washing systems are currently being tested on a variety of contaminated soils, including metals and radionuclides.

A number of physical soil washing processes are currently being marketed. Published flowsheets for these processes show different combinations of unit operations. However, the appropriate design of a soil washing system depends on the remedial action objectives, the specific : ontaminants, and soil characteristics, including the percentage of fines and contaminant distribution between soil size fractions. Consequently, a soil washing process is often modified, for example, using a hydrocylone instead of a spiral classifier to operate more effectively under site-specific conditions.

Soils at this site may be well suited to physical soil washing, being predominantly coarse sands and gravels, with less than $10 \%$ fines (silts and clays). Contaminants in similar soils from the 300 Area were found to be on the surface of larger soil particles (and, therefore, amenable to removal by attrition scrubbing) or in soil particles less than 100 microns ( 0.0039 in. or 150 mesh) in diameter (Gerber 1992). An estimated $85 \%$ - $94 \%$ reduction in the volume of contaminated soil requiring further treatment or disposal could be achieved. However, treatability testing would be required to determine the actual effectiveness. This technology is retained for further consideration.

For the FS, a treatability study for soil washing would involve a combination of laboratory-scale testing and bench-scale testing. Laboratory-scale testing would determine the distribution of contaminants by particle size and include batch washing tests to determine the effectiveness of washing the various soil size fractions. Different washing solutions would be tested, such as varying $\mathrm{pH}$, adding surfactants, and possibly also evaluating chemical extraction of radionuclides. If soil washing appeared effective at this stage, the proposed soil washing process would be simulated using bench-scale equipment to estimate the effectiveness of the proposed process in achieving the theoretical effectiveness found in laboratory-scale tests. Bench-scale testing would also be conducted for a variety of washing conditions, such as varying solution:soil ratios. Field testing with pilot-scale equipment would be performed during the remedial design phase, should soil washing be part of the selected remediation alternative. A treatability study would add between several months to over a year to complete, depending on the results and the extent of the study. 


\subsubsection{Chemical Soil Washing (Radionuclide Extraction)}

Chemical soil washing is a treatment technology where a liquid solvent is used to extract contaminants, in this case, radionuclides from contaminated soil. The term "solvent extraction" is sometimes also used for this technology. Chemical soil washing differs from physical soil washing in that the purpose of the treatment is removal of contaminants from the soil, rather than separation of soil into contaminated and clean fractions.

The appropriate solvent will vary according to the contaminant to be extracted. Water, water with surfactants, acid, inorganic salts, and metal complexing chemicals (e.g., EDTA) have all been tested with varying degrees of success. Other, non-aqueous solvents have been used for extraction of organic contaminants, but these processes are not applicable to this site. Most of the extraction testing for metals and radionuclides has been restricted to the laboratory studies, as compared to soil washing of organic compounds which has been successful in field tests. Published data indicate that extraction of metals, including radionuclides, can be highly effective; however, the data also show large variation in effectiveness between sites.

A treatability study would be required to determine the effectiveness of chemical soil washing on soils from the 200-BP-1 operable unit. If effective, the implementabilty would also have to be determined, considering that chemical soil washing is unproven technology. Finally, a key factor in evaluating chemical soil washing (particularly in comparison to physical soil washing) is the cost of the solvent and the difficulty in treating the extract. Contaminant extraction is typically expensive, and yet only concentrates the contaminants into a sludge that still requires disposal (in contrast to organic contaminants, which can be degraded once extracted). However, because the effectiveness of the other retained ex-situ treatment technologies are also uncertain at this time, this technology is retained for further consideration.

\subsubsection{Fixation (Chemical Stabilization)}

Fixation, also called chemical stabilization or stabilization/solidification, involves mixing contaminated soil with binding agents to form a solid matrix that immobilizes the contaminants, and thereby reduces contaminant mobility (leachability) and associated risk. This technology should also reduce contaminant bioavailability. Fixation typically uses pozzolanic agents, such as cement, fly ash, and lime. Proprietary additives are available that are claimed to improve immobilization. Plasticizers and hardening agents are also available when specific bulk physical properties are needed.

Fixation is a common, established technology for treatment of wastes and soils contaminated by heavy metals or radionuclides. Metals are typically immobilized by both chemical bonding and physical entrapment; organic compounds are immobilized only by entrapment. Fixation is a proven technology for immobilization of the contaminants of concern for this operable unit, and is therefore retained for further consideration. 


\subsubsection{Vitrification}

Vitrification is a treatment process for immobilizing metals, including radionuclides, and other inorganic contaminants in a glass or ceramic matrix. For contaminated soil, the glassy matrix is derived from the soil itself, although glass frit or ceramic admix may also be used. Treatability testing on other low-level radioactive wastes has shown that low levels of contaminant release in leachate can be achieved. However, because published data often omits leaching rates for the untreated material, it is often not clear how much decrease in leachability is actually achieved via treatment.

When used ex-situ, vitrification is typically performed in a ceramic melter, rotary kiln, or similar equipment. Organic compounds, if present, are destroyed via oxidation or pyrolysis. On this basis, ex-situ vitrification can be considered thermal treatment. However, it is classified as physical treatment for this site because its purpose, contaminant immobilization, is the same as that for in-situ fixation.

Because very low leaching rates are possible, vitrification is a component of most highlevel nuclear waste programs. Vitrification plants have been successfully operated in Europe. Nunierous test programs to vitrify highly radioactive liquids and sludge have been successfully completed in the U.S. As a result, vitrification facilities are either under construction or in the planning stages at several DOE facilities including the Hanford Site (Wicks et al. 1991). These facilities typically employ ceramic melters and are highly automated to minimize personnel exposure.

Vitrification processes using rotary kiln incinerators and similar industrial equipment have been developed for hazardous waste remediation, and could be effective for remediating low-level radioactive soil contamination. Rotary kiln vitrification of low level radioactive soils could be more cost-effective than the vitrification processes developed for high-level nuclear waste because higher processing rates should be achievable. However, this application is still under development.

Vitrification is generally not the preferred technology for low-level radioactive wastes because other treatments, such as fixation, are much less expensive and the high degree of protection afforded by vitrification is not required. However, because ex-situ vitrification is potentially more effective than fixation and other ex-situ treatment technologies for immobilization of radionuclides, it is retained for further consideration.

\subsubsection{Encapsulation}

Encapsulation immobilizes contaminants by enclosing the waste or contaminated soil in an inert and impermeable jacket. Encapsulation may be achieved using thermoplastic resins, bitumen, or similar compounds. Polymer-based encapsulation and solidification is a developed technology and is commercially available for small hazardous and radioactive applications (DOE 1988). Use of polybutadiene and polyethylene has been tested on low-level radioactive waste (Freeman 1989).

ncapsulation contains contaminated material on a macro scale, so that its effectiveness depends on maintaining the integrity of the containment provided by the jacket. In contrast, fixation and vitrification provide microencapsulation, meaning that 
contaminants remained immobilized even if the monolith that results from treatment is physically disrupted.

Encapsulation is used with high-level nuclear wastes to provide additional protection following primary stabilization. However, for the low concentrations of radionuclides in soil at this site, fixation or vitrification would not require additional encapsulation. As stand-alone treatment, fixation or vitrification would be more effective and reliabie for equivalent cost. This technology is, therefore, not retained.

\subsubsection{Biological Treatment}

Biological treatment is a class of technologies commonly applied for destruction of organic contaminants. Biological treatment can be performed ex-situ and in-situ, with varying effectiveness, and may be accomplished by aerobic oxidation or anaerobic reduction processes. Biological treatment technologies for soils generally fall into two classes: land treatment or landfarming, and aqueous biotreatment of slurries in tanks or ponds. Although preliminary research has indicated that biological uptake of metals may be useful for site remediation, biological treatment of soils is generally not considered applicable to metals and radionuclides, (the primary contaminants of concern at the 200-BP1 operable unit) and is not retained.

\subsubsection{Thermal Treatment}

Thermal treatment technologies are primarily designed for destruction of organic contaminants. Incineration is the most common thermal treatment technology, of which there are a number of processes with varying strengths and weakness. Incinerators destroy organic compounds via high-temperature oxidation. Pyrolysis uses high temperatures to degrade organic compounds in the absence of oxygen. Thermal desorption also uses heat in the absence of oxygen, but the purpose is to vaporize the organic contaminants for recovery and recycling or for removal via treatment of the offgas. Vitrification, sometimes considered a thermal treatment technology, is addressed above as a stabilization (immobilization) technology. Thermal treatment technologies for destruction of organic contaminants are not applicable to metals and radionuclides, which cannot be destroyed, and are therefore, not retained.

\subsection{IN-SITU TREATMENT}

This section considers a wide range of technologies for in-situ treatment where the contaminants are treated in place and no excavation is necessary. Metals and radionuclides cannot be destroyed by treatment. Heavy metal toxicity can be reduced via chemical conversion to a less toxic compound of the metal. Effective toxicity due to radioactivity can be reduced via containment (shielding), but the inherent radioactivity remains. Therefore, treatment for radionuclides focuses on reducing mobility or volume.

As with ex-situ treatment, the purpose of in-situ treatment is to reduce the toxicity, mobility or volume of contaminated material. The same classes of treatment that are available for excavated soil are generally available for in-situ treatment. However, the 
treatment conditions are very different. As a consequence, the effectiveness, implementability and cost of in-situ treatment technologies are typically very different from the corresponding ex-situ technology.

For in-situ treatment of soils, mobility reduction is accomplished by changing the physical and/or chemical characteristics of the soil matrix to decrease contaminant leachability. Volume reduction is accomplished by removing (extracting) contaminants from the soil, leaving behind less contaminated soil (total removal is generally not possible). Extracted contaminants still require treatment and disposal.

In many cases, excavation of contaminated soil is either not feasible due to the depth of contamination or is not advisable because the short-term risks created by excavation exceed the benefits of treatment or disposal following excavation. Thus, the key advantage to in-situ treatment is that excavation of the soil is avoided. However, the key disadvantage to in-situ treatment is that the treatment process cannot be controlled nearly as well as the same treatment in a reactor or other procoss equipment following excavation. This lesser control results from a combination of greater difficulties in achieving desired process conditions, and the inherent inhomogeneity of the subsurface. Therefore, an in-situ treatment process is, in general, less effective at achieving treatment objectives and less reliable in achieving uniform treatment than the corresponding ex-situ treatment process. Treatment effectiveness is also often difficult to verify. Comparison of remedial alternatives involving in-situ and ex-situ treatment thus require careful evaluation of the advantages and disadvantages of each, on a site-specific basis.

\subsubsection{Soil Flushing}

Soil flushing is an in-situ washing process in which the soil is flooded with a flushing solution to extract contaminants, followed by treatment of the flushing solution above-ground to remove the contaminants. The technique can be applied to unsaturated and saturated zones where contaminants are sorbed to the soil matrix. Aqueous flushing solutions are most commonly considered, although non-aqueous solutions have been proposed. At this site, most of the radionuclide contaminants have low solubility in water, although cobalt- 60 , technetium- $\rightarrow 9$ and nitrate are expected to be flushed more rapidly that total uranium and plutonium-238 and -239. Use of other solutions (acids or chelating agents) would have unknown effects on the soil matrix. Thus, the effectiveness of this technology for the 200-BP-1 operable unit is questionable.

Uniform application of the flushing solution, and hence uniform and reliable treatment, is difficult. For this operable unit, which lacks an impermeable strata across the site to serve as a bottom barrier, collection of the flushing solution would be difficult and unreliable. In the worst case, unrecovered flushing solution could mobilize contaminants into the environment via the groundwater pathway.

Even if implementable, the flushing system and wastewater treatment system for the operable unit would be expensive. In addition, radioactive sludge would be generated from treatment of the flushing solution, which would require landfill disposal, possibly preceded by stabilization. This technology is unproven and may be ineffective at this site, and yet would only move the contaminants and the associated risk, from one location to another. It is therefore not retained. 


\subsubsection{In-Situ Fixation}

This technology involves in-place mixing of pozzolanic agents (grout, fly ash, lime, etc.) to accomplish in-situ fixation (chemical stabilization). Risk is reduced by immobilizing contaminants. Fixation technology is well established (see the discussion above for ex-situ treatment) for treatment of metals, including radionuclides. However, a treatabiiity study would be necessary to determine effectiveness, which depends on a number of site-specific factors. Fixation (ex-situ and in-situ) has been used at radioactive waste sites.

Grout injection to form barrier walls has been used for many years. In-situ fixation, sometimes also called in-situ grouting or deep soil mixing, is a relatively new application of grout injection technology for soil treatment. Where contamination is limited to shallow soils, a variety of mixing techniques can be used. Treatment at depth, such as would be needed for this site, is usually accomplished by drilling with large augers to mix the soil in place while grout or other fixation agents are injected. Mixing zones are overlapped to ensure treatment of all soil within the contaminated zone. Grout injection would be used to handle underground pipes, large voids, small boulders, and open gravels. Larger boulders encountered at depth would be grouted in place; such boulders encountered near the surface would be drilled through using conventional drilling techniques. The treated soil cures to a stable, cement-like matrix. The key to the effectiveness of in-situ fixation is achieving a uniformly high degree of mixing and distribution of admix. As with any in-situ treatment technology, this can be hard to ensure and verify.

In-situ fixation can be performed using commercially available equipment to depths of approximately $15 \mathrm{~m}(50 \mathrm{ft})$. Greater treatment depths, such as may be necessary for this site, can be achieved, but require specialized equipment. In addition, the large gravel and cobbles found in soils at this site would impede mixing. In-situ fixation using drilling techniques, especially to the depths involved at this site, would progress slowly and consequently would be expensive. Of the potentially feasible in-situ treatment technologies, in-situ fixation is the best understood and most easily implemented, and is therefore retained for further consideration.

\subsubsection{In-Situ Vitrification}

In-situ vitrification (ISV) works by heating a mass of soil until it melts. This technology uses a high-voltage electrical current applied to the soil to immobilize contaminants in a glassy mass. Because the process works by heating the contaminated soil, it can be considered thermal treatment. However, it is classified as physical treatment for this site because its purpose, contaminant immobilization, is the same as that for in-situ fixation.

Metals, including radionuclides, and most inorganic compounds are potentially amenable to vitrification. During the process, organic compounds are either destroyed by the high temperatures or driven to the surface as vapors where they are collected and treated. Inorganic compounds, including radionuclides, are incorporated into a glassy mass. Contaminant leaching rates from the glass are low, thus minimizing the potential for contaminant migration to groundwatei: However, because published data often omits leaching rates for the untreated material, it is often not clear how much decrease in 
leachability is actually achieved via treatment, although it is expected to be a very large decrease.

ISV is accomplished by inserting electrodes into the contaminated soil and passing current between them. The electrical resistance of the soil causes it to heat up until the soil melts. The current is then discontinued and the melt solidifies into a glassy mass. While the soil is being melted, volatile compounds, including water and many organic chemicals, are driven off and migrate through the soil to the ground surface. These gaseous phases are collected by a hood covering the treatment area and are treated to remove contaminants.

ISV is still in the developmental stage. It has been applied on an experimental basis to two cribs on the Hanford Site (Luey et al. 1992). The contaminated soil masses were vitrified to depths of 4.9 and $4.3 \mathrm{~m}$ (16 and $14 \mathrm{ft}$ ), respectively. For at least one of the cribs, this was less than the desired depth of 20 feet, which was the extent of contamination. Deeper melting was limited by layers of 2.5 to $7.6 \mathrm{~cm}$ (1 to 3 in.) diameter gravel that formed part of the drainage system under the crib. These results were analyzed in detail, and it was concluded that such layers can significantly slow the melting process in the downward direction. A task force evaluating the results of the first experiment stated that until larger equipment is available, "engineering techniques are recommended to enhance downward growth for applications in excess of $5 \mathrm{~m}$ [16 ft] (Luey et al. 1992)." These engineering techniques are still under development and have not been tested.

The maximum radionuclide concentrations below the 200-BP-1 cribs were generally observed between depths of 3-9 $\mathrm{m}$ (15-30 ft) (DOE/RL 1993). Below this zone, concentrations decrease until they become approximately uniformly low at a depth of about $30 \mathrm{~m}(100 \mathrm{ft})$. To apply $1 \mathrm{SV}$, substantial excavation would be required to provide complete treatment, including excavation of some of the most contaminated soils, defeating the purpose of in-situ treatment. It is possible that ISV may be sufficiently developed at some future time to address these problems, but the evaluation for this site must consider the current state of the technology. Because of its depth limitations, the existing ISV technology is incapable of treating even the zone of maximum contamination at this site. For these reasons, ISV is not applicable to the 200-BP-1 operable unit and is not retained.

\subsection{WASTEWATER TREATMENT}

Wastewater treatment is not directly applicable to the remediation of soils of the 200-BP-1 operable unit. However, several of the soil treatment technologies retained for development of remedial alternatives produce aqueous waste streams that require treatment prior to discharge or disposal. In addition, alternatives may require treatment of contaminated surface water. As treatment of waste-water and contaminated surface water can be an important concern in evaluating soil remediation technologies and alternatives, potentially applicable wastewater treatment technologies have been included in the screening process. 


\subsubsection{Chemical Precipitation}

Precipitation is a technology for removing metals, other inorganic contaminants, and/or solids from water. It has been practiced for decades in the field of municipal water supply and wastewater treatment. Precipitation is also proven technology for removal of radionuclides from wastewater. This technology could be applied to wastewater from treatment of soils or contaminated surface water at the 200-BP-1 site. Precipitation produces a sludge for disposal often in conjunction with further treatment such as fixation.

Lime and certain organic polymers are common precipitation chemicals. Coprecipitation, where a compound such as iron is added to precipitate along with target metals, should be investigated because of its potential to greatly reduce the quantity of sludge generated. Metals precipitation is usually feasible and cost effective for removal of metals from aqueous wastes. However, this technology alone may not be able to meet potential discharge criteria and may require additional treatment stages such as ion exchange to meet discharge or disposal criteria. Metals precipitation is retained for further consideration.

\subsubsection{Ion Exchange}

Ion-exchange resins are often used to remove dissolved metallic or other inorganic ions from wastewater, and is routinely used at DOE facilities to remove radionuclides from liquid wastes. Ion exchange is often used to remove metals to low concentrations. Spent resin must either be landfilled or regenerated. Ion exchange is retained for possible use in treating wastewater generated during soil treatment.

\subsubsection{Reverse Osmosis}

Reverse osmosis can be used to remove both organic and inorganic compounds from water. The process use's differential diffusion through a semi-permeable membrane to concentrate contaminants in an aqueous concentrate. The concentrate is then further treated to remove the contaminants for disposal. This technology has been used to concentrate metals or other compounds from a dilute waste stream to allow economic reprocessing of the wastes, such as recovery of valuable metals, and in general is not an ion specific. It has been used for removal of uranium from solution. This process is more difficult to operate and can be more expensive than ion exchange. It may be desirable to concentrate wastewater contaminants as pretreatment prior to use of another wastewater treatment technology to produce a more cost-effective treatment train. This technology is therefore retained for further consideration.

\subsubsection{Membrane Filtration}

Inorganic ions can be removed from wastewater by using membrane filtration to concentrate the contaminants. The contaminated water is applied to one side of the membrane, and a stripping solution to ihe other. The membrane has microscopic pores that hold an organic solvent capable of removing the contaminant from the wastewater by forming a chemical complex. The stripping solution then removes the contaminant from 
the solvent. The stripping solution must then be treated to remove the contaminarts for final disposal. An advantage of this process is that the membranes are ion specific, and selection of an appropriate membrane can enhance contaminant recovery.

This technology has been shown to successfully remove uranium from liquid waste, but is still in the development stage. Because other technologies are available that are both effective and proven, this technology is not retained.

\subsubsection{Gravity Separation}

Gravity separation is a proven, effective method for removing oil and solids from wastewater.

A gravity separator can be as simple as a settling basin, where solids settle to the bottom and are periodically removed. Plate separators are rapidly replacing or augmenting basin separators because they achieve the same results using less space. In this process, the wastewater is passed through a chamber packed with parallel plates. However, plate separatois an: not suitable for high solids wastewater because solids will build up too quickly and clog the unit. Clarifiers are tanks designed for gravity separation, and are the most commonly used means of removing solids from wastewaters with high solids contents. This technology is retained for further consideration.

\subsubsection{Solids Filtration}

Strainers and filters are proven and effective for removing suspended solids from wastewater prior to further treatment. Solids filtration is therefore retained as a wastewater treatment technology.

\subsubsection{Dewatering}

Gravity separation, precipitation, and other wastewater treatment technologies produce sludges with high water content. Normally, dewatering is used to reduce the quantity of sludge requiring disposal by reducing the water content of the sludge. The appropriate dewatering process will depend on the quantity and characteristics of the sludge. Common dewatering technologies include belt filter presses that typically achieve $30 \%-50 \%$ solids in dewatered sludge, recessed plate filter presses that typically achieve $40 \%-70 \%$ solids, and sludge drying.

Sludge drying in ovens or kilns is normally not cost-effective and is practiced only when extremely dry sludge is required. In arid climates, sludge drying in lined evaporation ponds is sometimes feasible. Evaporation ponds require a large surface area, take longer to dry the sludge, and would require controls to ensure that wind did not disperse dried sludge. However, sludge drying can economically achieve higher solids content than filter presses.

Dewatering of sludges will probably be necessary where wastewater treatment is required for this operable unit. It is retained for further consideration. 


\subsubsection{Carbon Adsorption}

Carbon adsorption is an established process for removal of organic compounds from wastewater. Activated carbon is available in both powdered and granular forms. The granular form is more commonly used and can be thermally regenerated. Although incidental removal of metals can occur, carbon adsorption is not as effective as other technologies specifically intended for removal of metals from wastewater. This technology is therefore not applicable to water treatment at this operable unit, and is not retained.

\subsubsection{Air Stripping}

This technology involves passing air through water in countercurrent flow so that volatile contaminants will move from the water into the air. The air is then treated to destroy or remove the contaminants, typically by incineration or vapor carbon adsorption. Air stripping has been successfully used for removing volatile organic compounds (VOCs) from water. Since VOCs are not contaminants of concern at this operable unit, this technology is not applicable and is not retained.

\subsubsection{Ultraviolet Photooxidation}

Oxidation of organic contaminants with ultraviolet (UV) light uses the energy available in short wavelength radiation, in combination with ozone or hydrogen peroxide, to destroy organic compounds via oxidation. Since this technology is only used for organic contaminants, it is not applicable to this operable unit and is not retained.

\subsubsection{Biological Treatment}

Biological treatment is a class of technologies commonly applied for destruction of organic contaminants in wastewater. Biological treatment can be performed ex-situ and in-situ, with varying effectiveness. Biological treatment technologies include trickling filters, activated sludge, packed-bed bioreactors, and land spreading.

Recently, investigation has started on removal of metals from aqueous wastes by microorganisms. However, these techniques are experimental and unproven. Biological treatment is generally considered not applicable to metals and radionuclides. Removal of metals and radionuclides can be accomplished using other existing technologies that have been proven effective. Biological treatment is, therefore, not retained.

\subsection{DISPOSAL}

Disposal is a general response action for final disposition of waste. Disposal is containment following excavation, as compared to in-situ containment such as in-situ fixation or construction of surface barriers and leaving the contaminants in place. Disposal relocates contaminants from one place to another; it is not treatment to destroy or detoxify contaminants. However, if needed, treatment can be used prior to disposal. For example, radioactive wastes are commonly treated by fixation or vitrification prior to disposal. To be 
justified, excavation and disposal should provide greater protection of human health and the environinent than can be achieved by in-situ containment for a given site.

\subsubsection{Engineered Landfill within Hanford Site (Environmental Restoration Storage \& Disposal Facility [ERSDF])}

An engineered landfill, the Environmental Restoration Storage and Disposal Facility (ERSDF), is currently planned for construction on the Hanford Site. This landfill will be designed for low-level radioactive waste, mixed waste, and hazardous waste from remediation activities throughout the Hanford Site. The final design of the ERSDF has not been completed, but will comply with applicable regulations and DOE policies for disposal of the wastes to be received, and will be fully permitted. Appropriate monitoring will be provided during operation and following closure of the facility. All applicable regulations and DOE policies regarding closure and post-closure care will also be followed.

In contrast to offsite landfills, transportation of contaminated soil from the 200-BP-1 site would not be a major concern. The hauling distance would be short and the contaminated material would not leave the Hanford Site. Standard Hanford safety and environmental controls, including packaging standards and personnel protection, would be used. Additional controls would be used if appropriate.

The permitting process should provide review to ensure the effectiveness and reliability of the facility. Conventional, well-developed technologies and methods will be used to construct and operate the facility. Therefore, the ERSDF is considered readily implementable. Disposal of the 200-BP-1 operable unit contaminated soil and other wastes in the ERSDF is retained for further consideration.

\subsubsection{Engineered Landfill at the 200-BP-1 Operable Unit Site}

A landfill could be constructed at the 200-BP-1 site, similar in design to the ERSDF, for disposal of contaminated soil from this site. However, it is more difficult both technically and administratively, and is therefore less reliable, to construct and monitor separate landfills for each operable unit than for a single Hanford landfill. The ERSDF should also be more cost-effective per unit volume of contaminated soil or other waste disposed. Therefore, construction of a landfill dedicated to soil and other wastes from the 200-BP-1 site is rejected in favor of landfill disposal in the ERSDF.

\subsubsection{Offsite Landfill}

Use of an offsite landfill for permanent disposal is similar in concept to the other landfill options discussed above. The offsite facility would probably be a general low-level waste facility serving a state or regional area. The disadvantages of using an offsite disposal facility are that (1) there are few facilities prepared to accept soil contaminated with low levels of radioactivity, (2) transportation distances would be large, with the associated potential risk of contaminant release, (3) public opposition to offsite disposal of Hanford waste is likely to be high and (4) significant administrative difficulties are expected 
in removing waste from the Hanford Site. For these reasons, offsite disposal is not considered a viable alternative and is not retained.

\subsubsection{Geologic Repository}

A geologic repository is an underground disposal facility constructed in a stable geulogic setting with very low rates of groundwater movement. With this approach, waste is isolated from humans and the ecosystem, thereby minimizing risk to both. The design goal of a geologic repository is to prevent exposure of biological receptors to radioactive waste or radioactive constituents for at laast 10,000 years. However, no geologic repository for radioactive wastes is currently available.

A geologic repository for high-level nuclear waste (spent nuclear fuel and byproduct wastes) is proposed for cons ruction at Yucca Mountain, Ne'rada. Another repository for transuranic waste (TRU), the Waste isclation Pilot Plant (WIPP), is presently under construction near Carlsbad, New Mexico and may be operational within a few years. Because space at any geological repository will be limited anit there is a backlog of high-level nuclear waste, disposal of all soil contaminated with lo ${ }^{*}$ concentrations of radionuclides from sites such as 200-BP-1 at Yucca Mountain or WIPP would not be feasible.

The very high levels of protectiveness and redundancy appropriate for high-level nuclear waste are not recessary to protect of human health and the environment from the relatively low concentrations of radionuclides in soil at the 200-BP-1 site. In addition, transportation of radioactive materials presen's significant administrative diffirulties and has the potential for release of contaminants during transport. CERCLA specifically discourages offsite disposal of wastes (EPA 1988).

Use of a geologic repository is not erivisioned as a primary element of remediation for this operable unit. However, it is possible that contaminated soil encountered during soil remediation or waste generated frorn soil treatment (e.g., wastewater sludge) could meet regulatory or DOE policy definitions that require disposal in a geologic repository.

Therefore, a geologic repository is retained as an alternative to landfill disposal, if required.

\subsection{SUMMARY OF TECHNOLOGY SCREENING}

The technologies retained after screening are summarized below:

- Institutional Controls

- Soil Barrier

- Modified RCRA Barrier

- Hanford Barrier

- Physical Soil Washing (Aqueous Physical Separation)

- Chemical Soil Washing (Radionuclide Extraction)

- Fixation (Chemical Stabilization)

- Ex-situ Vitrification

- In-situ Fixation

- ERSDF Disposal 
DOE/RL-93-35, Rev. 0

- Geologic Repository

Additional support technologies retained following screening are:

- Removal (Excavation)

- Dust Control

- Surface Water Management

- Waste Water Treatment

- Precipitation

- Ion Exchange

- Reverse Osmosis

- Gravity Separation

- Solids Filtration

- Dewatering 
DOE/RL-93-35, Rev. 0

Table 4-1. Identification and Screening of Technologies and Process Options. (Sheet 1 of 4)

\begin{tabular}{|c|c|c|}
\hline Technology & Screening Comments & $\begin{array}{l}\text { Retained } \\
\text { (Yes/No) }\end{array}$ \\
\hline \multicolumn{3}{|l|}{ Institutional Controls } \\
\hline $\begin{array}{l}\text { Access restrictions } \\
\text { Fencing } \\
\text { Security personnel }\end{array}$ & Useful as component of overall site remedy & Yes \\
\hline Warning markers & Useful as component of overall site remedy & Yes \\
\hline $\begin{array}{l}\text { Land use restrictions } \\
\text { Zoning } \\
\text { Deed restrictions }\end{array}$ & Useful as component of overall site remedy & Yes \\
\hline Monitoring & Required element of site remedy & Yes \\
\hline \multicolumn{3}{|l|}{ Removal } \\
\hline $\begin{array}{c}\text { Excavation } \\
\text { Backhoe } \\
\text { Bulldozer } \\
\text { Clamshell } \\
\text { Dragline }\end{array}$ & $\begin{array}{l}\text { Necessary component of ex-situ treatment or disposal; } \\
\text { increases potential short-term risk due to worker expo- } \\
\text { sure and potential dust release. }\end{array}$ & Yes \\
\hline \multicolumn{3}{|l|}{ In-situ Containment } \\
\hline Dust control & $\begin{array}{l}\text { Useful during remedial construction site remedy; not a } \\
\text { permanent remedy. }\end{array}$ & Yes \\
\hline $\begin{array}{l}\text { Surface water } \\
\text { management }\end{array}$ & $\begin{array}{l}\text { Use as a component of site remediation (e.g., in con- } \\
\text { junction with capping) }\end{array}$ & Yes \\
\hline Surface barriers & $\begin{array}{l}\text { Cost-effective means of minimizing contaminant migra- } \\
\text { tion and reducing risk by preventing direct contact } \\
\text { with contaminated soil }\end{array}$ & Yes \\
\hline Soil barrier & $\begin{array}{l}\text { Cost-effective method of preventing contaminant mi- } \\
\text { gration via air and surface water; may reduce infiltra- } \\
\text { tion. }\end{array}$ & Yes \\
\hline Asphalt barrier & $\begin{array}{l}\text { Not reliable as a permanent remedy due to cracking; } \\
\text { high maintenance requirements }\end{array}$ & No \\
\hline Concrete barrier & $\begin{array}{l}\text { Not reliable as a permanent remedy due to cracking; } \\
\text { high maintenance requirements }\end{array}$ & No \\
\hline $\begin{array}{l}\text { Synthetic membrane } \\
\text { barrier }\end{array}$ & $\begin{array}{l}\text { Ineffective for stand-alone protection due to uncertain } \\
\text { long-term reliability }\end{array}$ & No \\
\hline $\begin{array}{l}\text { Low-permeability clay } \\
\text { barrier }\end{array}$ & $\begin{array}{l}\text { Clay alone subject to desiccation and therefore not } \\
\text { reliable as a permanent remedy }\end{array}$ & No \\
\hline
\end{tabular}


Table 4-1. Identification and Screening of Technologies and Process Options. (Sheet 2 of 4)

\begin{tabular}{|c|c|c|}
\hline Technology & Screening Comments & $\begin{array}{l}\text { Retained } \\
\text { (Yes/No) }\end{array}$ \\
\hline $\begin{array}{l}\text { Low-permeability } \\
\text { composite Barrier } \\
\text { Modified RCRA } \\
\text { Hanford barrier }\end{array}$ & $\begin{array}{l}\text { Effective, permanent methods of preventing contami- } \\
\text { nant migration via air, surface water, and groundwater. } \\
\text { Cost-effectiveness depends on degree of redundancy in } \\
\text { cap design. }\end{array}$ & Yes \\
\hline $\begin{array}{l}\text { Vertical barriers } \\
\text { Slurry wall } \\
\text { Sheet piling } \\
\text { Grout curtain } \\
\text { Freeze wall }\end{array}$ & $\begin{array}{l}\text { Not effective in vadose zone because infiltration is } \\
\text { primarily vertical; use in saturated zone to be ado'ressed } \\
\text { in the feasibility study for the groundwater operabie } \\
\text { unit. }\end{array}$ & No \\
\hline \multicolumn{3}{|l|}{ Horizontal barriers } \\
\hline Grout injection & Difficult to implement a reliable, effective barrier & No \\
\hline Freeze wall & $\begin{array}{l}\text { Difficult to implement in vadose zone due to low mois- } \\
\text { ture content; requires active maintenance for effective- } \\
\text { ness; high cost of long-term operation makes unsuitable } \\
\text { for permanent containment }\end{array}$ & No \\
\hline Ex-situ Treatment & $\begin{array}{l}\text { Ex-situ treatment requires excavation and, therefore, } \\
\text { creates risk over containment or in-situ treatment via } \\
\text { worker exposure and the potential for offsite migration } \\
\text { in dust or stormwater }\end{array}$ & \\
\hline \multicolumn{3}{|l|}{ Physical/Chemical } \\
\hline Dry soil sieving & Not as effective as soil washing & No \\
\hline $\begin{array}{l}\text { Physical soil washing } \\
\text { (aqueous physical sep- } \\
\text { aration) }\end{array}$ & $\begin{array}{l}\text { Potential for reduction of soil volume requiring further } \\
\text { treatment or disposal, possibly lowering cost of remedy } \\
\text { (would require treatability study). }\end{array}$ & Yes \\
\hline $\begin{array}{l}\text { Chemical soil washing } \\
\text { (radionuclide extrac- } \\
\text { tion) }\end{array}$ & $\begin{array}{l}\text { Potential for removing radionuclides from soil; would } \\
\text { produce radioactive sludge requiring disposal }\end{array}$ & Yes \\
\hline $\begin{array}{l}\text { Fixation (chemical } \\
\text { stabilization) }\end{array}$ & $\begin{array}{l}\text { Potentially feasible for immobilizing site contaminants } \\
\text { (requires treatability study) }\end{array}$ & Yes \\
\hline Vitrification & $\begin{array}{l}\text { Potentially feasible for immobilizing site contaminants } \\
\text { (requires treatability study) }\end{array}$ & Yes \\
\hline $\begin{array}{l}\text { Encapsulation } \\
\text { Thermoplastic } \\
\text { Bitumen (asphalt) }\end{array}$ & $\begin{array}{l}\text { Fixation is more effective and reliable for equivalent } \\
\text { cost }\end{array}$ & No \\
\hline $\begin{array}{l}\text { Biological } \\
\text { Land treatment } \\
\text { Slurry biotreatment }\end{array}$ & Not applicable to metals or radionuclides & No \\
\hline
\end{tabular}


Table 4-1. Identification and Screening of Technologies and Process Options. (Sheet 3 of 4)

\begin{tabular}{|c|c|c|}
\hline Technology & Screening Comments & $\begin{array}{l}\text { Retained } \\
\text { (Yes/No) }\end{array}$ \\
\hline $\begin{array}{l}\text { Thermal } \\
\text { Incineration } \\
\text { Pyrolysis } \\
\text { Thermal desorption } \\
\text { In-situ Treatment }\end{array}$ & Not applicable to metals or radionuclides & No \\
\hline $\begin{array}{l}\text { Soil flushing (in-situ soil } \\
\text { washing) }\end{array}$ & $\begin{array}{l}\text { Unreliable and unproven; flushing solution difficult to } \\
\text { control and recover; treatment of flushing solution } \\
\text { generates sludge requiring disposal and therefore sim- } \\
\text { ply relocates risk }\end{array}$ & No \\
\hline In-situ fixation & Potentially feasible & Yes \\
\hline In-situ vitrification & Experimental, not applicable to this site & No \\
\hline Wastewater Treatment & $\begin{array}{l}\text { Not applicable as primary technologies for soil. Would } \\
\text { be used to treat liquid wastes generated by primary } \\
\text { treatment technologies }\end{array}$ & \\
\hline Precipitation & $\begin{array}{l}\text { Proven technology; potentially feasible for removal of } \\
\text { radionuclides from wastewater; produces sludge requir- } \\
\text { ing disposal }\end{array}$ & Yes \\
\hline lon exchange & $\begin{array}{l}\text { Proven technology; potentially feasible for removal of } \\
\text { radionuclides from wastewater; produces sludge requir- } \\
\text { ing disposal }\end{array}$ & Yes \\
\hline Reverse osmosis & $\begin{array}{l}\text { Potentially feasible for concentrating radionuclides into } \\
\text { concentrated wastewater for further treatment }\end{array}$ & Yes \\
\hline Membrane filtration & $\begin{array}{l}\text { Still under development; effective and proverı technolo- } \\
\text { gies are available. }\end{array}$ & No \\
\hline Gravity separation & Common component of wastewater treatment systems & Yes \\
\hline Solids filtration & Common component of wastewater treatment system & Yes \\
\hline $\begin{array}{l}\text { Dewatering } \\
\text { Filter press } \\
\text { Evaporation }\end{array}$ & $\begin{array}{l}\text { Probably required for sludges from wastewater treat- } \\
\text { ment prior to disposal }\end{array}$ & Yes \\
\hline Carbon adsorption & Not applicable for metals/radionuclides & No \\
\hline Air stripping & Not applicable for metals/radionuclides & No \\
\hline UV-photooxidation & Not applicable for metals/radionuclides & No \\
\hline Biological treatment & Not applicable for metals/radionuclides & No \\
\hline
\end{tabular}


Table 4-1. Identification and Screening of Technologies and Process Options. (Sheet 4 of 4)

\begin{tabular}{|c|c|c|}
\hline Technology & Screening Comments & $\begin{array}{l}\text { Retained } \\
\text { (Yes/No) }\end{array}$ \\
\hline Disposal & $\begin{array}{l}\text { Landfill disposal requires excavation and, therefore, } \\
\text { creates risk over containment (in-situ disposal) via wor- } \\
\text { ker exposure and the potential for offsite migration in } \\
\text { dust or stormwater }\end{array}$ & \\
\hline $\begin{array}{l}\text { Engineered landfill with- } \\
\text { in Hanford site (ERSDF) }\end{array}$ & $\begin{array}{l}\text { Implementable and effective; more costly but theoreti- } \\
\text { cally more effective than in-situ containment. }\end{array}$ & Yes \\
\hline $\begin{array}{l}\text { Engineered landfill at } \\
200-B P-1 \text { site }\end{array}$ & $\begin{array}{l}\text { ERSDF easier to monitor and maintain (more reliable } \\
\text { and implementable) and less costly than several sepa- } \\
\text { rate landfills at operable unit sites. }\end{array}$ & No \\
\hline Offsite landfill & $\begin{array}{l}\text { Potential risk higher than onsite landfill disposal due to } \\
\text { transportation; CERCLA prefers onsite disposal; high } \\
\text { administrative difficulties. }\end{array}$ & No \\
\hline Geologic repository & $\begin{array}{l}\text { Same difficulties as offsite landfill, but may be required } \\
\text { if high-level or transuranic wastes are generated during } \\
\text { remediation }\end{array}$ & Yes \\
\hline
\end{tabular}




\subsection{ASSEMBLY AND SCREENING OF REMEDIATION ALTERNATIVES}

Remediation technologies retained following the screening process presented in Chapter 4 are assembled into remedial alternatives for the 200-BP-1 soils operable unit in this chapter. The technologies are combined to create a wide range of alternatives that represent various approaches to achieving remedial action objectives. The methodology for assembling alternatives is briefly discussed in Section 5.1. Each alternative is described in Section 5.2 in sufficient detail to distinguish primary strengths and weaknesses. Section 5.3 presents a screening evaluation of the assembled alternatives against short- and long-term aspects of effectiveness, implementability, and cost. The purpose of the screening evaluation is to reduce the number of alternatives that will undergo more thorough analysis and evaluation in Chapter 6. Finally, a summary of the retained alternatives is included in Section 5.4.

\subsection{ASSEMBLY OF ALTERNATIVES}

Based on CERCLA Guidance and the NCP, remediation alternatives are developed to achieve the following goals (EPA 1988):

- Be protective of human health and the environment.

- $\quad$ Attain ARARs to the maximum extent feasible.

- Be cost-effective.

- Utilize permanent solutions and alternate treatment or resource recovery technologies to the maximum extent practicable.

- Satisfy the statutory preference for treatment.

- Minimize the need for long-term maintenance and monitoring.

CERCLA Guidance requires that a broad range of alternatives be formulated, examined, and presented to decision makers for selection of a preferred remedial alternative (EPA 1988). CERCLA Guidance also places an emphasis on those alternatives that provide treatment of contaminants, and on alternatives that treat or dispose of contaminants on the contaminated site. Accordingly, the technologies and process options that were identified in Chapter 4 as being appropriate for use at the 200-BP-1 operable unit are formulated into a wide range of remedial alternatives that employ the following strategies:

1. No action (required by the NCP).

2. Limited action (e.g., maintaining institutional controls).

3. Containment of contaminated materials with little or no treatment, but being protective of human health and the environment. Containment can be 
achieved by construction of surface barriers, leaving contaminants in place, or by excavating the contaminants and placing them in a landfill.

4. Treatment that reduces the mobility, effective toxicity, and/or volume of contaminated materials. In the case of radionuclides at the 200-BP-1 operable unit, the contaminants of concern cannot be destroyed, and so direct reduction in toxicity is not possible. Treatment alternatives can be implemented in-situ, leaving the treated contaminants in place, or ex-situ, requiring excavation of contaminants prior to treatment. In the latter case, the treated soils can either be returned to the excavation as backfill, or can be placed in a landfill. In some treatment processes, the waste stream may be split, with some components going to each of these locations.

\subsection{DESCRIPTION OF ALTERNATIVES}

A broad range alternatives are formulated from the technologies and process options identified in Chapter 4. The key elements of each alternative are described and briefly discussed below. In addition to a No Action alternative, and an alternative limited to Institutional Controls, 17 alternatives were developed. Included are 3 surface barrier alternatives, 9 excavation alternatives that include treatment $(5$ of which also include surface barriers), 2 excavation and disposal alternatives, and 3 in-situ treatment alternatives. A summary of these remediation alternatives is presented in Table 5-1.

In the sections below, the required No Action and Institutional Controls alternatives are presented first. Institutional Controls are a component of the majority of the remaining alternatives, and the Institutional Controls alternative is referenced frequently to save repetitious description. Barrier alternatives are introduced next, as they are also components of several other treatment alternatives. Excavation, treatment and disposal alternatives follow next, with details of excavation and treatment $r$ rcesses introduced once, and referenced thereafter, again to save repetitious description. Finally, the in-situ treatment alternatives are presented at the end of the section.

\subsubsection{Alternative 1: No Action}

\section{Description}

A No Action alternative is required for each site evaluated under the CERCLA process under the NCP. A No Action alternative would leave the operable unit in its current state. In accordance with EPA's definition of this alternative, it is assumed that none of the currently active institutional controls would be continued under a No Action alternative. However, operation and maintenance of a monitoring system is part of the No Action alternative to document the future conditions at the operable unit.

As an interim remedial measure, contaminated surface soils and contaminants from unplanned releases at the site have been consolidated over the cribs and covered with 0.5 $0.6 \mathrm{~m}(1.5-2 \mathrm{ft})$ of clean soil. 
Under these conditions, the No Action alternative provides the base condition for comparison of remediation alternatives for soils (see Chapter 7).

\section{Discussion}

Contaminated soils at this site are currently covered with a layer of clean soil. So long as this cover remains intact, it prevents direct human and environmental contact with contaminated soils, and prevents direct exposure to radionuclides above the $10^{-6}$ risk level. In addition, the soil cover prevents contact with surface water runoff and wind, preventing migration of contaminants by surface water and airborne pathways. Under these current conditions, the site poses no risk to human health or the environment (DOE-RL 1993).

However, without continued institutional controls, unrestricted industrial use of the site could result in penetration of the clean soil layer by human activities or as a result of biological intrusion such as the growth of deep rooted plants, digging by burrowing animals, or activities of ground nesting insects.

In addition, modeling of vadose zone contaminant migration assuming a net infiltration of $1 \mathrm{~cm}(0.4 \mathrm{in}$.) per year (approximating near current conditions) through the contaminated soils predicts that total uranium concentrations in groundwater will exceed MCLs in several hundred years (DOE-RL 1993). Consequently, this alternative alone is not effective over the long term in achieving the remedial action objective of preventing additional contamination of groundwater above ARARs.

\subsubsection{Alternative 2: Institutional Controls}

\section{Description}

Institutional controls include fencing and marking of the site, and deed restrictions on use of the site and of the groundwater beneath the site. Institutional controls also include maintenance activities. Fencing would be maintained around the operable unit to prevent site access. Depending on the disposition of surrounding operable units, the site could be fenced by itself or in combination with other units. Warning markers would be placed on the fencing and buried in site soil to discourage trespass and excavation.

Deed restrictions registered with the Benton County Auditor would designate the site as a permanent disposal area not suited to other use. Groundwater use restrictions would prevent withdrawals of groundwater within the site boundary and within the identified contaminant plume, and would be coordinated with remedial actions for groundwater undertaken by the 200 East Aggregate Area FS.

Maintenance activities include maintenance of the fence and fence markers, maintenance and repairs to the clean soil cover, and maintenance of the existing groundwater monitoring system. Maintenance of the clean soil cover would include control of deep-rooted plants, burrowing animals, and if necessary, ground nesting insects (to prevent them from bringing contaminants to the surface). Teriodic inspections of the operable unit and analysis of groundwater sample results would determine the need for maintenance activities. 
A groundwater monitoring system is also a component of this alternative. The system is provided to monitor contaminant concentrations reaching groundwater beneath the operable unit over time so that the effectiveness of the alternative may be assessed and additional actions taken in the event that contaminant levels threaten to exceed remedial action objectives.

\section{Discussion}

Preventing site access would minimize further the low potential for direct human and environmental exposure to contaminated soils associated with the No Action alternative. Trespass (and thus potential contact) is highly unlikely with the current level of site security. The potential for trespass could be somewhat higher if security measures are decreased in the future. Biological intrusion and resulting transport of contaminants would be minimized by maintenance activities.

Because institutional controls do nothing to reduce infiltration, vadose zone transport of uranium is still expected to reach groundwater within several hundred years, assuming a net of $1 \mathrm{~cm}(0.4 \mathrm{in}$.) per year of infiltration. Therefore, institutional controls do not improve long term effectiveness for groundwater protection above that offered by the No Action alternative.

Institutional controls are protective of human health and the environment but rely on active intervention for continued effectiveness. Key intervention actions include maintenance activities and enforcement of groundwater use and deed restrictions. Institutional controls do not include engineered physical barriers or removal of contaminants from the site.

Under current conditions, the site poses no imminent risk to human health or the environment. The cumulative risk from all pathways under current conditions (Phase I RI Baseline Risk Assessment) is less the 10*6 (DOE-RL 1993). Therefore, even if this alternative were not considered suitable as a permanent remedy, it could be selected subject to reconsideration once remedial actions are selected for neighboring sites such as the 241-BY tank farm.

\subsubsection{Alternative 3: Biointrusion Barrier}

\section{Description}

The concept of a biointrusion barrier for the 200-BP-1 operable unit consists of a

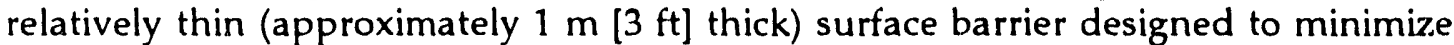
potential biological contact with contaminated soils, and hence minimize the potential migration of contaminants by biological pathways. The barrier is also designed for long term performance (in excess of several hundred years) with very little maintenance.

Of particular concern are deep-rooted plants that have the potential to bring radionuclides to the surface if permitted to grow on the unprotected surface of the operable unit. The biointrusion barrier is also designed to discourage burrowing animals from digging dens over the operable unit. A final biological vector to consider is the possibility of migration of contaminants due to the activities of ground nesting insects as 
they move to and from deep nests. In addition, the surface of the barrier would be resistant to wind erosion.

Potential drawbacks of a barrier designed exclusively for protection from biointrusion include the possibility that it will increase net infiltration of precipitation due to the high permeability of its surface layers, and the lack of transpiration due to the elimination of surface vegetation.

Institutional controls such as fencing, warning markers, and deed restrictions would be added to the barrier to prevent site access and inappropriate site use. The barrier would be maintained over a post-closure period, during which it would be monitored to verify its effectiveness. For the purposes of evaluating this alternative it is assumed that institutional controls would be maintained following the post-closure period but monitoring would no longer be necessary.

\section{Discussion}

This alternative protects human health and the environment by preventing direct contact with contaminated soil and preventing off-site migration of contaminants in surface water or airborne dust. The biointrusion barrier would prevent transport of contaminants by burrowing animals and deep-rooted plants. Such an engineered barrier would be more effective and more reliable than the current non-engineered clean soil cover.

Measurements of infiltration in naturally occurring materials that are similar to those proposed for the biointrusion barrier indicate that a rate of up to $10 \mathrm{~cm}(4 \mathrm{in}$.) per year is not unreasonable. Modeling of vadose zone transport of uranium with a $10 \mathrm{~cm}$ (4 in.) per year infiltration rate predicts that uranium concentrations would exceed ARARs more quickly than under current site conditions, which are estimated to be less than $1 \mathrm{~cm}$ ( 0.4 in.) per year. A more detailed evaluation of migration of uranium under various infiltration rates in provided in Section 6.4.1.3.

A surface barrier must remain intact to be effective. Institutional controls would be required to prevent unsuitable site uses, including construction or other activities that could result in penetration of the barrier. A monitoring system similar to that included in Alternative 2 would be provided. No contaminants are removed from the operable unit under this alternative.

\subsubsection{Alternative 4: Modified RCRA Barrier}

\section{Description}

RCRA Subtitle $C$ barriers are designed for hazardous waste landfill facilities, with the primary functional goal of preventing infiltration of precipitation through the landfill cover, waste layers, and landfill liner system. The proposed design is based on standard RCRA guidance to be used for protection of hazardous waste sites, modified to use alternative materials for increased longevity, on the order of 500 to 1,000 years. The barrier

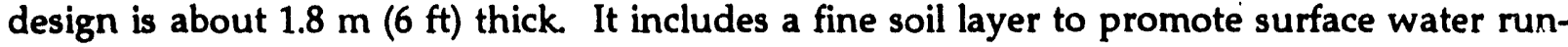
off and evapotranspiration, a drainage layer to transport infiltration away from the capped area, and a low-permeability moisture barrier, made of asphalt with a base course, to 
reduce the net downward infiltration of precipitation that also functions as a barrier to deep biological intrusion. No attempt is made to prevent growth of shallow-rooted vegetation, as such plants promote evapotranspiration and help reduce net infiltration.

\section{Discussion}

The modified RCRA barrier protects human health and the environment by providing a surface barrier preventing contact with contaminated soils, as do the other barrier alternatives. The modified RCRA barrier would provide greater protection against infiltration of surface water through contaminated soil, actually reducing infiltration below current levels, although the Hanford Barrier is expected to be even more effective in this regard. Therefore, the modified RCRA barrier would increase the time required for uranium to migrate to groundwater in concentrations in excess of ARARs to several thousands of years. In addition, the peak concentrations of uranium would be reduced. A more detailed evaluation of migration of uranium under various infiltration rates is provided in Section 6.4.1.3.

Institutional controls and monitoring would be performed as described for Alternative 2. No contaminants are removed from the operable unit under this alternative.

\subsubsection{Alternative 5: Hanford Barrier}

\section{Description}

The Hanford Barrier is a surface barrier specifically designed for Hanford Site remediation. It is designed to prevent biointrusion and migration of long-lived radionuclides by drastically reducing net infiltration, and its components take advantage of the local arid climate in minimizing infiltration. The Hanford Barrier is the thickest (about

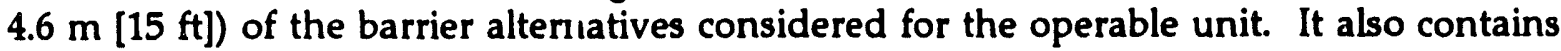
the greatest number of layers, including fine soil layers to promote surface water runoff, an evapotranspiration layer and a capillary break to inhibit percolation, a drainage layer to transport any infiltration away from the covered area and also prevent biological intrusion, and a final low-permeability moisture barrier. The layers of this design have functional redundancy and the design is intended to require no maintenance over time periods on the order of 1,000 years or more.

\section{Discussion}

The Hanford Barrier would not necessarily be more effective initially than Alternatives 3 or 4 . However, because of its thickness and multiple protective layers, the Hanford Barrier would be expected to remain effective for a much longer period of time than other surface barrier designs. It is also expected to require less maintenance as a result of its design objectives and the greater thickness of it top two layers. For these reasons, the Hanford Barrier is considered to be more reliable for this operable unit than Alternatives, 3 and 4.

Institutional controls and monitoring would still be performed as described for the other barrier alternatives. However, ongoing maintenance and institutional controls are less important with the Hanford Barrier than the barrier designs in the other alternatives. 
The Hanford Barrier is expected to reduce infiltration to near zero, thus greatly extending the time until total uranium concentrations in groundwater exceed ARARs.

\subsubsection{Alternative 6: Excavation and Soil Washing of Most Contaminated Soil with a RCRA Barrier}

\section{Description}

In this alternative, soils at the 200-BP-1 site that contain the highest levels of contamination would be excavated and treated to achieve volume reduction. Based on available data, it is assumed that physical soil washing would be effective for this purpose. Reduction in contaminant mobility is not achieved with this process.

The largest concentrations of radionuclides are 4.6-9.1 $\mathrm{m}(15-30 \mathrm{ft})$ below ground surface (DOE-RL 1993). As described in Section 3.4.2, the depth of significant contamination requiring remediation is assumed to be $15 \mathrm{~m}(50 \mathrm{ft})$ for the purpose of analysis and comparison of alternatives. Excavation under this alternative is formulated to remove the majority of contaminants, and is therefore assumed to extend $15 \mathrm{~m} \mathrm{(50 \textrm {ft } )}$ below ground surface.

Soil fractions from washing with contaminant levels exceeding remedial action objectives would be stabilized as necessary to meet disposal requirements, and then disposed of in the ERSDF. A geologic repository would be used in place of the ERSDF for contaminated soil where regulations or DOE policy require use of a geologic repository. To minimize the potential for exposure, excavation would not occur until construction of the ERSDF (or geologic repository, if applicable) is completed, thus avoiding above-ground storage of contaminated soils.

Following treatment, soil fractions with contaminant levels below remedial action objectives would be returned to the excavation. The balance of the excavation site would be backfilled to current grade with clean fill, compacted, and graded for proper drainage. This backfill (treated soil and clean fill) would provide a thick cover for the site. Based on

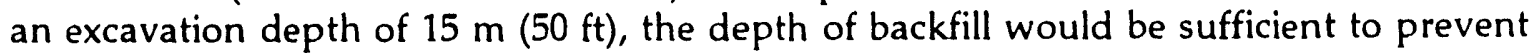
biological intrusion to depths where unexcavated contaminants remain in place.

Inclusion of silt size fractions in the clean backfill and growth of surface vegetation would promote evapotranspiration and thereby minimize infiltration. However, a low permeability RCRA barrier is included to prevent uranium currently existing below $15 \mathrm{~m}$ $(50 \mathrm{ft})$ in unexcavated soils from impacting groundwater in concentrations above ARARs within 500-600 years. Inclusion of a RCRA barrier is expected to increase the time at which total uranium concentrations in groundwater will exceed ARARs from several hundred to several thousand years. A more detailed evaluation of the residual risk to groundwater of unexcavated soil is provided in Section 6.4.1.3.

Because some contaminated soil would remain at the site after remedial action, institutional controls and monitoring would be required for this alternative. 


\section{$\underline{\text { Discussion }}$}

As discussed in Section 4.4, both physical soil washing and chemical soil washing have the potential to reduce the volume of contaminated material at this site. Physical soil washing would provide direct volume reduction by separating the most contaminated soil particles from relatively clean soil particles. Chemical soil washing would achieve volume reduction less directly. The liquid extract from chemical soil washing would contain the concentrated contaminants. The treatment of the extract would produce a sludge from precipitation of metals or spent ion exchange resin requiring disposal in the ERSDF (or a geologic repository, if necessary). However, the total volume of the sludge and solids from treatment of the liquid waste should be significantly less than the initial volume of contaminated soil.

For the purposes of this feasibility study, it is not necessary to make a final selections between the two soil washing processes. Despite their differences, the two processes have sufficient similarities to permit a valid comparison to the other remedial alternatives when considered is a single alternative. Of the two soil washing options, physical soil washing would be easier to implement and much less expensive. Chemical soil washing would be attempted only if physical soil washing were unable to attain remedial action objectives.

In evaluating this alternative, it will be assumed that physical soil washing can achieve the effectiveness in volume reduction suggested by available data. Should this alternative be selected, its effectiveness would be confirmed by a treatability study. Uncertainties in the selection of soil washing processes are not expected to prevent the selection of a remedial action based on the information provided in this feasibility study. Selection of this alternative would require reconsideration only if 1) the treatability study could not confirm predicted effectiveness for physical soil washing, and 2) chemical soil washing were also unable to provide equivalent effectiveness. It is not anticipated that the differential cost between physical and chemical soil washing will be a deciding factor in selecting between alternatives. The differential cost will be addressed in the event that the selection of a remedial action depends on quantification of this cost uncertainty.

This alternative would result in removal of the majority of the contamination at this site, both in terms of mass and concentration. Reducing the volume of contaminated material, given preference by SARA, is provided by soil washing. However, the potential risks posed by the excavated and treated contaminants would be relocated from the operable unit to a nearby disposal site (the ERSDF). The theoretical increase in protectiveness resulting from treatment thus depends on the difference in protection provided by disposal in the ERSDF and that provided by construction of a surface barrier covering the cleaned soils and the remaining contaminants in place on the operable unit.

\subsubsection{Alternative 7: Excavation and Soil Washing of All Contaminated Soil}

\section{Description}

This alternative is similar to Alternative 6, with the addition that all soil with contaminant levels that could result in concentrations in groundwater exceeding ARARs would be excavated and treated. Since all such contaminants will be removed, a low 
permeability barrier is not a conyonient of this alternative. A soil washing processes, as described for Alternative 6 , would also be included in this alternative.

Based on vadose zone fate and transport modeling, it is estimated that soils to depths of more than $46 \mathrm{~m}$ ( $150 \mathrm{ft}$.) would have to be excavated to prevent total uranium concentrations from exceeding ARARs in groundwater within several hundred years, assuming current existing infiltration rates at the operable unit on the order of $1 \mathrm{~cm}(0.4$ in.) per year. Excavation to even greater depths would be necessary to remove all contaminated soils. Because the residual risk would be insignificant, institutional controls and monitoring would not be required for the site. However, institutional controls and monitoring would presumably be required for the ERSDF where separated contaminants would be disposed.

\section{$\underline{\text { Discussion }}$}

The potential risk at the 200-BP-1 operable unit due to contaminated soil would be eliminated under this alternative. The site could therefore be released fur un restricted use, provided this use is also compatible with remedial action at neighboring operable units such as the single shell tanks at the 241-BV Tank Farm in the 200-BP-7 operable unit. However, the contaminants and their associated risk would simply be relocated to a nearby facility, albeit to a more controlled site (the ERSDF). Iin addition, excavation to depths required to remove all of the contaminants would be extremely difficult to implement, and is not expected to be cost effective. Implementability of this alternative and its relationship to the adjacent 200-BP-7 operable unit are discussed in more detail in Section 5.3.

\subsubsection{Alternative 8: Excavation and Soil Washing of Most Contaminated Soil with Vitrification and a RCRA Barrier}

\section{Description}

This alternative contains all of the elements of Aiternative 6 , and adds vitrification of the contaminated soil fraction (or sludge, in the case of chemical soil washing) prior to disposal. This alternative requires construction and operation of two distinct treatment systems, to be run in series. A RCRA surface barrier is required with this alternative to limit migration of uranium remaining below the excavation limit of $15 \mathrm{~m}(50 \mathrm{ft})$ to groundwater in concentrations that exceed ARARs in less than approximately 1,000 years.

As with Alternative 6 , the excavation would be backfilled with the relatively clean fraction of treated soil and some imported clean fill. Institutional controls and monitoring of the operabie unit would be provided.

\section{Disrussion}

In addition to the treatment benefits discussed under Alternative 6, vitrification provides a high degree of contaminant immobilization. As a result, this alternative reduces both the volume of cortaminated soil and the mobility of the contaminants, as preferred by SARA. Reduction in contaminant mobility reduces the potential for affecting groundwater in the event of containment failure at the ERSDF where the vitrified materials would be disposed. The risk to groundwater beneath the operable unit is the same under this 
alternative as under Alternative 6. However, due to the benefits of vitrification, this alternative should be more effective and more reliable than Alternative 6 . It is also more expensive.

\subsubsection{Alternative 9: Excavation and Fixation of Most Contaminated Soil}

\section{Description}

In this alternative, soil at the 200-BP-1 site that contains contaminant levels that will exceed RAOs within 1,000 years would be excavated and treated by fixation (chemical stabilization) to immobilize contaminants. Volume reduction would not be achieved by this alternative, however, as fixation often results in a small volume increase. As with Alternatives 6 and 8 , contaminants will be excavated to a depth of $15 \mathrm{~m}(50 \mathrm{ft})$ to provide treatment of the majority of the contaminants of concern. The treated soil would be returned to the excavation.

Treated soils will be compacted in the excavation and graded for proper drainage. Under this first fixation alternative, a RCRA barrier is not included. The treated soils and clean backfill will form a cover over the uranium remaining below the $15 \mathrm{~m}$ ( $50 \mathrm{ft}$ ) excavation depth. The clean backfill will have a silt size fraction component, and vegetation will be permitted to grow over the cover to reduce infiltration and enhance evapotranspiration, partially mitigating the driving force for uranium transport to groundwater.

Because contaminants will remain on the operable unit, appropriate institutional controls and monitoring would be provided.

\section{Discussion}

This alternative would provide treatment to reduce the mobility of contaminants, as preferred by SARA. Fixation typically increases the volume of contaminated material between $5 \%-20 \%$ (sometimes more). Fixation is generally considered the appropriate treatment to immobilize contaminants with low concentrations of radionuclides, such as those found at the 200-BP-1 operable unit. However, a treatability study is expected to be required to assure effectiveness and determine leachability under the site-specific conditions at the operable unit.

Due to the lack of an engineered cover, this alternative would not prevent bioinstrusion or infiltration. Despite the reduction in contaminant mobility provided by treatment, leachability is not expected to be zero, and infiltration is expected move around and through the unsaturated backfill soils, and proceed downward to the groundwater table. Lack of an engineered surface barrier is expected to result in migration of the

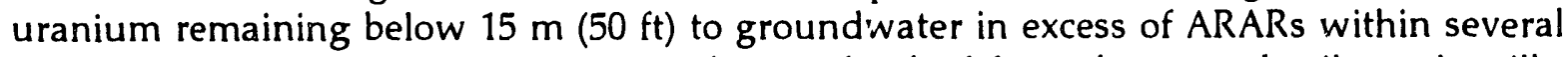
hundreds of years. Any contaminants that are leached from the treated soil matrix will add to these concentrations in groundwater. 


\subsubsection{Alternative 10: Excavation and Fixation of Most Contaminated Soil with a RCRA Barrier}

\section{Description}

This alternative contains all of the elements of Alternative 9, and adds a RCRA

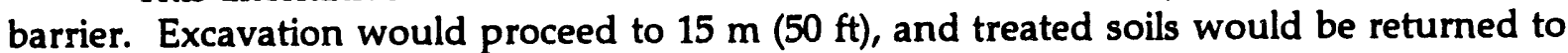
the excavation as backfill. While fixation immobilizes contaminants, and typically lowers the leachability of treated soil, a low-permeability RCRA barrier is required to meet RAOs due to the presence of uranium below the excavation limit of $15 \mathrm{~m}(50 \mathrm{ft})$. A RCRA barrier is expected to limit infiltration to below current levels, and increase the time required for total uranium concentrations to reach groundwater from several hundred years to several thousand years, while decreasing peak total uranium concentrations.

As with Alternative 9, appropriate institutional controls and monitoring would be provided.

\section{Discussion}

This alternative would provide the same reduction in the mobility of contaminants through treatment as Alternative 9, as preferred by SARA. The addition of a barrier increases effectiveness of this alternative by greatly increasing the time period over which RAOs for groundwater will be met, and by preventing off-site transport of the treated soil by wind and surface water. The cost of the barrier is expected to represent a modest increase in the cost of the alternative, but a smaller fraction than that required by excavation and treatment.

\subsubsection{Alternative 11: Excavation and Fixation of All Contaminated Soil}

\section{Description}

This alternative is similar to Alternative 7 , with fixation taking the place of soil washing. All soil with contaminant levels that result in exceedance of remedial action objectives would be excavated and treated, resulting in an excavation depth that exceeds 46 $\mathrm{m}(150 \mathrm{ft})$. All of the treated soils will be returned to the excavation as backfill, reducing residual risk on the operable unit to an insignificant level. However, since the contaminants are not removed from the site despite being immobilized, appropriate institutional controls and monitoring would still be necessary under this alternative. Inclusion of silt size fractions in a thin surface layer of clean backfill and growth of surface vegetation would promote evapotranspiration and thereby minimize infiltration, reducing the possibility of leaching contaminants from the treated soils.

\section{Discussion}

This alternative should be more effective than Alternative 10 because it treats all of the contaminated soil. The additional protection of groundwater is marginally greater than that provided by Alternative 10, since RAOs should never be exceeded once all of the contaminants are treated. However, it should be noted that the majority of the 
contamination is in the upper $15 \mathrm{~m}(50 \mathrm{ft})$, both in terms of mass and concentration, and would be treated in Alternative 10.

Treating the additional soil below $15 \mathrm{~m}(50 \mathrm{ft})$ would more than double the treatment cost of this alternative compared to Alternative 10. The excavation costs would increase much more dramatically, and would only affect the residual risk at the operable unit beyond the 1,000 year time frame. In addition, excavation to depths required to remove all of the contaminants would be extremely difficult to implement, and is not expected to be cost effective. Implementability of this alternative and its relationship to the adjacent 200-BP-7 operable unit are discussed in more detail in Section 5.3 below.

\subsubsection{Alternative 12: Excavatiun and Vitrification of Most Contaminated Soil}

\section{Description}

This alternative is similar to Alternative 9, with the exception that vitrification rather than fixation would be used to achieve contaminant immobilization. Excavation would proceed to a depth of approximately $15 \mathrm{~m}(50 \mathrm{ft})$ below ground surface, with all of the excavated soils being treated in an ex-situ vitrification plant, as described in Section 4.4.5. This alternative differs from Alternative 8 in that the vitrified soils would be replaced in the excavation, and not placed in the ERSDF. As a result, the risk associated with the vitrified soils remains within the 200-BP-1 operable unit.

No low permeability barrier is included in this alternative. The glass-like nature of the replaced vitrified soil is expected to be an effective impediment to biological intrusion. Appropriate institutional controls and monitoring would be provided.

\section{Discussion}

Vitrification should provide greater immobilization and lower leachability of the contaminants from treated soil, resulting in greater effectiveness than the fixation process included in Alternative 9. Vitrification would be expected to increase the volume of contaminated material slightly. Vitrification is generally considered the best single means of immobilizing high-level radioactive contamination, although it is significantly more expensive the fixation. While it may be more than is required for the low level contaminants at 200-BP-1, it is expected to be effective. However, because treatment effectiveness is site-specific, a treatability study would be required to determine if vitrification is significantly more effective than fixation for soils at this site.

Without an engineered, low permeability barrier as a cover, this alternative would not prevent infiltration and potential migration of uranium to ground water. Uranium in unexcavated soils below $15 \mathrm{~m}(50 \mathrm{ft})$ is expected to reach groundwater in concentrations in excess of ARARs within several hundred years at an infiltration rate of $1 \mathrm{~cm}(0.4 \mathrm{in}$.) per year. 


\subsubsection{Alternative 13: Excavation and Vitrification of Most Contaminated Soil with a RCRA Barrier}

\section{Description}

This alternative contains all of the elements of Alternative 12, and adds a RCRA barrier. Excavation would proceed to $15 \mathrm{~m}(50 \mathrm{ft})$, and treated soils would be returned to the excavation as backfill. While vitrification immobilizes contaminants, and typically lowers the leachability of treated soil, a low-permeability RCRA barrier is required to meet RAOs due to the presence of uranium below the excavation limit of $15 \mathrm{~m}(50 \mathrm{ft})$. A RCRA barrier is expected to limit infiltration to below current levels, and increase the time required for total uranium concentrations to reach groundwater to several thousand years, while decreasing peak total uranium concentrations.

The glass-like nature of the replaced vitrified soil is expected to be effective impediment to biological intrusion in addition to the presence of an asphalt layer in the RCRA barrier. Appropriate institutional controls and monitoring would be provided.

\section{Discussion}

This alternative would provide the same reduction in the mobility of contaminants through treatment as Alternative 12, as preferred by SARA. The addition of a barrier increases effectiveness of this alternative by greatly increasing the time period over which RAOs for groundwater will be met, and by providing additional protection from exposure to radiation in the vitrified soil. The cost of the barrier is expected to represent a modest increase in the cost of the alternative, but a smaller fraction that required by excavation and treatment.

\subsubsection{Altemative 14: Excavation and Vitrification of All Contaminated Soil}

\section{Description}

This alternative contains the same elements as Alternative 12, with the exception that all soil with contaminant levels that result in exceedance of remedial action objectives would be excavated and treated, resulting in an excavation depth that exceeds $46 \mathrm{~m}$ (150 $\mathrm{ft}$ ). All of the treated soils will be returned to the excavation as backfill, reducing residual risk on the operable unit to an insignificant level. However, since the contaminants are not removed from the site despite being immobilized, appropriate institutional controls and monitoring would still be necessary under this alternative. Inclusion of silt size fractions in a thin surface layer of clean backfill and growth of surface vegetation would promote evapotranspiration and thereby minimize infiltration, reducing the possibility of leaching contaminants from the treated soils.

\section{Discussion}

This alternative should be more effective than Alternative 13 because it treats all of the contaminated soil. The additional protection of groundwater is marginally greater than that provided by Alternative 13, since RAOs should never be exceeded once all of the contaminants are treated. However, it should be noted that the majority of the 
contamination is in the upper $15 \mathrm{~m}(50 \mathrm{ft})$, both in terms of mass and concentration, and would be treated in Alternatives 12 and 13.

Treating the additional soil below $15 \mathrm{~m}(50 \mathrm{ft})$ would more than double the treatment cost of this alternative compared to Alternatives 12 and 13 . The excavation costs would increase much more dramatically, and would only affect the residual risk at the operable unit beyond the 1,000 year time frame. In addition, excavation to depths required to remove all of the contaminants would be extremely difficult to implement, and is not expected to be cost effective. Implementability of this alternative and its relationship to the adjacent 200-BP-7 operable unit are discussed in more detail in Section 5.3 below.

\subsubsection{Alternative 15: Excavation and Disposal of Most Contaminated Soil with a RCRA Barrier}

\section{Description}

In this alternative, soil at the 200-BP-1 site that contains most of the contamination would be excavated and disposed in the ERSDF. Contaminants will be excavated to a

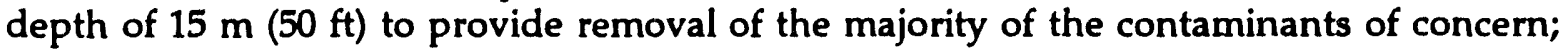
volume reduction would not be achieved by this alternative. A geologic repository would be used in place of the ERSDF for contaminated soil, where regulations or DOE policy require use of a geologic repository. To minimize the potential for exposure, excavation would not occur until construction of the ERSDF (or geologic repository, if applicable) is completed, thus avoiding above-ground storage of contaminated soils.

The excavation would then be filled to grade with clean fill, compacted, and graded for proper drainage. Inclusion of silt size fractions in the clean backfill and growth of surface vegetation would promote evapotranspiration and thereby minimize infiltration. However, a low permeability RCRA barrier is included to prevent uranium currently existing below $15 \mathrm{~m} \mathrm{(50} \mathrm{ft)} \mathrm{in} \mathrm{unexcavated} \mathrm{soils} \mathrm{from} \mathrm{impacting} \mathrm{groundwater} \mathrm{in}$ concentrations above ARARs within 500-600 years. Inclusion of a RCRA barrier is expected to increase the time at which total uranium concentrations in groundwater will exceed ARARs to several thousand years.

Because some contaminated soil would remain at the site after remedial action, institutional controls and monitoring would be required for this alternative.

\section{Discussion}

This alternative would result in the removal of most of the contamination from the 200-BP-1 site, both in terms of mass and concentration. However, the potential risk due to the contaminants would simply be relocated to a nearby disposal site (the ERSDF).

Contaminated soil would remain at the site, requiring institutional controls and monitoring.

The potential risks posed by the excavated contaminants would be relocated from the operable unit to a nearby disposal site (the ERSDF). The theoretical increase in protectiveness resulting from removal thus depends on the difference in protection provided by disposal in the ERSDF and that provided by construction of a surface barrier covering the remaining contaminants in place on the operable unit. 


\subsubsection{Alternative 16: Excavation and Disposal of All Contaminated Soil}

\section{Description}

This alternative contains the same elements as Alternative 14 , with the exception that all soil with contaminant levels that result in exceedance of remedial action objectives would be excavated disposed in the ERSDF, resulting in an excavation depth that exceeds $46 \mathrm{~m}$ (150 ft). To minimize the potential for exposure, excavation would not occur until construction of the ERSDF (or geologic repository, if applicable) is completed, thus avoiding above-ground storage of contaminated soils. The excavation would be backfilled with clean fill and graded for proper drainage.

\section{Discussion}

The potential risk at the 200-BP-1 operable unit due to contaminated soil would be eliminated under this alternative. The site could therefore be released for unrestricted use, provided this use is also compatible with remedial action at neighboring operable units such as the single shell tanks at the 241-BY Tank Farm in the 200-BP-7 operable unit. However, the contaminants and their associated risk would simply be relocated to a nearby facility, albeit to a more controlled site (the ERSDF). In addition, excavation to depths required to remove all of the contaminants would be extremely difficult to implement, and is not expected to be cost effective. Implementability of this alternative and its relationship to the adjacent 200-BP-7 operable unit are discussed in more detail in Section 5.3 below.

Institutional controls and monitoring would presumably be required for the ERSDF.

\subsubsection{Alternative 17: In-situ Fixation of Most Contaminated Soil}

\section{Description}

In this alternative, the most contaminated soil would be treated in place by fixation. Deep soil mixing would be accomplished by drilling with large augers to mix the soil in place while grout or other fixation agents are injected (see Section 4.5.2). Mixing zones are overlapped to ensure treatment of all soils in the contaminated zone, in this case beneath the cribs to a depth of $15 \mathrm{~m}(50 \mathrm{ft})$. The cribs and piping networks would be treated via pressure grouting. A RCRA barrier is not included in this alternative. Appropriate institutional controls and monitoring would be provided.

\section{Discussion}

This alternative would provide treatment to reduce the mobility of contaminants within the mixing zone, as preferred by SARA. Fixation typically increases the volume of contaminated material between $5 \%-20 \%$ (sometimes more). Fixation is generally considered the appropriate treatment to immobilize contaminants with low concentrations of radionuclides, such as those found at the 200-BP-1 operable unit. However, a treatability study would be required to select appropriate fixative agents and determine effectiveness (leachability) under the site-specific conditions at the operable unit. 
Due to the lack of an engineered cover, this alternative would not prevent biointrusion and infiltration. Despite the reduction in contaminant mobility provided by treatment, leachability is not expected to be zero, and infiltration is expected move around and through the unsaturated backfill soils, and proceed downward to the groundwater table. Lack of an engineered surface barrier is expected to result in migration of the uranium remaining below $15 \mathrm{~m}(50 \mathrm{ft})$ to groundwater in excess of ARARs within several hundreds of years. Any contaminants that are leached from the treated soil matrix will add to these concentrations in groundwater.

\subsubsection{Alternative 18: In-situ Fixation of Most Contaminated Soil with a RCRA Barrier}

\section{Description}

This alternative contains all of the elements of Alternative 17, and adds a RCRA

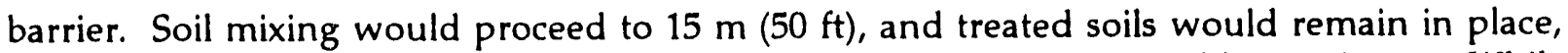
forming a more or less solid mass, through which infiltration will be able to migrate. While fixation immobilizes contaminants, and typically lowers the leachability of treated soil, a low-permeability RCRA barrier is required to meet RAOs due to the presence of uranium

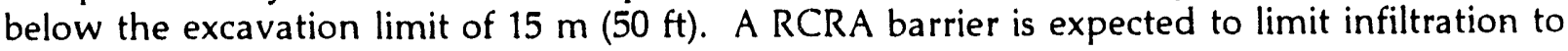
below current levels, and increase the time required for total uranium concentrations to reach groundwater to several thousand years, while decreasing peak total uranium concentrations.

As with Alternative 17, appropriate institutional controls and monitoring would be provided.

\section{Discussion}

This alternative would provide the same reduction in the mobility of contaminants through treatment as Alternative 17, as preferred by SARA. The addition of a barrier increases effectiveness of this alternative by greatly increasing the time period over which RAOs for groundwater will be met, and by preventing biointrusion. The cost of the barrier is expected to represent a modest increase in the cost of the alternative, but a smaller fraction than that required by excavation and treatment.

\subsubsection{Alternative 19: In-situ Fixation of All Contaminated Soil}

\section{Description}

This alternative is similar to Alternative 18 , with the exception that all soil with contaminant levels that result in exceedance of remedial action objectives would be treated in place. This would require deep soil mixing and grout injection to depths that exceeds $46 \mathrm{~m}(150 \mathrm{ft})$. All of the treated soils will remain in place, reducing residual risk on the operable unit to an insignificant level. However, since the contaminants are not removed from the site despite being immobilized, appropriate institutional controls and monitoring would still be necessary under this alternative. Inclusion of silt size fractions in a thin surface layer of clean backfill and growth of surface vegetation would promote 
evapotranspiration and thereby minimize infiltration, reducing the possibility of leaching contaminants from the treated soils.

\section{Discussion}

This alternative would provide treatment to reduce the mobility of contaminants, as preferred by SARA. This alternative should also be more effective than Alternative 18 because it treats all of the contaminated soil. The additional protection of groundwater is marginally greater than that provided by Alternative 18 , since RAOs should never be exceeded once all of the contaminants are treated. It should be noted once again that the majority of the contamination is in the upper $15 \mathrm{~m}(50 \mathrm{ft})$, both in terms of mass and concentration, and would be treated in Alternatives 17 and 18.

The implementability of this alternative is also questionable. In-situ fixation can be performed using commercially available equipment to depths of approximately 50 feet. Treatment to depths of $100-200$ feet, such as would be required to treat all of the contaminated soil at this site, would require specially built equipment. Fixation to such depths are difficult to achieve at any site, but the large cobbles found frequently in site soils could prevent reaching the desired depth in some locations or preventing effective mixing. Even where it is possible to reach the desired depth, verifying effectiveness would be extremely difficult. Further, treatment to great depth would proceed very slowly, and the low productivity would make this alternative very expensive, and probably not cost effective. Finally, the additional efforts to implement Alternative 19 over those required by Alternatives 17 and 18 would only affect the residual risk at the operable unit beyond the 1,000 year time frame.

\subsection{SCREENING OF ALTERNATIVES}

In this section, the remediation alternatives are screened to produce a refined list for detailed development and evaluation in Chapter 6. Once again, the criteria used for screening alternatives are effectiveness, implementability and cost (see Section 4 for definitions).

An alternative can be rejected because it is not sufficiently effective relative to another alternative or is not believed to be feasible to implement. An alternative can also be rejected by comparison to another alternative that is at least as effective for less cost, or is easier to implement for equivalent cost. An alternative can also be rejected in the case where the additional increase in effectiveness or implementability is not justified by the increased cost, provided the retained alternative is sufficiently protective of human health and the environment. In general, however, alternatives are not rejected solely on the basis of cost. This remains a screening analysis, and under this preliminary evaluation alternatives are retained unless a clear basis for rejection can be found. These screening principles are applied to the 19 formulated alternatives in the remainder of this section. 


\subsubsection{No Action and Insitutional Controls}

While there is no current risk at the operable unit, Alternative 1 (No Action) is not considered sufficiently protective of human health and the environment over the long term, but is retained for compliance with the NCP. While there are legitimate concerns regarding the ongoing required maintenance and the long term reliability of Institutional Controls (Alternative 2), this alternative is expected to be the most cost-effective of the remediation alternatives, and is therefore also retained as a separate alternative.

\subsubsection{Barrier Alternatives}

At this stage of the FS, all three of the surface barrier alternatives (alternatives 3,4 , and 5) would be implementable. The relative effectiveness of the barriers can be argued, but given the need to present decision makers with as wide a range of options as possible, screening of the barriers on the basis of effectiveness was considered to be inappropriate at this stage of the process. Because alternatives are not generally screened on the basis of cost alone, all three barrier alternatives are carried forward into detailed analysis.

\subsubsection{Alternatives Requiring Excavation}

The technical implementability of the alternatives requiring deep excavation is a major concern. An unshored $46 \mathrm{~m}$ (150 ft) excavation at the 200-BP-1 site is not feasible along the boundary with the 241-BY tank farm because, at that depth, the steepest allowable side slope of the excavation (1.5H:1V [horizontal:vertical]) would intersect the tanks. This raises concerns regarding the stability of the tanks and their foundations, and of possible worker exposure to potentially contaminated soils, direct exposure from tank wastes, and construction accidents possible in working under these conditions. Therefore, some type of retaining wall would need to be used along this edge of the excavation.

Economically viable retaining walls for deep excavations require some type of anchor system, generally described as tiebacks. There are several risks associated with installing tiebacks in the 241-BY tank farm area. For a $46 \mathrm{~m}$ (150 ft) high retaining wall, tiebacks of about 20 to $27 \mathrm{~m}$ ( 65 to $90 \mathrm{ft}$ ) in length would be required, depending on the type of retaining wall used. The nearest ta.nks in the 241 BY Tank Farm are about 24 to 37 $\mathrm{m}$ ( 80 to $120 \mathrm{ft}$ ) from the boundary of the 200-BP-1 operable unit. This is insufficient margin for error, especially considering the magnitude of problem created if a construction accident occurs. The tanks or pipelines could be accidently penetrated during tieback installation. Disturbance of adjacent ground could cause settlement and structural damage to the tanks. Drilling into a contaminated zone near a tank could expose construction

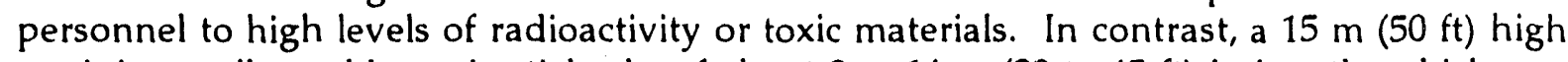
retaining wall would require tiebacks of about 9 to $14 \mathrm{~m} \mathrm{(30}$ to $45 \mathrm{ft}$ ) in length, which provides a relatively more acceptable margin for error. The $15 \mathrm{~m}(50 \mathrm{ft})$ high wall would allow removal of most of the contaminated soil and is thus retained in the pertinent alternatives.

Based on these excavation considerations, Alternatives 7, 11, 14, and 16 are all rejected from further consideration in the FS. These alternatives include deep excavation coupled with soil washing, ex-situ fixation, ex-situ vitrification, and direct disposal in the 
ERSDF. By contrast, Alternatives 6, 8, 10,13, 15 are retained, based on the better technical feasibility of excavation to $15 \mathrm{~m}(50 \mathrm{ft})$. These alternatives include modest excavation coupled with soil washing, soil washing and vitrification, ex-situ fixation, ex-situ vitrification, and direct disposal. In addition, each of these alternatives includes a RCRA barrier as a component. The RCRA barrier is feasible and implementable at the operable unit.

\subsubsection{Effectiveness Evaluation With and Without Barriers}

Pair-wise comparisons of the remaining alternatives for comparing relative effectiveness provides the basis for further elimination of alternatives. Alternative 9, Excavation and Fixation of Most Contaminated Soil, is rejected by comparison to Alternative 10, Excavation and Fixation of Most Contaminated Soil with a RCRA Barrier, based on the much greater effectiveness in achieving RAOs with a barrier component included in the alternative. Alternative 12, Excavation and Vitrification of Most Contaminated Soil, is rejected by comparison to Alternative 13, Excavation and Vitrification of Most Contaminated Soil with a RCRA barrier. Finally, Alternative 17, In-situ Fixation of Most Contaminated Soil, is rejected by comparison to Alternative 18, In-situ Fixation of Most Contaminated Soil with a RCRA barrier, again favoring the benefits of the barrier component.

In all three cases, the barrier provides significant increase in effectiveness of groundwater protection. The increase in relative effectiveness results in screening-out the less effective alternatives, despite the increased cost of the barrier components of the more effective alternatives.

\subsubsection{Cost-Effectiveness Evaluation}

A second round of pair-wise comparisons, this time comparing incremental effectiveness and implementability with incremental cost, provides the final alternative screening. Alternative 13, Ex-situ Vitrification (without soil washing) is rejected by comparison to Alternative 10, Ex-situ Fixation. Fixation is the standard technology for immobilization of radionuclides in low concentrations, such as those found at the 200-BP-1 operable unit. By contrast, vitrification is the standard technology for immobilization for radionuclides in high concentrations (Alternative 8 ). While vitrification is considered more effective than fixation, it achieves this effectiveness at a significantly greater cost that is not justified for the unconcentrated contaminants at the operable unit.

Alternative 19, In-situ Fixation of All Contaminated Soil, is rejected on the basis of poor implementability and also by comparison to Alternative 18, In-situ Fixation of Most Contaminated Soil with a RCRA barrier. As indicated in Section 5.2.19, in-situ fixation to

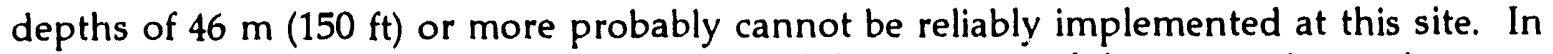
addition, Alternative 18 provides treatment of the majority of the contaminants in terms of mass and concentration. Therefore, compared to Alternative 18, Alternative 19 provides only marginal additional effectiveness for much greater cost, and so is rejected. 


\subsection{SUMMARY OF RETAINED ALTERNATIVES}

The screening process used in Section 5.3 has resulted in 10 alternatives being carried forward. They cover a broad range of containment and treatment options that have been passed on based on their ability to meet RAOs under the site-specific conditions at the 200-BP-1 operable unit.

The alternatives remaining after screening are all considered sufficiently effective and implementable to warrant detailed evaluation. However, the relative effectiveness and implementability of these alternatives is variable and will be evaluated based on detailed analysis in Chapter 6 . In particular, the cost and cost-effectiveness of the retained alternatives are highly variable. The retained alternatives are:

1 No Action

2 Institutional Controls

3 Biointrusion Barrier

$4 \quad$ Modified RCRA Barrier

5 Hanford Barrier

6 Excavation and Soil Washing wit 1 a RCRA Barrier

8 Excavation, Soil Washing and Vit ification with a RCRA Barrier

10 Excavation and Fixation with a RCRA Barrier

15 Excavation and Disposal with a RCRA Barrier

18 In-situ Fixation with a RCRA Barrier 
DOE/RL-93-35, Rev. 0

Table 5-1. Summary of Remediation Alternatives and Screening. (Sheet 1 of 4)

\begin{tabular}{|c|c|c|c|c|}
\hline \multicolumn{2}{|c|}{$\begin{array}{l}\text { Alternative } \\
\text { No. Name }\end{array}$} & \multicolumn{2}{|c|}{ Description (Key Elements) } & \multirow{2}{*}{$\begin{array}{c}\text { Retained? } \\
\text { (Yes/No) }\end{array}$} \\
\hline 1 & No Action & \multicolumn{2}{|c|}{$\begin{array}{l}\text { No remedial action; existing controls not maintained; } \\
\text { monitoring. }\end{array}$} & \\
\hline 2 & $\begin{array}{l}\text { Institutional } \\
\text { Controls }\end{array}$ & \multicolumn{2}{|c|}{$\begin{array}{l}\text { Deed restrictions; warning markers; fencing with } \\
\text { periodic maintenance; monitoring. }\end{array}$} & Yes \\
\hline 3 & Biointrusion Barrier & & $\begin{array}{l}\text { Cover all contaminated areas with a barrier } \\
\text { designed to prevent vegetative growth and } \\
\text { biointrusion but allowing increased } \\
\text { infiltration. } \\
\text { Implement and maintain institutional controls } \\
\text { and monitoring. }\end{array}$ & Yes \\
\hline 4 & RCRA Barrier & 2. & $\begin{array}{l}\text { Cover all contaminated areas with a } \\
\text { low-permeability barrier similar to designs for } \\
\text { hazardous waste sites. } \\
\text { Implement and maintain institutional controls } \\
\text { and monitoring. }\end{array}$ & Yes \\
\hline 5 & Hanford Barrier & $\begin{array}{l}1 . \\
2 .\end{array}$ & $\begin{array}{l}\text { Cover all contaminated areas with the low- } \\
\text { permeability Hanford Barrier. } \\
\text { Implement and maintain institutional controls } \\
\text { and monitoring. }\end{array}$ & Yes \\
\hline 6 & $\begin{array}{l}\text { Excavation and Soil } \\
\text { Washing of Most } \\
\text { Contaminated Soil } \\
\text { with a RCRA } \\
\text { Barrier }\end{array}$ & $\begin{array}{l}1 . \\
2 . \\
3 . \\
4 . \\
5 . \\
6 .\end{array}$ & $\begin{array}{l}\text { Excavate soil with the highest contamination. } \\
\text { Treat excavated soil by a soil washing process } \\
\text { to reduce the quantity of contaminated } \\
\text { material remaining after treatment. } \\
\text { Backfill treated soils meeting remedial action } \\
\text { objectives on-site. } \\
\text { Cover the backfilled excavation with a low- } \\
\text { permeability barrier. } \\
\text { Dispose of sludge or contaminated soil from } \\
\text { treatment in the ERSDF (or geologic } \\
\text { repository, if required). } \\
\text { Implement and maintain institutional controls } \\
\text { and monitoring. }\end{array}$ & Yes \\
\hline 7 & $\begin{array}{l}\text { Excavation and Soil } \\
\text { Washing of All } \\
\text { Contaminated Soil } \\
\text { (No Barrier) }\end{array}$ & & $\begin{array}{l}\text { Excavate all soil with contaminant levels } \\
\text { exceeding remedial action objectives. } \\
\text { Treat excavated soil by a soil washing process } \\
\text { to reduce the quantity of contaminated } \\
\text { material remaining after treatment. } \\
\text { Backfill treated soils meeting remedial action } \\
\text { objectives on-site. } \\
\text { Dispose of sludge or contaminated soil from } \\
\text { treatment in the ERSDF (or geologic } \\
\text { repository, if required. }\end{array}$ & No \\
\hline
\end{tabular}


Table 5-1. Summary of Remediation Alternatives and Screening. (Sheet 2 of 4)

\begin{tabular}{|c|c|c|c|c|}
\hline \multicolumn{2}{|c|}{$\begin{array}{l}\text { Alternative } \\
\text { No. Name }\end{array}$} & \multicolumn{2}{|c|}{ Description (Key Elements) } & \multirow{2}{*}{$\begin{array}{c}\begin{array}{c}\text { Retained? } \\
\text { (Yes/No) }\end{array} \\
\text { Yes }\end{array}$} \\
\hline 8 & $\begin{array}{l}\text { Excavation and Soil } \\
\text { Washing of Most } \\
\text { Contaminated Soil } \\
\text { with Vitrification } \\
\text { and a RCRA } \\
\text { Barrier }\end{array}$ & $\begin{array}{l}1 . \\
2 . \\
3 . \\
4 . \\
5 . \\
6 . \\
7 .\end{array}$ & $\begin{array}{l}\text { Excavate soil with the highest contamination. } \\
\text { Treat excavated soil by a soil washing process } \\
\text { to reduce the quantity of contaminated } \\
\text { material remaining after treatment. } \\
\text { Backfill treated soils meeting remedial action } \\
\text { objectives on-site. } \\
\text { Cover the backfilled excavation with a low- } \\
\text { permeability barrier. } \\
\text { Vitrify sludge or contaminated soil from } \\
\text { treatment. } \\
\text { Dispose of vitrified sludge or contaminated } \\
\text { soil from treatment in the ERSDF (or } \\
\text { geologic repository, if required. } \\
\text { Implement and maintain institutional controls } \\
\text { and monitoring. }\end{array}$ & \\
\hline 9 & $\begin{array}{l}\text { Excavation and } \\
\text { Fixation of Most } \\
\text { Contaminated Soil } \\
\text { (No Barrier) }\end{array}$ & $\begin{array}{l}1 . \\
2 . \\
3 . \\
4 .\end{array}$ & $\begin{array}{l}\text { Excavate soil with the highest contaminant } \\
\text { levels. } \\
\text { Treat excavated soil by fixation to immobilize } \\
\text { contaminants. } \\
\text { Return treated soil to the excavation. } \\
\text { Implement and maintain institutional controls } \\
\text { and monitoring. }\end{array}$ & No \\
\hline 10 & $\begin{array}{l}\text { Excavation and } \\
\text { Fixation of Most } \\
\text { Contaminated Soil } \\
\text { with a RCRA } \\
\text { Barrier }\end{array}$ & $\begin{array}{l}1 . \\
2 . \\
3 . \\
4 . \\
5 .\end{array}$ & $\begin{array}{l}\text { Excavate soil with the highest contaminant } \\
\text { levels. } \\
\text { Treat excavated soil by fixation to immobilize } \\
\text { contaminants. } \\
\text { Return treated soil to the excavation. } \\
\text { Cover the backfilled excavation with a low- } \\
\text { permeability barrier. } \\
\text { Implement and maintain institutional controls } \\
\text { and monitoring. }\end{array}$ & Yes \\
\hline 11 & $\begin{array}{l}\text { Excavation and } \\
\text { Fixation of All } \\
\text { Contaminated Soil } \\
\text { (No Barrier) }\end{array}$ & $\begin{array}{l}1 . \\
2 . \\
3 . \\
4 .\end{array}$ & $\begin{array}{l}\text { Excavate all soil with contaminant levels } \\
\text { exceeding remedial action objectives. } \\
\text { Treat excavated soil by fixation to immobilize } \\
\text { contaminants. } \\
\text { Return treated soil to the excavation. } \\
\text { Implement and maintain institutional controls } \\
\text { and monitoring. }\end{array}$ & No \\
\hline 12 & $\begin{array}{l}\text { Excavation and } \\
\text { Vitrification of } \\
\text { Most Contaminated } \\
\text { Soil (No Barrier) }\end{array}$ & $\begin{array}{l}1 . \\
2 . \\
3 . \\
4 .\end{array}$ & $\begin{array}{l}\text { Excavate soil with the highest contaminant } \\
\text { levels. } \\
\text { Treat excavated soil by vitrification to } \\
\text { immobilize contaminants. } \\
\text { Return treated soil to the excavation. } \\
\text { Implement and maintain institutional controls } \\
\text { and monitoring. }\end{array}$ & No \\
\hline
\end{tabular}


Table 5-1. Summary of Remediation Alternatives and Screening. (Sheet 3 of 4)

\begin{tabular}{|c|c|c|c|c|}
\hline \multicolumn{2}{|c|}{$\begin{array}{l}\text { Alternative } \\
\text { No. Name }\end{array}$} & \multicolumn{2}{|c|}{ Description (Key Elements) } & \multirow{2}{*}{$\begin{array}{c}\text { Retained? } \\
\text { (Yes/No) } \\
\text { No }\end{array}$} \\
\hline 13 & $\begin{array}{l}\text { Excavation and } \\
\text { Vitrification of } \\
\text { Most Contaminated } \\
\text { Soil with a RCRA } \\
\text { Barrier }\end{array}$ & $\begin{array}{l}1 . \\
2 . \\
3 . \\
4 . \\
5 .\end{array}$ & $\begin{array}{l}\text { Excavate soil with the highest contaminant } \\
\text { levels. } \\
\text { Treat excavated soil by vitrification to } \\
\text { immobilize contaminants. } \\
\text { Return treated soil to the excavation. } \\
\text { Cover the backfilled excavation with a low- } \\
\text { prrmeability barrier. } \\
\text { Implement and maintain iustitutional controls } \\
\text { and monitoring. }\end{array}$ & \\
\hline 14 & $\begin{array}{l}\text { Excavation and } \\
\text { Vitrification of All } \\
\text { Contaminated Soil } \\
\text { (No Barrier) }\end{array}$ & $\begin{array}{l}1 . \\
2 . \\
3 . \\
4 . \\
5 .\end{array}$ & $\begin{array}{l}\text { Excavate all soil with contaminant levels } \\
\text { exceedirg remedial action objectives. } \\
\text { Treat excavated soil by vitrification to } \\
\text { immobilize contaminants. } \\
\text { Return treated soil to the excavation. } \\
\text { Cover the backfilled excavation with a low } \\
\text { permeability barrier. } \\
\text { Implement and maintain institutional controls } \\
\text { and monitoring. }\end{array}$ & No \\
\hline 15 & $\begin{array}{l}\text { Excavation and } \\
\text { Disposal of Most } \\
\text { Contaminated Soil } \\
\text { with a RCRA } \\
\text { Barrier }\end{array}$ & $\begin{array}{l}1 . \\
2 . \\
3 . \\
4 . \\
5 .\end{array}$ & $\begin{array}{l}\text { Excavate soil with the highest contaminant } \\
\text { levels. } \\
\text { Dispose of excavated soil in the ERSDF (or } \\
\text { geologic repository for some soil, if } \\
\text { required). } \\
\text { Backfill the excavation with clean soil. } \\
\text { Cover the backfilled excavation with a low- } \\
\text { permeability barrier. } \\
\text { Implement and maintain institutional controls } \\
\text { and monitoring. }\end{array}$ & Yes \\
\hline 16 & $\begin{array}{l}\text { Excavation and } \\
\text { Disposal of All } \\
\text { Contaminated Snil } \\
\text { (No Barrier) }\end{array}$ & $\begin{array}{l}1 . \\
2 .\end{array}$ & $\begin{array}{l}\text { Excavate all soil with contaminant levels } \\
\text { exceeding remedial action objectives. } \\
\text { Dispose of excavated soil in the ERSDF (or } \\
\text { geologic repository for some soil, if } \\
\text { required). }\end{array}$ & No \\
\hline 17 & $\begin{array}{l}\text { In Situ Fixation of } \\
\text { Most Contaminated } \\
\text { Soil (No Barrier) }\end{array}$ & $\begin{array}{l}1 . \\
2 .\end{array}$ & $\begin{array}{l}\text { Treat soil with the highest contaminant levels } \\
\text { in place by fixation. } \\
\text { Implement and maintain institutional controls } \\
\text { and monitoring. }\end{array}$ & No \\
\hline 18 & $\begin{array}{l}\text { In Situ Fixation of } \\
\text { Most Contaminated } \\
\text { Soil with a RCRA } \\
\text { Barrier }\end{array}$ & $\begin{array}{l}1 . \\
2 . \\
3 .\end{array}$ & $\begin{array}{l}\text { Treat soil with the highest contaminant levels } \\
\text { in place by fixation. } \\
\text { Cover all contaminated areas with a low- } \\
\text { permeability barrier. } \\
\text { Implement and maintain institutional controls } \\
\text { and monitoring. }\end{array}$ & Yes \\
\hline
\end{tabular}


DOE/RL-93-35, Rev. 0

Table 5-1. Summary of Remediation Alternatives and Screening. (Sheet 4 of $)$

\begin{tabular}{|c|l|ll|c|}
\hline \multicolumn{2}{|c|}{$\begin{array}{l}\text { Alternative } \\
\text { No. }\end{array}$} & Name & $\begin{array}{l}\text { Rescription (Key Elements) } \\
\text { (Yes/No) }\end{array}$ \\
\hline 19 & $\begin{array}{l}\text { In Situ Fixation of } \\
\text { All Contaminated } \\
\text { Soil (No Barrier) }\end{array}$ & 1. & $\begin{array}{l}\text { Treat all soil with contaminant levels } \\
\text { exceeding remedial action objectives in place } \\
\text { by fixation. } \\
\text { Implement and maintain institutional controls } \\
\text { and monitoring. }\end{array}$ & No \\
\hline
\end{tabular}




\subsection{DEVELOPMENT AND EVALUATION OF REMEDIATION ALTERNATIVES}

\subsection{INTRODUCTION}

In this chapter, remediation alternatives retained after screening in Chapter $\mathbf{5}$ are further developed and evaluated. For ease of reference, the alternatives have been renumbered and their names simplified. These alternatives are:

$\begin{array}{ll}\text { A } & \text { No Action } \\ \text { B } & \text { Institutional Controls } \\ \text { C } & \text { Biointrusion Barrier } \\ \text { D } & \text { RCRA Barrier } \\ \text { E } & \text { Hanford Barrier } \\ \text { F } & \text { Excavation and Soil Washing } \\ \text { G } & \text { Excavation and Soil Washing with Vitrification } \\ \text { H } & \text { Excavation and Fixation } \\ \text { I } & \text { ERSDF Disposal } \\ \text { J } & \text { In-Situ Fixation }\end{array}$

A summary of the alternatives is presented in Table 6-1. These alternatives provide a complete range of alternative actions for evaluation and comparison. The remediation alternatives are described and evaluated below.

It is necessary to make a number of design assumptions to fully develop and evaluate each alternative. These design assumptions are illustrative of how the technologies would be used in the alternatives. However, the design assumptions used here are not necessarily the same as the design basis that would be used for the final, detailed design. In most cases, additional investigations would be necessary to allow final design. For example, additional soil sampling would be performed prior to excavation or in-situ treatment to better define the extent of soil contamination, and a treatability study would be needed for any of the treatment technologies.

\subsection{COMMON DESIGN ELEMENTS}

Several alternatives share common elements in their formulation. To avoid repetition, this section presents the descriptions of elements common to two or more alternatives. These common elements are then referenced in the descriptions of the alternatives.

\subsubsection{Institutional Controls}

With the exception of Alternative A (No Action), all of the alternatives include institutional controls as a key component of remedial action. Institutional controls are required because none of the other alternatives would provide long-term effectiveness without such controls. Institutional controls for this site include fencing, warning markers, site use restrictions, and groundwater use restrictions. These controls are consistent with 
current plans for dedication of the 200 East Area as a permanent waste management and disposal area (HFSUWG 1992).

Fencing would be maintained around the site to prevent site access. Depending on the disposition of surrounding operable units, the site could be fenced by itself or in combination with other units.

Warning signs would be placed on the fencing to discourage trespass. Warning markers would also be buried at the site to warn against excavation, in the event the other institutional controls fail. The buried markers probably would be ceramic disks with pictorial symbols and written warnings stating that radioactive contamination is present in the soil to discourage further digging.

Deed restrictions would designate the site as a permanent disposal area not suited to other use. With these restrictions, it is unlikely that the U.S. government would relinquish ownership of the site and would retain direct control of the site to prevent adverse site use. Groundwater use restrictions would prohibit withdrawal of groundwater affected by the site.

\subsubsection{Monitoring}

Monitoring is included as part of all alternatives, including the "no action" alternative. Separate monitoring programs will be used for the short term (during remedial action) and the long term (following completion of remediation). Detailed monitoring plans will be developed for the selected remedy during final design.

Short-term monitoring is conducted during remediation to 1) ensure that there are no adverse off-site effects from remediation, 2) provide quality control, and 3) to evaluate the performance of the remedy. The primary potential off-site concern is airborne dust or emissions. To monitor air quality, air sampling stations will be established around the perimeter of the 200-BP-1 operable unit. Samples will be routinely collected and analyzed.

Long-term monitoring is conducted to allow timely maintenance of fencing and barriers and to ensure that the remedy continues to perform as expected over time. Periodic site inspections (including surveying of barrier elevations, where applicable) should be sufficient for determining maintenance needs and monitoring performance of barriers (including detecting biological intrusion). Although groundwater is primarily being addressed in the 200 East Aggregate Area groundwater operable unit, additional groundwater monitoring will be needed to monitor the performance of the selected remedy with respect to migration of contaminants from site soils to groundwater. For example, site-specific groundwater monitoring would verify that technetium- 99 concentrations continue to decline as expected, and that no significant uranium impacts from the site are detected (since modeling predicts uranium impacts will not occur until a time frame after monitoring will probably have terminated).

Other types of monitoring are required by particular alternatives. Examples include radiation monitoring during soil excavation, sampling and analysis of soils for excavation and treatment, quality control monitoring of treated soil, and construction inspection of 
barrier. The specifics of these monitoring programs will be determined during final design for the selected remedy. The design assumptions for monitoring are:

- Installation of 4 groundwater monitoring wells.

- Long-term monitoring is performed for 30 years after remediation is completed and then stops. However, on a present-value basis, a longer monitoring period would not significantly impact cost.

- Groundwater monitoring frequency is higher initially (the first 5 years), and then decreases to a lower level.

- A comprehensive review of remedy performance is performed every 5 years as required under CERCLA.

\subsubsection{Excavation}

Several of the remediation alternatives involve ex-situ treatment or disposal of contaminated soils. To accomplish this, the soils will need to be excavated. The Phase I RI found contamination down to a depth of approximately $72 \mathrm{~m} \mathrm{(236} \mathrm{ft)} \mathrm{(DOE-RL} \mathrm{1993).} \mathrm{The}$ extent of excavation would be determined based on a cleanup standard, which would be developed in the event an excavation alternative is selected. This cleanup standard would also be used to distinguish "clean" and "contaminated" soils in soil washing (Alternatives F and G). However, as discussed in Section 5.3, excavation of soils below a depth of approximately $15 \mathrm{~m}(50 \mathrm{ft})$ is not feasible and would not depend on the cleanup standard.

The high radioactivity of some of the soils is expected to raise concerns about dust control and surface water contamination. Consequently, the excavation would be performed under a temporary enclosure. This enclosure will prevent dust from leaving the excavation and also prevent surface water from contacting contaminated soil in the excavation. The enclosure would operate under negative air pressure to ensure no leakage of contaminated air, and would have HEPA filters on the ventilation system exhaust, with monitoring to verify performance.

Soil would be excavated primarily using backhoes and bulldozers, with front-end loaders to move excavated soil to stockpiles. To minimize radiation exposure of workers, shielded and/or remotely operated excavation equipment would be used. It is expected that excavation productivity would be greatly decreased by the combined effects of the enclosure and robotics.

Unshored excavations to 50-foot depths are not feasible along the boundary with the 241-BY Tank Farm because the excavations would come too close to the tanks (about 20 feet). Therefore, some type of retaining wall and/or shoring system would be used along this boundary. Remote operations would have limited applicability in constructing the retaining wall. Retaining walls are not needed along the other boundaries, where the excavation could be enlarged, if necessary, if contaminated soil is found beyond the initial excavation boundaries. 
The location of the retaining wall, the areas of contaminated soil, and the limits of the open cut excavation are shown on Figure 6-1. the design assumptions for excavation are:

$\begin{array}{ll}\text { Depth of excavation: } & 15 \mathrm{~m}(50 \mathrm{ft}) \\ \text { Side slope: } & 1.5 \mathrm{H}: 1 \mathrm{~V} \\ \text { Retaining wall length: } & 245 \mathrm{~m}(800 \mathrm{ft}) \\ \text { Retaining wall type: } & \text { soil nailed }\end{array}$

Area excavated (not including side slope excavation): $15,700 \mathrm{~m}^{2}\left(168,400 \mathrm{ft}^{2}\right)$

A soil-nailed wall has been selected because its technical difficulties are representative of many wall systems and its cost is at the lower end of the range for retaining wall types. Soil nailing involves reinforcing the soil mass with tiebacks (the nails) and retaining the excavation face with shotcrete. It is a top-down construction method, where the support system is installed as excavation proceeds. After a lift is excavated, boreholes are drilled perpendicular to the wall face. The nail, typically a $2.5-\mathrm{cm}(1-\mathrm{in}$.)diameter steel bar, is centered in the hole, which is then filled with grout. A layer of steel mesh is placed over the nails to increase the structural strength of the shotcrete. Shotcrete is then applied to the excavation face. The next lift is then excavated and the installation process is repeated.

\subsubsection{Surface Barriers}

The proposed surface barriers have all been designed for longevity with low maintenance using natural earthen materials, although the Hanford Barrier and RCRA Barrier also incorporate an asphalt layer. All barriers have been designed to prevent biotic intrusion. The Hanford Barrier and RCRA Barrier have also been designed to limit infiltration, whereas, the Biointrusion Barrier contains no such design elements and may actually result in a net increase in infiltration compared to currently existing conditions.

For all alternatives that include barriers, the area of contamination to be covered is the same. The barrier dimensions (length and width) extend $15 \mathrm{~m}(50 \mathrm{ft}$ ) beyond the boundaries of the contaminated areas to provide a buffer zone against infiltration into contaminated soil from the edges of the barrier. This buffer zone is larger than the $4.6 \mathrm{~m}$ $(20 \mathrm{ft})$ buffer zone used for excavation alternatives to account for the uncertainty in the effects of vadose zone moisture migration near the surface at the perimeter of the barrier and the possible impacts on near surface contaminant migration over the design life (up to $1,000 \mathrm{yrs})$ of the barrier.

In considering barrier dimensions, there are three "area" considerations of importance. The "crib area" is the area defined by the outer perimeter of the crib infiltration gravels. The "effective barrier area" is the area covered by the full thickness of the barrier cross section, which is the area of the cribs plus that of the buffer zone described above. Finally, the "barrier footprint" is the effective area plus the area covered by the barrier side slopes. At a slope of $2 \mathrm{H}: 1 \mathrm{~V}$, this amounts to an additional area that constitutes the true perimeter of the barrier system. For consistency in evaluating and comparing barrier alternatives, the sizes of all barrier areas in this FS report refer to the effective barrier area over which the barrier maintains is full cross-sectional thickness. The 
effective barrier areas to be covered are shown in Figure $6-2$ and total $22,000 \mathrm{~m}^{2}$ $\left(238,000 \mathrm{ft}^{2}\right)$.

\subsubsection{ERSDF Disposal}

The ERSDF is a permanent disposal facility (landfill) for Hanford wastes that is presently in the conceptual design stage. As currently envisioned, it will consist of a series of large trenches expected to accommodate about $23,000,000 \mathrm{~m}^{3}\left(30,000,000 \mathrm{yd}^{3}\right)$ in total. It will have facilities for receiving and handling various types of materials, including bulk solids. At the present time, it has not been determined whether those trenches receiving purely low-level radioactive waste will be lined. High-activity waste will be remotely handled and may require additional engineered barriers to protect workers. The type of cover for each trench has not been determined, but will be selected based on waste inventory and ARARs. The Hanford Barrier (Section 6.3.5) will be used if a high level of performance is required. Institutional controls and monitoring will be implemented for the ERSDF, including vadose-zone and groundwater monitoring.

For the purpose of the feasibility study, the following assumptions were made about ERSDF design:

- Barrier type:

- Liner system

(bottom to top): $\quad 1 \mathrm{~m}(3 \mathrm{ft})$ of low-permeability soil, a highdensity polyethylene (HDPE) liner, a geonet drainage layer, and $0.6 \mathrm{~m}(2 \mathrm{ft})$ of native soil to protect the liner during waste placement.

- Trench dimensions: $91 \mathrm{~m}(300 \mathrm{ft})$ wide at the top with $3 \mathrm{H}: 1 \mathrm{~V}$ side slopes.

- $\quad$ Costs for general ERSDF facilities will be incurred regardless of whether 200-BP-1 soil is disposed of in this facility. Therefore, only actual landfill construction costs to accommodate the anticipated volume of 200-BP-1 soils (cover and liner) are included in the unit cost for ERSDF disposal. Other development, operations and management costs are not included in disposal costs for 200-BP-1 soils.

\subsubsection{Transportation of Contaminated Soil}

For alternatives with on-site treatment, soil would most likely be transported to the treatment plant via an enclosed conveyor. This would result in less handling and potential spillage of the contaminated soil than truck transportation. However, maintenance of the conveyor would still result in worker exposure to contaminated soil and the potential for incidental spillage near the conveyor. Waste (either contaminated soil or sludge from treatment) would be hauled to the ERSDF for disposal in trucks. Truck hauling would be in bulk for low-activity waste, with controls similar to hazardous waste hauling (such as 
covered trucks), and in containers for high-activity waste. The trucks would be shielded to minimize worker exposure. Trucks would be decontaminated after loading and before hauling, and the contaminated washwater would be treated in a wastewater treatment system (see Section 6.2.8).

\subsubsection{Surface Water Management}

Surface water will be controlled during site remediation to prevent spread of contaminated material and minimize the amount of water requiring treatment due to contact with contaminated soil. Surface water controls will be performed in accordance with a best management practices (BMP) plan. Little contaminated surface water should be generated because of the low precipitation and careful surface water management.

All active remediation alternatives would include berms and ditches to prevent runon of surface water from outside the remediation area. Additional berms and ditches would be used to control surface water within remediation areas, and keep clean water away from contaminated soil to the maximum degree possible. For barrier alternatives (with no excavation or treatment), existing clean soil cover would be used in combination with careful construction staging to prevent or minimize contact of barrier construction equipment with contaminated soil.

For alternatives including excavation, the enclosure covering the excavation area (coupled with berms around the enclosure) would prevent surface water from entering the excavation area. To minimize contaminated surface water due to transport of contaminated soil, on-site treatment alternatives would use covered conveyors direct from the excavation area to the treatment plant. For bulk hauling to the ERSDF, the trucks would be loaded inside covered areas (e.g., the excavation enclosure). Nevertheless, some incidental spillage would be expected during maintenance and routine operations that could result in contaminated surface water. Contaminated water would be collected and treated in the wastewater treatment system (see Section 6.2.8).

\subsubsection{Wastewater Treatment}

Some alternatives would include a wastewater treatment system to treat and discharge process wastewater, equipment decontamination washwater, and contaminated surface water. The system would be skid-mounted for ease of installation. A process flow diagram for the wastewater treatment system is shown in Figure 6-3. The design assumptions for wastewater treatment are:

Treatment units: Distillation evaporation Wiped-film evaporator Fixation of evaporator sludge

System capacity: $\quad 1 \mathrm{~L} / \mathrm{sec}(17 \mathrm{gpm})$

Evaporator feed: $\quad 2,000 \mathrm{mg} / \mathrm{L}$ TDS (total dissolved solids)

Concentrate: $\quad 100,000 \mathrm{mg} / \mathrm{l}$ TDS

Evaporator sludge: $35 \%$ moisture

Sludge disposal: ERSDF 


\subsection{DESCRIPTION OF ALTERNATIVES}

\subsubsection{Alternative A: No Action}

The NCP requires that a "no action" alternative be included in remediation alternatives to provide a baseline for comparison to other alternatives. This alternative assumes the site is left in its current state, but without any of the currently active institutional controls. This alternative includes the existing clean soil cover $(46-61 \mathrm{~cm}$ [18-24 in.] thick) that was placed over the contaminated areas as an interim remedial measure. As required under CERCLA, performance monitoring would be implemented to monitor the actual effectiveness of the remedy (for comparison to expected performance).

\subsubsection{Alternative B: Institutional Controls}

This alternative consists of implementing and maintaining institutional controls as described in Section 6.2.1. This alternative also includes maintenance of the existing clean soil cover (46-61 cm [18-24 in.] thick) that was placed over the contaminated areas as an interim remedial measure. Site monitoring would track the performance of the remedy.

\subsubsection{Alternative C: Biointrusion Barrier}

This alternative consists of the following key elements:

1. Covering all contaminated areas with a barrier designed to prevent vegetative growth and biological intrusion.

2. Tmplementing and maintaining institutional controls and monitoring (Sections 6.2.1 and 6.2.2).

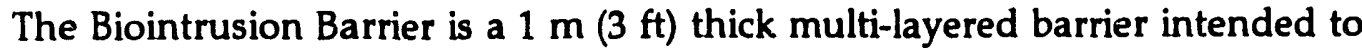
prevent contact with contaminated soils and to prevent plants or burrowing animals from bringing contaminated soil to the surface (i.e., contaminant migration via a biological pathway). Figure 6-4 shows a cross-section of this barrier design.

The primary functional layer is the crushed basalt, which provides a physical barrier to burrowing animals and plant roots. The overlying layers provide a soil filter to prevent fines (e.g., silts and clays) from entering the basalt layer and reducing its effectiveness. The top gravel layer is intended to resist erosion. The ability of this Barrier to exclude deep nesting insects such as ants is not certain.

Unlike the other barriers under consideration, the Biointrusion Barrier does not attempt to decrease infiltration of water through the contaminated soils. Because the basalt layer is very coarse with no fines, percolating water would quickly drain through this layer and it would not retain moisture through capillary tension. It is, therefore, expected to be dry most of the time. Consequently, there will be no moisture to attract downward development of root systems. However, most of the rainfall or snow melt on the cover 
surface will quickly percolate through the barrier into the underlying contaminated soil. This is expected to increase infiltration over current conditions.

\subsubsection{Alternative D: RCRA Barrier}

This alternative consists of the following key elements:

1. Covering all contaminated areas with a low-permeability barrier based on designs for hazardous waste sites.

2. Implementing and maintaining institutional controls and monitoring (Sections 6.2.1 and 6.2.2).

The RCRA Barrier is a multi-layered barrier intended to minimize infiltration, prevent biological intrusion, and resist erosion. The design presented here meets minimum technology requirements (MTRs) contained in 40 CFR 264.301 for hazardous wastes, but is a modification of the design recommended in EPA guidance (EPA 1989). Figure 6-5 shows a cross-section of this barrier design.

The major components of the RCRA Barrier are as follows:

- The top two layers consist of silt/gravel admix and silt. The purpose of these layers is to minimize infiltration. This is accomplished by promoting runoff, providing suitable soil for shallow-rooted vegetation that will enhance evapotranspiration, and providing nearsurface storage capacity for infiltration so that it can be removed by evapotranspiration and better support plant growth. Field lysimeter tests on this material indicate essentially zero recharge (Gee et al. 1992). The gravel mixed into the upper meter of the barrier is intended to resist erosion and burrowing animals. Plant cover will also resist erosion.

- The middle layer is a drainage layer to direct any infiltration percolating through the top layers away from the capped area. However, very little water is expected to penetrate the top evapotranspiration layers in the arid Hanford climate.

- The bottom layer of the RCRA Barrier is a coated asphaltic concrete that is intended to function as a low-permeability barrier to infiltration. Any water that percolates through the upper layers would be stopped by the asphalt and would drain laterally to the barrier edge. The asphalt is also expected to prevent biological intrusion (e.g., deep root systems or animal burrowing). The lowpermeability barrier in a typical RCRA design consists of a synthetic liner (e.g., HDPE) over recompacted clay. However, use of synthetic liners is relatively new and their performance over long time periods is unknown. Synthetic liners are known to be susceptible to tearing under stresses introduced by ground movement (e.g., settlement). Clay is susceptible to desiccation in the arid climate of this site, which 
would increase the permeability of the clay and thus lessen or destroy its effectiveness as a barrier to infiltration. Asphalt has been chosen by WHC a suitable low-permeability barrier based on predictions of its longevity under site conditions.

\subsubsection{Alternative E: Hanford Barrier}

This alternative consists of the following key elements:

1. Covering all contaminated areas with the Hanford Barrier.

2. Implementing and maintaining institutional controls and monitoring (Sections 6.2.1 and 6.2.2).

The Hanford Barrier is a multi-layer cover system designed to minimize infiltration, prevent biological intrusion, and resist erosion for a design life of at least one thousand years. It is intended to be an essentially permanent surface barrier for isolating radioactive wastes in arid climates. Figure 6-6 shows a cross-section of this barrier design.

The major components of this system are as follows:

- The top two layers are silt/gravel admix and silt. The purpose of this section is to promote runoff, minimize infiltration, and provide nearsurface storage capacity for infiltration so that it can be removed by evapotranspiration. Field lysimeter tests on this material indicate essentially zero recharge (Gee et al. 1992). The silt will also provide a suitable medium to support shallow-rooted vegetation, which in turn will enhance evapotranspiration and resist erosion. The gravel mixed into the upper meter of the barrier is intended to resist erosion.

The next layers consist of a graded soil filter overlying a layer of crushed basalt. This section is intended to form a capillary break, provided that unsaturated conditions are maintained above the crushed basalt, so that water will be transmitted across this zone only via vapor transport. Vapor transport of water through soil is expected to reduce infiltration to negligible amounts. The crushed basalt layer is also expected to deter deep-rooted vegetation. The geotextile filter at the top of this section is intended to facilitate construction by preventing mixing of soil types; its longevity is not pertinent to barrier performance.

- The lower portion of the barrier, consisting of drainage rock and asphaltic concrete, is designed to function as a low-permeability moisture barrier. The asphaltic concrete incorporates a spray-applied styrene-butadiene modified top coat. Any moisture which passes through the upper layers would be stopped by the asphalt and would drain laterally to the barrier edge. The asphalt is also expected to prevent biological intrusion (i.e., plant roots or burrowing mammals or insects). 


\subsubsection{Alternative F: Soil Washing}

This alternative consists of the following key elements:

1. Excavating soil with the highest contamination.

2. Treating excavated soil by a soil washing process to reduce the quantity of contaminated material remaining after treatment.

3. Backfilling treated soils meeting remedial action objectives in the excavation.

4. Covering the backfilled excavation with the RCRA Barrier.

5. Disposing of sludge or contaminated soil from treatment in the ERSDF (or geologic repository, if required).

6. Implementing and maintaining institutional controls and monitoring (see Sections 6.2.1 and 6.2.2).

The purpose of this alternative is to minimize the volume of soil requiring disposal by obtaining a soil fraction or treatment sludge with higher contaminant cincentrations than the feed soil. As discussed in Sections 4.4.2 and 4.4.3, this can be accomplished by physical soil washing (primarily a separation process) or chemical soil washing (primarily an extraction process). Physical soil washing is used in this alternative to represent both forms of soil washing because it would be easier to implement and less expensive than chemical soil washing, and thus results in the best evaluation of the soil washing alternatives (Alternatives $\mathrm{F}$ and $\mathrm{G}$ ). Because of the lack of site-specific treatability data, it has been assumed that this treatment would be effective. If these alternatives appear likely to be selected, then a treatability study would be needed to determine the actual effectiveness of physical and/or chemical soil washing. However, if the alternatives are unlikely to be selected even with the assumed effectiveness, then no treatability study is necessary.

Physical soil washing separates soil fractions with high concentrations of contaminants from relatively clean soil fractions. Very often, contaminants are found to have preferentially sorbed to the fine soils (silt and clay), leaving the coarser soils (gravel and sand) relatively clean. Figure 6-7 presents the process flow diagram for soil washing. The design assumptions for soil washing are:

$\begin{array}{ll}\text { Quantity of soil treated: } & 240,000 \mathrm{~m}^{3}\left(312,000 \mathrm{yd}^{3}\right) \\ & 487,000 \text { tonnes }(443,000 \text { tons) } \\ \text { Treatment time: } & 5 \text { years } \\ \text { Operating basis: } & 220 \text { days/year, } 24 \text { hours/day (60\% on-line) } \\ \text { Processing rate } & 18 \text { tonnes/hr }(16.8 \text { tons } / \mathrm{hr}) \\ \text { In-place soil fines: } & 6 \% \text { (average) } \\ \text { Percent soil for disposal: } & 15 \% \text { (contaminated fines from treatment) }\end{array}$

Excavation is described in Section 6.2.3. Design assumptions for ERSDF disposal are given in Section 6.2.5. A RCRA barrier (see Section 6.3.4) would be placed to minimize 
infiltration through untreated contaminated soil and thereby meet groundwater ARARs for uranium. Design assumptions for surface barriers are given in Section 6.2.4.

The soil washing process would begin with screening through a grizzly to remove large particles or other materials (e.g., broken piping) in the feed soil that would jam equipment. The screened soil would be collected in a feed hopper. From the hopper, a bucket conveyor would take the soil to a rotary washer, which would essentially be a trommel screen without the screen. The soil would be mixed with water at the washer inlet. The tumbling action would break up soil clods and remove fine soils from the surface of coarse particles. From the washer, the soil-water slurry would pass through two screens in series (or a single multi-stage screen). The first screen would remove soil particles larger than $19 \mathrm{~mm}(3 / 4 \mathrm{in}$.$) , and the second ivould remove particles larger than 2$ $\mathrm{mm}(9 \mathrm{mesh})$. These soils would be tested against the cleanup standard. This cleanup standard would be the same standard used for excavating contaminated soils (see Section 6.2.2). Soils meeting the cleanup standard would be used as clean backfill for the excavation. Soils not meeting the cleanup standard would be either recycled for further treatment or transported to the ERSDF for disposal, depending on the degree of residual contamination. It is assumed that nearly all of these coarse soils can be washed to meet the cleanup standard.

Sand particles (smaller than $2 \mathrm{~mm}$ ) would be separated from the fines (smaller than $74 \mu \mathrm{m}$ [200 mesh]) in a hydrocyclone (wet cyclone). The sand would then be washed by attrition scrubbing, which uses particle abrasion during vigorous mixing to scrub off the more-contaminated surface of the particles. Attrition scrubbing produces additional fines (i.e., the removed surfaces). Froth from soil washing (i.e., floating soil particles) would be combined with the other fines for dewatering and disposal. The soil-water slurry from attrition scrubbing would go through a hydrocyclone to remove fines; separation at $149 \mu \mathrm{m}$ (100 mesh) is assumed to account for inefficiency in separation (i.e., to ensure nearly all of the silt and clay is removed) and because very fine sand may not meet the cleanup standard. Water from the sand fraction would be drained using a dewatering screen. The sand would then be tested against the cleanup standard. As with the coarser soils removed in screening, the sand fraction could be recycled or disposed if it does not meet the cleanup standard. Soil meeting the cleanup standard would be used as clean backfill for the excavation.

The slurry of fines and water would go to a clarifier to allow gravity separation of the solids. Chemical additives (typically polymers) would be used to enhance settling. Solids that do not settle would be removed from the water by multi-media filtration before recycling. Filter backwash would go to the clarifier. The soil washing process requires addition of water (makeup water) to replace water retained by treated soils (both clean and contaminated fractions). Additional water treatment is required only on completion of soil washing, to treat contaminated water in equipment and piping.

The fines would be dewatered to approximately $50 \%$ moisture content (by volume) using a filter press. If the dewatered fines have low activity, they would be loaded directly into trucks for bulk transport to the ERSDF for disposal. High-activity fines would be containerized and loaded on flat trucks for ERSDF disposal. It is assumed that a standard steel box with dimensions of $1.2 \mathrm{~m} \times 0.6 \mathrm{~m} \times 1.8 \mathrm{~m}(4 \mathrm{ft} \times 2 \mathrm{ft} \times 6 \mathrm{ft}$ ) would be used. 
The soil size fractions are provided here for illustration; the appropriate screen meshes would be determined in a treatability study. Likewise, the treatability study would determine the percentages of clean soil and contaminated fines that would be obtained.

The treatment plant would be within a shielded concrete building to contain contaminated materials and minimize exposure to radiation during treatment. The treatment system would be heavily automated to minimize exposure of operation and maintenance personnel to the contaminants. Robotics within the plant will consist of remotely operated master-slave manipulators for both routine and non-routine adjustments to the process equipment. Crane-mounted lifting and handling devices and other remote manipulators would facilitate remote maintenance as well as operations.

\subsubsection{Alternative G: Excavation and Soil Washing with Vitrification}

This alternative consists of the following key elements:

1. Excavating soil with the highest contamination.

2. Treating excavated soil by a soil washing process to reduce the quantity of contaminated material remaining after treatment.

3. Backfilling treated soils meeting remedial action objectives in the excavation.

4. Covering the backfilled excavation with the RCRA Barrier.

5. Vitrifying sludge or contaminated soil from treatment.

6. Disposing of vitrified sludge or contaminated soil from treatment in the ERSDF (or geologic repository, if required).

7. Implementing and maintaining institutional controls and monitoring (see Sections 6.2.1 and 6.2.2).

Soil excavation, transport to the soil washing facilities, and the soil washing process would be the same as described for Alternative F (see Section 6.3.6). Figure 6-8 presents a process flow diagram for vitrification. Design assumptions for this alternative is the same as for Alternative $\mathrm{F}$, with the following additions for vitrification:

Soil treated:

Quantity of soil treated:

Dewatered fines from soil washing

Treatment time:

$173,000 \mathrm{~m}^{3}\left(133,000 \mathrm{yd}^{3}\right)$

Operating basis:

5 years (simultaneous with soil washing)

Processing rate

220 days/year, 24 hours/day ( $60 \%$ on-line)

2.3 dry tonnes $/ \mathrm{hr}$ ( 2.5 tons $/ \mathrm{hr}$ )

4.5 wet tonnes $/ \mathrm{hr}(5.0 \mathrm{tons} / \mathrm{hr}$ )

Soda ash addition:

0.3 tonnes $/ \mathrm{hr}(0.3$ tons $/ \mathrm{hr})$

Off-gases (mostly $\mathrm{CO}_{2}$ ):

0.15 tonnes $/ \mathrm{hr}(0.17$ tons $/ \mathrm{hr})$ 
Excavation is described in Section 6.2.3. Disign assumptions for ERSDF disposal are given in Section 6.2.5. A RCRA barrier (see Section 6.3.4) would be placed to minimize infiltration through untreated contaminated soil and thereby meet groundwater ARARs for uranium. Design assumptions for surface barriers are given in Section 6.2.4.

Following soil washing, the dewatered, contaminated soil fines would be transported by covered conveyor to an on-site vitrification plant. At the vitrification facility, soda ash would be added to the contaminated soil to act as flux. The mixture would be melted together in a plasma-arc furnace or similar thermal unit. The molten material would be poured into steel boxes (the same type as used for high-activity fines in Alternative $G$ ) which would serve as molds and would provide added safety and ease of handling. After cooling, the vitrified materials would be loaded onto shielded trucks and transported to the ERSDF for disposal. The vitrification process has an air discharge that would be treated and monitored.

The treatment plants (soil washing and vitrification) would be contained within separate shielded concrete buildings to contain contaminated materials and minimize exposure to radiation during treatment. The treatment system would be heavily automated to minimize exposure of operation and maintenance personnel to the contaminants. Robotics within the plant will consist of remotely operated master-slave manipulators for both routine and non-routine adjustments to the process equipment. Crane-mounted lifting and handling devices and other remote manipulators would facilitate remote maintenance as well as operations.

\subsubsection{Alternative H: Excavation and Fixation}

This alternative consists of the following key elements:

1. Excavaing soil with the highest contamination.

2. Treating excavated soil by firation (chemical stabilization) to immobilize contaminants.

3. Returning treated soil to the excavation.

4. Covering the backfilled excavation with the "CRA Barrier.

5. Implementing an $j$ maintaining institutional controls and monitoring (Sections 6.2.1 and 6.2.2).

Fixation would provide treatment to immobilize contaminants in excavated site soils. A process flow diagram for fixation is provided in Figure 6-9. The design assumptions for this alternative are:

$\begin{array}{ll}\text { Quantity of soil treated: } & 240,000 \mathrm{~m}^{3}\left(312,000 \mathrm{yd}^{3}\right) \\ & 405,600 \text { tonnes }(447,100 \text { tons }) \\ \text { Treatment time: } & 5 \text { years } \\ \text { Operating basis: } & 220 \text { days/year, } 24 \text { hours } / \text { day }(60 \% \text { online) } \\ \text { Processing rate } & 15.2 \text { tonnes } / \mathrm{hr}(16.7 \text { tons } / \mathrm{hr})\end{array}$




$\begin{array}{ll}\text { Fixation mixture: } & 70 \% \text { soil } \\ & 15 \% \text { portland cement } \\ & 5 \% \text { fly ash } \\ & 10 \% \text { water }\end{array}$

Volume increase due to treatment: $25 \%$

Excavation is described in Section 6.2.3. Design assumptions for ERSDF disposal are given in Section 6.2.5. A RCRA barrier (Section 6.3.4) would be placed to minimize infiltration through untreated contaminated soil and thereby meet groundwater ARARs for uranium. Design assumptions for surface barriers are given in Section 6.2.4.

Soil would be preprocessed for fixation by screening through a grizzly to reject large-size particles that could interfere with equipment or treatment effectiveness. The remaining soils would then be crushed to less than $19 \mathrm{~mm}(0.75$ in.) size. The crushed materials would be mixed with fly ash, cement, and water. The actual mix would need to be determined with treatability studies. Treatability studies would also be needed to determine the types of cement and fly ash required to achieve the fixation and leachability properties desired in the treated soil.

The stabilization operations would be handled remotely behind shielding walls with the operators locat $d$ in areas of low (based on ALARA) or no radioactivity. The chemical storage and blending operations would not require remote operation but would require shielding to protect workers from the nearby soil crushing operation and soil/reagent mixing operations. Robotics within the plant will consist of remotely operated manipulators designed and constructed to permit full operation of the plant including all routine and non-routine adjustments to the process equipment. Crane mounted lifting and handling devices and other remote manipulators will be of sufficient strength and agility to permit precise handling of material and facilitate remote equipment repair and replacement.

\subsubsection{Alternative I: Excavation and ERSDF Disposal}

This alternative consists of the following key elements:

1. Excavating soil with the highest contamination.

2. Disposing of excavated soil in the ERSDF (or geologic repository for some soil, if required).

3. Backfilling the excavation with clean soil.

4. Covering the backfilled excavation with the RCRA Barrier.

5. Implementing and maintaining institutional controls and monitoring (Sections 6.2.1 and 6.2.2).

Excavation is described in Section 6.2.3. Soil would be transported in bulk in trucks from the site excavation to the ERSDF. To avoid risks due to above-ground storage of contaminated soil, excavation would not begin until an ERSDF cell has been constructed 
and permitted for site wastes. The estimated volume of soil requiring disposal at ERSDF is the same amount of soil requiring treatment for Alternatives $F, G$ and $\mathrm{H}-405,000$ tonnes (447,100 tons). Design assumptions for ERSDF disposal are given in Section 6.2.5. A RCRA barrier (Section 6.3.4) would be placed over the 200-BP-1 operable unit area to minimize infiltration through untreated contaminated soil and thereby meet groundwater ARARs for uranium. Design assumptions for surface barriers are given in Section 6.2.4.

\subsubsection{Alternative J: In-Situ Fixation}

This alternative consists of the following key elements:

1. Treating soil with the highest contaminant levels in place by fixation (chemical stabilization).

2. Covering treated area with the RCRA Barrier.

3. Implementing and maintaining institutional controls and monitoring (Sections 6.2.1 and 6.2.2).

The objective of fixation is to minimize the potential for migration of soil contaminants to groundwater. In-situ fixation (in-situ grouting) is intended to accomplish immobilization without the need for excavation that would create significant exposure of site workers to the contaminants. Fixation would also lower the permeability of the soil, which may lower the rate of leaching and of infiltration through the treated soil.

Figure 6-10 provides a process flow diagram for in-situ fixation. The area and volume of contaminated soil to be treated is the same as the area of soil considered for excavation. The design assumptions for in-situ fixation are:

Area treated:

Depth of treatment:

Treatment method:

Treatment rate:

Number of rigs:

Treatment time:

Fixation method:

Fixative application rate:

Mixing plant:

Permeability of treated soil: $10^{-6}$ to $10^{-7} \mathrm{~cm} / \mathrm{sec}\left(10^{-3}\right.$ to $10^{-4} \mathrm{ft} /$ day $)$ field permeability

A RCRA barrier (Section 6.3.4) would be placed to minimize infiltration through untreated contaminated soil and thereby meet groundwater ARARs for uranium. Design assumptions for surface barriers are given in Section 6.2.4.

In-situ fixation is a process where a fixation mixture is mixed into contaminated soils using mechanical agitators. For in-place fixation to the depths required for this site, augers that are capable of drilling into the soil as well as mixing would be used. Underground obstructions can impede or prevent auger mixing. At this site, these obstructions would 
include large boulders sometimes found in the subsurface and underground pipelines. Areas not accessible by auger drilling would be treated by jet grouting. Jet grouting applies the fixation mixture by pressure injection, but without the mixing accomplished by augering. Jet grouting should decrease the mobility of contaminants, but not as effectively as fixation with mixing. Mixing allows micro-encapsulation of contaminants; grout injection is more of an macro-encapsulation technique. Thus, the effectiveness of in-situ fixation at this site would be decreased where auger mixing is prevented.

The augers and grout circulation equipment would be contaminated by intimate contact with radioactive soil. The augers would be abandoned in place (i.e., left encased in the treated soil, which hardens when cured). Some components of the mixing plant would require extensive decontamination or disposal as radioactive waste.

Auger drilling can be messy. Careful stormwater management would be required. Berms would be used around the treatment area to prevent stormwater run-on. Contaminated stormwater would be collected and added to the fixation mixture (which requires addition of water).

Common fixation agents include portland cement, fly ash, and lime. A number of additives, primarily proprietary, are available that sometimes improve immobilization or other properties of the treated soil. These additives include silicates, zeolites, and clay minerals (e.g. bentonite). A site-specific treatability study would be required to determine the appropriate fixation additives and degree of immobilization that can be achieved.

Quality control of in-situ fixation could be difficult. The mixing is not as thorough as for above-ground treatment, and the treated soil is therefore less homogenous. Also, visual observations of treated soil cannot be made in addition to sample testing. Sampling of treated soil requires drilling, which results in fewer and less representative samples when compared to above-ground treatment. Periodic coring would be used to obtain soil samples for leachate testing and other quality control tests. Properties of the fixation mixture (e.g., slump) and rates of fixative addition would be monitored.

\subsection{EVALUATION OF REMEDIATION ALTERNATIVES}

A detailed evaluation of the remediation alternatives is presented in this section. Each alternative is evaluated using seven criteria specified in the NCP in 40 CFR 300.430 . The results of this evaluation are used in the comparative evaluation in Chapter 7 to support remedy selection. The seven criteria are:

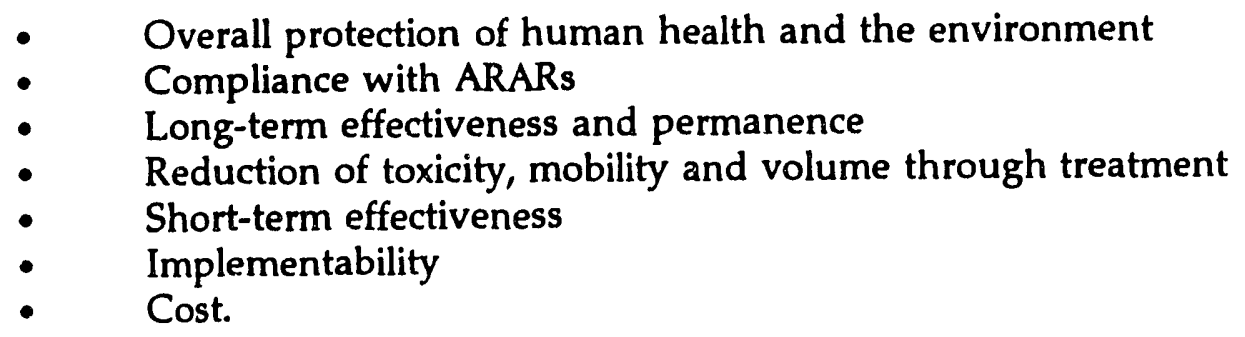

Two additional criteria required for evaluation are state acceptance and community acceptance. The evaluation of state acceptance will be included after the FS is reviewed by 
Ecology. Community acceptance will be evaluated after the proposed plan has been prepared and reviewed, and will be considered in the decision documented in the Record of Decision (ROD).

\subsubsection{Common Evaluation Elements}

A number of key considerations affect the evaluation of several alternatives in the same or similar ways. To avoid repetition and aid clarity, these considerations are discussed in this section.

6.4.1.1 Overall Protection of Human Health and the Environment. In accordance with the NCP, this criteria is used to assess the ability of the alternatives to adequately protect human health and the environment, in both the short- and long-term. Alternatives are assessed for their ability to meet the RAOs, which were established in Section 3.2. This criteria is defined in the NCP as a threshold criteria, which all alternatives must meet.

All of the alternatives retained for detailed analysis are capable of meeting this criteria to differing degrees. The primary differences in the alternatives relate to the potential for significant short-term impacts, primarily to workers engaged in remediation activities, for those alternatives that involve excavation and potential for exposure to radiation. An evaluation is provided in Section 6.4.2 of each of the alternatives overall protectiveness, considering both long and short-term effectiveness.

Institutional controls are included with all alternatives (with the exception of Alternative A - No Action) to ensure overall protection of human health and the environment. Since the primary contaminants of concern are radionuclides which cannot be destroyed, some form of containment with institutional controls will be required with all of the remaining alternatives.

The primary pathways of concern for the 200-BP-1 operable unit are direct exposure to contaminated soils and future long-term potential for exposure via the groundwater pathway. For direct external exposure to occur, contaminated materials would have to be exposed by removal of the overlying non-contaminated soils, and any barriers that were placed over the site in conjunction with one of the other alternatives. These materials could be brought to the surface as a result of biological intrusi, $n$ or human activities.

Institutional controls can be effective in limiting risk by preventing human exposure to contaminated site soils and groundwater. Institutional controls can, therefore, mitigate the effects of any incremental exposure to site contaminants. The Institutional Controls alternative also includes maintenance activities for at least 100 years to prevent deeprooting plants and burrowing animals or deep-nesting insects from becoming established at the site. Maintenance of the soil cover and/or any barrier installed in conjunction with one of the other alternatives would also be conducted.

The key concern with institutional controls is permanence. Institutional controls rely on active intervention (fencing that requires maintenance, enforcement of land and groundwater use restrictions, etc.) to be effective. The DOE Order $5820.2 \mathrm{~A}$ directs evaluations to assume that institutional controls are lost 100 years after remediation. For 
comparison, the barrier and treatment alternatives will remain effective even without maintenance for a long time, provided the barriers are not destroyed by human activities.

The Institutional Control alternative includes some on-site activities such as fencing and burying warning disks. These activities would not involve significant exposure to contaminated soils, and worker risk to implement institutional controls is, therefore, negligible.

6.4.1.2 Compliance with ARARs. Compliance with ARARs is also a threshold criterion that must be met by the preferred alternative. Evaluation of this criterion involves determining if the alternative will meet all the applicable or relevant and appropriate federal and state ARARs described in Section 3.1. Final determination of ARARs will be made by EPA as the Lead Regulatory Agency in consultation with Ecology and DOE. As described in Section 3.1, if an ARAR is not met, the basis for justifying one of the six waivers allowed under CERCLA may be provided. If a waiver is not possible, the alternative must be eliminated from further consideration.

Contaminant-Specific ARARs. As indicated in Section 3.1, several of the federal regulations that are potential ARARs include performance standards for groundwater protection based on the drinking water MCLs in 40 CFR 141. Determination of the appropriate ARAR for long-term performance is needed to determine compliance with ARARs for the various alternatives evaluated in this FS.

A performance standard of 1,000 years is currently required in 40 CFR 191 . The proposed rule published February 10, 1993 (58 FR 7924) increases this performance standard to 10,000 years. Although this regulation is not applicable because the contaminated soils do not meet the definition of waste subject to the requirements of 40 CFR 191, the longterm performance standards are potentially relevant and appropriate because of the presence of the long-lived radionuclide uranium that could impact groundwater within this time frame (vadose zone modeling results predict that plutonium will not impact groundwater within this time frame). However, the regulations are meant to be applied to engineered geologic repositories such as the WIPP facility and Yucca Mountain. Therefore, these performance standards are not considered ARARs for the 200-BP-1 operable unit.

Standards for long-term performance are also contained in 40 CFR 192. These regulations require remedial actions taken to stabilize uranium and thorium mill tailings be designed to be effective for up to 1,000 years to the extent reasonably achievable, and no less than 200 years for any case. This requirement, although not applicable to the 200-BP-1 operable unit, is considered relevant and appropriate because of the presence of uranium as a contaminant of concern.

DOE has recently proposed rulemaking in 10 CFR 834 , which promulgate as regulation, standards for protection of the public and the environment from radiation currently addressed in DOE Order 5400.5. These regulations include performance standards requiring that potential effects be assessed over the long term (greater than 1,000 years). Until promulgated, the DOE order and proposed rulemaking are TBCs. However, the 10 CFR 834 regulations will be applicable to remedial actions at 200-BP-1 when promulgated. 
All the alternatives provide for compliance with contaminant-specific ARARs described in Section 3.1, with the exception of the current discharges of technetium-99, cobalt -60 , and nitrate, and future potential discharges of uranium. Based on information provided in the Phase I RI Report, technetium- 99 and cobalt- 60 are currently discharging to groundwater at concentrations resulting in exceedance of MTCA Method B standards. Nitrate is also discharging to groundwater in concentrations that contribut ' $\mathrm{S}$ area contamination in excess of the drinking water MCL. None of the alternatives will meet these standards for technetium-99, cobalt-60, and nitrate. Therefore, if these standards are determined to be ARARs, an application for a waiver will be necessary.

The basis for the waiver will include:

- The concentrations of technetium- 99 and cobalt-60 are already below drinking water MCLs and are declining toward the MTCA Method B standard, and the concentration peak has long since reached groundwater

- The nitrate concentration peak has long since reached groundwater and is currently declining in concentration

- Upgradient groundwater concentrations of nitrate attributable from other sources are in excess of the drinking water MCL, and the $200-\mathrm{BP}-1$ operable unit is only contributing an additional $10-20 \mathrm{mg} / \mathrm{L}$ (as $\mathrm{NO}_{3}$ )

- Given the groundwater contamination already present from other sources, the cost of adhering to the standard far outweighs any marginal benefit to human health and the environment

- The added impacts to groundwater from this operable unit for technetium-99, cobalt-60, and nitrate can be most effectively addressed in the 200 East Groundwater Aggregate Area remediation, if needed.

Uranium will eventually reach groundwater in hundreds to thousands of years, depending on the infiltration rates assumed in the vadose zone modeling, at concentrations in excess of drinking water MCLs. Depending on the alternative selected and it's effect on infiltration, and depending on the final ARARs determination, a waiver may be required. However, if the long-term performance standards of 1,000 years, provided in 10 CFR 192 and proposed in rulemaking by DOE in 10 CFR 834, are determined to be the appropriate ARAR, no waiver will be required for most alternatives. The exceptions include No Action, Institutional Controls and the Biointrusion Barrier alternatives.

The basis for the uranium waiver, if required, will likely include:

- $\quad$ The vadose zone modeling was conservative and probably overestimates the future groundwater concentrations

- Uranium concentrations will not exceed the standard for hundreds of years under current conditions. 
Location-Specific ARARs. As stated in Section 3.1, no location-specific ARARs have been identified for the 200-BP-1 operable unit.

Action-Specific ARARs. Compliance with action-specific ARARs described in Section 3.1 will be required for all alternatives. The most significant action-specific ARARs apply to those alternatives that include excavation and handling of radioactive materials. The action-specific ARARs that may apply to these alternatives include:

- National Emissions Standards for Hazardous Air Pollutants (NESHAPs) for Emissions of Radionuclides other than Radon from DOE Facilities (40 CFR 61, Subpart H)

- $\quad$ NRC Standards for Protection Against Radiation (10 CFR 20)

- NRC Requirements for Packaging and Transportation of Radioactive Material (10 CFR 71)

- Health and Environmental Protection Standards for Uranium and Thorium Mill Tailings (40 CFR 192)

- Occupational Safety and Health Administration (OSHA) Standards (29-CFR 1926 and 1910)

- $\quad$ National Ambient Air Quality Standards (40 CFR 50)

- Washington General Regulations for Air Pollution (WAC 173-400)

- Washington Ambient Air Quality Standards and Emission Limits for Radionuclides (WAC 173-480)

- Washington Safety and Health Standards (WAC 296-24)

- Washington Model Toxics Control Act (WAC 173-340)

- Washington Radiation Protection Standards (WAC 246).

Compliance with the action-specific requirements of the NESHAPs would be achieved through reporting and record-keeping as required. Shielding, remote operation and other engineering controls, and worker monitoring would be used to achieve compliance with the NRC, OSHA and Washington health and safety standards. In addition, all construction activities would follow OSHA and Washington Industrial Safety and Health Administration (WISHA) practices for worker safety. Installation of best available radionuclide control technology (BARCT) and any additional air pollution control technology including reasonably available control technology (RACT) and best available control technology (BACT) would be used to achieve compliance with Federal and Washington State air pollution regulations for control of dust, radionuclide and other emissions to levels required by the referenced regulations.

Additional action-specific ARARs include federal RCRA regulations and Washington State Dangerous Waste Regulations (which are substantially equivalent to the federal 
regulations). Perhaps the most significant portions of these regulations are the closure performance standards and requirements for landfill closure and post-closure care. The closure performance standards are found in 40 CFR Part 264.111 and WAC 173-303-610(2). The landfill closure and post-closure care requirements are found in 40 CFR part 264.310 and WAC 173-303-665(6). These regulations are not applicable to the 200-BP-1 operable unit because the site is not a facility regulated under RCRA or State Dangerous Waste Regulations. However, the closure performance standards are relevant and appropriate to all alternatives and some of the landfill closure and post-closure care requirements are potentially relevant and appropriate to the barrier alternatives.

The closure performance standards require that facilities be closed in a manner that: minimizes the need for further maintenance; controls, minimizes or eliminates to the extent necessary to protect human health and the environment, post-closure escape of dangerous waste, dangerous constituents, leachate, contaminated run-off, or dangerous waste decomposition products to the ground, surface water, groundwater, or the atmosphere; and returns the land to the appearance and use of surrounding land areas to the degree possible given the nature of the previous dangerous waste activity. Other evaluation criteria (i.e. overall protection of human health and the environment, long-term effectiveness, and short-term effectiveness) address requirements similar to the performance standards. Therefore, the alternatives will not be evaluated independently for compliance with this ARAR.

The RCRA landfill closure and post-closure care requirements include minimum design requirements for the final landfill cover. The cover must be designed to:

- Provide long-term minimization of migration of liquids through the closed landfill;

- Function with minimum maintenance;

- $\quad$ Promote drainage and minimize erosion or abrasion of the cover;

- Accommodate settling and subsidence so that the cover's integrity is maintained; and

- Have a permeability less than or equal to the permeability of any bottom liner or natural subsoils present.

The Hanford Barrier and modified RCRA Barrier have been specifically designed to ensure equivalency with these requirements. The Biointrusion Barrier was not designed to meet these requirements and will not comply if this ARAR is determined to be relevant and appropriate for the 200-BP-1 operable unit.

6.4.1.3 Long-Term Effectiveness and Permanence. As stated in the NCP, the alternatives are evaluated to determine the long-term effectiveness and permanence they afford, as well as the degree of certainty that the alternative will prove successful (i.e., reliability). There are many common attributes between the various barrier alternatives that are different from common attributes of the various excavation and treatment alternatives in terms of this criteria. These common elements are discussed in this section, with the evaluation of each alternative provided in Section 6.4.2. 
Barrier Alternatives. The long term effectiveness afforded by barrier alternatives is estimated by evaluating the ability of the barrier to reduce the residual risk associated with the contaminants over which the barriers are placed. All the barrier alternatives provide long-term protection from direct contact and external exposure to radiation. The barriers also are designed to resist biological intrusion (i.e., plant roots, burrowing mammals, and ground-nesting insects), which can result in contaminant transport. Both the Hanford Barrier and the RCRA Barrier are also designed to protect groundwater by decreasing infiltration of water through contaminated soil. This is accomplished by including moisture retention layers to enhance evapotranspiration and low-permeability layers to act as moisture barriers and prevent infiltration. However, the Biointrusion Barrier is expected to result in increased infiltration over existing conditions. This is due to the lack of any fine grained materials to retain moisture for evapotranspiration, and to the lack of any low permeability layers to prevent infiltration. The result is an increase in residual risk via the groundwater pathway for the bioinfusion barrier relative to the other barrier alternatives.

The reliability of a barrier is evaluated as its ability to successfully provide long term effectiveness in reducing the risks associated with residual contaminants. All barrier alternatives are constructed of natural materials and are designed to be long-lasting if undisturbed, with minimal to no maintenance requirements. However, no barrier can, by itself, prevent intentional penetration by a technologically advanced society. Institutional controls are therefore an integral component of barrier effectiveness and permanence. However, the thicker and more robust the design, the more resistant it will be to both intentional and accidental intrusion and the less its effectiveness will depend on maintenance, should institutional controls be terminated.

Vadose zone transport modeling was conducted to evaluate the effects of various infiltration rates through the barriers and the long-term effectiveness in meeting the RAOs specified in Section 3.2 for groundwater protection. Infiltration rates of $1 \mathrm{~cm} / \mathrm{yr}(0.4 \mathrm{in} . / \mathrm{yr})$, $10 \mathrm{~cm} / \mathrm{yr}(4 \mathrm{in} / \mathrm{yr}$ ) and $22.5 \mathrm{~cm} / \mathrm{yr}(9 \mathrm{in} . / \mathrm{yr})$ were previously evaluated in the 200-BP-1 operable unit RI report. For comparison of effectiveness of barrier alternatives, additional simulations at infiltration rates of $0.01 \mathrm{~cm} / \mathrm{yr}(0.004 \mathrm{in} / \mathrm{yr})$ and $0.1 \mathrm{~cm} / \mathrm{yr}(0.04 \mathrm{in} . / \mathrm{yr})$ were modeled. All other input parameters to the model were the sarne as described in Section 5.2.3.2 of the 200-BP-1 operable unit RI Report (DOE/RL 1993).

The modeling results reported in the 200-BP-1 operable unit RI indicate that at an infiltration rate of $1 \mathrm{~cm} /$ year $(0.4 \mathrm{in} . / \mathrm{yr})$ (conservatively assumed for the current conditions), uranium concentrations will first exceed the proposed federal MCL of $30 \mathrm{pCi} / \mathrm{L}$ in a few hundred years and will peak at about 3,000 pCi/L in around 4,500 years (Figure 6-11). This information was used as the basis for comparison of the No Action and Institutional Controls alternative with the barrier alternatives.

An infiltration rate of $0.1 \mathrm{~cm} / \mathrm{yr}(0.04 \mathrm{in} / \mathrm{yr})$ may be more realistic of current conditions with a soil cover providing moisture retention and evapotranspiration. As shown in Figure 6-12, at this infiltration rate, uranium is expected to exceed the proposed $\mathrm{MCL}$ in approximately 6,000 years, and reach $90 \mathrm{pCi} / \mathrm{L}$ with concentiations still increasing at 10,000 years, which was the limit of the simulation conducted.

The estimated infiltration rate for both the RCRA Barrier and the Hanford Barrier is expected to be less than $0.1 \mathrm{~cm} / \mathrm{yr}(0.04 \mathrm{in} . / \mathrm{yr})$ and possibly less than $0.01 \mathrm{~cm} / \mathrm{yr}$ 
( $0.004 \mathrm{in} . / \mathrm{yr})$. Under the latter condition, the transport model predicts that uranium concentrations would not exceed the MCL for over 10,000 years (Figure 6-13).

The scenario at $10 \mathrm{~cm} / \mathrm{yr}$ (4 in./yr) was included in the 200-BP-1 operable unit RI report (DOE/RL 1993). The modeling was conducted assuming the $10 \mathrm{~cm} / \mathrm{yr}$ (4 in./yr) infiltration rate from the time discharge ceased. While this infiltration rate is considered unreasonably high for conditions that have existed since the cribs were used until the present, it is considered a reasonable maximum for infiltration through the Biointrusion Barrier. This Barrier allows drainage of infiltration with little evaporation and no transpiration.

Although the $10 \mathrm{~cm} / \mathrm{yr}(4 \mathrm{in} . / \mathrm{yr}$ ) rate of infiltration would not occur until after the Biointrusion Barrier was installed, the simulation conducted for the RI was considered sufficient for comparison purposes. As shown in Figure 6-14, at an infiltration rate of 10 $\mathrm{cm} / \mathrm{yr}$ uranium concentrations are predicted to have already approached the concentration of the proposed MCL by 1992 . Concentrations peak at about $8,000 \mathrm{pCi} / \mathrm{L}$ in approximately 500 years. A comparison of simulation results is shown on Figure 6-18.

It is important to note that the preceding discussion is based on vadose zone modeling of migration of uranium through unsaturated soils over very long time periods. Although this is the best information currently available, its uncertainty is very high. This uncertainty should be considered in determining the applicability and relevance of potential ARARs.

Excavation. Excavation is a key component of Alternatives $F, G, H$, and $I$. To avoid duplication, elements of long-term effectiveness common to the excavation aspects of all alternatives are addressed in the following discussion. Differences in each alternative are discussed in their respective evaluations in Section 6.4.2.

Vadose zone modeling was performed to evaluate the long-term effectiveness for protection of groundwater of removing contaminated soil (or immobilizing contaminants) down to depths of 15,30 , and $45 \mathrm{~m}(50,100$, and $150 \mathrm{ft})$. All simulations were done assuming $1 \mathrm{~cm} / \mathrm{yr}(0.4 \mathrm{in} . / \mathrm{yr})$ of recharge to allow comparison with the conservative estimate of existing conditions. The results are shown on Figures 6-15, 6-16 and 6-17. A comparison of modeling simulations is shown on Figure 6-18.

Concentrations were modelled for uranium at the top of the unconfined aquifer at the edge of the cribs. For the various excavation scenarios, the $30 \mathrm{pCi} / \mathrm{L}$ proposed $\mathrm{MCL}$ is first exceeded at around 700 years, regardless of depth of soil removal (or in-situ fixation). However, peak concentrations decrease significantly as more of the contaminated soils are removed. This indicates that uranium already present in deeper portions of the soil column is sufficient to cause exceedance of the uranium MCL. Thus, excavation or in-situ treatment to depths much greater than is technically feasible is required to prevent discharge of uranium to groundwater at concentrations that will result in exceedance of the proposed drinking water MCL. An excavation to $15 \mathrm{~m}(50 \mathrm{ft})$ was determined to be the practical limits for evaluating removal alternatives. As shown in Figure 6-15, at an infiltration rate of $1 \mathrm{~cm} / \mathrm{yr}(0.4 \mathrm{in} . / \mathrm{yr})$, removal of the upper $15-\mathrm{m}(50 \mathrm{ft})$ of soil reduces the peak concentration to about $1,800 \mathrm{pCi} / \mathrm{L}$ (compared to the peak concentration with no removal of $4,500 \mathrm{pCi} / \mathrm{L}$ ). However, the time until the drinking water $\mathrm{MCL}$ is reached 
remains essentially unchanged at about 700 years. As a result, the RCRA Barrier has been included with all excavation alternatives to ensure long-term effectiveness.

ERSDF Disposal. Removal and disposal of contaminated materials in the ERSDF would remove a corresponding component of the risk from both the direct contact and, to a more limited extent, groundwater pathways at the 200-BP-1 site. However, disposal at ERSDF merely relocates the risks to a central disposal site (i.e., centralized containment).

In general, it is preferable to have a central, well-controlled site rather than many scattered sites that would be harder to control and maintain. For sites where it is practical to remove all inntamination above remedial action levels, ERSDF disposal is particularly attractive to allow unrestricted use of the site after remediation. However, for the 200-BP-1 site, because significant contamination will remain following remediation, a barrier is included in all alternatives, and institutional controls are included to ensure the barrier's effectiveness. Therefore, much of the attractiveness of ERSDF disposal is not applicable for this site.

The relative effectiveness and permanence of ERSDF disposal and on-site containment depends on the ERSDF design and the barrier selected for the site. If the ERSDF is covered with the same barrier as the 200-BP-1 operable unit and is unlined, there is essentially no difference in the long-term effectiveness and permanence of containment on-site and ERSDF containment.

For this evaluation, it is assumed that the ERSDF has a low-permeability bottom liner and is covered with a Hanford Barrier. In this case, the redundant protection of the liner at the ERSDF would provide greater reliability than on-site containment alone at the 200-BP-1 operable unit. In addition, the ERSDF would also provide greater reliability and permanence than alternatives not using a Hanford Barrier.

The ERSDF is expected to be only slightly more effective at preventing direct contact or groundwater contamination than the Hanford Barrier, RCRA Barrier and the other alternatives with a low-permeability barrier.

6.4.1.4 Short-Term Effectiveness. Short-term effectiveness of the alternatives is evaluated to consider risks posed to the community during implementation, potential impacts to workers and the effectiveness and reliability of protective measures, and potential environmental impacts. Common aspects of the alternatives in terms of this criteria are provided in the following discussion. A detailed evaluation of the alternatives is provided in Section 6.4.2.

Barrier Alternatives. No off-site community impacts are associated with imiplementing the barrier alternatives. The highly-contaminated crib soils at the $200-B P-1$ site are overlain by about $3 \mathrm{~m}(10 \mathrm{ft})$ of soil with relatively low levels of contamination. These in turn are covered with an $18-24$ in $(46-61 \mathrm{~cm})$ thick layer of clean soil. The baseline risk assessment indicates that direct exposure under either thie industrial or residential scenario is not a health risk. Therefore it may be inferred that direct exposure during the few months required to construct any of the barriers over existing site soils will not be a significant health risk to workers, as well. In addition, the shielding increases with each layer of the barrier that is placed. Consequently, worker exposure to radiation is not a concern for these alternatives. 
The environmental impacts associated with the barrier alternatives relate to sources of the soils (borrow areas) used for construction. Soil sources for barrier construction are assumed to be developed within the Hanford Site. A borrow area would temporarily disrupt local vegetation and animal habitat. After construction has been completed, these areas could be recontoured and revegetated.

Excavation Alternatives. Control measures are available and can be readily implemented to ensure that risks to humans away from the 200-BP-1 site are negligible during remedial action. Fugitive dust emissions would be controlled by enclosing or covering areas where contaminated soil is being handled. Any discharges with potential off-site effects (e.g., air emissions or surface water discharge from treatment) would be subject to discharge limitations and monitoring to ensure protection of human health. Surface water run-on and run-off controls (Section 6.2.7) would minimize the quantity of surface water that could become contaminated and would prevent off-site transport of contaminated materials in surface water. Therefore, risks outside of the 200-BP-1 site would be negligible.

The primary human health impacts during remediation are associated with potential accidents and exposure to radiation by workers conducting the remedial activities. Statistics obtained from the U.S. Department of Labor (1992) for similar types of construction activities were used to calculate accident rates to workers conducting the remedial activities. These statistics may not be representative of accident rates on the Hanford Site due to high level of emphasis placed on worker health and safety. Hanford Site-specific statistics on worker accident rates have been requested and will be incorporated in the next draft of the FS, as appropriate.

Although the nuclear industry has data on worker exposure incidents, this information may not be readily transferrable to the remedial activities since remedial activities at major DOE sites have not occurred and the type of work involved is somewhat different than typically performed in the nuclear industry. As with accident rates, Hanford Site-specific statistics on average annual dose of radiation workers involved in similar activities has been requested, and will be incorporated in the next draft of the FS, as appropriate.

Risk to workers potentially exposed to radiation are based on the types of activities where such exposure may occur, the number of workers potentially exposed, and the duration of exposure. To allow for comparison of alternatives, the number of workers potentially exposed to the maximum allowable radiation exposure of 5 rem/year for raciiation workers, based on DOE Order 5480.11, Radiation Protection for Occupational Workers, was assumed. In practice, shielding and safety practices would be employed in accordance with the ALARA process and actual exposures may be less than the maximum allowable assumed for this FS. However, expected exposures would require detailed design and preparation of a Safety Analysis Report (SAR), which is beyond the scope of this FS.

Excavation of the highly contaminated upper $15 \mathrm{~m}(50 \mathrm{ft})$ of soil could result in significant worker exposure. Robotics would be used when possible when excavating highactivity soils, but some work in close proximity to radioactive contaminated soil could not be avoided. To protect against off-site exposure and surface water contamination, the excavation would be enclosed. The enclosure will tend to raise the concentration of contaminated dust in the work area, unless additional dust suppression measures (which have associated disadvantages) are used. Use of remotely-operated loaders is feasible. 
However, the processes for installing the retaining wall system are too complex to allow remote operation. Therefore, a high level of shielding will be required for these activities. Such shielding would consist of shielded operator enclosures with filtered air supplies.

Approximately 12 persons will be involved in constructing the soil-nailed wall, not including excavation personnel. It is estimated that the wall will require approximately 200 days (8-hour-shifts) to construct.

Excavation will require about 5 personnel, with a duration of about 750 days (8hour shifts). Some personnel, such as truck drivers, will not be in the zone of maximum exposure (the excavation) on a continuous basis. Other personnel, such as surveyors, supervisors, inspectors, mechanics, health technicians, etc., will be required. These personnel will not be in the zone of maximum contamination on an ongoing basis. For evaluation purposes, it is assumed that 10 personnel are exposed on a $50 \%$ basis. However, because of the need to shift out workers that have reached the allowable annual dose, it is assumed that 20 personnel/yr reach the $5 \mathrm{rem} / \mathrm{yr}$ allowable exposure during the 5 year duration of the excavation activities. Based on these assumptions, 500 total rems of exposure are estimated.

This is only an estimate for comparison purposes with other alternatives. A more precise exposure analysis depends on details of the excavation procedure, soil handling, and transportation, and would not be available until final design of the excavation system. Rerivtely-operated equipment will be used if $n^{\circ}$ cessary, and sufficient shielding and safety practices would be employed so that personnel exposure limits are as low as reasonably achievable and in no case greater than 5 rem/year effective annual dose equivalent, as required by DOE order 5480.11, Radiation Protection for Occupational Workers. However, robotic excavation is seldom practiced and difficult to perform. Shielding and additional protective measures will increase the difficulty of the work and greatly lower productivity. It is believed that adequate worker protection can be achieved, although cost impacts will be substantial and some equipment development will be required. These impacts are reflected in the cost estimates and evaluation of implementability of each of the alternatives that require such protective measures.

An additional source of risk is industrial accidents that would be expected on any construction project. The estimated level of activity for all excavation activities is about 17,500 person-days. This number is higher than the estimate for exposure because (1) derating factors for partial-time exposure are not appropriate and have not been applied and (2) activities involved with backfilling the excavated area, which do not have exposure risk, have been included. Based on statistics obtained by the U.S. Department of Labor (1992), the expected fatality rate for construction workers is about $6 \times 10^{-7}$ per person-day. This translates into a risk of 0.01 fatalities for excavation. Similarly, the lost-time accident rate for construction workers is about $2 \times 10^{-4}$ per person-day. On this basis, four lost-time accidents would be expected during the course of excavation.

The ecological impacts of all alternatives are considered roughly equivalent. In its current condition, the site has been significantly impacted by human activities. Considering the proximity to other operable units in the 200 Area, the impact of human activities will continue over the short term, with or without remedial action at this particular site. Similarly, eventual ecological restoration will be determined following completion of remedial activities throughout the 200 Area. 
ERSDF Disposal. Worker and environmental risk due to exposure to site contaminants would are possible during transportation to the ERSDF and placement of the contaminated material in the ERSDF cell. The greatest worker risk would not be radiation exposure, but transportation accidents due to congested truck traffic.

High-activity wastes would most likely be containerized and handled remotely with heavy shielding. Exposure in these cases would be low and is estimated to be negligible in comparison to exposure due to excavation or treatment.

Low-activity wastes $v$ uld be transported by truck in bulk. Shielding and some means of dust control would be required. Without strict controls, radiation exposure could easily exceed that of containerized handling of high-activity wastes. However, the exposure is estimated to be negligible in comparison to exposure due to excavation, and has therefore not been included in the detailed analysis.

6.4.1.5 General Cost Assumptions. Cost estimates are based on the alternative descriptions and design assumptions stated in the descriptions of the alternatives (Section 6.3). The cost estimates for the alternatives are presented on a net present value basis. Unit costs are based on typical costs for similar commercial work. However, the costs have been increased to reflect reduced productivity due to remote operation of equipment, safety requirements (e.g., shielding and dust containment), and similar factors. Unit costs were obtained in early 1993, or were adjusted to 1993 from earlier estimates. Unit costs for barrier materials and for engineering and construction surveillance were provided by Westinghouse Corporation. The net interest rate of $5 \%$ is the rate recommended by the EPA for feasibility study cost estimates. The maintenance and monitoring period of 30 years is the same as the hazardous waste post-closure period. However, a longer pericid would not significantly affect the present value cost of the alternatives. Cost esiimate tables for the alternatives are presented in Appendix A, starting with a summary cost table (Table A-1). Backup cost information is presented in Appendix B.

\subsubsection{Detailed Evaluation of Alternatives}

\subsubsection{Alternative A: No Action}

Overall Protection of Human Health and the Environment. Contamir.ated scis at this site are currently covered with a layer of clean soil. So long as this cover :'emains intact, it prevents direct contact with contaminated soils and limits exposure to radiation. In addition, the soil cover prevents contact with surface water runoff and wind, thereby eliminating migration of contaminants by these pathways. Under these conditions, the risk posed to human health or the environment by this site is substantially less than $1 \times 10^{-6}$ (DOE/RL 1993).

However, without continued institutional controls, unrestricted industrial use of the site could result in penetration of the barrier by human activities. In addition, biological intrusion such as the growth of deep-rooting plants or digging by burrowing animals (e.g., rodents or insects), could result in transport of contaminated soils to the surface, where exposure could occur. 
The No Action alternative provides better short-term effectivenes: and therefore, better overall protection of human health than the alternatives that require excavation and treatment and the in-situ fixation alternative, because no workers would be exposed to radiation. This alternative also does not include any potential for worker accidents that potentially could result from all the other alternatives (with the exception of Institutional Controls).

Compliance with Potential ARARs. The No Action alternative would meet all potential ARARs except those related to uranium, technetium-99, cobalt- 60 , and nitrate concentrations in groundwater as discussed in Section 6.4.1.2.

Long-Term Effectiveness and Permanence. While there is no current risk to human health and the environment, long-term effectiveness depends on the existing soil cover remaining intact. If the land were released for unrestricted use and if no other controls were in place, a variety of activities could occur than would present risk to human health and the environment. These activities and potential exposure could result from:

- Excavation into contaminated soil

- Agricultural use bringing radioactive contaminants into food products

- Erosion of the relatively thin soil cover

- Biointrusion into the contaminated soil and potential transport to the surface

- Use of contaminated groundwater beneath the site.

Therefore, no action (without institutional controls) does not provide long-term effectiveness and is not a permanent remedy.

Reduction of Toxicity, Mobility, and Volume Through Treatment. No treatment is provided by this alternative.

Short-Term Effectiveness. No exposure to site contaminants is associated with implementing this alternative. It therefore has high short-term effectiveness.

Implementability. Because no action is required for this alternative, it is the easiest alternative to implement.

Cost. The only costs associated with this alternative are for performance monitoring, which is required under the NCP for all alternatives. The estimated cost of this alternative is $\$ 1.14$ million (Table A-2). Assumptions for monitoring cost estimates were provided in Section 6.2.2. General assumptions used for all cost estimates are described in Section 6.4.1.5.

\subsubsection{Alternative B: Institutional Controls}

Overall Protection of Human Health and the Environment. As described in Section 6.4.1.1, this aiternative provides overall protection of human health and the environment, and institutional controls are included with all other alternatives. The 
baseline risk assessment for this site (DOE/RL 1993) shows that the site does not currently pose a threat to human health or the environment. As long as institutional controls are maintained, exposure is prevented and there is no risk. However, due to uncertainty as to the reliability of long-term institutional controls, this alternative is not as effective as the barrier or excavation and treatment alternatives that include additional protection in the event that institutional controls are terminated.

Institutional controls can be effective in limiting risk by preventing human exposure to contaminated site soils and groundwater. Institutional controls can, therefore, mitigate the effects of any incremental exposure to site contaminants. The Institutional Controls alternative also includes maintenance activities for at least 100 years to prevent deeprooting plants and burrowing animals or deep-nesting insects from becoming established at the site. Maintenance of the soil cover and/or any barrier installed in conjunction with one of the other alternatives would also be conducted.

The Institutional Control alternative includes some on-site activities such as fencing and burying warning disks. These activities would not involve significant exposure to contaminated soils, and worker risk to implement institutional controls is therefore negligible.

As with the No Action alternative, Institutional Controls does not pose the shortterm risk of accidents or radiation exposure to workers associated with the excavation and treatment alternatives and the In-Situ Fixation alternative. This alternative also does not pose significant worker risk due to accidents that could be associated with the heavy construction activities required to construct barriers.

Compliance with Potential ARARs. The Institutional Controls alternative would meet all potential ARARs to the same degree as No Action and with the exceptions related to uranium, technetium- 99 , cobalt- 60 , and nitrate concentrations in grourdwater as described in Section 6.4.1.2.

Long-Term Effectiveness and Permanence. By preventing exposure, institutional controls are effective at limiting risk to human health. With maintenance of the existing soil cover, direct exposure and off-site migration of contaminants in surface water or airborne dust is prevented. However, contaminant migration via deep-rooting plants or burrowirig animals ("biological intrusion") remains possible. This would be minimized by maintenance of the soil cover.

The key concern with institutional controls is permanence. Institutional controls rely on active intervention (fencing that requires maintenance, enforcement of land and groundwater use restrictions, etc.) to be effective. For comparison, barriers will remain effective even without maintenance for a long time. DOE Order 5820.2A directs evaluations to assume that institutional controls are lost 100 years after remediation.

Reduction of Toxicity, Mobility, and Volume Through Treatment. No treatment is provided by this alternative.

Short-Term Effectiveness. Establishing institutional controls will involve some onsite activities such as fencing and burying waming disks. These activitics would not 
involve significant potential for worker accidents or exposure to contaminated soils. Therefore, worker risk is negligible and short-term effectiveness is high.

Implementability. Placement of institutional controls on the 200-BP-1 operable unit involves only routine fence construction, shallow digging, and filing legal documents. This is the next easiest alternative to implement after Alternative A - No Action.

Cost. The estimated cost of this alternative is $\$ 1.24$ million (Table A-3).

Assumptions used for developing the cost estimate for Institutional Controls is 6.2.1 and monitoring cost assumptions are provided in Section 6.2.2. General assumptions for cost estimates are described in Section 6.4.1.5.

\subsubsection{Alternative C: Biointrusion Barrier}

Overall Protection of Human Health and the Environment. This alternative would provide a reasonably high degree of overall protection to human health and the environment, when included with Institutional Controls. Institutional controls provides much of the protection of human health and the environment for this alternative (Section 6.4.1.1). The Biointrusion Barrier provides additional protection over institutional controls alone for direct contact exposure to radiation. However, the design of this barrier would result in increased infiltration over current conditions, rapidly increasing the rate at which uranium impacts groundwater. Therefore, this alternative does not rate as high as Alternative B - Institutional Controls for overall protection of human health and the environment.

Compliance with ARARs. A waiver would likely be required for this alternative, since it does not meet the 1,000 year performance criteria for ensuring compliance with the drinking water MCLs for uranium, as discussed in Section 6.4.1.3. Otherwise, this alternative would meet all potential ARARs except those related to current discharges of technetium-99, cobalt-60, and nitrate, and the closure requirements for RCRA landfills described in Section 6.4.1.2.

Long-Term Effectiveness and Permanence. This alternative would provide longterm effectiveness and permanence through institutional controls and containment (Sections 6.4.1.1 and 6.4.1.3). The Biointrusion Barrier could provide a long-term effective barrier to human contact or biological intrusion. However, because the barrier is relatively thin and depends on several filter layers, it is potentially susceptible to disruption from human activities (e.g., traffic, agriculture, construction, etc.).

If the Biointrusion Barrier functions as intended for a few hundred years, it will provide significant protection for human health from external radiation exposure to the near surface contaminated soils. Although the design is primarily to provide a barrier to biotic intrusion, rather than achieving a certain lifetime, natural materials were specified with the idea of increasing longevity. No testing of this Barrier has been performed, and the expected lifetime is difficult to evaluate. However, it is possible that the Biointrusion Barrier could withstand erosion for a' few hundred years. Durability over 1,000 years must be considered low, and the ability to function over 10,000 years is highly unlikely.

Although the design of the Biointrusion Barrier seems reasonable, it has not been tested in the field. In addition, the Barrier may not prevent insects, such as ants, that can 
pass through the coarse basalt from burrowing into the underlying soils. Studies are planned in the near future to evaluate the magnitude of this problem, but at present this aspect of performance must be considered uncertain.

With respect to human intrusion, both the sand and gravel filters are located within $0.3 \mathrm{~m}(1 \mathrm{ft})$ of the ground surface, they are potentially susceptible to disruption from vehicular traffic, agriculture, construction, and similar activities. Mixing of these layers could destroy their effectiveness and thus allow fine material to penetrate the crushed basalt layer. This in turn could allow deep-rooted plants to become established.

As described in Section 6.4.1.3, the Biointrusion Barrier would result in increased infiltration over current conditions. An assumed recharge rate of $10 \mathrm{~cm} / \mathrm{yr}(4 \mathrm{in} / \mathrm{yr})$ was used to estimate infiltration through the barrier. Based on this recharge rate, the Biointrusion Barrier does not provide long-term effectiveness for protection of groundwater (Figure 6-14). Therefore, it is less protective than the other barrier designs, and also less protective of groundwater quality than Institutional Controls alone (with the existing soil cover).

Reduction of Toxicity, Mobility, and Volume Through Treatment. No treatment is provided by this alternative.

Short-Term Effectiveness. As described in Section 6.4.1.4, worker exposure to radiation is not a concern for the barrier alternatives.

To determine the potential for worker accidents during installation the level of effort for constructing the barrier was determined. Estimated levels of effort for major construction activities are as follows:

Excavating and Screening Soil Materials

Hauling

Spreading and Compacting

Other On-site Activities

Total:
400 person-days

2,500 person-days

500 person-days

400 person-days

3,800 person-days

Based on statistics obtained by the U.S. Department of 'Labor (1992), the expected fatality rate for construction workers is about $6 \times 10^{-7}$ per person-day. This translates into a risk of 0.002 fatalities for construction of the Biointrusion Barrier, which is considered negligible. Similarly, the lost-time accident rate for construction workers is about $2 \times 10^{-4}$ per person-day. On this basis, one lost-time accident would be expected during the course of Barrier construction.

Because of the lack of radiation exposure and the low accident rates, the short-term effectiveness of this alternative is high.

Implementability. This alternative is readily implemented. The Biointrusion Barrier will be constructed of natural earth materials using conventional well-proven construction techniques. Sufficient materials are available on the Hanford Site.

Cost. The estimated cost of this alternative is 3.47 million (Table A-4). This is the lowest cost of all barrier alternatives. Base unit costs and derived unit costs for this cost 
estimate are provided in Tables B-2 and B-3. General assumptions for cost estimates for all barriers is provided in Section 6.2.3. Assumptions specific to the Biointrusion Barrier are provided in Section 6.3.3. General assumptions for cost estimates are described in Section 6.4.1.5.

\subsubsection{Alternative D: RCRA Barrier}

Overall Protection of Human Health and the Environment. This alternative provides high overall protection of human health and the environment, especially when included with Institutional Controls as described in Section 6.4.1.1. The RCRA Barrier provides additional protection, in the event that Institutional Controls are terminated during the 1,000-year period of concern. The RCRA Barrier provides long-term protection from direct contact exposure and biointrusion, and will also reduce infiltration significantly, thereby decreasing the potential for soil contaminants to migrate to groundwater. The RCRA Barrier also rates high in short-term effectiveness because there is negligible risk of radiation exposure for workers.

Compliance with ARARs. This alternative would meet all potential ARARs with the exception of the current discharges of technetium-99, cobalt-60, and nitrate described in Section 6.4.1.2. The RCRA Barrier, if it remains intact is expected to reduce the infiltration rates sufficiently to protect groundwater from impact due to uranium discharges for more than the 1,000-year period of concern. In addition, a substantial effort has been conducted to demonstrate compliance with the RCRA landfill cover design requirements of $40 \mathrm{CFR}$ Part 264.310 and WAC 173-303-665. Therefore, this alternative rates higher than the Biointrusion Barrier for compliance with ARARs.

Long-Term Effectiveness and Permanence. This alternative would provide a high degree of long-term effectiveness and permanence, especially with use of institutional controls (Sections 6.4.1.1 and 6.4.1.3). It should provide good performance in minimizing infiltration through contaminated soil. The estimated infiltration rate through the RCRA Barrier is $<0.1 \mathrm{~cm} / \mathrm{yr}(0.04 \mathrm{in} / \mathrm{yr})$. As discussed in Section 6.4.1.3, this rate of infiltration will provide long-term protection of groundwater. Because the RCRA Barrier is only moderately thick relative to the Hanford Barrier, the RCRA Barrier would offer good resistance to accidental human intrusion, but low resistance to deliberate intrusion (e.g., excavation). The reliability over long time periods is uncertain for this barrier, both in terms of retaining low permeability and in terms of erosion resistance. No testing of this Barrier has been performed, and of course there are no field data over long time periods. However, it seems likely that the RCRA Barrier will withstand erosion for a few hundred years. Durability over 1,000 years is uncertain, and the ability to function over 10,000 years is considered low.

With respect to inadvertent human intrusion, assuming loss of institutional controls, the RCRA Barrier is expected to be more effective than the Biointrusion Barrier but less effective than the Hanford Barrier. The moderately thick $2 \mathrm{~m}(6 \mathrm{ft}) \mathrm{RCRA}$ barrier provides some mass of material that would need to be removed to expose contaminated soil. There are several layers which would not function as intended if mixed or otherwise disturbed, including the layers used for filters, drainage, and moisture/biota barriers. These layers are

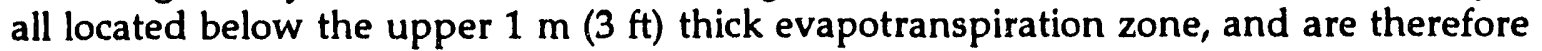
probably well protected from surficial activities such as agriculture and traffic. The function of the uppermost silt layers would not be seriously degraded by disturbance. 
A key question for this barrier design is the longevity of the asphalt layer. Although asphalt is a natural material and is expected to be stable over long periods of time, it may be susceptible to loss of volatiles or other degradation mechanisms that could cause deterioration or cracking. Studies are planned in the near future to evaluate whether this is a problem and determine which asphalt compositions are most appropriate for use.

Reduction of Toxicity, Mobility, and Volume Through Treatment. No treatment is provided by this alternative.

Short-Term Effectiveness. As described in Section 6.4.1.4, worker exposure to radiation is not a concern for the barrier alternatives.

To determine the potential for worker accidents during installation the level of effort for constructing the barrier was determined. Estimated levels of effort for major construction activities are as follows:
Excavating and Screening Soil Materials
Hauling
Spreading and Compacting
Other On-site Activities
Total:

$$
\begin{array}{r}
800 \text { person-days } \\
4,400 \text { person-days } \\
700 \text { person-days } \\
500 \text { person-days } \\
6,400 \text { person-days }
\end{array}
$$

Based on statistics obtained by the U.S. Department of Labor (1992), the expected fatality rate for construction workers is about $6 \times 10^{-7}$ per person-day. This translates into a risk of 0.004 fatalities for construction of the RCRA Barrier, which is considered negligible. Similarly, the lost-time accident rate for construction workers is about $2 \times 10^{-4}$ per personday. On this basis, one lost-time accident would be expected during the course of Barrier construction.

Based on the low accident rate and lack of radiation exposure the short-term effectiveness of this alternative is high.

Implementability. This alternative can be readily implemente $?$, although it contains more layers and would be expected to be somewhat more difficult to construct than the Biointrusion Barrier. The RCRA Barrier will be constructed of natural earth materials using conventional construction methods. Sufficient materials to construct the Barrier are available on the Hanford Site.

Cost. The estimated cost of this alternative is 5.65 million (Table A-5). This cost is more than the Biointrusion Barrier but less than the Hanford Barrier. Base unit costs and derived unit costs for this cost estimate are provided in Tables B-2 and B-3. Assumptions used for cost estimates for the RCRA Barrier is provided in Section 6.3.4. General assumptions for cost estimates are described in Section 6.4.1.5.

\subsubsection{Alternative E: Hanford Barrier}

Overall Protection of Human Health and the Environment. This alternative is expected to be highly protective of human health and the environment, especially when included with Institutional Controls as described in Section 6.4.1.1. The Hanford Barrier provides additional protection, in the event that Institutional Controls are terminated 
during the 1,000-year period of concern. The Hanford Barrier provides a large physical mass for long-term protection from direct contact exposure and biointrusion, and will also reduce infiltration significantly, thereby decreasing the potential for soil contaminants to migrate to groundwater. The Hanford Barrier also rates high in short-term effectiveness because there is negligible risk of radiation exposure for workers. The Hanford Barrier rates slightly higher than the RCRA Barrier because of increased reliability and the extensive performance assessment that has been conducted. Additional studies are currently underway to evaluate the performance of the Hanford Barrier, with a prototype planned for installation over the 216-B-57 crib.

Compliance with ARARs. Same as for the RCRA Barrier (Section 6.4.2.4).

Long-Term Effectiveness and Permanence. The Hanford Barrier has been designed to remain effective for at least 1,000 years with little or no maintenance. Therefore, this barrier is rated highest of the barrier alternatives, especially in the event Institutional Controls are terminated.

Erosion and damage from human activities are the most likely causes of Barrier failure. The large total thickness and relatively coarse texture of the component soils of the Barrier is expected to adequately resist erosion. Some landforms on the Hanford Site (such as ripple marks) that are comprised of coarse-textured soils have survived since the catastrophic flood events that formed them about 10,000 to 14,000 years ago, supporting the assumption of the Barrier's ability to withstand erosion.

With respect to damage from human activities, the Hanford Barrier provides a significant mass of material that would need to be removed to expose contaminated soil. There are several soil layers that would not function as intended if mixed or otherwise disturbed, including the layers used for filters, capillary breaks, and drainage. However, these layers are all located below the upper $2 \mathrm{~m}(6 \mathrm{ft})$ thick evapotranspiration zone, and are therefore well protected from surficial activities such as agriculture and traffic. The function of the uppermost silt layers would not be seriously degraded by disturbance. In addition, the geometry and size of the Hanford Barrier provide clear visual evidence that a human structure is present. One enhancement for the Barrier consists of burying layers of ceramic disks at several depths within the uppermost soil layers. These disks would contain information to warn potential intruders against digging further. As discussed for the RCRA Barrier (Section 6.4.2.4), the longevity of the asphalt layer as a low-permeability layer is uncertain and requires further study.

A disadvantage of the Hanford Barrier is that large volumes of uniform soils would be attractive as future borrow sources for local construction projects by persons ignorant of the Barrier's purpose. The likelihood of such a scenario is difficult to predict, and it is reasonable to argue that a society capable of using such materials will be sophisticated enough to realize their purpose.

Reduction of Toxicity, Mobility, and Volume Through Treatment. No treatment is provided by this alternative.

Short-Term Effectiveness. As described in Section 6.4.1.4, worker exposure to radiation is not a concern for the barrier alternatives. 
To determine the potential for worker accidents during installation the level of effort for constructing the barrier was determined. Estimated levels of effort for major construction activities are as follows:
Excavating and Screening Soil Materials
Hauling
Spreading and Compacting
Other On-site Activities
Total

$$
\begin{array}{r}
1,600 \text { person-days } \\
8,500 \text { person-days } \\
1,000 \text { person-days } \\
800 \text { person-days } \\
11,900 \text { person-days }
\end{array}
$$

Based on statistics obtained by the U.S. Department of Labor (1992), the expected fatality rate for construction workers is about $6 \times 10^{-7}$ per person-day. This translates into a risk of 0.007 fatalities for construction of the Hanford Barrier, which is considered negligible. Similarly, the lost-time accident rate for construction workers is about $2 \times 10^{-4}$ per person-day. On this basis, two lost-time accidents would be expected during the course of Barrier construction.

Based on the low accident rate and the lack of radiation exposure, the short-term effectiveness of this alternative is relatively high.

Implementability. This alternative is readily implemented, although it contains more layers and would be expected to be somewhat more difficult to construct than the RCRA Barrier. The Hanford Barrier will be constructed of natural earth materials using conventional construction methods. Sufficient materials are expected to be available on the Hanford Site or in the local area.

Cost. The estimated cost of this alternative is 8.47 million (Table A-6). Base unit costs and derived unit costs for this cost estimate are provided in Tables B-2 and B-3. Assumptions used for cost estimates for the Hanford Barrier is provided in Section 6.3.5. General assumptions for cost estimates are described in Section 6.4.1.5.

\subsubsection{Alternative F: Excavation and Soil Washing}

Overall Protection of Human Health and the Environment. This alternative is expected to provide long-term protection of human health and the environment. However, to achieve long-term protection, it requires construction of a low-permeability barrier over the unexcavated contaminated soils and Institutional Controls at the ERSDF site (Section 6.1.3).

This alternative has potential for significant short-term impacts due to worker exposure to radiation during the excavation and soil washing activities. Therefore, this alternative does not rate very high for overall protection of human health.

Compliance with ARARs. Because this alternative relies on the RCRA Barrier to be effective for protection of groundwater and use of the Hanford Barrier for soils disposed at the ERSDF, compliance with contaminant specific ARARs is considered the same as for the RCRA Barrier (Section 6.4.2.4). However, a number of action-specific ARARs will have to be complied with to prevent air pollution, for wastewater treatment, radioactive material transport and most importantly for worker protection. These ARARs are described in Section 6.4.1.2. 
Long-Term Effectiveness and Permanence. This alternative would provide longterm effectiveness and permanence primarily through institutional controls and a surface barrier (Sections 6.4.1.3). ERSDF disposal offers only slightly better performance than onsite containment with a RCRA Barrier (Section 6.4.1.3), and would provide greater reliability and permanence.

Reduction in Toxicity, Mobility, or Volume Through Treatment. Soil washing is estimated to reduce the volume of excavated soil by approximately $85 \%$. Volume reduction would not be provided for soil that is not excavated. No treatment to reduce toxicity or contaminant mobility is provided.

Short-Term Effectiveness. Worker exposure for excavation activities was discussed in Section 6.4.1.4. Workers conducting soil washing will be potentially exposed to radiation during transport of materials from the excavation to the soil washing facility, during the soil washing process, while transferring the fines containing most of the radioactivity to the ERSDF for disposal and while conducting maintenance activities on soil washing equipment.

To determine potential accident rates and worker exposure to radiation the following assumptions were used:

Construction of Facilities

Washing Operations

Total
6,620 person-days

33,100 person-days

39,720 person-days

Based on statistics obtained by the U.S. Department of Labor (1992), the expected fatality rate for construction workers is about $6 \times 10^{-7}$ per person-day, while that for manufacturing operations is about $9 \times 10^{-8}$ per person day. This translates into a combined risk of 0.007 fatalities during the soil washing plant construction and operations, which is considered negligible. Similarly, the lost-time accident rate for both construction and manufacturing workers is about $2 \times 10^{-4}$ per person-day. On this basis, eight lost-time accidents would be expected during the course of soil washing activities.

For evaluation purposes, it is assumed that the shift operators, helpers and maintenance workers are the personnel primarily exposed to radiation up to the $5 \mathrm{rem} / \mathrm{yr}$ maximum dose allowable. Based on the number of personnel potentially exposed and the duration of the soil washing activities 125 rems of exposure are assumed for the soil washing portion of this alternative. This exposure would be combined with the assumed 500 rem exposure related to excavation for a total of 625 rem exposure for Alternative $F$.

As with the other alternatives this is only an estimate for comparison purposes. A more precise exposure analysis depends on details of the soil washing procedure, soil handling, and transportation, and would not be available until final design of the soil washing system. Remotely-operated equipment will be used if necessary, and sufficient shielding and safety practices would be employed so that personnel exposure limits are as low as reasonably achievable and in no case greater than 5 rem/year effective annual dose equivalent, as required by DOE order 5480.11, Radiation Protection for Occupational Workers. 
Based on the high potential for radiation exposure to workers, the short-term effectiveness of this alternative is low.

Implementability. The ability to implement excavation at this site is low, as discussed in Section 6.2.3. In addition, implementability generally decreases as complexity increases. Soil washing, as presented for this alternative, is a complex and unproven process that would require unique design and construction. The plant would be especially difficult to operate and maintain because of its robotics and the high levels of radioactivity that will be present when treating some of the site soils. This alternative would be difficult to implement.

Cost. The estimated cost of this alternative is $\$ 182$ (see Table A-7). General assumptions for cost estimates are described in Section 6.4.1.5. Base unit costs and derived unit costs are provided in Tables B-2 and B-3. A detailed cost estimate for the soil washing process is provided in Table B-4. A detailed cost estimate for excavation is provided in Table B-9.

\subsubsection{Alternative G: Excavation and Soil Washing with Vitrification}

Overall Protection of Human Health and the Environment. This alternative is rated highest of all alternatives for long-term protection of human health and the environnent. However, to achieve long-term protection, it requires construction of a lowpermeability barrier over the unexcavated contaminated soils and Institutional Controls at the ERSDF site. The permanence and reliability would be increased over the institutional controls and barrier alternatives by removing most of the mass of contaminants (via soil washing) for disposal in the ERSDF (Section 6.4.1.3). Additional protection over soil washing alone would be provided by vitrification.

This alternative has potential for significant short-term impacts due to worker exposure to radiation during the excavation, soil washing and vitrification activities. Therefore, this alternative does not rate very high for overall protection of human health.

Compliance with ARARs. Because this alternative relies on the RCRA Barrier to be effective for protection of groundwater at the 200-BP-1 site and use of the Hanford Bariier for soils disposed at the ERSDF, compliance with contaminant specific ARARs is considered the same as for the RCRA Barrier (Section 6.4..2.4). However, a number of action-specific ARARs will have to be complied with to prevent air pollution, for wastewater treatment, radioactive material transport and most importantly for worker protection. These ARARs are described in Section 6.4.1.2.

Long-Term Effectiveness and Permanence. This alternative would provide the highest level of long-term effectiveness and permanence by vitrifying the most contaminated soils and disposing them in the ERSDF. However, long-term performance for protection of groundwater at the 200-BP-1 site would be similar to that of the RCRA Barrier. Vitrification is expected to provide better long-term effectiveness and permanence at immobilizing contaminants than direct disposal or fixation.

Reduction of Toxicity, Mobility, and Volume Through Treatment. Soil washing is estimated to reduce the volume of excavated soil by approximately $85 \%$. Some additional volume reduction would occur as a result of vitrification. Vitrification would significantly 
reduce the mobility of contaminants (e.g. uranium) for protection of groundwater, while not significantly affecting the already low mobility of others (e.g., cesium) that are tightly bound to soil. Contaminants would not be immobilized in soil that is not excarated.

Short-Term Effectiveness. The worker accident rates and radiation exposure for excavation and soil washing in Alternative $\mathrm{F}$ would also apply to this alternative. In addition, workers conducting this alternative would also be subject to accidents and exposure through operations of the vitrification plant. There will be increased worker risk due to the high temperatures and large quantities of electricity needed for vitrification. Thus, worker risk is higher for soil washing with vitrification than soil washing alone.

To determine potential accident rates and worker exposure to radiation, it was assumed that the vitrification plant will use separate shift operators than are used for the soil washing facility. The helpers and maintenance workers for the soil washing facility are also assumed for the vitrification plant. On this basis, the following levels of effort are estimated:

$\begin{array}{ll}\text { Construction of Facilities } & 10,275 \text { person-days } \\ \text { Washing and Vitrification Operations } & \text { 51,375 person-days } \\ \text { Total } & 61,675 \text { person-days }\end{array}$

Based on statistics obtained by the U.S. Department of Labor (1992), the expected fatality rate for construction workers is about $6 \times 10^{-7}$ per person-day, while the rate for manufacturing operations is about $9 \times 10^{-8}$ per person day. This translates into a combined risk of 0.01 fatalities during the vitrification construction and operations (including the soil washing component), which is considered negligible. Similarly, the lost-time accident rate for both construction and manufacturing workers is about $2 \times 10^{-4}$ per person-day. On this basis, twelve lost-time accidents would be expected during the course of vitrification construction and operation activities.

For evaluation purposes, it is assumed that the shift operators, helpers and maintenance workers are the personnel primarily exposed to radiation up to the $5 \mathrm{rem} / \mathrm{yr}$ maximum dose allowable. Based on the number of personnel potentially exposed and the duration of the vitrification activities 50 rems of exposure are assumed for the vitrification portion of this alternative. This exposure would be combined with the assumed 625 rem total exposure related to excavation and soil washing for a total of 675 rem exposure for Alternative F.

As with the other alternatives this is only an estimate for comparison purposes. A more precise exposure analysis depends on details of the vitrification plant operations, shielding and other worker safety procedures and would not be available until final design of the vitrification system. Remotely-operated equipment will be used if necessary, and sufficient shielding and safety practices would be employed so that personnel exposure limits are as low as reasonably achievable and in no case greater than 5 rem/year effective annual dose equivalent, as required by DOE order 5480.11 , Radiation Protection for Occupational Workers.

Based on the high potential for radiation exposure to workers, the short-term effectiveness of this alternative is low. 
Implementability. Excavation and soil washing would be difficult to implement, as discussed for Alternative $F$ (Section 6.4.2.6). Vitrification of radioactive soils is a relatively new and complex technology that wouid require development and testing prior to use. Radioactivity would make operation and repair of soil washing and vitrification equipment difficult. This alternative would be more difficult to implement than soil washing alone.

Cost. This alternative would be the most expensive of the alternatives evaluated. The estimated cost of this alternative is $\$ 268$ (see Table A-8). General assumptions for cost estimates are described in Section 6.4.1.5. Base unit costs and derived unit costs are provided in Tables B-2 and B-3. Detailed cost estimates for the soil washing and vitrification processes are provided in Tables B-4 and B-5, respectively. A detailed cost estimate for excavation is provided in Table B-9.

\subsubsection{Alternative $\mathrm{H}$ : Excavation and Fixation}

Overall Protection of Human Health and the Environment. This alternative is expected to provide for long-term protection of human health and the environment. However, to achieve long-term protection, it requires construction of a low-permeability barrier over the unexcavated contaminated soils and Institutional Controls at the ERSDF site. The permanence and reliability would be increased slightly over the institutional controls and barrier alternatives by removing most of the mass of contaminants for disposal in the ERSDF (Section 6.1.3). Additional protection over soil washing alone would be provided by fixation. However, fixation is not as permanent and reliable as vitrification.

This alternative has potential for significant short-term impacts due to worker exposure to radiation during the excavation and fixation process. Therefore, this alternative does not rate very high for overall protection of human health. This alternative protects human health and the environment.

Compliance with ARARs. Because this alternative relies on the RCRA Barrier to be effective for protection of groundwater at the 200-BP-1 site and use of the Hanford Barrier for soils disposed at the ERSDF, compliance with contaminant specific ARARs is considered the same as for the RCRA Barrier (Section 6.4.2.4). However, a number of action-specific ARARs will have to be complied with to prevent air pollution, for wastewater treatment, radioactive material transport and most importantly for worker protection. These ARARs are described in Section 6.4.1.2.

Long-Term Effectiveness and Permanence. This alternative is considered second only to vitrification in terms of long-term effectiveness and permanence. The permanence and reliability is enhanced slightly over disposal with no treatment (Alternatives $F$ and $I$ ) by immobilizing the contaminants (via fixation), prior to disposal in the ERSDF. However, long-term performance for protection of groundwater at the 200-BP-1 site would be similar to that of the RCRA Barrier.

Fixation would not prevent direct contact with contaminated materials, nor would it significantly reduce risk due to direct exposure to radioactive contamination. Fixation may reduce the likelihood of biological intrusion due to the cement-like matrix, but this is uncertain. The reliability and permanence of fixation is likely to be high; however this is uncertain because there are no data available on the effectiveness of fixation beyond 100 
years. Thus, this alternative does not offer better performance than alternatives with impermeable barriers, but may offer some additional reliability and permanence.

Reduction of Toxicity, Mobility, and Volume Through Treatment. Fixation would significantly reduce the mobility of some contaminants in treated soil (e.g., uranium), while not significantly affecting the mobility of others (e.g., cesium) that are already tightly bound to soil. Contaminants would not be immobilized below the excavation depth. Due to the addition of the Portland cement and fly ash required to fix contaminants, the total volume of treated material would increase by an estimated $25 \%$ over the in-place volume of contaminated soil.

Short-Term Effectiveness. Worker exposure for excavation activities was discussed in Section 6.4.1.4. Workers conducting fixation will be potentially exposed to radiation during transport of materials from the excavation to the fixation facility, during the fixation process, while transferring the materials to the ERSDF for disposal and while conducting maintenance activities on equipment.

To determine potential accident rates and worker exposure to radiation, the following assumptions were used:

\section{Construction of Facilities \\ Fixation Operations \\ Total}

$\begin{array}{r}5,525 \text { person-days } \\ 27,625 \text { person-days } \\ \hline 33,150 \text { person-days }\end{array}$

Based on statistics obtained by the U.S. Department of Labor (1992), the expected fatality rate for construction workers is about $6 \times 10^{-7}$ per person-day, while that for manufacturing is about $9 \times 10^{-8}$ per person-day. This translates into a combined risk of 0.006 fatalities during the soil fixation plant construction and operations, which is considered negligible. Similarly, the lost-time accident rate for both construction and manufacturing workers is about $2 \times 10^{-4}$ per person-day. On this basis, seven lost-time accidents would be expected during the course of fixation activities.

For evaluation purposes, it is assumed that the shift operators, helpers and maintenance workers are the personnel primarily exposed to radiation up to the $5 \mathrm{rem} / \mathrm{yr}$ maximum dose allowable. Based on the number of personnel potentially exposed and the duration of the soil washing activities 125 rems of exposure are assumed for the soil washing portion of this alternative. This exposure would be combined with the assumed 500 rem exposure related to excavation for a total of 625 rem exposure for Alternative $F$.

As with the other alternatives this is only an estimate for comparison purposes. A more precise exposure analysis depends on details of the soil washing procedure, scil handling, and transportation, and would not be available until final design of the soil washing system. Remotely-operated equipment will be used if necessary, and sufficient shielding and safety practices would be employed so that personnel exposure limits are as low as reasonably achievable and in no case greater than 5 rem/year effective annual dose equivalent, as required by DOE order 5480.11 , Radiation Protection for Occupational Workers.

Based on the high potential for radiation exposure to workers, the short-term effectiveness of this alternative is low. However, because soil washing would have 
Section 6.4.1.2. The RCRA Barrier placed over the treated soil is expected to reduce the infiltration rates sufficiently to protect groundwater from impact due to uranium discharges for more than the 1,000-year period of concern.

Long-Term Effectiveness and Permanence. This alternative would provide longterm effectiveness and permanence primarily through institutional controls and containment. The permanence and reliability would be enhanced by immobilizing most of the mass of contaminants (via fixation).

Fixation alone would not prevent direct contact with contaminated materials, nor would it significantly reduce risk due to direct exposure to radioactive contamination. Fixation may reduce the likelihood of biological intrusion due to the cement-like matrix, but this is uncertain. The reliability and permanence of fixation is likely io be high; however this is uncertain because there are no data available on the effectiveness of fixation beyond 100 years. Thus, this alternative does not offer better performance than alternatives with impermeable barriers, but may offer additional reliability and permanence.

Difficulties with in-place injection and mixing of fixative decrease the reliability of achieving the desired degree of treatment relative to ex-situ fixation. In-situ fixation is therefore less effective than ex-situ fixation.

Reduction of Toxicity, Mobility, and Volume Through Treatment. Fixation would significantly reduce tice mobility of some contaminants in treated soil (e.g., uranium), while not significantly affecting the mobility of others (e.g., cesium) that are already tightly bound to soil. Contaminants would not be immobilized below the treatment depth. The mass of treated contaminated material would increase by an estimated $25 \%$. Some of this increase would be expressed as increased volume; the remainder would fill existing pore space to some extent.

Short-term Effectiveness. Because in-situ fixation involves drilling into the contaminated zone with augers, there will be some worker exposure. However, it is expected to be significantly less than any of the excavation alternatives. For purposes of comparison with the other alternatives a conservative estimate of the total rems of worker exposure during implententation of soil fixation is based on the assumption that 2 auger rigs would be operated $24 \mathrm{hr} / \mathrm{d}$ for 60 weeks. Five workers would be subject to radiation exposure for each shift up to the maximum allowable $5 \mathrm{rem} /$ year exposure. The resulting total man-rems of exposure based on these assumptions is 150 .

In addition to the workers being subject to radiation exposure, workers would also be involved in activities that could result in accidents. About 12,600 person-days are anticipated to be required to conduct the in-situ fixation alternative at the 200-BP-1 operable unit. Based on statistics obtained by the U.S. Department of Labor (1992), the expected fatality rate for construction workers is about $6 \times 10^{-7}$ per person-day. This translates into a risk of 0.008 fatalities for in-situ fixation, which is considered negligible. Similarly, the lost-time accident rate for construction workers is about $2 \times 10^{-4}$ per personday. On this basis, three lost-time accidents would be expected during the course of in-situ fixation. The short-term effectiveness of this alternative is moderate, but greater than alternatives involving ex-situ treatment. 
Implementability. This alternative is readily implemented. Fixation is widely used for immobilization of metals in contaminated soil. It has been tested and used on radioactive wastes (Holden 1989; Stone 1979). In-situ fixation is being field tested on radioactive waste sites (Francis 1991).

Grout injection has been widely used for cutoff walls and is considered established technology. Deep soil mixing equipment is readily available from multiple vendors. In-situ fixation has been demonstrated on a CERCLA site (EPA 1990). Different contractors are available for fixation and deep soil mixing.

Cost. The estimated cost of this alternative is $\$ 53$ (see Table A-11). General assumptions for cost estimates are described in Section 6.4.1.5. Base unit costs and derived unit costs are provided in Tables B-2 and B-3. A detailed cost estimate for in-situ fixation is provided in Table B-7. 
DOE/RL-93-35, Rev: 0




LOE/RL-93-35, Rev. 0

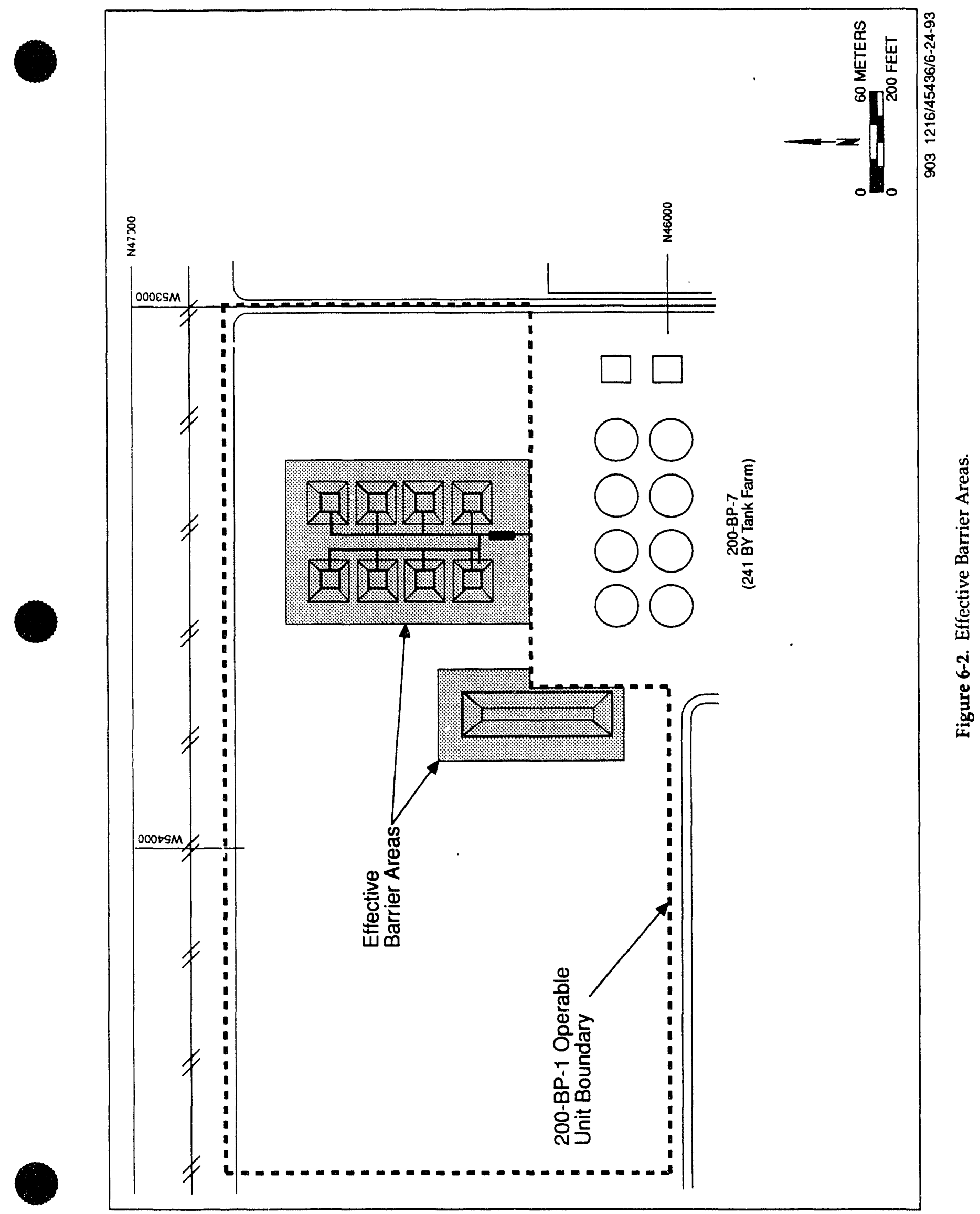


DOE/RL-93-35, Rev. O

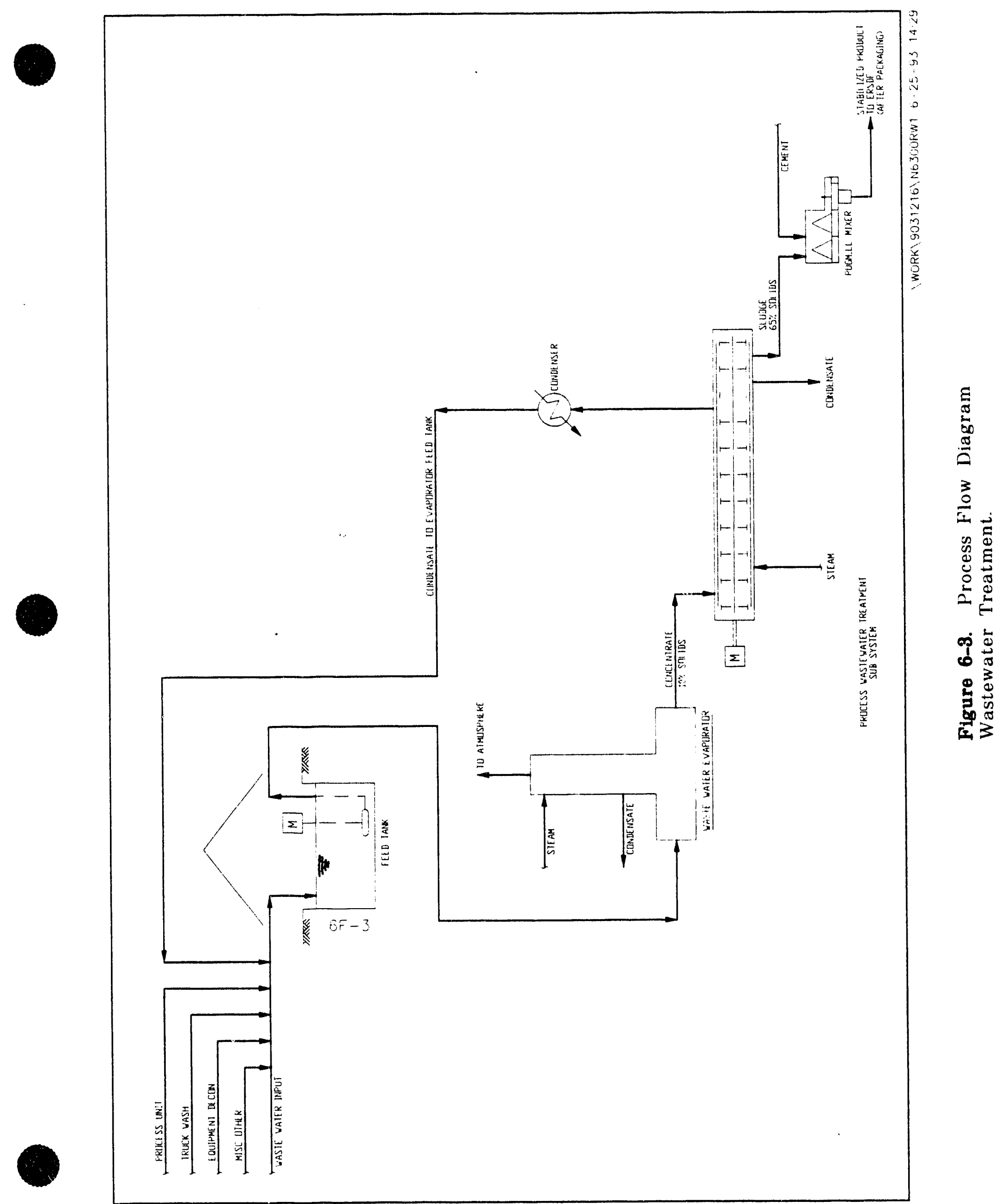

$6 F-3$ 
DOE/RL-93-35, Rev. 0

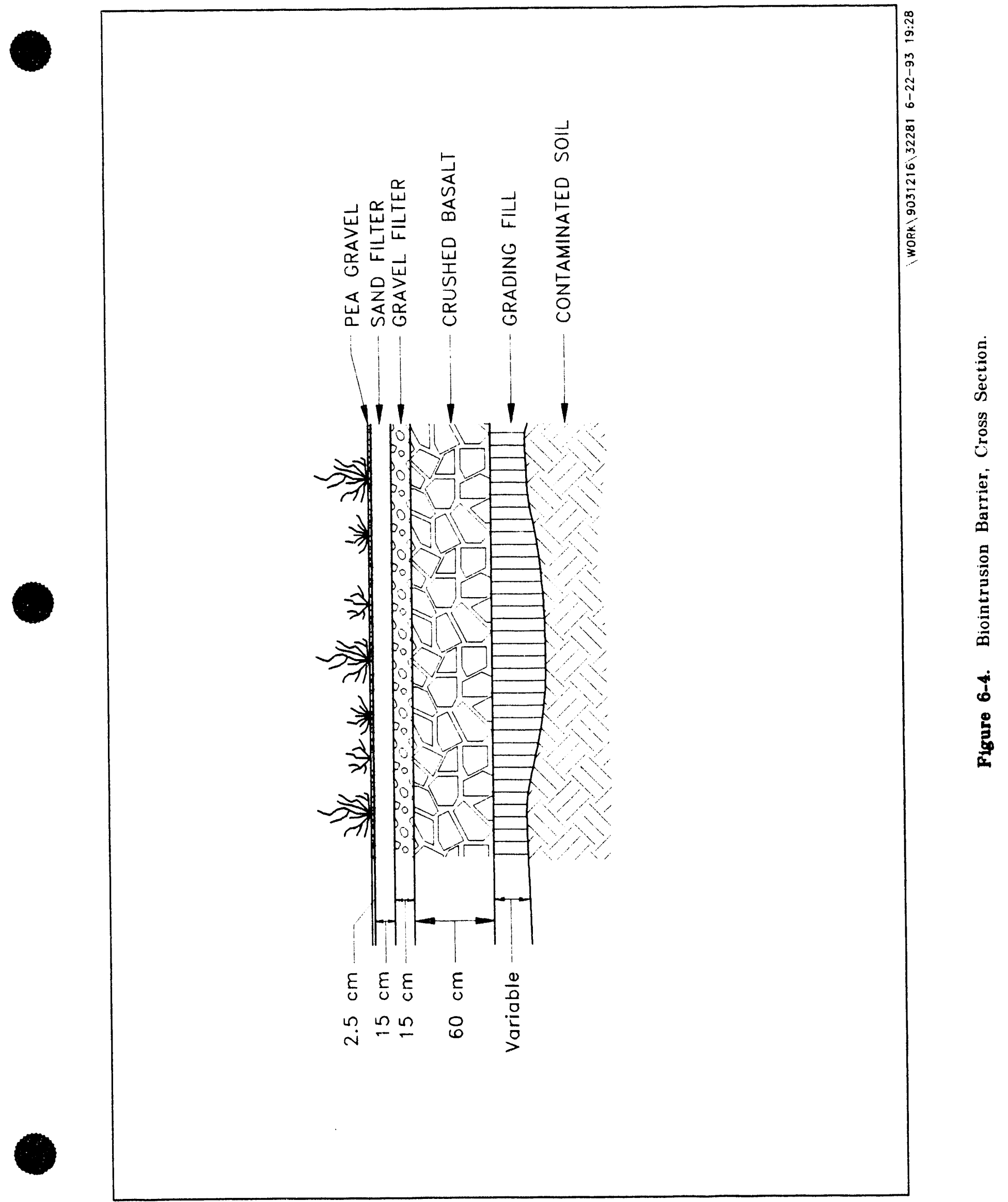




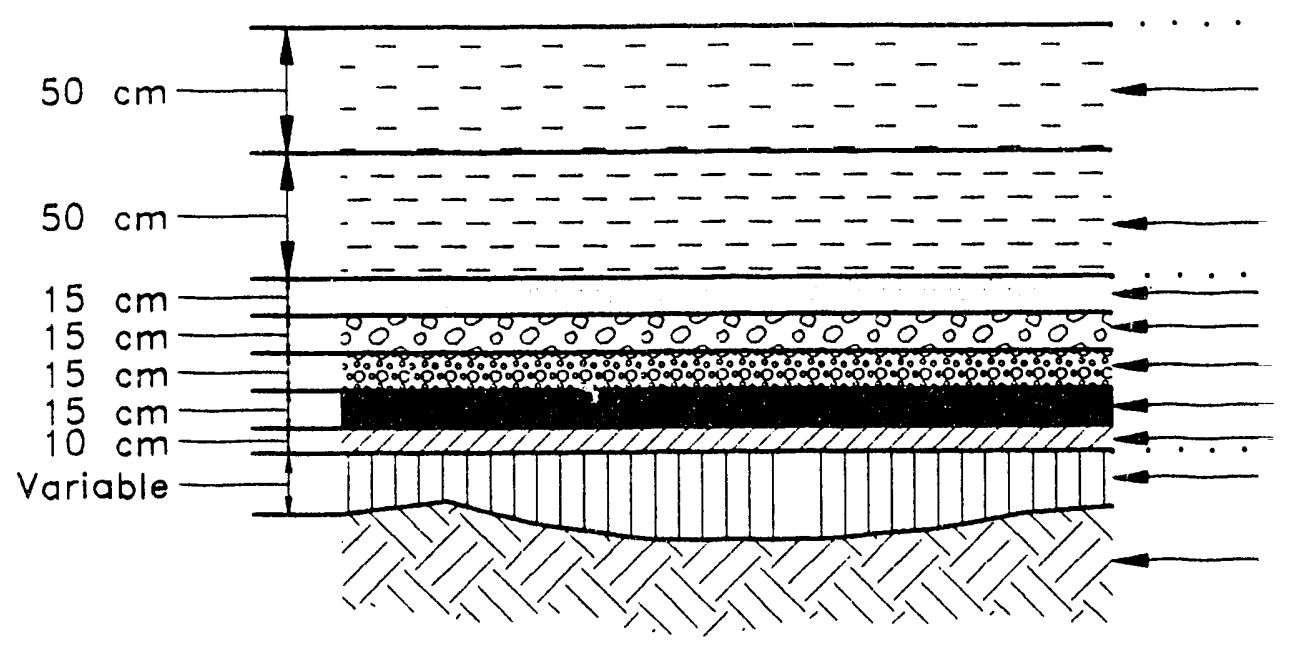




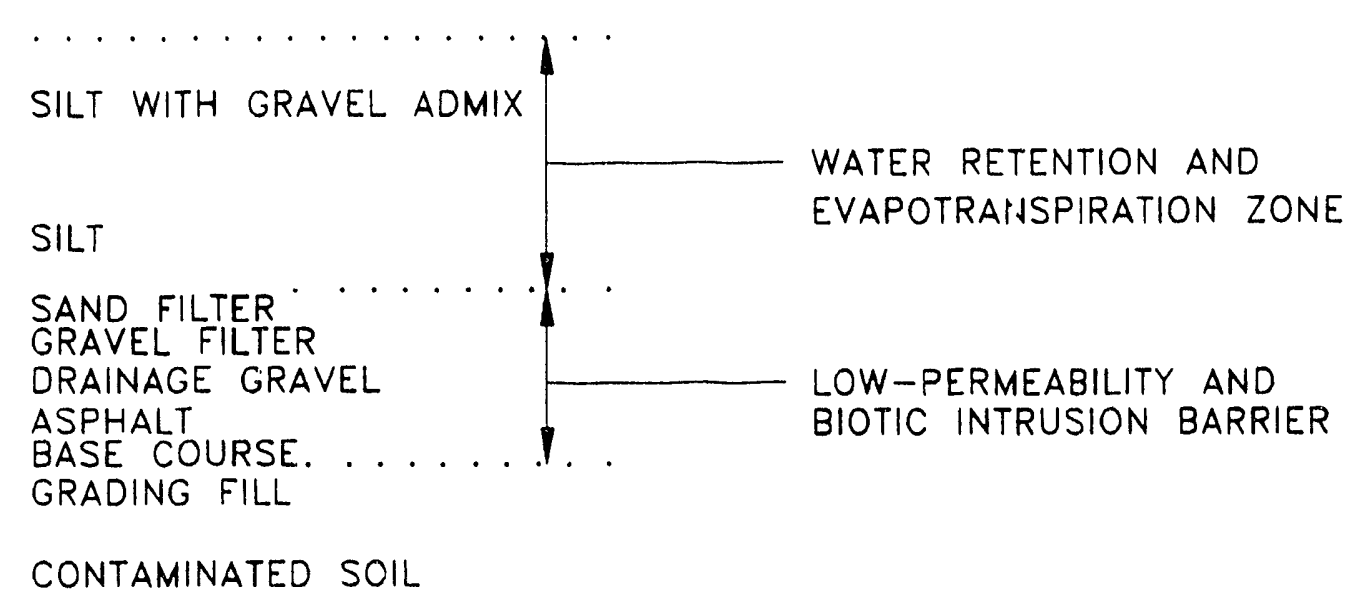

Figure 6-5. Modified RCRA Subtitle C Barrier. Cross Section. 


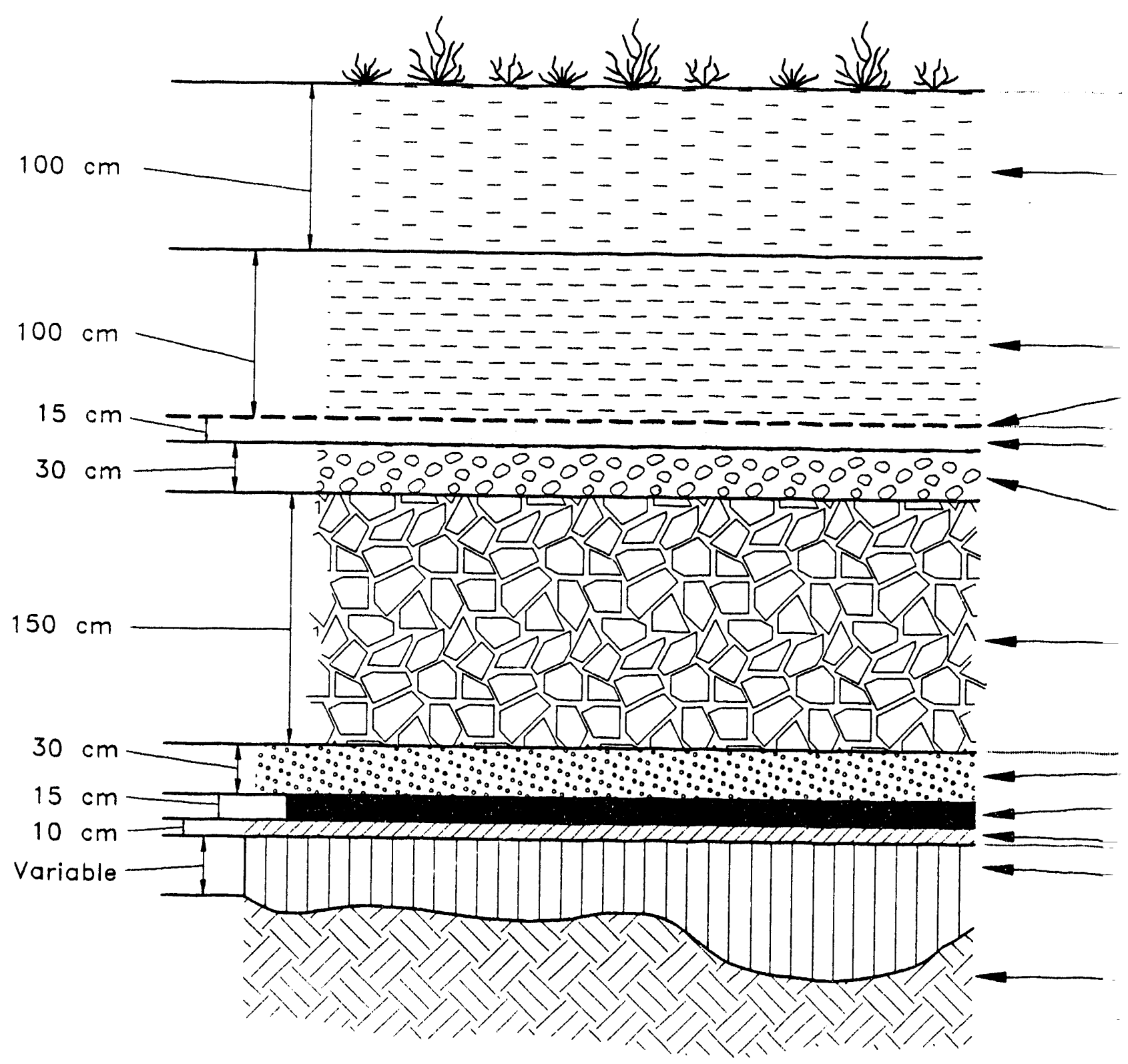


- GEOTEXTILE FILTER

- SAND FILTER

- GRAVEL FILTER

- CRUSHED BASALT

CAPILLARY AND BIOTIC INTRUSION BARRIER

- CONTAMINATED SOIL

Figure 6-6. Hanford Barrier, Cross Section. 


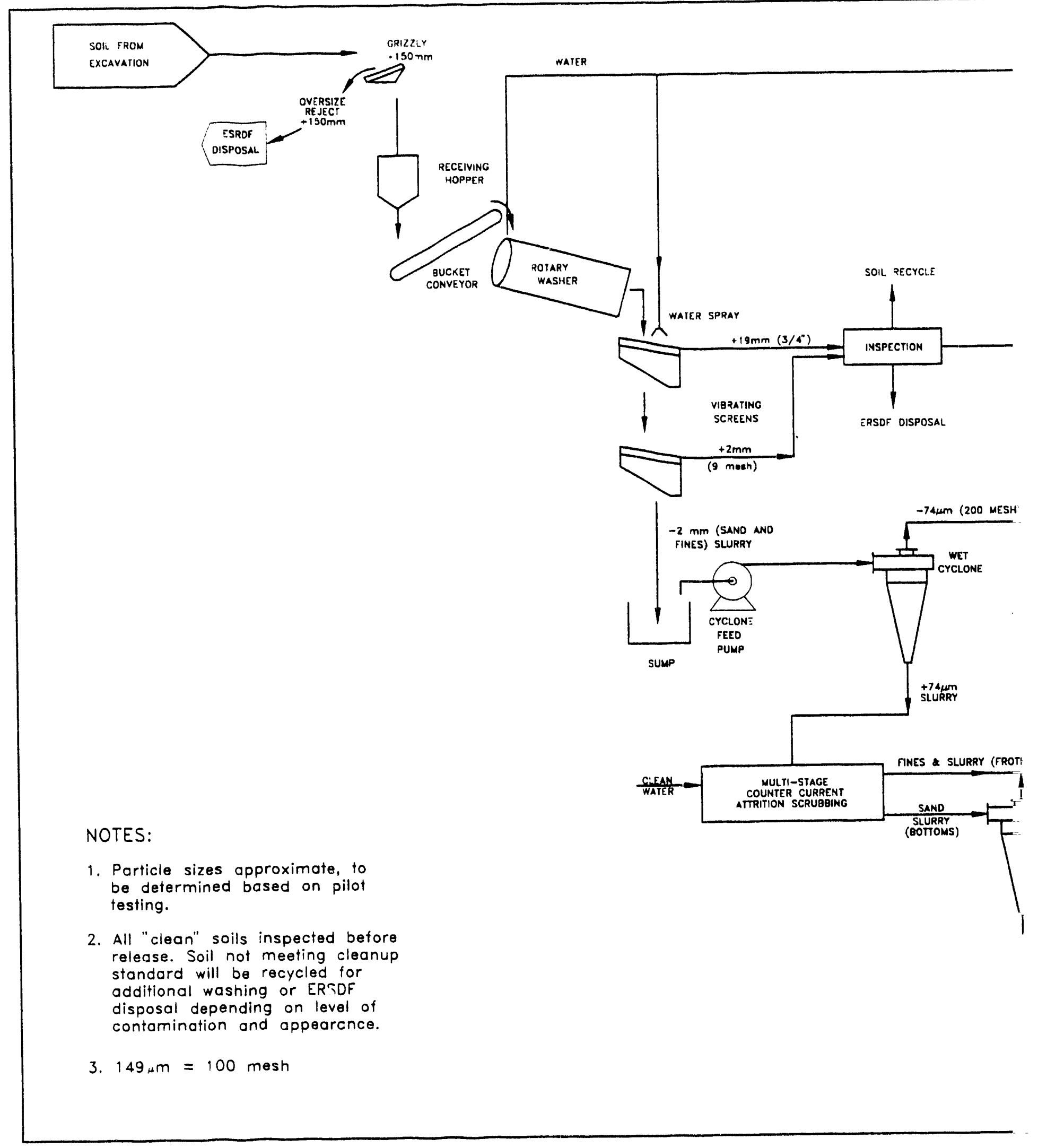




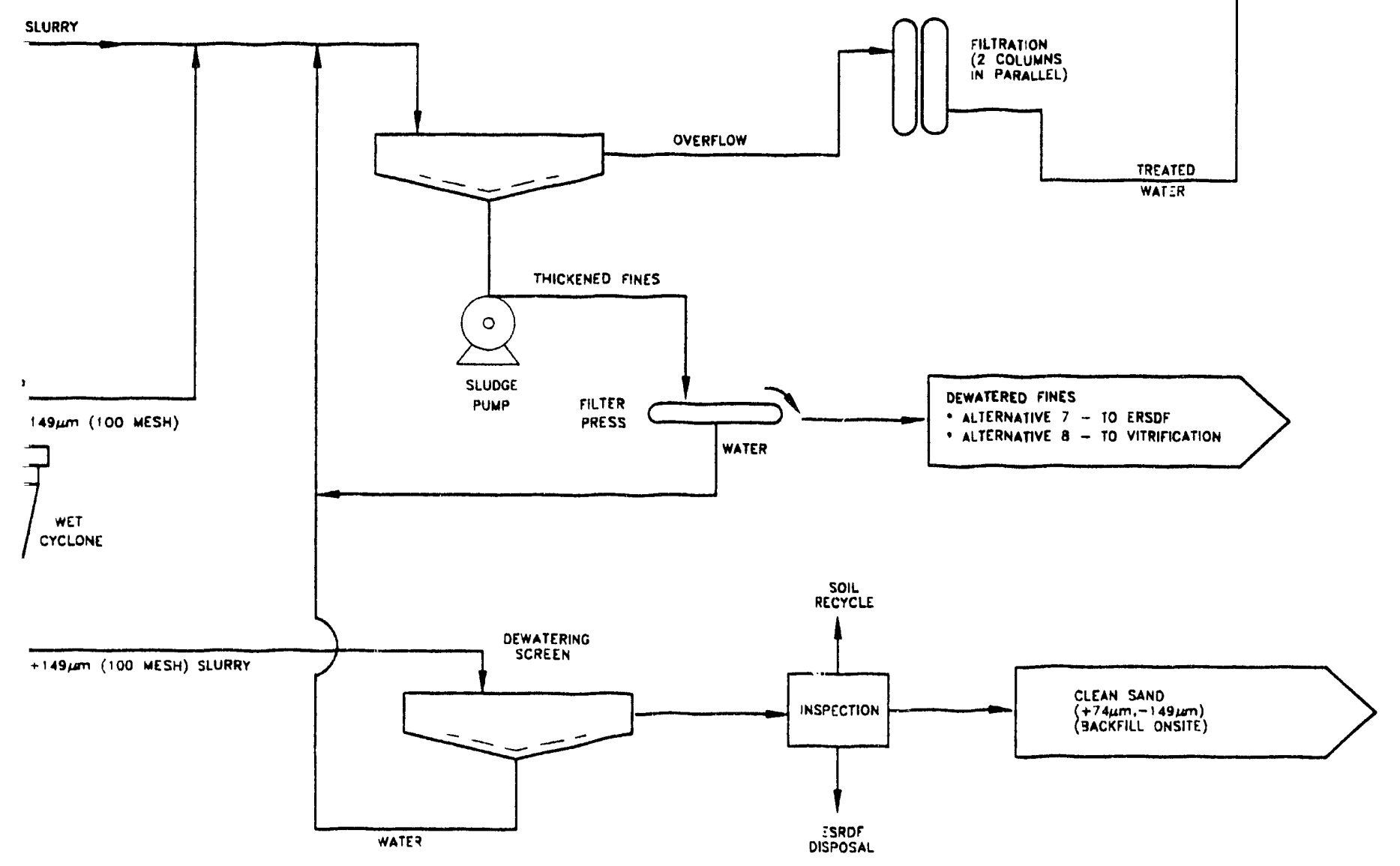

Figure 6-7. Soil Washing Process Flow Diagram. 


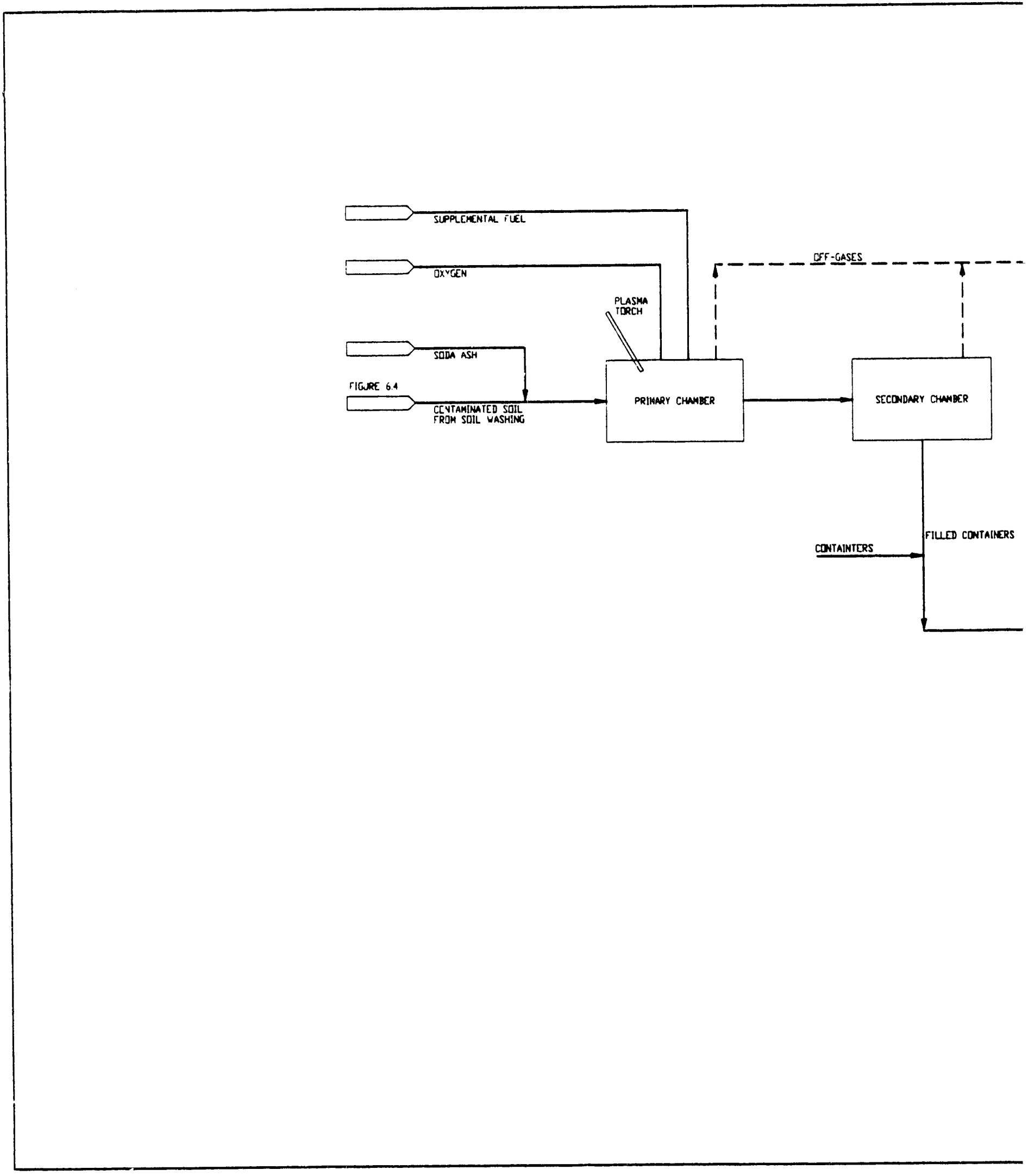




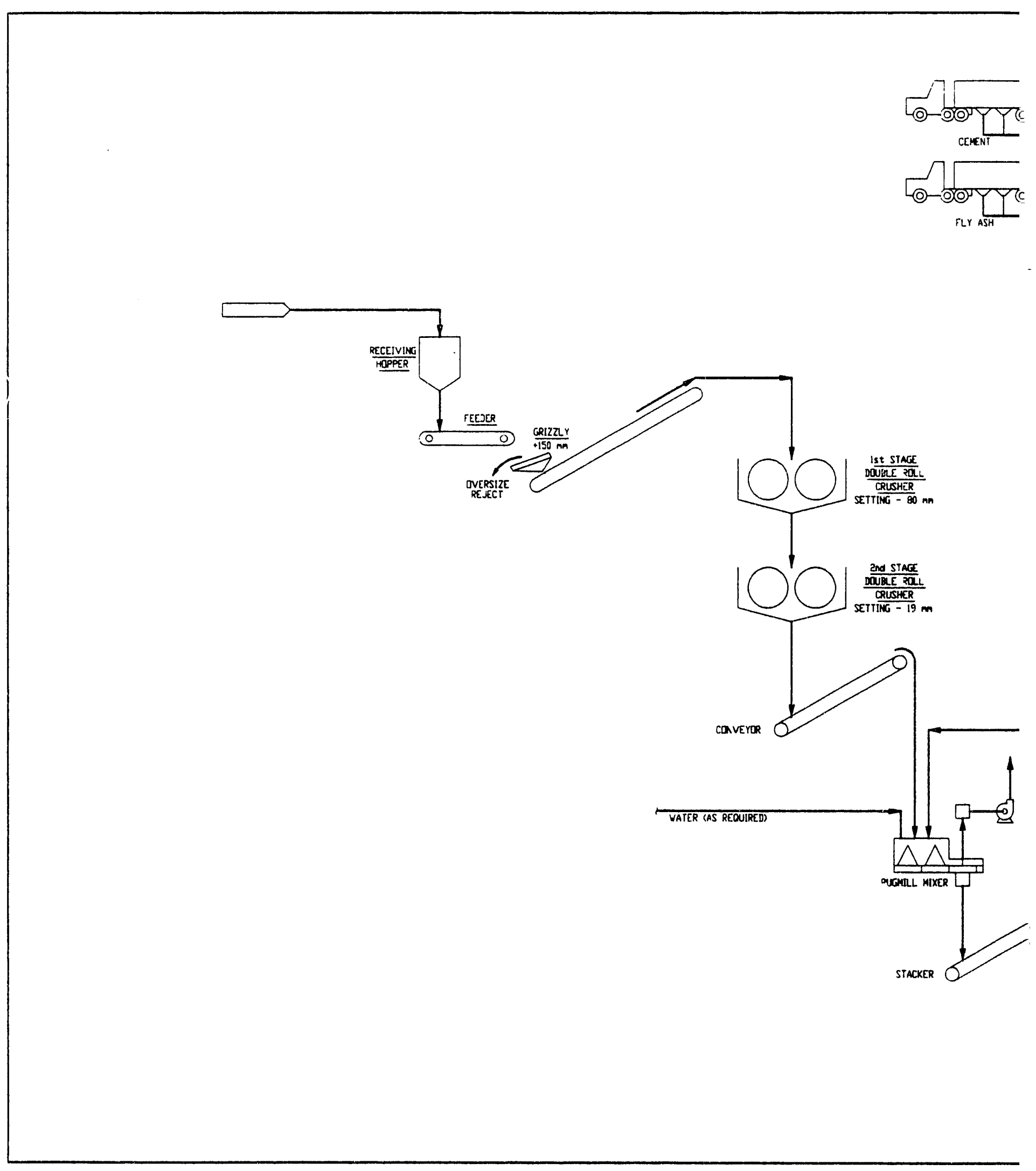




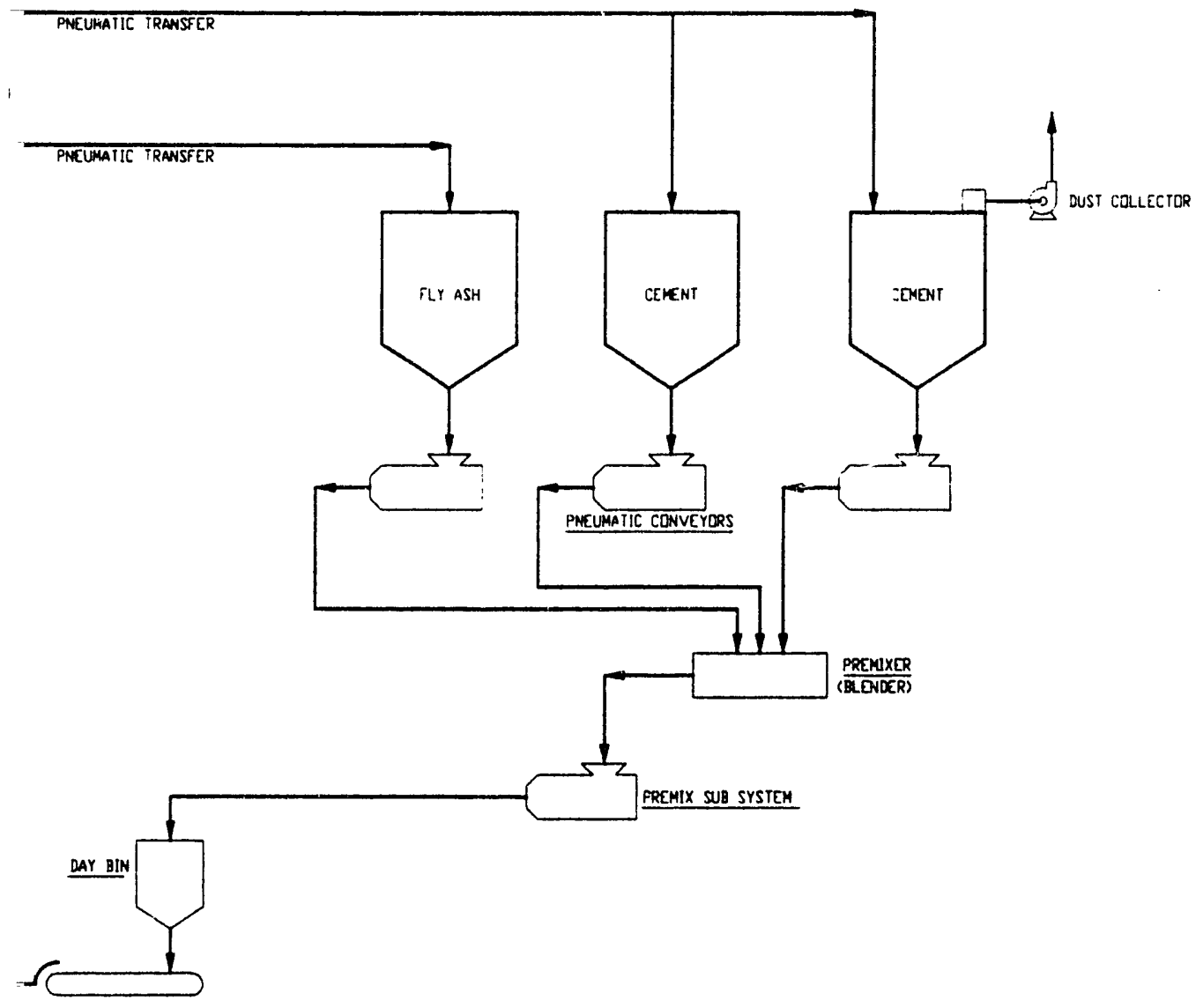

JST CQ_LECTOR
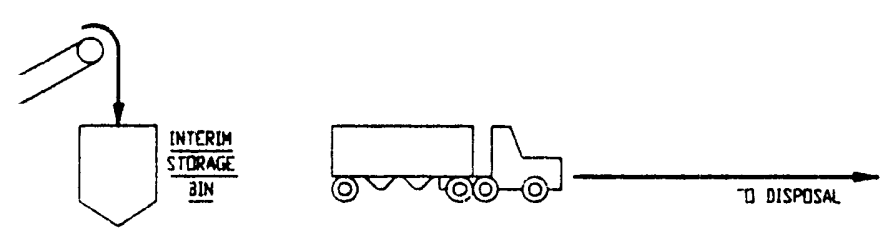
DOE/RL-93-35, Rev. 0

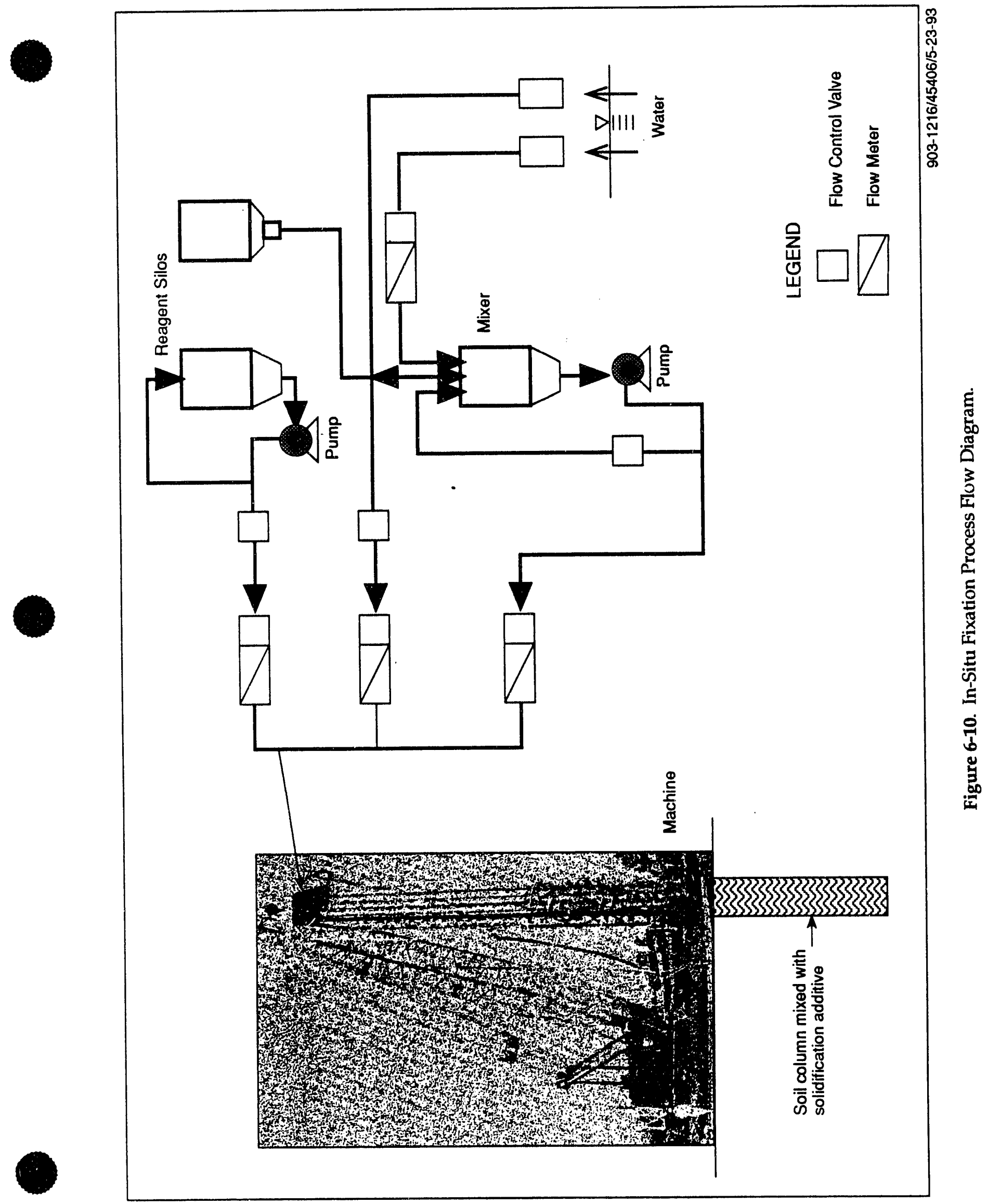


DOE/RL-93-35, Rev. 0

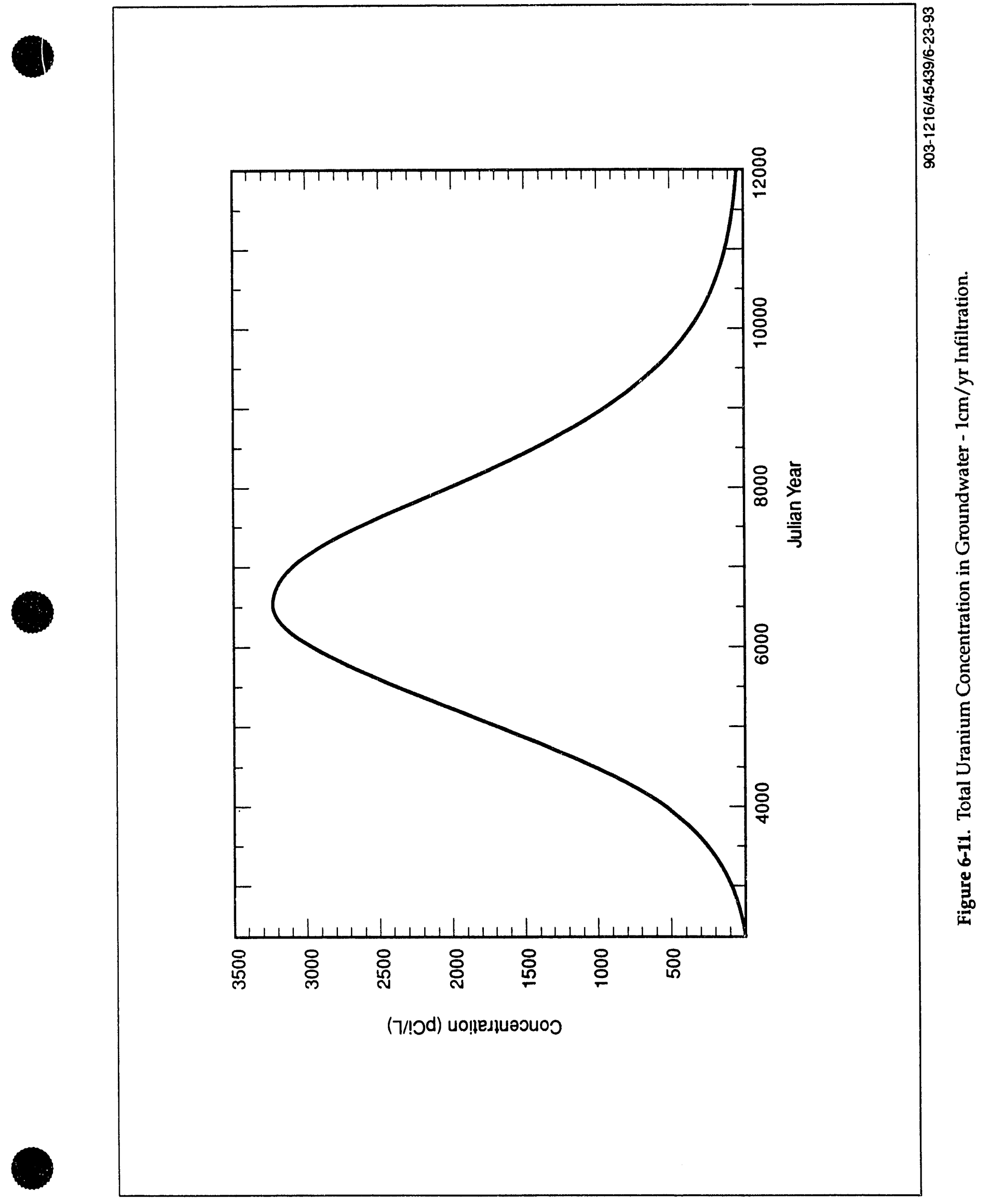


DOE/RL-93-35, Rev. 0

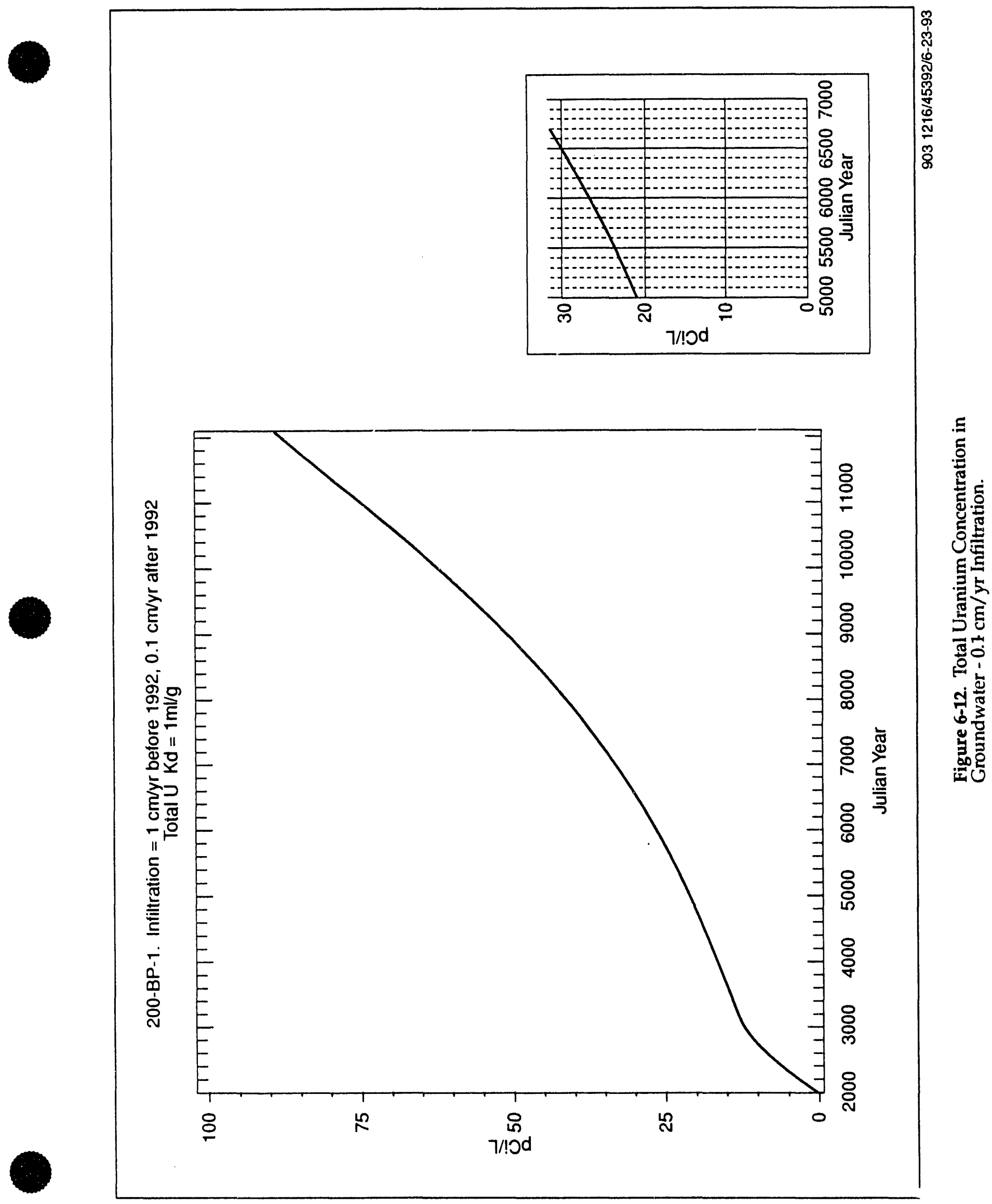


DOE/RL-93-35, Rev. 0

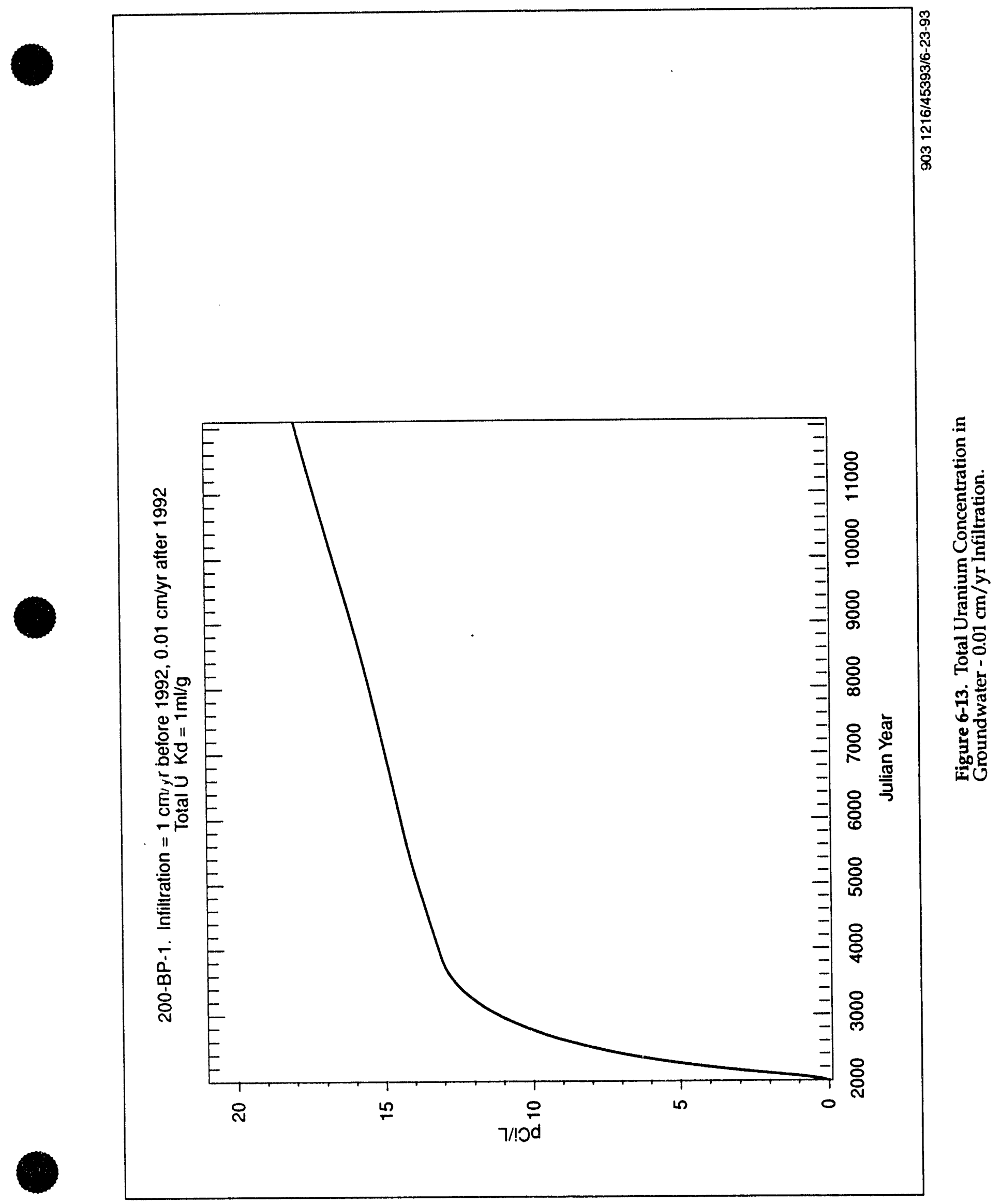


DOE/RL-93-35, Rev. 0

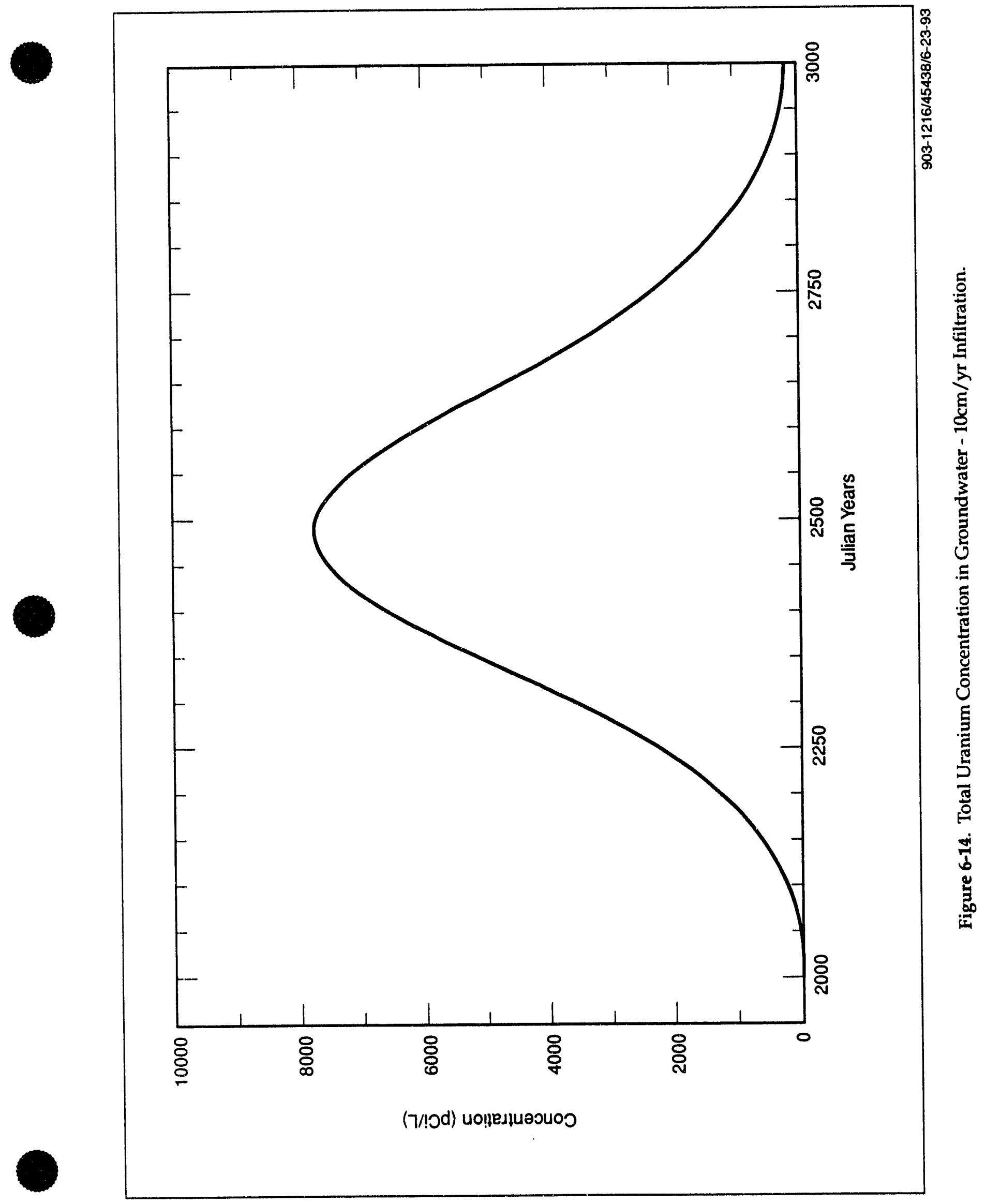


DOE/RL-93-35, Rev. 0

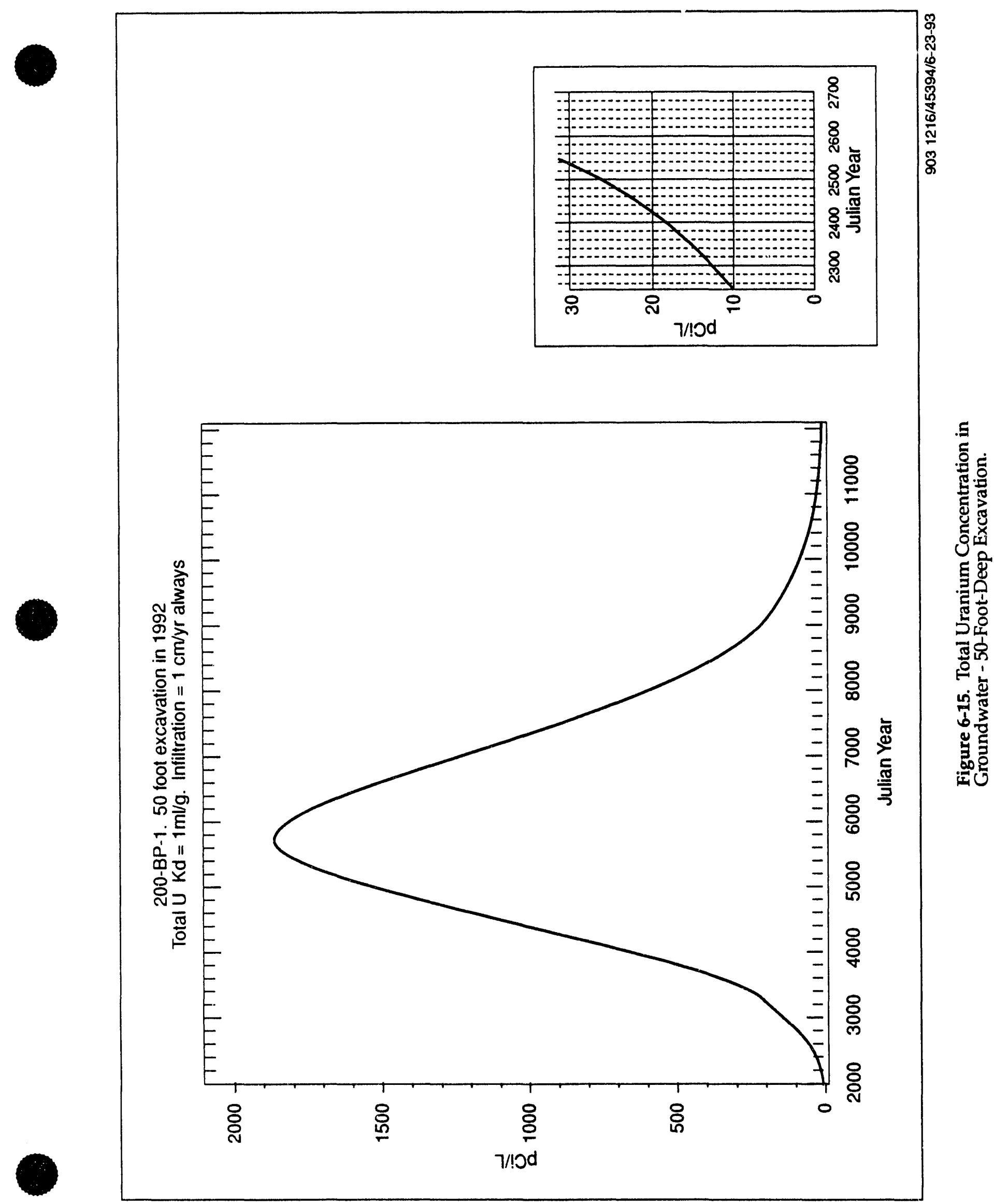


DOE/RL-93-35, Rev. 0

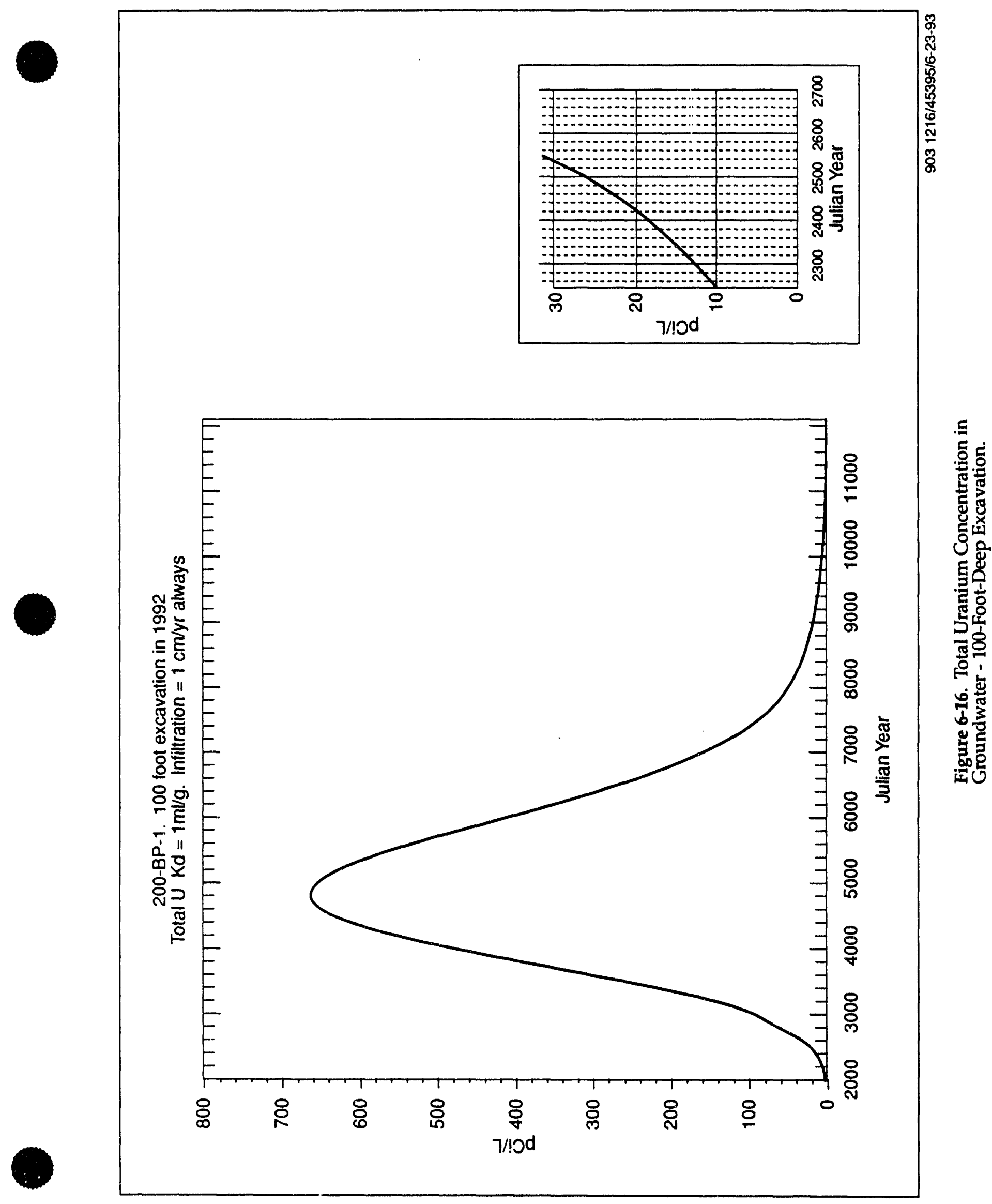


DOE/RL-93-35, Rev. 0

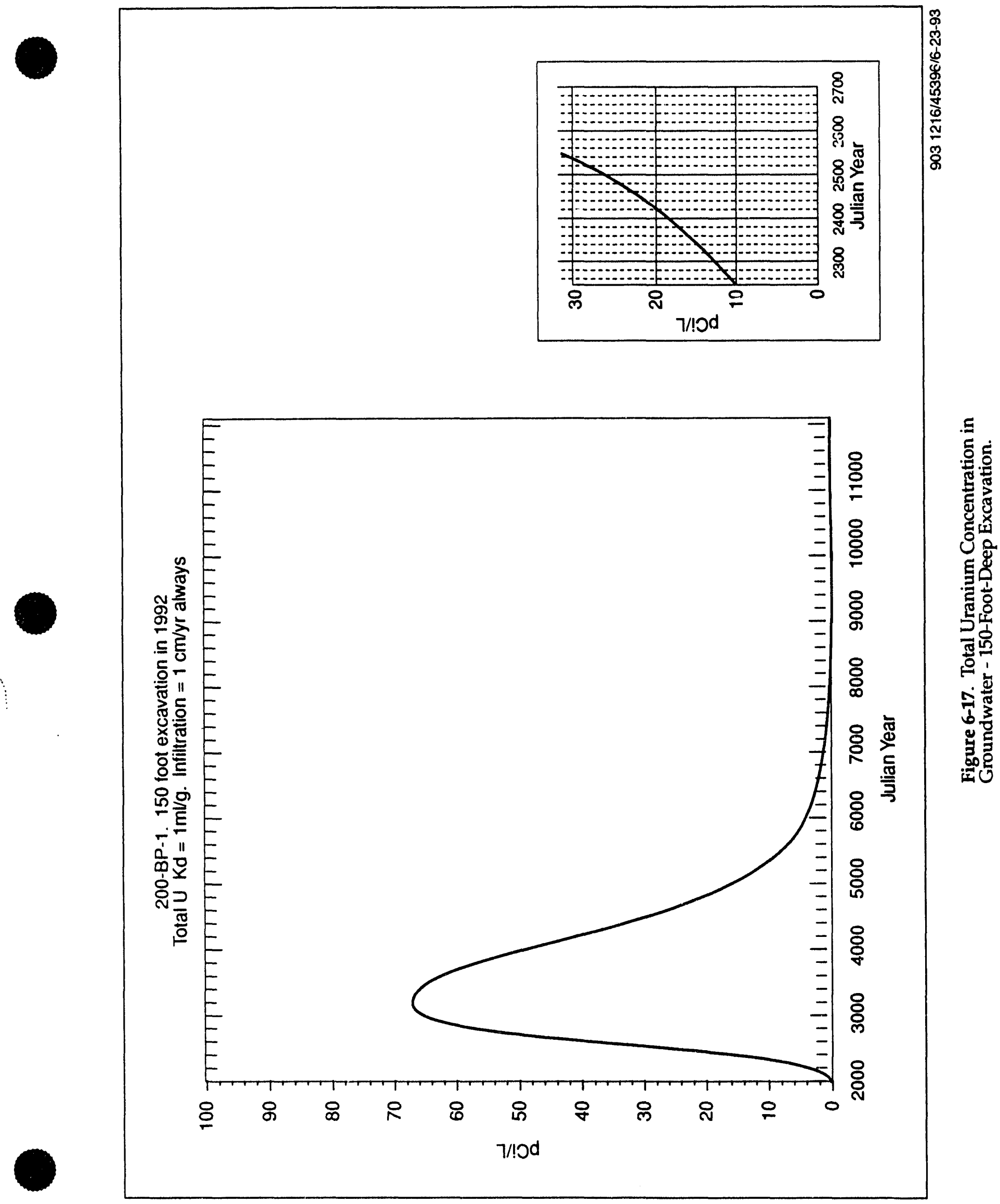




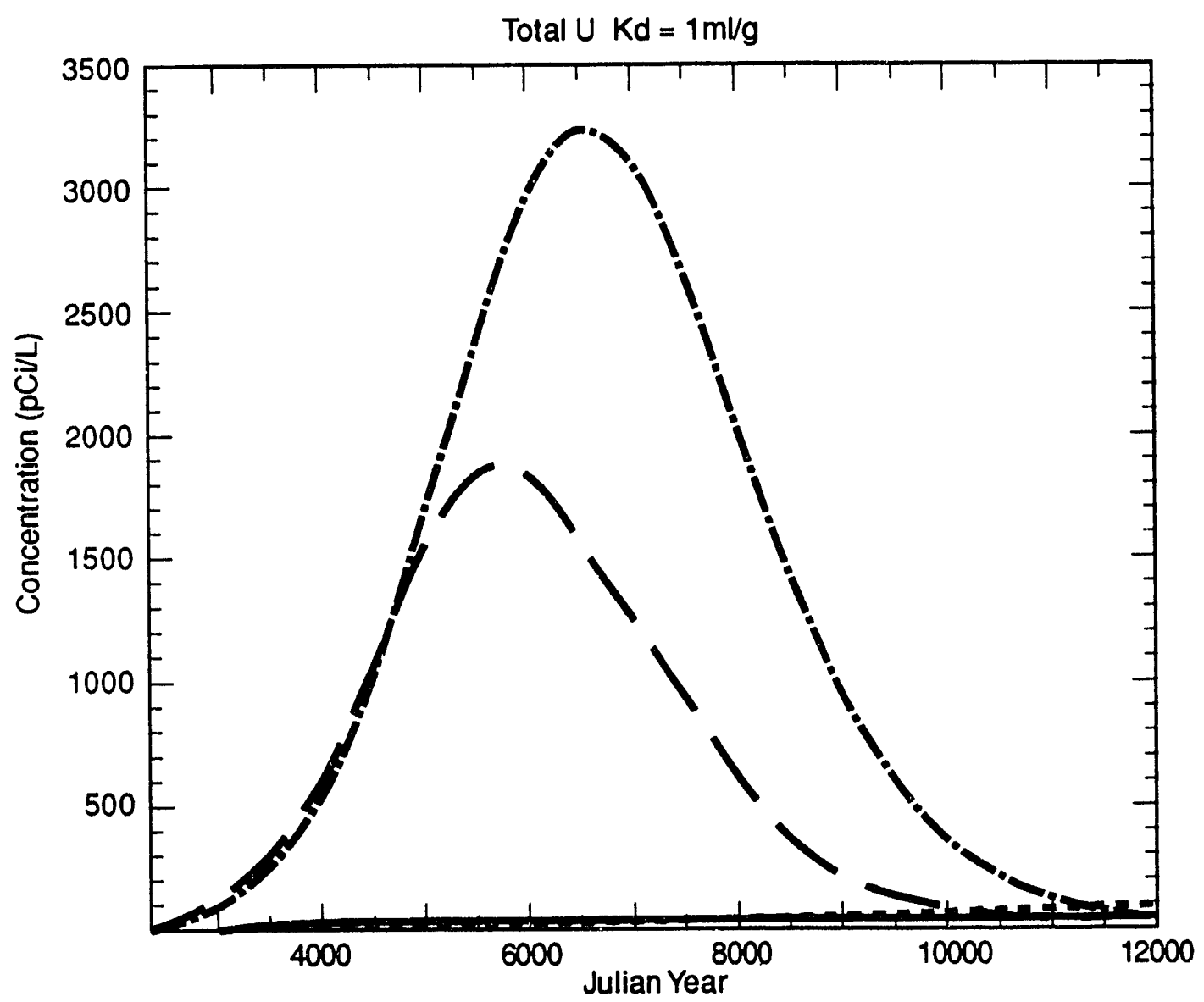

- 50-Foot Deep Excavation in $1992-$ Infiltration $=1 \mathrm{~cm} / \mathrm{yr}$

-... 1cm/yr Infiltration

- - $0.1 \mathrm{~cm} / \mathrm{yr}$ Infiltration - Infiltration $=1 \mathrm{~cm} / \mathrm{yr}$ before 1992, $0.1 \mathrm{~cm} / \mathrm{yr}$ after 1992

$0.01 \mathrm{~cm} / \mathrm{yr}$ Infiltration - Infiltration $=1 \mathrm{~cm} / \mathrm{yr}$ before 1992, $0.01 \mathrm{~cm} / \mathrm{yr}$ after 1992

Figure 6-18. Total Uranium Concentration in Groundwater - Comparison. 
Table 6-1. Rernediation Alternatives Retained for Detailed Evaluation. (Sheet 1 of 2)

\begin{tabular}{|c|c|c|c|}
\hline \multicolumn{2}{|c|}{$\begin{array}{l}\text { Alternative } \\
\text { No. Name }\end{array}$} & \multicolumn{2}{|c|}{ Description (Key Elements) } \\
\hline A & No Action & \multicolumn{2}{|c|}{ No remedial action; existing controls not maintained. } \\
\hline B & Institutional Controls & \multicolumn{2}{|c|}{$\begin{array}{l}\text { Deed restrictions; warning markers; fencing with periodic } \\
\text { maintenance. }\end{array}$} \\
\hline C & Biointrusion Barrier & & $\begin{array}{l}\text { Cover all contaminated areas with a barrier } \\
\text { designed to prevent biological growth. } \\
\text { Implement and maintain institutional controls and } \\
\text { monitoring. }\end{array}$ \\
\hline $\mathrm{D}$ & Modified RCRA Barrier & 1. & $\begin{array}{l}\text { Cover all contaminated areas with a } \\
\text { low-permeability barrier similar to designs for } \\
\text { hazardous waste sites. } \\
\text { Implement and maintain institutional controls and } \\
\text { monitoring. }\end{array}$ \\
\hline E & Hanford Barrier & & $\begin{array}{l}\text { Cover all contaminated areas with the low- } \\
\text { permeability Hanford Barrier. } \\
\text { Implement and maintain institutional controls and } \\
\text { monitoring. }\end{array}$ \\
\hline $\mathrm{F}$ & $\begin{array}{l}\text { Excavation and Soil } \\
\text { Washing }\end{array}$ & $\begin{array}{l}1 . \\
2 . \\
3 . \\
4 . \\
5 . \\
6 .\end{array}$ & $\begin{array}{l}\text { Excavate soil with the highest contamination. } \\
\text { Treat excavated soil by a soil washing process to } \\
\text { reduce the quantity of contaminated material } \\
\text { remaining after treatment. } \\
\text { Backfill treated soils meeting remedial action } \\
\text { objectives on-site. } \\
\text { Cover the backfilled excavation with a low- } \\
\text { permeability barrier. } \\
\text { Dispose of sludge or contaminated soil from } \\
\text { treatment in the ERSDF (or geologic repository, if } \\
\text { required. } \\
\text { Implement and maintain institutional controls and } \\
\text { monitoring. }\end{array}$ \\
\hline G & $\begin{array}{l}\text { Excavation and Soil } \\
\text { Washing with Vitrification }\end{array}$ & $\begin{array}{l}1 . \\
2 . \\
3 . \\
4 . \\
5 . \\
6 . \\
\text { 7. }\end{array}$ & $\begin{array}{l}\text { Excavate soil with the highest contamination. } \\
\text { Treat excavated soil by a soil washing process to } \\
\text { reduce the quantity of contaminated material } \\
\text { remaining after treatment. } \\
\text { Backfill treated soils meeting remedial action } \\
\text { objectives on-site. } \\
\text { Cover the backfilled excavation with a low- } \\
\text { permeability barrier. } \\
\text { Vitrify sludge or contaminated soil from treatment. } \\
\text { Dispose of vitrified sludge or contaminated soil } \\
\text { from treatment in the ERSDF (or geologic } \\
\text { repository, if required. } \\
\text { Implement and maintain institutional controls and } \\
\text { monitoring. }\end{array}$ \\
\hline
\end{tabular}


Table 6-1. Remediation Alternatives Retained for Detailed Evaluation. (Sheet 2 of 2)

\begin{tabular}{|c|c|c|c|}
\hline \multicolumn{2}{|c|}{$\begin{array}{l}\text { Alternative } \\
\text { No. Name }\end{array}$} & \multicolumn{2}{|c|}{ Description (Key Elements) } \\
\hline $\mathrm{H}$ & Excavation and Fixation & $\begin{array}{l}1 . \\
2 . \\
3 . \\
4 . \\
4 .\end{array}$ & $\begin{array}{l}\text { Excavate soil with the highest contaminant levels. } \\
\text { Treat excavated soil by fixation to immobilize } \\
\text { contaminants. } \\
\text { Return treated soil to the excavation. } \\
\text { Cover the backfilled excavation with a low- } \\
\text { permeability barrier. } \\
\text { Implement and maintain institutional controls and } \\
\text { monitoring. }\end{array}$ \\
\hline I & ERSDF Disposal & $\begin{array}{l}1 . \\
2 . \\
3 . \\
4 . \\
5 .\end{array}$ & $\begin{array}{l}\text { Excavate soil with the highest contaminant levels. } \\
\text { Dispose of excavated soil in the ERSDF (or } \\
\text { geologic repository for some soil, if required). } \\
\text { Backfill the excavation with clean soil. } \\
\text { Cover the backfilled excavation with a low- } \\
\text { permeability barrier. } \\
\text { Implement and maintain institutional controls and } \\
\text { monitoring. }\end{array}$ \\
\hline$J$ & In Situ Fixation & $\begin{array}{l}1 . \\
2 . \\
3 .\end{array}$ & $\begin{array}{l}\text { Treat soil with the highest contaminant levels in } \\
\text { place by fixation. } \\
\text { Cover ali contaminated areas with a low- } \\
\text { permeability barrier. } \\
\text { Implement and maintain institutional controls and } \\
\text { monitoring. }\end{array}$ \\
\hline
\end{tabular}




\subsection{COMPARATIVE EVALUATION OF ALTERNATIVES}

The primary purpose of the FS is to provide as much information as possible to assist the decision makers and the public in selecting the preferred remedial alternative. The detailed analysis of alternatives presented in Chapter 6 includes an evaluation of each alternative against the seven technical criteria as required by the NCP in 40 CFR 300.430 (e)(9). This chapter uses the analysis in Chapter 6 to develop comparative evaluations of the alternatives. In accordance with the NCP and CERCLA guidance, the preferred alternative is not identified in the FS. Rather, all of the information supporting a comparative analysis should be presented in the FS, leaving identification of the preferred alternative to the decision makers; in this case the signatories to the Tri-Party Agreement: the DOE, the EPA, and Ecology. Following review of this FS, the DOE, the EPA and Ecology will prepare a proposed plan identifying the preferred alternative, which is provided with the FS for public review and comment. The final decision will be documented in the ROD for site remediation.

\subsection{EVALUATION CRITERIA}

The NCP requires evaluation of remedial alternatives in terms of 9 criteria described in 40 CFR 300.430(e)(9):

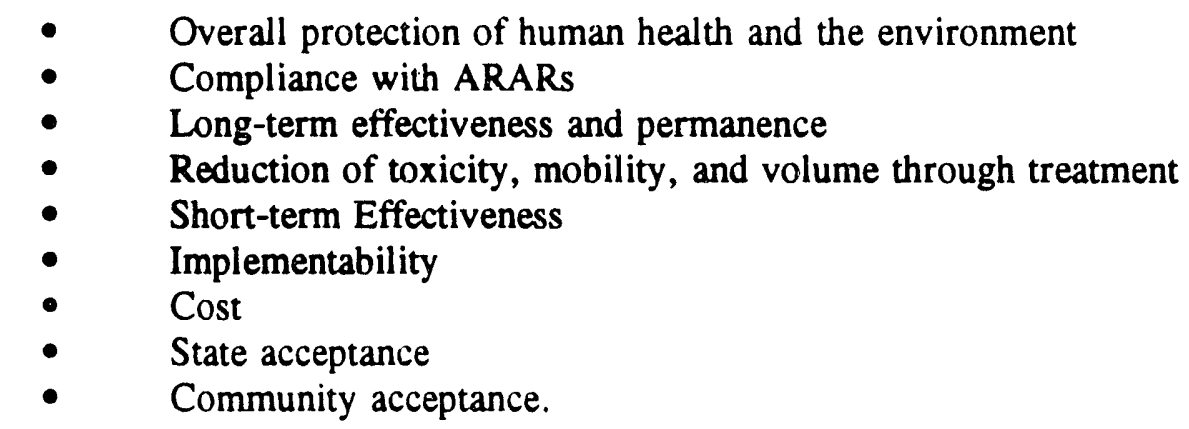

Each of the evaluation criteria are defined in detail below in terms of their specific applicability to the 200-BP-1 operable unit remedial alternatives. Although the NCP and EPA guidance (EPA 1988) form the basis for the specific criteria definitions, a number of the element: contained in the NCP and guidance were either not applicable or insignificant when comparing the 200-BP-1 operable unit remedial alternatives. For example, since radionuclides cannot be destroyed or transformed into less hazardous substances, reduction of toxicity is not applicable. The criteria have been refined accordingly.

In general, the criteria definitions provided in the next section are intended to be as precise as possible. Well-defined criteria will minimize misunderstandings between the concernad parties and facilitate effective communication during selection of the preferred alternative. In addition, the definitions have been refined to minimize the overlap of considerations that often exists among the criteria. This allows decision makers to consider each criterion independently and minimizes double counting of criteria. In addition, the criteria definitions are formulated to facilitate value comparisons between the criteria; that is, determining the value of each criterion in terms of the other criteria. 


\subsubsection{Overall Protection of Human Health and the Environment}

This criterion is a threshold criterion that must be met by the selected alternative. It will not be used during the comparative evaluation of the alternatives because it relies on the assessments conducted for other criteria, i.e., long term effectiveness and permanence, reduction of toxicity, mobility and volume, short term effectiveness, and compliance with ARARs. It is not an independent criterion but is rather an umbrella criterion under which the others fall.

\subsubsection{Compliance with ARARs}

Compliance with ARARs is also a threshold criterion that must be met by the preferred alternative. Evaluation of this criterion involves determining if the alternative will meet all the federal and state ARARs. If an ARAR is not met, the basis for justifying one of the six waivers allowed under CERCLA may be provided. If a waiver is not possible, the alternative must be eliminated from further consideration.

As described in Section 6.4.1.2, none of the alternatives satisfy the following potential ARARs:

- The MTCA Method B standards for current technetium-99 and cobalt-60 discharges to groundwater

- The MCL for current nitrate discharge to groundwater

Whether or not MTCA Method B standards and current discharges exceeding MCLs are valid ARARs must be determined by the regulators. In addition, the appropriate ARAR for the period of performance for future discharges of uranium in excess of MCLs must also be determined by the regulators. Depending on the final ARAR determination, application for a waiver may be necessary. The alternatives are equivalent in terms of compliance with ARARs, for current discharges, and the period of performance for future discharges of uranium is best evaluated in terms of long-term effectiveness. Therefore, this criterion will not be utilized in the comparative evaluation.

\subsubsection{Long-term Effectiveness and Permanence}

Long-term effectiveness and permanence addresses risks remaining at the site after the remedial alternative has been implemented. This involves an estimate of the residual risk associated with each alternative in comparison to the baseline risk assessment, and an evaluation of the adequacy and reliability of controls. Risks during the implementation period are addressed under short-term effectiveness.

The Phase I RI Report and baseline risk assessment indicated that significant risk levels would be associated with the 200-BP-1 operable unit due to direct exposure and future releases to groundwater. The risk associated with direct exposure is expected to be orders of magnitude greater than the risk associated with the groundwater pathway. However, the risk assessment assumed that direct exposure would occur after the contaminated soils were excavated and exposed at the surface. The risk assessment also assumed that groundwater directly beneath the site would be extracted and consumed. 
Given the two operable exposure pathways and their associated risks, long-term effectiveness and permanence will be measured in the terms of the following remedial action objectives:

- $\quad$ Reducing the potential for intrusion and exposure to the contaminated soil, - Minimizing future groundwater contamination.

Currently, contaminated soils at the 200-BP-1 operable unit are not exposed at the surface and no one is drinking groundwater impacted by releases from the operable unit; consequently, the actual current risk associated with the 200 BP-1 operable unit is $<10^{-6}$. This risk level will remain unchanged as long as the current institutional controls are maintained. Institutional controls are included in all the alternatives except Alternative A (No Action). Therefore, with the exception of the No Action alternative, the residual risk associated with the alternatives is $<10^{-6}$ (assuming no degradation of institutional controls). Any significant difference between the alternatives is due to differences between the adequacy and reliability of controls. Considerations that are significantly different for the candidate alternatives and that will be addressed under this criterion include the following:

- $\quad$ Presence of a barrier and differences in reliability between the barrier alternatives,

- Reliability of reduction of volume and/or mobility due to treatment, and

- Removal and disposal of the most contaminated material in the ERSDF, which may have slightly more reliable containment and institutional controls.

Note that treatment is addressed in this criteria only to the extent that it improves the adequacy and reliability of controls. Treatment specifically to reduce volume and mobility is addressed in the next criterion.

In general, both risks to human health and to the environment are included in this criterion. For the 200-BP-1 operable unit, however, which is located far from the Columbia River or any other readily accessible portion of the undisturbed environment, human health risks should greatly exceed any environmental risks. This is particularly true with regards to the groundwater pathway, since concentrations in groundwater extracted near the site (a human pathway) would be much higher than concentrations at the river (both a human and environmental exposure pathway). Biota intrusion into the subsurface contaminated soils is a long-term concern because it may bring contaminants to the surface and result in human exposure. Since no critical habitats or sensitive environments are present in the immediate vicinity of the operable unit, only human health will be considered when comparing the alternatives in terms of long-term effectiveness and permanence.

\subsubsection{Reduction of Toxicity, Mobility, and Volume through Treatment}

In accordance with the NCP, a preference for treatment must be included in the CERCLA process. Since the toxicity of radionuclides cannot be reduced, the only types of treatment included in the alternatives are mobility reduction (fixation and vitrification) and volume reduction (soil washing). This criterion will be measured in terms of whether the alternative reduces volume and/or mobility through treatment. Effectiveness and reliability of the treatment, which is addressed under long-term effectiveness and permanence, will not be addressed under this criterion. 


\subsubsection{Short-term Effectiveness}

Short-term effectiveness addresses the consequences of the alternative during implementation. In general, the following types of consequences are included:

- $\quad$ Risk to the community,

- $\quad$ Risk to the workers,

- $\quad$ Risk to the environment, and

- Time until remedial action objectives are achieved.

The only significant short-term exposure pathway for the community is the air pathway. The baseline risk assessment indicated that exposures due to a worst case air release, with all subsurface contaminated soils exposed on the surface, would not exceed

$10^{-6}$ to any off-site community. Therefore, risk to the community should be insignificant when compared with worker risk and will not be considered in the alternative comparison.

Although the excavation and capping alternatives will involve significant disruption of the ground surface, the 200-BP-1 operable unit is already a disturbed area and does not currently support significant or unique ecological resources. Therefore, environmental impacts, such as habitat destruction, are not a significant element in short-term effectiveness and will not be addressed in the evaluation.

The amount of time until the remedial objectives are achieved is only a factor if the current risks are significant. As explained in Section 7.1.3, the risk associated with the 200-BP-1 operable unit is currently $<10^{-6}$ and will remain at this level as long as institutional controls are maintained. Therefore, short-term risk to human health is not significantly impacted by the time required to achieve remedial action objectives.

In short, the only significant element of short-term effectiveness is worker risk. Worker risk includes both physical and radiation exposure hazards associated with construction, operation, and maintenance of remedial alternatives. Physical hazard will be measured in terms of expected worker fatalities and radiation exposure will be measured in terms of total rems of worker exposure during implementation of the alternative. Both of these measiures incorporate the rate of occurrence or exposure, the number of workers, and duration. Therefore, less dangerous activities that require many workers or are longer in duration may have higher total fatalities and radiation exposure, than more dangerous activities with fewer workers or shorter duration.

\subsubsection{Implementability}

Implementability factors can be divided into technical feasibility, administrative feasibility, and availability of services and materials. Implementability issues become more significant as the complexity of the alternative increases and as the reliance on innovative technology increases.

Implementability issues are important to decision makers because they effect the potential for delays, cost overruns, unfavorable public opinion, and even failure. Expected costs and effectiveness (short and long term) are addressed in other criteria. 
The primary implementability issues for the 200-BP-1 operable unit remedial alternatives include:

- Complexity of the remedial alternative in terms of facilities, equipment, and scheduling,

- Necessity of excavation shoring to protect the nearby single-shell tanks in the 241-BY Tank Farm,

- Amount of landfill space required (this is important because the availability of landfill space is not guaranteed), and

- Likelihood of technical problems associated with untested technology and potential for cost overruns.

Implementability will be measured in terms of how these factors increase the potential for problems during implementation and the necessity for contingency planning.

\subsubsection{Cost}

Costs for each of the alternatives were provided in Chapter 6 and supported in the Appendices. These cost estimates included both capital costs and the present value of operation and maintenance costs. Costs are relatively straight forward to estimate and compare. Cost does not include indirect factors, such as the change in land value after remediation is completed. In addition, total life cycle costs have not been considered. For example, if a Hanford Barrier were installed prior to remediation of the 241-BY Tank Farm and then destroyed when the tank farm is remediated, replacement costs or changes to the final remedial alternative for the 200-BP-1 operable unit have not been considered. While it is proper to consider such costs, the uncertainties in the likely remediation of adjacent operable units prevents a valid consideration of complete life cycle costs. The potential for cost overruns is considered under implementability.

\subsubsection{State Acceptance}

In accordance with the NCP, State concerns cannot be incorporated until comments are received on the FS, but they may be discussed in the proposed plan.

\subsubsection{Community Acceptance}

The NCP, in Section 430 (e)(9)(iii)(I), states that assessment of community concerns may not be completed until comments on the proposed plan are received. The concerns of the public will be reviewed and discussed by the DOE, the EPA and Ecology to determine if the preferred alternative remains the most appropriate remedial action for the 200-BP-1 operable unit. 


\subsection{METHODOLOGY}

The methodology used for comparison of the remedial alternatives includes the following steps:

1) Determine the relative scores for each alternative against the five evaluation criteria. As defined in Section 7.1, comparisons are made for long-term effectiveness, short-term effectiveness, reduction in toxicity, mobility, and volume through treatment, implementation ability and cost. These scores should not reflect any value judgements and they should represent measurable performance criteria to the greatest extent possible. Overall protection, compliance with ARARs, and state and community acceptance are not considered for the reasons stated previously.

2) Develop normalized criteria scores using a value function to translate the relative scores to a preference rating. This value function should reflect the values of the decision makers and may be linear or non-linear. The normalized criteria scores will be on a scale of zero to ten, with zero being the least preferred alternative and 10 being the most preferred alternative.

3) Weight the criteria in terms of relative importance to the decision makers.

4) Calculate the composite scores for each alternative using a multi-variate decision analysis computer program.

5) Determine the sensitivity of the results to the value function used to develop the normalized criteria scores.

6) Determine the sensitivity of the results to weighting of the criteria.

For criteria that can be measured quantitatively, (such as short-term risk and cost) assigning the relative scores was straight-forward. For the other criteria, however, relative scores were based upon qualitative comparisons and professional judgement.

With the exception of cost, linear value functions were used for developing the normalized criteria scores. Non-linear value functions are generally more appropriate when the raw criteria scores are spread over a large range and the perceived benefit is not proportional from one end of the range to the other end, as was the case with the cost criteria.

The results using best engineering judgement to establish weighting of criteria are provided in this report. Other weighting schemes are the responsibility of the decision makers, and should be considered, evaluated, discussed, and carefully examined during discussions between the concerned parties. In fact, different parties may prefer different weightings. Similarly, differing value functions may also be considered. Differences between the parties will be resolved during negotiations and will lead ultimately to the selection of an overall preferred alternative.

A sensitivity analysis using the best engineering judgement criteria weightings is provided in Section 7.5. Since the results of the sensitivity analysis are dependant upon the starting point, or base case, this sensitivity study provides a starting point for discussion among decision makers. Sensitivity of the results to changes in the criteria value functions is only conducted for cost which applied a nonlinear value function. Sensitivity of the results to criteria weighting is provided for all the criteria. 
Sensitivity of the results should be reevaluated when the decision makers have reached consensus on the general form of the value functions and the weighting of the criteria.

Although the methodology described above could be conducted using a spreadsheet program, a multi-variate decision analysis computer program called HIPRE 3+ (Hämäläinen, 1992) was used for the FS. This program facilitates interactive input of information, sensitivity analysis of the results, and graphical display of the output. The program can be obtained from Santa Monica Software in Malibu, California.

\subsection{COMPARISON OF ALTERNATIVES}

Relative scores for each of the alternatives against each of the five comparison criteria are provided in this section.

\subsubsection{Long-term Effectiveness and Permanence}

Relative scores for each of the alternatives in terms of long-term effectiveness and permanence were assessed directly and are provided in Table 7-1. Note that the most significant factor in long-term effectiveness is institutional controls, which are included in all the alternatives except the No Action alternative. This is because institutional controls will maintain the current risk at $<10^{-6}$. The only benefit obtained from any other actions are strictly in terms of permanence and reliability and are considered less significant.

As discussed in Section 7.1.3, differences in terms of permanence are associated with the type of surface barrier, the location of the most contaminated material and the treatment benefits. The scores listed in Table 7-1 are based upon the following assumptions:

- The benefit associated with Institutional Controls over no-action is considered equal to the additional benefit associated with Alternative G. Therefore, Institutional Controls is scored a 5.

- The Biointrusion Barrier alternative provides additional reliability against biota intrusion compared with Institutional Controls. But this reliability is only important if institutional controls fail, and in the meantime the rate of infiltration is increased by the bio barrier. Due to the infiltration increase the Biointrusion Barrier is scored lower (i.e., 4) than Institutional Controls alone.

- The RCRA Barrier and the Hanford Barrier alternatives provide infiltration reduction and increased reliability in terms of preventing intrusion when compared with Institutional Controls. These benefits are considered to be approximately 40-60 percent of the benefits associated with going from No Action to Institutional Controls. Therefore, the Modified RCRA Barrier is scored a seven and the Hanford Barrier is scored an eight.

- Two of the excavation alternatives, which include disposal in the ERSDF with no treatment are considered relatively equal to the Hanford Barrier alternative; all three alternatives are scored an 8 . This is primarily because the ERSDF is presumed to include a Hanford Barrier. Any benefits from increased control 
over the ERSDF are countered by the fact that the contamination rumaining in the 200-BP-1 operable unit would be covered by a RCRA barrier in the excavation alternatives. Note that the Excavation and Soil Washing alternative, which only reduces volume and would result in a more hazardous concentrate, is not considered a significant improvement in permanence and reliability.

- The fixation alternatives are considered more reliable than the Hanford Barrier because fixation provides a second type of protection above and beyond that of a surface barrier; these alternatives are scored a 9. Both of the fixation alternatives include a RCRA Barrier over the 200-BP-1 operable unit. Therefore, the incremental benefit of going from the RCRA Barrier to the fixation alternatives is considered to be twice the incremental benefit of going from the RCRA Barrier to the Hanford Barrier. Although Ex-situ Fixation is considered slightly more effective than In-situ Fixation, the difference is too small to warrant differentiating the scores.

- The Excavation, Soil Washing, and Vitrification alternative includes disposal of the most contaminated material in the ERSDF and a RCRA barrier over the 200-BP-1 operable unit; this alternative is scored a 10. Vitrification combined with disposal in the ERSDF under a Hanford Barrier is considered a 10 percent improvement over the fixation alternatives.

A linear value function was used to transform these criteria scores to a normalized preference scale; therefore, the preference scores are the same as the criteria scores.

\subsubsection{Reduction of Toxicity, Mobility, and Volume through Treatment}

Since the toxicity of radionuclides cannot be reduced except through decay with time, none of the alternatives reduce toxicity. Four of the ten alternatives include some form of treatment that results in reduction of mobility and/or volume. The remaining six alternatives are assigned a score of zero for this criterion. Scores for the four treatment alternatives assume that volume reduction (via soil washing) and mobility reduction (via fixation or vitrification) are equivalent. Therefore, alternatives with either volume reduction or mobility reduction are scored a five and the one alternative (Alternative $G$ ) with both volume and mobility reduction is scored a 10 . Treatment scores for the alternatives are summarized in Table 7-2. A linear value function was used to transform these criteria scores to a normalized preference scale; therefore, the preference scores are the same as the criteria scores.

\subsubsection{Short-term Effectiveness}

Short-term effectiveness will include two sub-criteria: total worker radiation exposure (in rems) and probability of an accident resulting in a worker fatality.

Radiation exposure is measursi as the assumed total radiation exposure measured in rems. This information was provided in Chapter 6 for each of the alternatives and is summarized in Table 73. Total radiation exposure for the alternatives ranges from 0 to 770 rems. These measurements of 
short-term effectiveness will be transformed to a normalized preference scale of zero to ten using a linear value function. A graph of the value function is shown on Figure 7-1.

Probability of a fatal worker accident ranges from 0 to 0.031 . Ayain, a linear value function was used to transform the criteria scores into normalized preference scores on a scale of zero to ten. A graph of value function is shown in Figure 7-2.

\subsubsection{Implementability}

The scores for implementability were assessed directly and are shown in Table 7-4. They rely upon the following assumptions:

- No implementability difficulties are associated with the No Action alternative, which is scored a 10.

- Because the implementability issues associated with imfiementation of Institutional Controls are insignificant compared with exxcavation complexities and potential problems, Institutional Controls are scored the same as the No Action alternative.

- Compared with excavation alternatives, the implementability issues associated with surface barrier construction are minor. Differences between the barriers are insignificant and they are all scored a 9.

- In-situ soil fixation is a more complex and less developed technology then barrier construction. For this reason, the In-situ Fixation alternative is scored a 7 .

- Although excavation in itself is not more complex than barrier construction, the measures necessary to prevent significant worker exposure will be very complex, including remote equipment, decontamination facilities, and dust control to prevent air releases. The shoring for the nearby tank farms will also add significant complexity. For these reasons, the excavation and disposal alternative with no treatment will be scored a 2 .

- The fixation and soil washing facilities will involve additional complexities above and beyond those associated with excavation. Therefore, scores for these alternatives will be lowered to 1 .

- The Excavation, Soil Washing and Vitrification alternative will be scored a zero with regards to implementability $(0)$ due to having two treatment facilities.

A linear value function was used to transform these scores to a normalized preference scale; therefore, the preference scores are the same as the criteria scores. 


\subsubsection{Cost}

Costs for each of the alternatives were provided in Chapter 6 and are summarized in Table 7-5. Costs for the alternatives range from $\$ 1.1$ million to $\$ 254$ million. These cost measurements were transformed to a zero to ten preference scale using the value function shown on Figure 7-3. An inverse linear value function would imply that a cost decrease from $\$ 20$ million to $\$ 10$ million would be equivalent to a cost decrease from $\$ 240$ million to $\$ 230$ million. In reality, a cost decrease of $\$ 10$ million over $\$ 240$ million is not as significant as cutting costs from $\$ 20$ million to $\$ 10$ million. Instead, the value function utilized in this evaluation decreases at a rate of $\$ 4$ million per preference unit between $\$ 0$ and $\$ 30$ million, and $\$ 90$ million per preference unit between $\$ 30$ million and $\$ 255$ million. If desired, other value tunctions could be used by the decision makers.

\subsection{WEIGHTING OF THE CRITERIA}

Criteria weights should reflect the values of the decision makers and can be determined by developing equivalency relationships between the criteria. Equivalency relationships are determined by asking the decision makers to trade off criteria units. For example, how many units of short-term effectiveness would the decision makers trade for a unit of long-term effectiveness? Note that the scale of the units must be considered in making such tradeoffs.

Weightings based on best engineering judgement used for the analysis are provided in Table 7-6. Examples of the resulting equivalency relationships include the following:

- One preference unit of long-term effectiveness equals 10 preference units of treatment.

- $\quad$ One preference unit of long-term effectiveness equals 4 preference units of short-term effectiveness. Since short-term effectiveness consist of 50 percent worker radiation exposure and 50 percent accidental worker fatalities, one preference unit of long-term effectiveness is equivalent to either 616 rems of worker radiation exposure or 0.025 accidental worker fatalities.

- One unit of long-term effectiveness equals 6.7 units of implementability.

- One unit of long-term effectiveness equals $\$ 4$ million when costs are between $\$ 0$ and $\$ 10$ million, $\$ 8$ million when costs are between $\$ 10$ million and $\$ 30$ million, $\$ 16$ million when costs are between $\$ 30$ million and $\$ 70$ million, and $\$ 80$ million when costs are between $\$ 70$ million and $\$ 270$ million.

The composite scores resulting from these weights are listed in Table 7-6 and graphically displayed in Figure 7-4. For these criteria weights, the Hanford Barrier has the highest composite score. In general, composite scores for the other barrier alternatives and the Institutional Controls alternative are significantly higher than the composite scores for the excavation alternatives. The composite scores for the No Action and In-situ Fixation alternatives are between the surface barrier alternatives and the excavation alternatives. Given these criteria weights, the composite scores are most dependent upon cost and long-term effectiveness and relatively insensitive to the remaining three criteria. 


\subsection{SENSITIVITY STUDY}

Sensitivity calculations were performed to demonstrate the sensitivity of the results to changes in weighting of the criteria. The results of the sensitivity study only consider changes in one criterion weight at a time. Changing more than one criterion weight at a time may provide different results but the number of combinations are too numerous to provide in this document. Changing multiple criteria weights should be conducted during discussions between the decision makers and should reflect the values of the decision makers. The purpose of these sensitivity calculations is too provide information to the readers of this FS and the decision makers.

The sensitivity of the composite scores to changes in weighting of long-term effectiveness and permanence is shown in Figure 7-5. As shown in this figure, as the importance of this criteria decreases from 0.4, the highest scoring alternative switches from the Hanford Barrier to Institutional Controls (at a weight of approximately 0.3 ). As the importance of long-term effectiveness increases from 0.4, the highest scoring alternative switches from the Hanford Barrier to Alternative $G$ Excavation, Soil Washing and Vitrification (at a weight of approximately 0.8 ).

The sensitivity of the composite scores to changes in weighting of short-term effectiveness and permanence is shown in Figure 7-6. As shown in this figure, decreasing the importance of short-term effectiveness does not change the highest scoring alternative. As the importance of short-term effectiveness increases from 0.1 , the highest scoring alternative switches from the Hanford Barrier to Institutional Controls (at a weight of approximately 0.35 ).

The sensitivity of the composite scores to changes in weighting of implementability is shown in Figure 7-7. As shown in this figure, the highest scoring alternative does not change as the importance of this criterion decreases. As the importance of implementability increases from 0.06 , the highest scoring alternative switches from the Hanford Barrier to Institutional Controls (at a weight of approximately 0.3 ).

The sensitivity of the composite scores to changes in weighting of treatment effects is shown in Figure 7-8. As shown in this figure, the highest scoring alternative remains the Hanford Barrier as the importance of this criterion decreases. As the importance of treatment effects increases from 0.04 , the highest scoring alternative switches from the Hanford Barrier to Alternative G - Excavation, Soil Washing, and Vitrification (at a weight of approximately 0.3 ).

The sensitivity of the composite scores to changes in weighting of cost is shown in Figure 7-

9. As shown in this figure, as the importance of this criterion decreases from 0.4 , the highest scoring alternative switches from the Hanford Barrier to In-situ Fixation (at a weight of approximately 0.1). As the importance of cost increases from 0.4, the highest scoring alternative switches from the Hanford Barrier to the RCRA Barrier (at a weight of approximately 0.5 ) and then to Institutional Controls (at a weight of approximately 0.55 ).

\subsection{SUMMARY AND CONCLUSIONS}

As described in the 200-BP-I operable unit Phase I RI Report, cribs 216-B-43 through 216-B49 which received the most concentrated wastes, were used in the mid 1950's and have received no discharges since 1955. Cribs 216-B-50 and 216-B-57 received high volumes of relatively lower concentrated wastes and were not used after 1975. High concentrations of cesium-137, and strontium-90 are found near the base of the cribs and pose a significant direct exposure risk. 
Discharges to these cribs have also resulted in groundwater contamination, with some contaminants (i.e., technetium-99, cobalt -60 and nitrate) currently reaching groundwater in excess of ARARs. However, the vast majority of the mobile contaminants have long since reached groundwater and contributions from the cribs are declining. Future long-term impacts to groundwater are primarily associated with uranium from the 216-B-43 through 216-B-50 cribs. There does not appear to be any potential for long-term groundwater impacts associated with crib 216-B-57.

The results of the baseline risk assessment indicate that given the existing institutional controls, the current risk from this operable unit is insignificant (i.e., < 106) (DOE/RL 1993). However, practical, rational, and cost effective remediation is required for long-term protection of human health and the environment. These conditions are expected to be typical of numerous waste disposal sites in the 200 Area. Since the FS for the 200-BP-1 operable unit will be the first FS completed in the 200 Area on the Hanford Site, the remedy selected for this site will establish precedence for similar problems at other 200 waste area groups.

Consideration must also be given in the selection of a remedy to the impacts and implications of potential remedial measures at adjacent operable units (i.e., the single-shell tanks in 241-BY tank farm in the 200-BP-7 operable unit). In addition, RI/FS activities are currently being conducted on an aggregate area basis. This process may result in selection of remedial alternatives that can be implemented more cost effectively on a large scale, than by implementing actions solely at the 200BP-1 operable unit.

For this FS composite scores were determined for the alternatives using weights for the comparison criteria. Given these weights, the highest scoring alternative was the Hanford Barrier, followed by the RCRA barrier, Institutional Controls, and the Biointrusion barrier. There is a significant drop to the next alternative, In-Situ Fixation, which scores slightly better than No Action. All the alternatives which include excavation scored significantly lower than the No Action alternative.

A sensitivity analysis was conducted to determine the sensitivity of the composite scores to weighting of the criteria. As illustrated on Figures 7-4 to 7-9, the Hanford Barrier is the highest scoring alternative across a broad range of criteria weights. Although these results may be different given alternative weighting of the criteria, it does reflect that the Hanford Barrier was specifically designed to provide cost-effective, long-term protection for waste sites similar to the 200-BP-1 operable unit.

While long-term groundwater impacts are significant risk drivers for the 216-B-43 through 216-B-50 cribs, this is not the case for crib 216-B-57. Although a comparative analysis was not conducted specifically for crib 216-B-57, Institutional Controls, and at most the Biointrusion Barrier would be expected to score the highest for the 216-B-57 crib. Crib 216-B-57 was not addressed separately because the decision has previously been made to install a prototype Hanford Barrier over this crib. The design is currently underway with installation planned during the upcoming months.

Although the results of the comparative analysis suggest that a combination of institutional controls and a low-impermeability barrier are appropriate for this site, it should be noted that institutional controls alone are adequate to ensure protectiveness of human health and the environment for the next 20 or more years. Deferring installation a barrier (or another alternative if selected by decision makers) until the remedial decisions for the adjacent 241-BY tank farm and the 200 aggregate area are reached would ensure overall cost effectiveness and consistency with other remedial measures. For example, if a barrier is selected as the preferred alternative for this site and it was 
DOE/RL-93-35, Rev. 0

installed prior to remediation of the 241-BY tank farm, there is potential that some or part of the barrier would be destroyed during tank farm remediation. In addition, it is possible that barriers would be selected as the preferred alternative for similar sites throughout the 200 Area. If this is the case, there could be increased cost effectiveness by including the 200-BP-1 operable unit barrier design and installation in remedying this area on a large scale, consistent with the aggregate area concepts. 
DOE/RL-93-35, Rev. 0

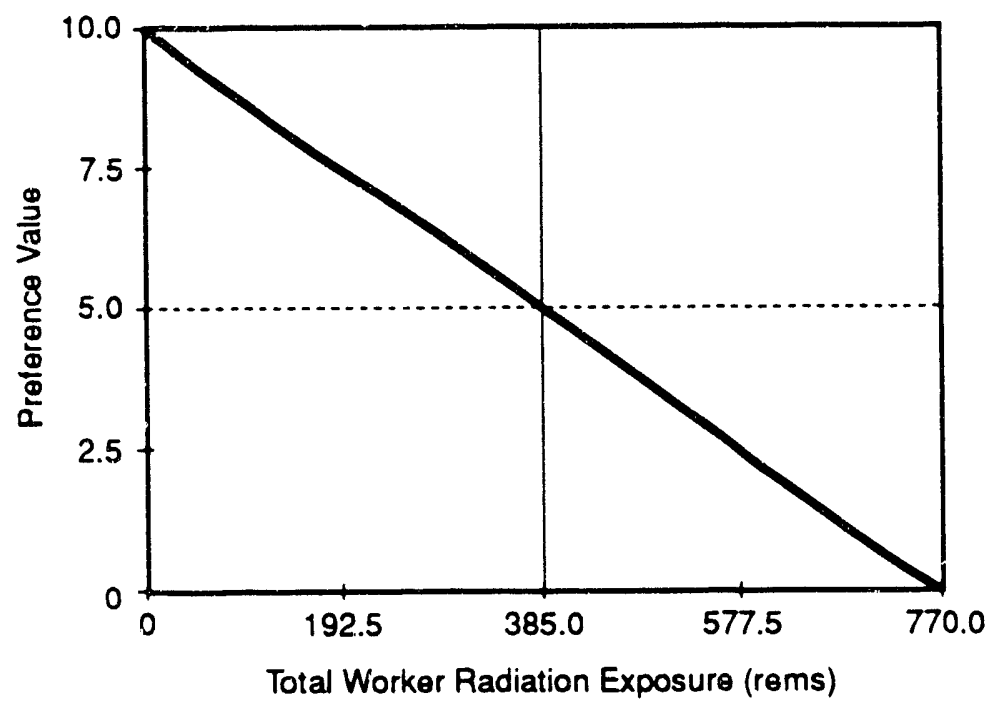

903 1216/98775/6-23-93

Figure 7-1. Value Function for Total Worker Radiation Exposure. 
DOE/RL-93-35, Rev. 0

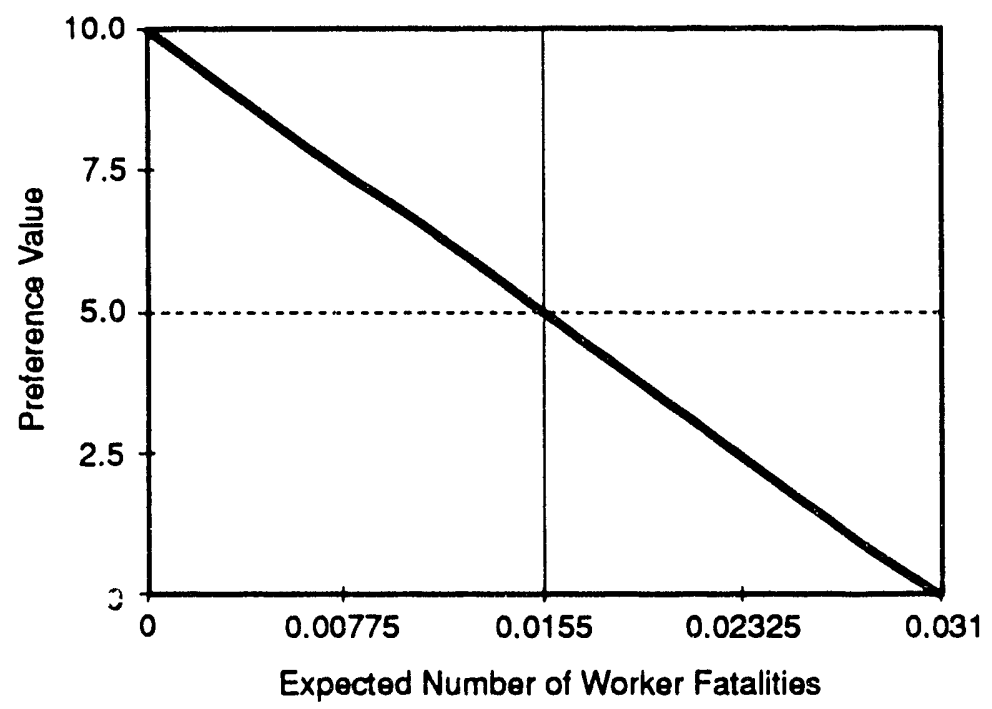

903 1216/98776/6-23-93

Figure 7-2. Value Function for Expected Number of Worker Fatalities from Accidents. 
DOE/RL-93-35, Rev. 0

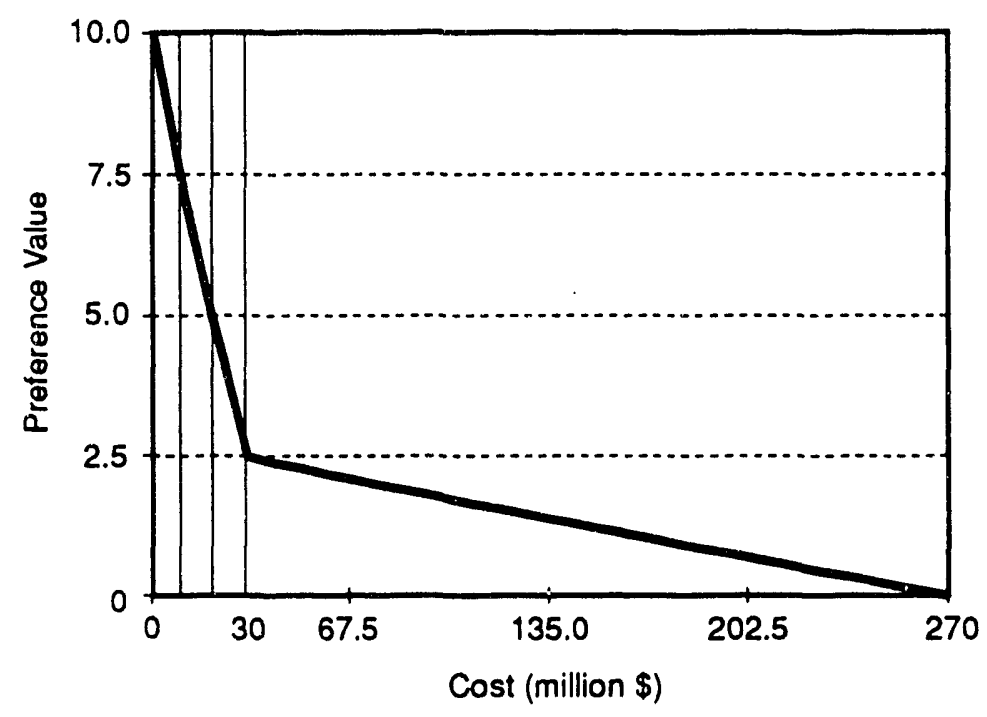

Figure 7-3. Value Function for Cost. 


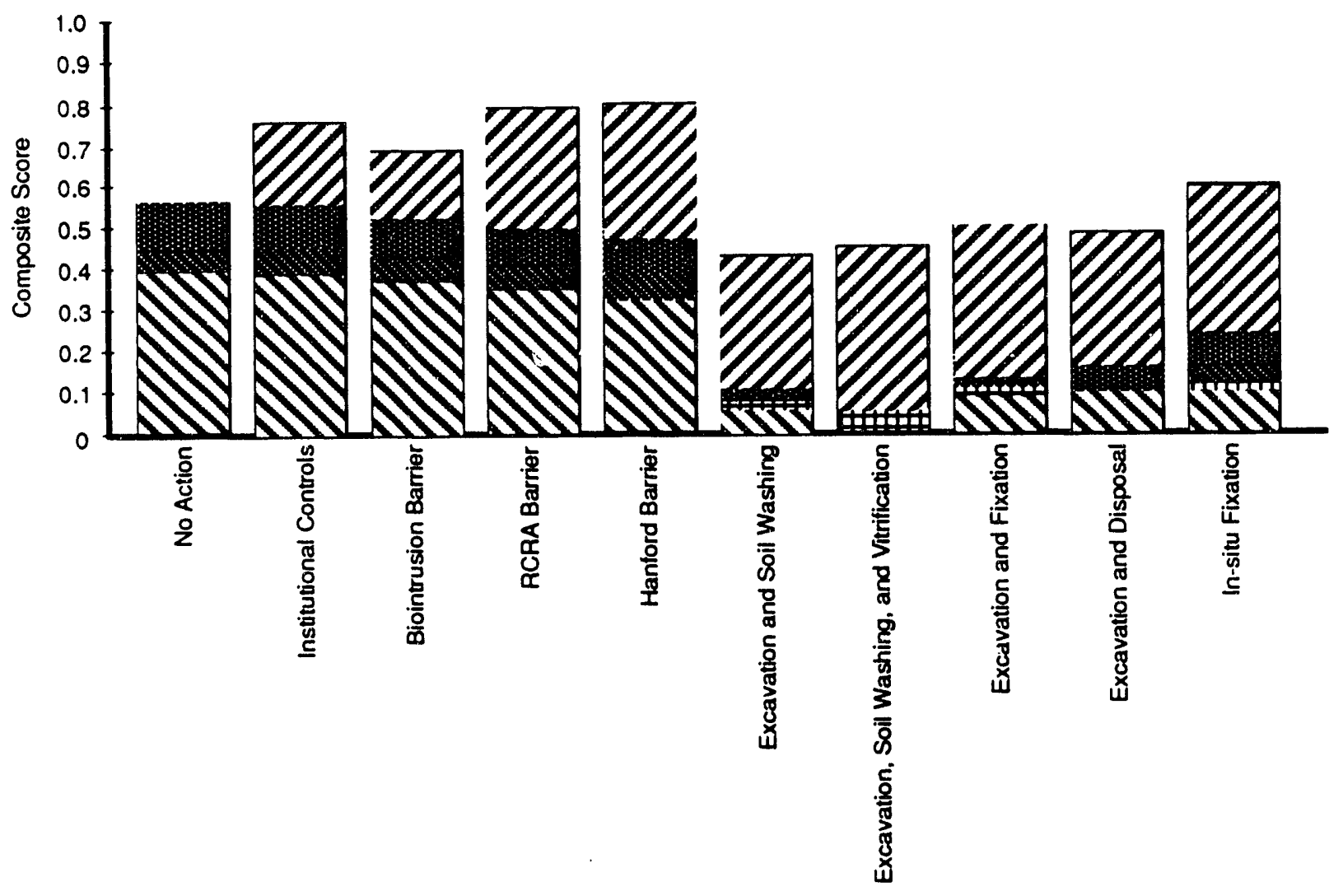

Figure 7-4. Composite Scores for Hypothetical Weighting of Criteria. 

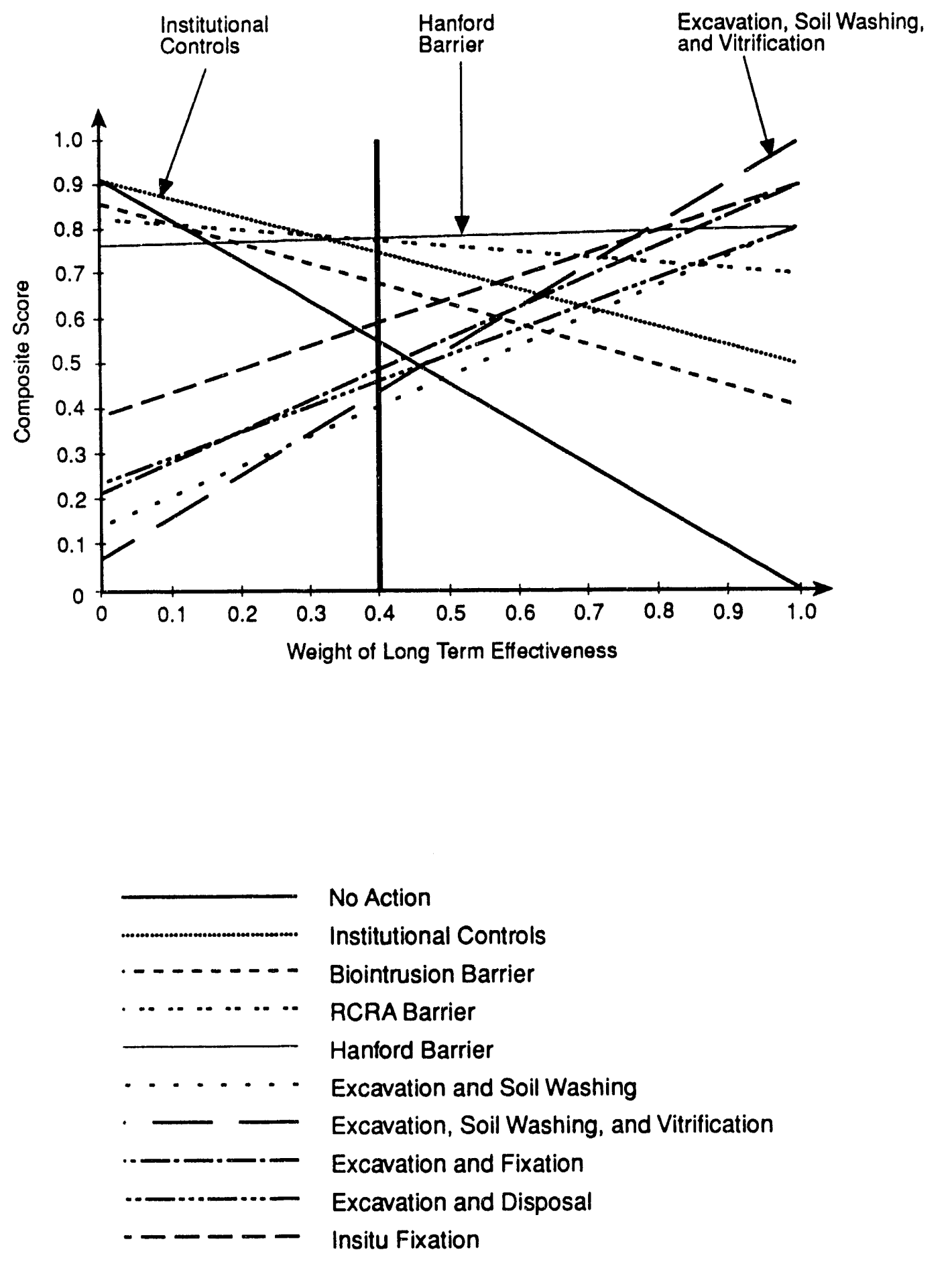

Figure 7-5. Sensitivity of Composite Scores to Weighting of Long Term Effectivness. 

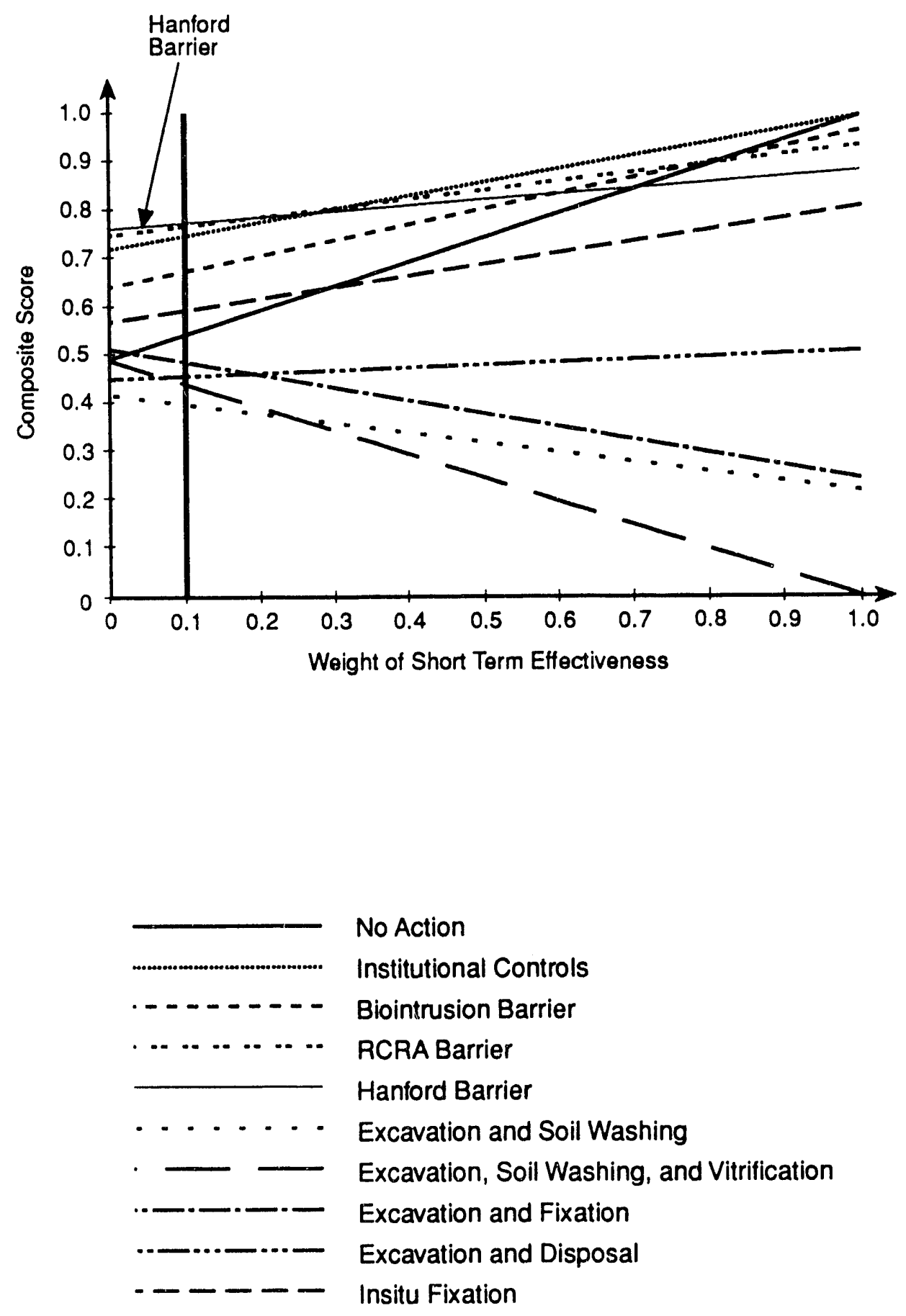

Figure 7-6. Sensitivity of Composite Scores to Weighting of Short Term Effectiveness. 

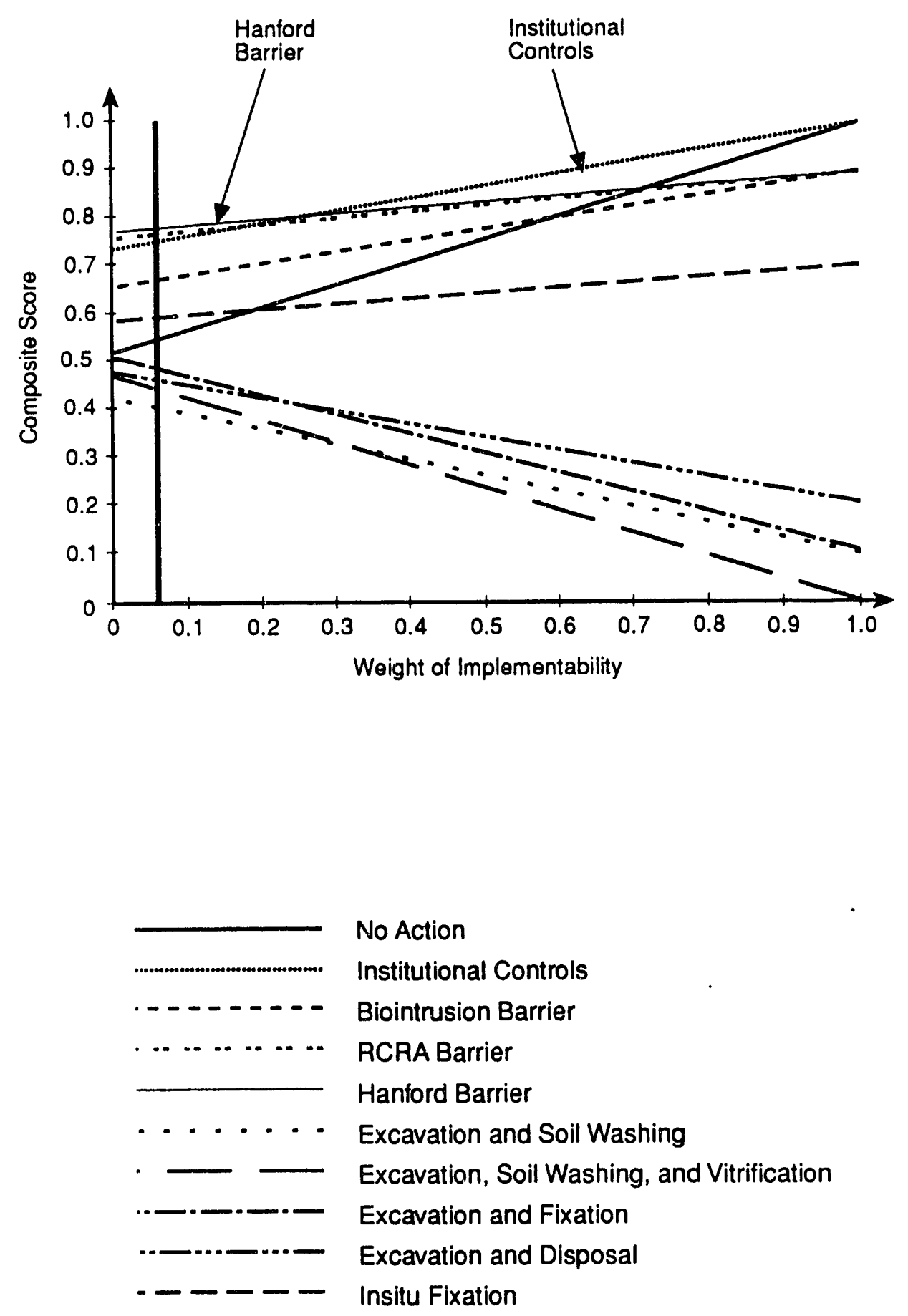

Figure 7-7. Sensitivity of Composite Scores to Weighting of Implementability. 

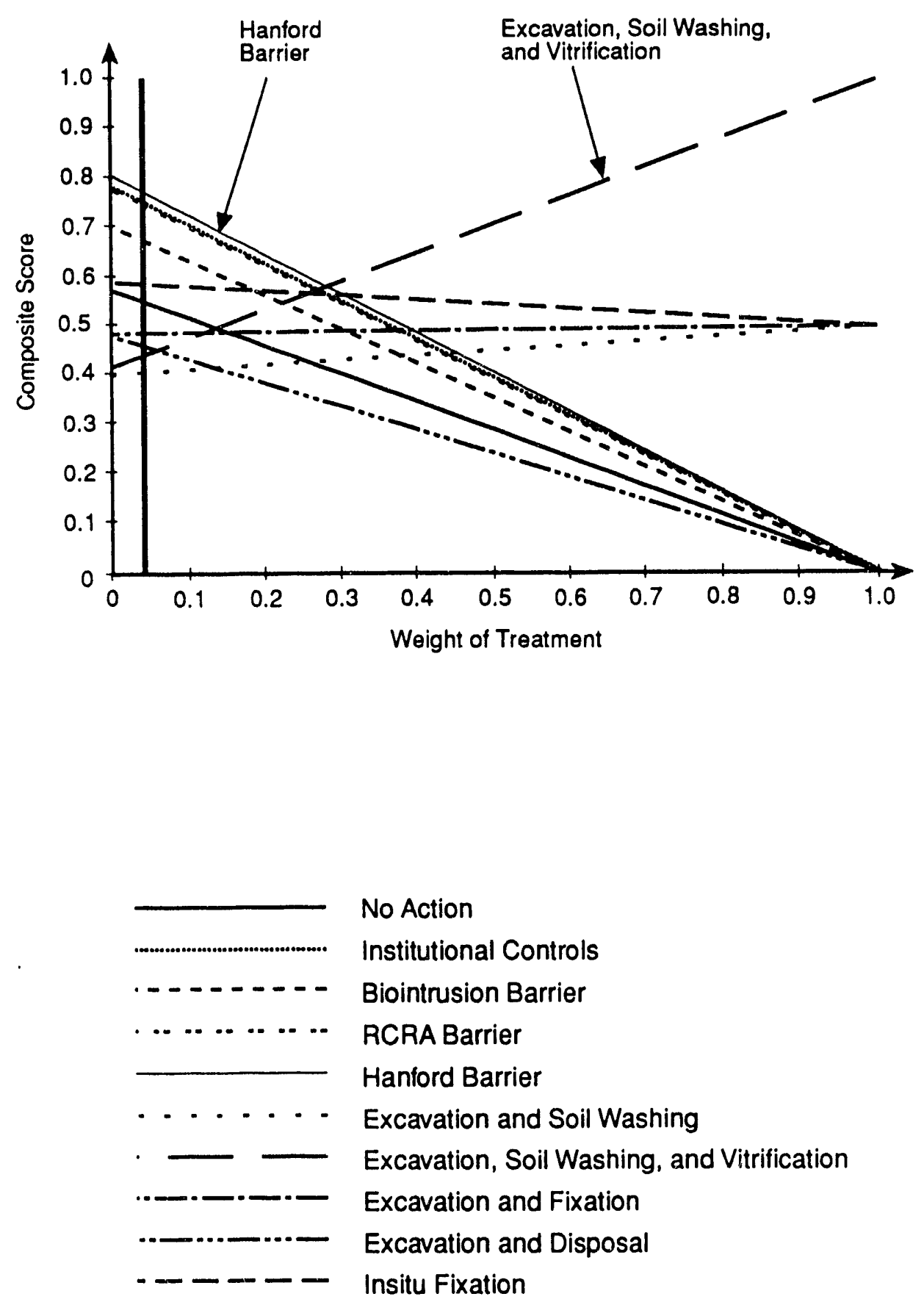

903 1216/98782/6-24-93

Figure 7-8. Sensitivity of Composite Scores to Weighting of Treatment. 
DOE/RL-93-35, Rev. 0
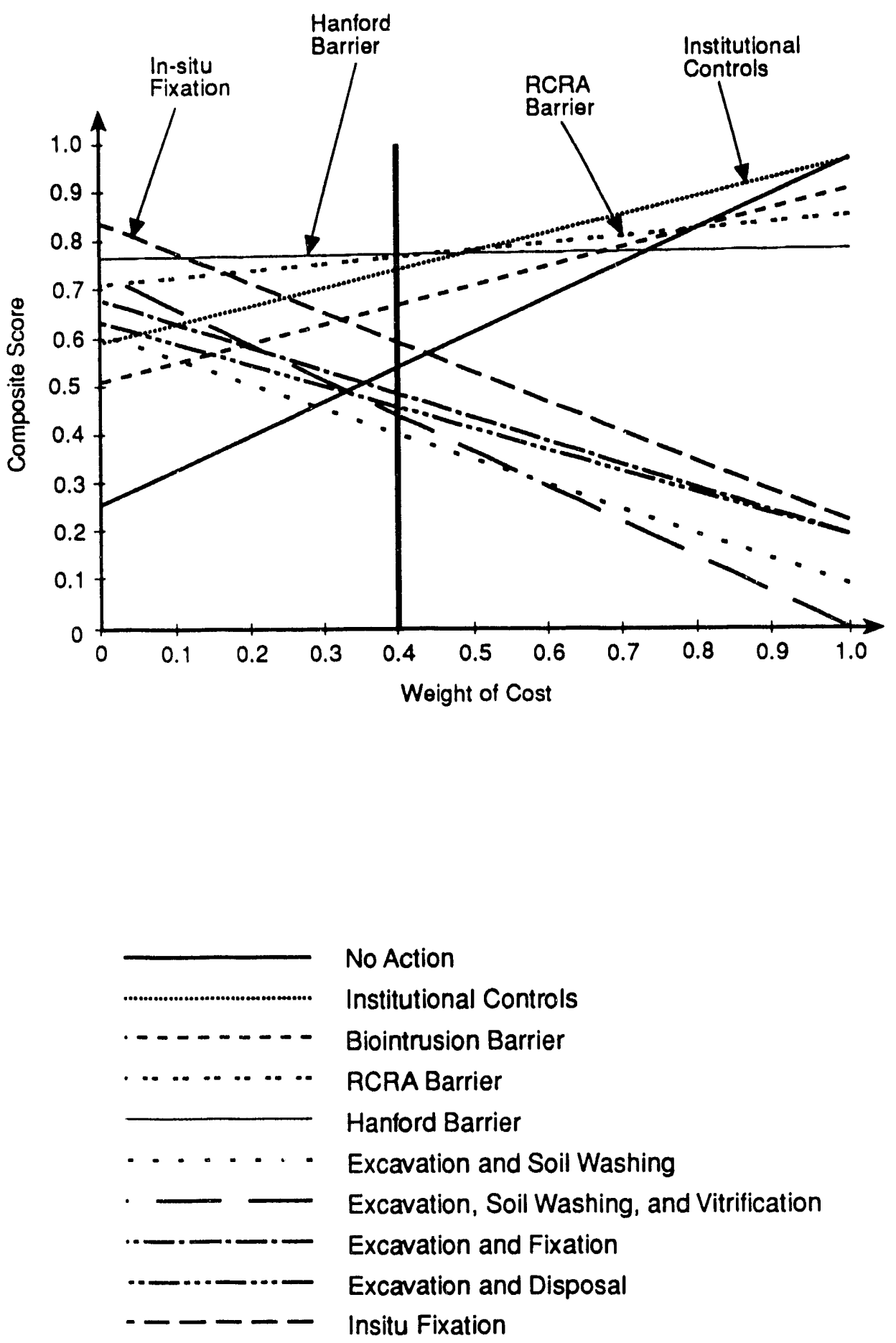

$9031216 / 98783 / 6-24-93$

Figure 7-9. Sensitivity of Composite Scores to Weighting of Cost. 
DOE/RL-93-35, Rev. 0

Table 7-1. Alternative Scores for Long-Term Effectiveness and Permanence.

\begin{tabular}{|c|c|c|}
\hline Alternative & Score & Rationale \\
\hline A) No Action & 0 & This alternative has the lowest effectiveness. \\
\hline C) Biointrusion Barrier & 4 & $\begin{array}{l}\text { Institutional Controls are a significant } \\
\text { improvement over no-action, but the bio } \\
\text { Barrier increases infiltration. }\end{array}$ \\
\hline B) Institutional Controls & 5 & $\begin{array}{l}\text { Institutional Controls are a significant } \\
\text { improvement over no-action. }\end{array}$ \\
\hline D) Modified RCRA Barrier & 7 & $\begin{array}{l}\text { The RCRA Barrier reduced infiltration } \\
\text { compared to existing surface materials. }\end{array}$ \\
\hline E) Hanford Barrier & 8 & $\begin{array}{l}\text { The Hanford Barrier is much thicker and } \\
\text { more reliable than the RCRA Barrier. }\end{array}$ \\
\hline $\begin{array}{l}\text { I) Excavation and Disposal with } \\
\text { RCRA Barrier }\end{array}$ & 8 & $\begin{array}{l}\text { The contaminated soils are placed in the } \\
\text { ERSDF with a Hanford Barrier. The slight } \\
\text { advantage gained by placement of the most } \\
\text { contaminated soils in the ERSDF (when } \\
\text { compared with the Hanford Barrier } \\
\text { alternative) is countered by the use of a } \\
\text { RCRA Barrier over the remaining soils. }\end{array}$ \\
\hline $\begin{array}{l}\text { F) Excavation and Soil Washing } \\
\text { with RCRA Barrier }\end{array}$ & 8 & $\begin{array}{l}\text { Same rational as Alternative I. Soil washing } \\
\text { does not significantly improve reliability. }\end{array}$ \\
\hline $\begin{array}{l}\text { J) In-Situ Fixation with RCRA } \\
\text { Barrier }\end{array}$ & 9 & $\begin{array}{l}\text { Fixation is worth more than the Hanford } \\
\text { Barrier because it provides a different type of } \\
\text { protection in case the Barrier fails. }\end{array}$ \\
\hline $\begin{array}{l}\text { H) Excavation and Ex-situ } \\
\text { Fixation with RCRA Barrier }\end{array}$ & 9 & $\begin{array}{l}\text { Same rational as Alternative J. Ex-situ fixation } \\
\text { is not significantly more reliable than in-situ } \\
\text { fixation. }\end{array}$ \\
\hline $\begin{array}{l}\text { G) Excavation, Soil Washing, } \\
\text { and Vitrification with RCRA } \\
\text { Barrier }\end{array}$ & 10 & $\begin{array}{l}\text { Vitrification is more effective than fixation } \\
\text { and the most contaminated soils are placed } \\
\text { in the ERSDF with a Hanford Barrier. }\end{array}$ \\
\hline
\end{tabular}


Table 7-2. Alternative Scores for Treatment.

\begin{tabular}{|l|l|l|}
\hline Alternative & Score & \multicolumn{1}{|c|}{ Rationale } \\
\hline A) No Action & 0 & No treatment. \\
\hline B) Institutional Controls & 0 & No treatment. \\
\hline C) Biointrusion Barrier & 0 & No treatment. \\
\hline D) Modified RCRA Barrier & 0 & No treatment. \\
\hline E) Hanford Barrier & 0 & No treatment. \\
\hline $\begin{array}{l}\text { I) Excavation and Disposal with } \\
\text { RCRA Barrier }\end{array}$ & 0 & No treatment. \\
\hline $\begin{array}{l}\text { F) Excavation and Soil Washing } \\
\text { with RCRA Barrier }\end{array}$ & 5 & Soil washing results in reduction of volume. \\
\hline $\begin{array}{l}\text { J) In-Situ Fixation with RCRA } \\
\text { Barrier }\end{array}$ & 5 & Fixation reduces mobility. \\
\hline $\begin{array}{l}\text { H) Excavation and Ex-situ } \\
\text { Fixation with RCRA Barrier }\end{array}$ & 7 & $\begin{array}{l}\text { Ex-situ fixation is more effective than in-situ } \\
\text { fixation and soil washing. }\end{array}$ \\
\hline $\begin{array}{l}\text { G) Excavation, Soil Washing, } \\
\text { and Vitrification with RCRA } \\
\text { Barrier }\end{array}$ & 10 & $\begin{array}{l}\text { Soil washing reduces volume and vitrification } \\
\text { reduces mobility. Vitrification is more effective } \\
\text { than fixation. }\end{array}$ \\
\hline
\end{tabular}


DOE/RL-93-35, Rev. 0

Table 7-3. Alternative Scores for Short-Term Effectiveness.

\begin{tabular}{|l|c|c|}
\hline Alternative & $\begin{array}{c}\text { Radiation } \\
\text { Exposure } \\
\text { (rems) }\end{array}$ & $\begin{array}{c}\text { Accident } \\
\text { Rate } \\
\text { (fatalities) }\end{array}$ \\
\hline A) No Action & 0 & 0 \\
\hline B) Institutional Controls & 0 & 0 \\
\hline C) Biointrusion Barrier & 0 & 0.002 \\
\hline D) Modified RCRA Barrier & 0 & 0.004 \\
\hline E) Hanford Barrier & 0 & 0.007 \\
\hline $\begin{array}{l}\text { F) Excavation and Soil Washing } \\
\text { with RCRA Barrier }\end{array}$ & 675 & 0.021 \\
\hline $\begin{array}{l}\text { G) Excavation, Soil Washing, } \\
\text { and Vitrification with RCRA } \\
\text { Barrier }\end{array}$ & 770 & 0.031 \\
\hline $\begin{array}{l}\text { H) Excavation and Ex-situ } \\
\text { Fixation with RCRA Barrier }\end{array}$ & 675 & 0.02 \\
\hline $\begin{array}{l}\text { I) Excavation and Disposal with } \\
\text { RCRA Barrier }\end{array}$ & 500 & 0.01 \\
\hline $\begin{array}{l}\text { J) In-Situ Fixation with RCRA } \\
\text { Barrier }\end{array}$ & 150 & 0.006 \\
\hline
\end{tabular}


Table 7-4. Alternative Scores for Implementability.

\begin{tabular}{|c|c|c|}
\hline Alternative & Score & Rationale \\
\hline A) No Action & 10 & No implementability difficulties. \\
\hline B) Institutional Controls & 10 & $\begin{array}{l}\text { Insignificant implementability issues associated } \\
\text { with implementation of Institutional Controls. }\end{array}$ \\
\hline C) Biointrusion Barrier & 9 & $\begin{array}{l}\text { Very minor implementability issues associated } \\
\text { with cap construction. }\end{array}$ \\
\hline D) Modified RCRA Barrier & 9 & $\begin{array}{l}\text { Very minor implementability issues associate. } \\
\text { with cap construction. }\end{array}$ \\
\hline E) Hanford Barrier & 9 & $\begin{array}{l}\text { Very minor implementability issues associated } \\
\text { with cap construction. }\end{array}$ \\
\hline $\begin{array}{l}\text { J) In-Situ Fixation with RCRA } \\
\text { Barrier }\end{array}$ & 7 & $\begin{array}{l}\text { Soil mixing is a more complex and less } \\
\text { developed technology then cap construction. } \\
\text { Includes potential for worker exposure, but } \\
\text { much less significant than excavation } \\
\text { alternatives. }\end{array}$ \\
\hline $\begin{array}{l}\text { I) Excavation and Disposal with } \\
\text { RCRA Barrier }\end{array}$ & 2 & $\begin{array}{l}\text { Requires shoring for nearby tank farms. } \\
\text { Excavation is much more complex operation } \\
\text { than cap construction. Significant potential for } \\
\text { worker exposure. }\end{array}$ \\
\hline $\begin{array}{l}\text { H) Excavation and Ex-situ } \\
\text { Fixation with RCRA Barrier }\end{array}$ & 1 & $\begin{array}{l}\text { Requires shoring for nearby tank farms. } \\
\text { Excavation is much more complex operation } \\
\text { than cap construction. Fixation plant involves } \\
\text { additional complexities. Significant potential for } \\
\text { worker exposure. }\end{array}$ \\
\hline $\begin{array}{l}\text { F) Excavation and Soil Washing } \\
\text { with RCRA Barrier }\end{array}$ & 1 & $\begin{array}{l}\text { Requires shoring for nearby tank farms. } \\
\text { Excavation is much more complex operation } \\
\text { than cap construction. Soil washing plant is } \\
\text { similar in complexity to fixation plant. } \\
\text { Significant potential for worker exposure. }\end{array}$ \\
\hline $\begin{array}{l}\text { G) Excavation, Soil Washing, } \\
\text { and Vitrification with RCRA } \\
\text { Barrier }\end{array}$ & 0 & $\begin{array}{l}\text { Requires shoring for nearby tank farms. Much } \\
\text { more complex operation than cap construction. } \\
\text { Includes two treatment facilities along with } \\
\text { associated complexity. Significant potential for } \\
\text { worker exposure. }\end{array}$ \\
\hline
\end{tabular}


DOE/RL-93-35, Rev. 0

Table 7-5. Alternative Cost.

\begin{tabular}{|l|c|}
\hline Alternative & Cost (millions) \\
\hline A) No Action & $\$ 1.1$ \\
\hline B) Institutional Controls & $\$ 1.2$ \\
\hline C) Biointrusion Barrier & $\$ 3.5$ \\
\hline D) Modified RCRA Barrier & $\$ 5.7$ \\
\hline E) Hanford Barrier & $\$ 8.5$ \\
\hline $\begin{array}{l}\text { F) Excavation and Soil Washing } \\
\text { with RCRA Barrier }\end{array}$ & $\$ 182$ \\
\hline $\begin{array}{l}\text { G) Excavation, Soil Washing, } \\
\text { and Vitrification with RCRA } \\
\text { Barrier }\end{array}$ & $\$ 268$ \\
\hline $\begin{array}{l}\text { H) Excavation and Ex-situ } \\
\text { Fixation with RCRA Barrier }\end{array}$ & $\$ 81$ \\
\hline $\begin{array}{l}\text { I) Excavation and Disposal with } \\
\text { RCRA Barrier }\end{array}$ & $\$ 82$ \\
\hline $\begin{array}{l}\text { J) In-Situ Fixation with RCRA } \\
\text { Barrier }\end{array}$ & $\$ 53$ \\
\hline
\end{tabular}


DOE/RL-93-35, Rev. 0

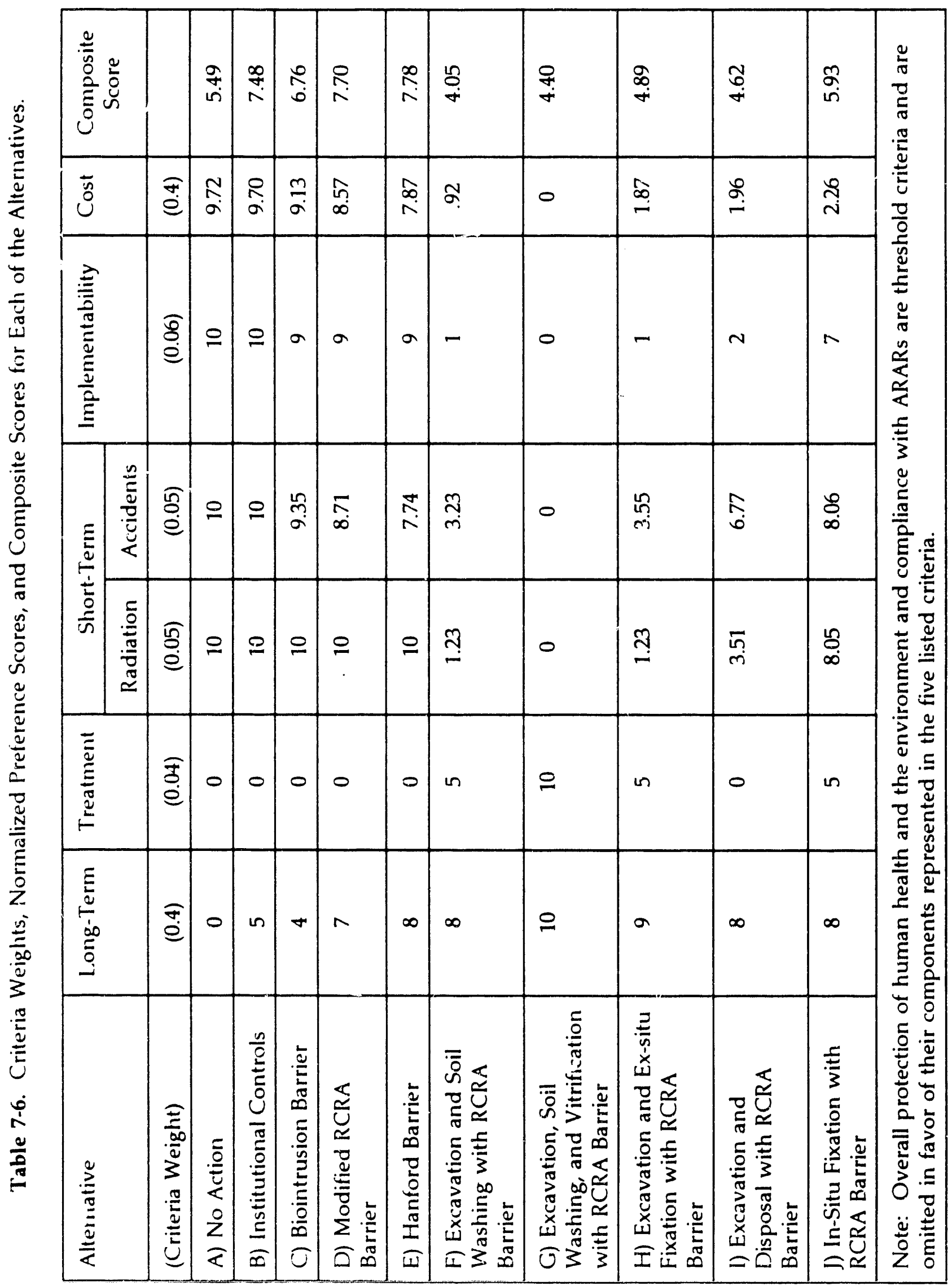




\subsection{REFERENCES}

American Nuclear Society, 1992, Spectrum '92: Proceedings of the International Topical Meeting on Nuclear and Hazardous Waste Management Spectrum, American Nuclear Society, Fuel Cycle and Waste Management Division, La Grange Park, Illinois.

Anderson, J.D., and Mudd D. C., 1979, History of the 200 Area Tank Farms, RHO-LD-79, Rockwell Hanford Operations, Richland, Washington.

Argonne, 1992, RESRAD, Ver sion 4.35, Argonne National Laboratory, Argonne, Illinois.

Bergeron, M.P., G.V. Last, and A.E. Reisena ser, 1987, Geohydrolngy of a Commercial Low-Leoel Radioactive Waste Disposal Facility Near Kichland, Washington, Pacific Northwest Laboratories, Richland, Washington.

Chambers, C.D., J. Willis, S. Giti-Pour, J.L. Zieleniewski, and J.F. Rickabaugh, 1990, Handbook on In-Situ Treatment of Hazardous Waste-Contaminated Soils, EPA/540/290/002, U.S. Environmental Protection Agency, Risk Reduction Engineering Laboratory, Washington, D.C.

Connelly, M.P., J. V. Borghese, C. D. Delaney, B. H. Ford, J. W. Lindberg, and S.J. Trent, 1992, Hydrogeologic Model for the 200 East Groundwater Aggregate Area, WHC-SD-EN-TI-019, Westinghouse Hanford Company, Richland, Washington.

Cullinane, M.J., Jr., L.W. Jones, and P.G. Malone, 1986, Handbook for Stabilization/Solidification of Hazardous Wastes, EPA/540/2-86/001, U.S.

Environrnental Protection Agency, Washington, D.C.

DOE-RL, 1990a, Remedial Investigation/Feasibility Study Work Plan for the 200-BP-1 Operable Unit Hanford Site, Richland, Washington, DOE/RL 88-32, U.S. Department of Energy, Richland, Washington.

DOE-RL, 1990b, Remedial Investigation/Feasibility Study Work Plan for the 300-FF-1 Operable Unit, Hanford Site, Richland, Washington, DOE-RL 88-31, Draft D, U.S. Department of Energy, Richland, Washington.

DOE-RL, 1992a, Hanford Site Waste Management Units Report, DOE-RL 88-30, U.S. Department of Energy, Richland Operations Office, Richland, Washington.

DOE-RL, 1993a, Phase 1 Remedial Investigation Report for 200-BP-1 Operable Unit, Hanford Site, Richland, Washington, Draft A, DOE/RL-92-76, U.S. Department of Energy, Richland, Washington.

DOE-RL, 1993b, Hanford Site Waste Information Data System (WIDS), data file accessed March 1993, U.S. Department of Ecology, Richland Operations Office, Richland, Washington. 
Ecology, EPA and DOE-RL, 1992, Hanford Federal Facility Agreement and Consent Order, Rev. 2, Washington Department of Ecology, Olympia, Washington, U.S. Environmental Protection Agency, Region X, Seattle, Washington, and U.S. Department of Energy, Richland Operations Office, Richland, Washington.

EG\&G, 1991, Remedial Technology Information System (RTIS), Version 1.0, EG\&G Idaho Inc., Idaho Falls, Idaho.

EPA, 1988, Technological Approaches to the Cleanup of Radiologically Contaminated Superfund Sites, EPA/540/2-88/002, U.S. Environmental Protection Agency, Washington, D.C.

EPA, 1988a, Guidance for Conducting Remedial Investigations and Feasibility Studies Under CERCLA; Interim Final, EPA540/G-89/004, U.S. Environmental Protection Agency, Office of Emergency and Remedial Response, Washington, D.C.

EPA, 1988b, CERCLA Compliance with Other Laws Manual; Interim Final, EPA540/G-89/006, U.S. Environmental Protection Agency, Office of Emergency and Remedial Response, Washington, D.C.

EPA, 1989a, Risk Assessment Guidance for Superfund: Volume 1, Human Health Evaluation Manual, Part A; Interim Final, EPA/540/1-89/002, U.S. Environmental Protection Agency, Washington, D.C.

EPA, 1989b, Superfund Innovative Technology Evaluation Program: Technology Profiles, EPA540/5-89/013, U.S. Environmental Protection Agency, Washington, D.C.

EPA, 1989, Technical Guidance Document: Final Covers on Hazardous Waste Landfills and Surface Impoundments, EPA530-SW-89-047, Office of Solid Waste and Emergency Response, Washington, D.C.

EPA 1990, International Waste Technologies/Geo-Con In-Situ Stabilization/Solidification: Applications Analysis Report, EPA/540/A5-89/004, U.S. Environmental Protection Agency, Risk Reduction Engineering Laboratory, Washington, D.C.

Fitzpatrick, V.F., J.L. Buelt, K.H. Oma, and C.L. Timmerman, 1984, "In-Situ Vitrification -A Potential Remedial Action Technique for Hazardous Wastes," in Management of Uncontrolled Hazardous Waste Sites, Proceedings of the Fifth National Conference on Management of Uncontrolled Hazardous Waste Sites, Hazardous Materials Control Research Institute, Silver Springs, Maryland, pp. 191-194.

Francis, C. W. and B. P. Spalding, 1991, In-Situ Grouting of Low-Level Burial Trenches with a Cement-Based Grout, Environmental Remediation Conference, Pasco, Washington.

Gee, G.W., M.J. Fayer, M.L. Rockhold, and M.D. Campbell, 1992, "Variations in Recharge at the Hanford Site", Northwest Science, Vol. 66, pp. 237-250. 
Hajek, B.F., 1966, Soil Survey: Hanford Project in Benton County, Washington, BNWL-243, Battelle Northwest Laboratories, Richland, Washington.

Haney, W.A., and J.F. Honstead, 1958, A History and Discussion of Specific Retention Disposal of Radioactive Liquid Wastes in the 200 Areas, HW-54599, General Electric Company, Hanford Operations, Richland, Washington.

Hanford Future Sites Uses Working Group, 1992, Future for Hanford: Uses and Cleanup, Hanford Future Sites Uses Working Group, Richland, Washington.

Hansen, J.E. and V.F. FitzPatrick, 1991, In Situ Vitrification Applications, Kirkland, Washington.

Hayward, W.M., 1992 , UN-216-E-17 Interim Stabilization Final Report, WHC-SD-DD-TI-064 Rev. 0, Westinghouse Hanford Company, Richland, Washington.

Hämäläinen, R.P. and L. Hannu, 1992, HIPRE 3+ User's Guide, Helsinki University of Technology Systems Analysis Laboratory.

Hoffman, K.M., 1992, 200-BP-1 Borehole Summary Report for Task 2, 4, \& 6, WHC-SD-EN-TI-054, Westinghouse Hanford Company, Richland, Washington.

Hoffman, K.M., S.J. Trent, K.A. Lindsey, and B.N. Bjornstad, 1992, Summary of the Geology of the 200-BP-1 Operable Unit, WHC-SD-EN-TI-037, Rev. 0, Westinghouse Hanford Company, Richland, Washington.

Holden, T., M. Diaz, J. Newton, and P. Sylvestri, 1989, How to Select Hazardous Waste Treatment Technologies for Soils and Sludge, Noyes Data Corporation, Park Ridge, New Jersey.

Hulstrom, L.C., 1992 , Climatological Summary of the 300 Area for the 300-FF-1 Operable Unit Remedial Investigation, WHC-SD-EN-TI- 005, Westinghouse Hanford Company, Richland, Washington.

Lindsey, K.A., B.N. Bjornstad, J. W. Lindberg, and K. M. Hoffman, 1992, Geologic Setting of the 200 East Area: An Update, WHC-SD- EN-TI-012, Rev. 0, Westinghouse Hanford Company, Richland, Washington.

Luey, J., S.S. Koegler, W.L. Kuhn, P.S. Lowery, and R.G. Winkelman, 1992, In Situ Vitrification of a Mixed-Waste Contaminated Soil Site: The 116-B-6A Crib at Hanford, PNL-8281, Pacific Northwest Laboratory, Battelle Memorial Institute, Richland, Washington.

PEI Associates, 1990, Inventory of Treatability Study Vendors, Volume I, EPA/540/290/003a, U.S. Environmental Protection Agency, Risk Reduction Engineering Laboratory, Washington, D.C. 
Rockhold, M.L., M.J. Fayer, G.W. Gee, and M.J. Kanyid, 1990, Natural Groundwater Recharge and Water Balance at the Hanford Site, PNL-7215, Pacific Northwest Laboratory, Richland, Washington.

Runchal, A.K., R. Sagar, and N.W. Kline, 1992, PORFLO-3: A Mathematical Model for Fluid Flow, Heat, and Mass Transport in Variably Saturated Geologic Media, Users Manual, Version 1.2, WHC-EP-0385, Westinghouse Hanford Company, Richland, Washington.

Sims, R. and J. Bass, 1984, Review of In-Place Treatment Techniques for Contaminated Surface Soils, Volume 1: Technical Evaluation, EPA/540/2-84/003a, U.S. Environmental Protection Agency, Municipal Environmental Research Laboratory, Cincinnati, Ohio.

Smoot, J.L., J.E. Szecsody, B. Sagar, G.W. Gee, and C.T. Kincaid, 1989, Simulations of Infiltration of Meteoric Water and Contaminant Plume Movement in the Vadose Zone at Single-Shell Tank 241-T-106 at the Hanford Site, WHC-EP-0332, Westinghouse Hanford Company, Richland, Washington.

Stenner, R.D., K.H. Cramer, K.A. Higley, S.J. Jette, D.A. Lamar, T.J. McLaughlin, D.R. Sherwood, and N.E. Van Houten, 1988, Hazard Ranking System Evaluation of CERCLA Inactive Waste Sites at Hanford, PNL-6456, Pacific Northwest Laboratory, Richland, Washington.

Steude, J., and B. Tucker, 1991, Selection of Innovative Technologies for the Remediation of Soils Contaminated with Radioactive and Mixed Wastes, Environmental Remediation Conference, Pasco, Washington, U.S. Department of Energy, Washington, D.C.

Stone, W.A., J.M. Thorpe, O.P. Gifford, and D.J. Hoitink, 1983, Climatological Summary for the Hanford Area, PNL-4622, Pacific Northwest Laboratory, Richland, Washington.

Stone, J.A., 1979, "Studies of Concrete as a Host for Savannah River Plant Radioactive Waste," in Scientific Basis for Nuclear Waste Management, Volume I, G.J. McCarthy, editor, Plenum Press, New York, pp. 443-452.

Thomas, C.W., D. L. Reid, and H. A. Treibs, 1956, Cobalt-60 in Groundwater and Separations Plant Waste Streams, HW-42612, General Electric Company, Hanford Atomic Products Operation, Richland, Washington.

U.S. Department of Labor, 1992, Occupational Injuries and Illnesses in the United States by Industry, 1990, Bulletin 2399, Bureau of Labor Statistics, Washington, D.C.

Van Genuchten, M.T., F.J., Leij, and S.R. Yates, 1991, RETC Code for Quantifying the Hydraulic Functions of Unsaturated Soils, EPAV00/2-91/065, U.S. Environmental Protection Agency, Washington, D.C.

Weather Bureau, 1966, Pan and Lake Evaporation, from Weather Bureau Technical paper No. 37, Weather Bureau. 
WHC, 1988, Groundwater Maps of the Hanford Site Separations Area - December 1987, WHC-EP-0142, Westinghouse Hanford Company, Richland, Washington.

WHC, 1988a, WHC-CM-7-5, Environmental Compliance Manual, Westinghouse Hanford Company, Richland, Washington.

Wicks, G.G., D.F. Bickford, and L.R. Bunnell, editors, 1991, Ceramic Transactions: Nuclear Waste Management IV, Proceedings of the Fifth International Symposium on Ceramics in Nuclear and Hazardous Waste Management, The American Ceramic Society, Inc., Westerville, Ohio.

Winges, 1991, User's Guide for the Fugitive Dust Model (FDM) (revised) Volume I: User's Instructions, EPA-910/9-88-202R, U.S. Environmental Protection Agency Region 10. 
DOE/RL-93-35, Rev. 0

APPENDIX A COST ESTIMATES FOR REMEDIATION ALTERNATIVES 


\section{CONTENTS}

\section{TABLES:}

A-1 Summary of Estimated Costs for Remediation Alternatives . . . . . . . . . A-1

A-2 Cost Estimate For Alternative $A$ - No Action $\ldots \ldots \ldots \ldots \ldots \ldots \ldots \ldots$ A-2

A-3 Cost Estimate for Alternative B - Institutional Controls . . . . . . . . . A-3

A-4 Cost Estimate for Alternative $C$ - Biointrusion Barrier . . . . . . . . . . . A-4

A-5 Cost Estimate for Alternative D - Modified RCRA Barrier . . . . . . . . . . A-5

A-6 Cost Estimate for Alternative E - Hanford Barrier . . . . . . . . . . . . A

A-7 Cost Estimate for Alternative F - Excavation and Soil Washing . . . . . . . . . A-7

A-8 Cost Estimate for Alternative G - Excavation and Soil Washing

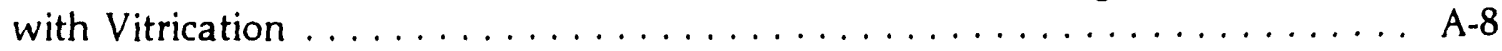

A-9 Cost Estimate for Alternative $\mathrm{H}$ - Excavation and Fixation . . . . . . . . . . A A 9

A-10 Cost Estimate for Alternative I - Excavation and ERSDF Disposal . . . . . . . A-10

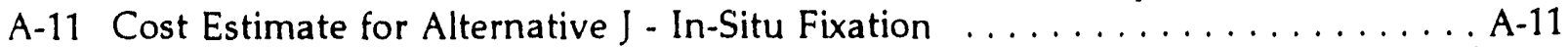


TABLE A-1. Summary of Estimated Costs for Remediation Alternatives.

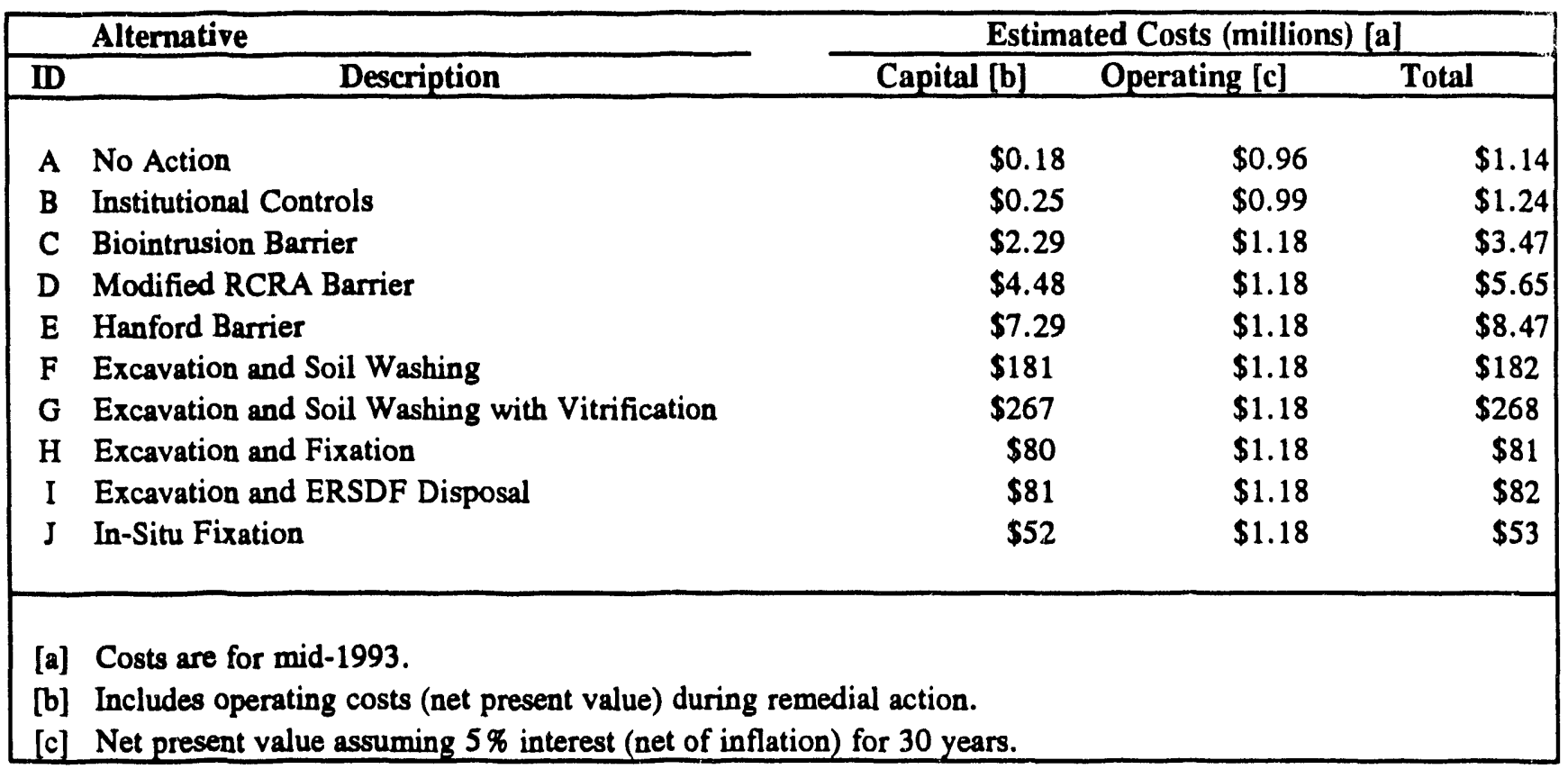


TABLE A-2. Cost Estimate for Alternative A - No Action.

\begin{tabular}{|c|c|c|}
\hline Item & Cost [a] & Notes \\
\hline \multicolumn{3}{|l|}{ CAPITAL COSTS: } \\
\hline Groundwater monitoring wells & $\$ 100,000$ & For long-term performance monitoring \\
\hline Contractor overhead and profit & 25,000 & \\
\hline Engineering and conatruction aurveillance & 30,000 & \\
\hline Contingency & 25,000 & \\
\hline TOTAL CAPITAL COSTS & $\$ 180,000$ & \\
\hline \multicolumn{3}{|l|}{ POST-CLOSURE CARE COSTS: } \\
\hline Present value of monitoring costs & $\$ 771,000$ & \\
\hline Contingency $25 \%$ & 193,000 & \\
\hline NET PRESENT VALUE COST FOR POST-CLOSURE CARE [b] & $\$ 964,000$ & \\
\hline TOTAL ALTERNATIVE COST (NET PRESENT VALUE) [C] & $\$ 1,140,000$ & Rounded to ten thousands \\
\hline $\begin{array}{l}\text { [a] Costs are for mid-1993. } \\
\text { [b] Monitoring for } 30 \text { yeara; interea (discount) rate of } 5 \text { percent, net of infla } \\
\text { [c] The aum of capital and operating coass and the net present value of the pe }\end{array}$ & iclosure care & - \\
\hline
\end{tabular}


DOE/RL-93-35, Rev. 0

TABLE A-3. Cost Estimate for Alternative B - Institutional Controls.




DOE/RL-93-35, Rev. $0^{\circ}$

TABLE A-4. Cost Estimate for Alternative C - Biointrusion Barrier.

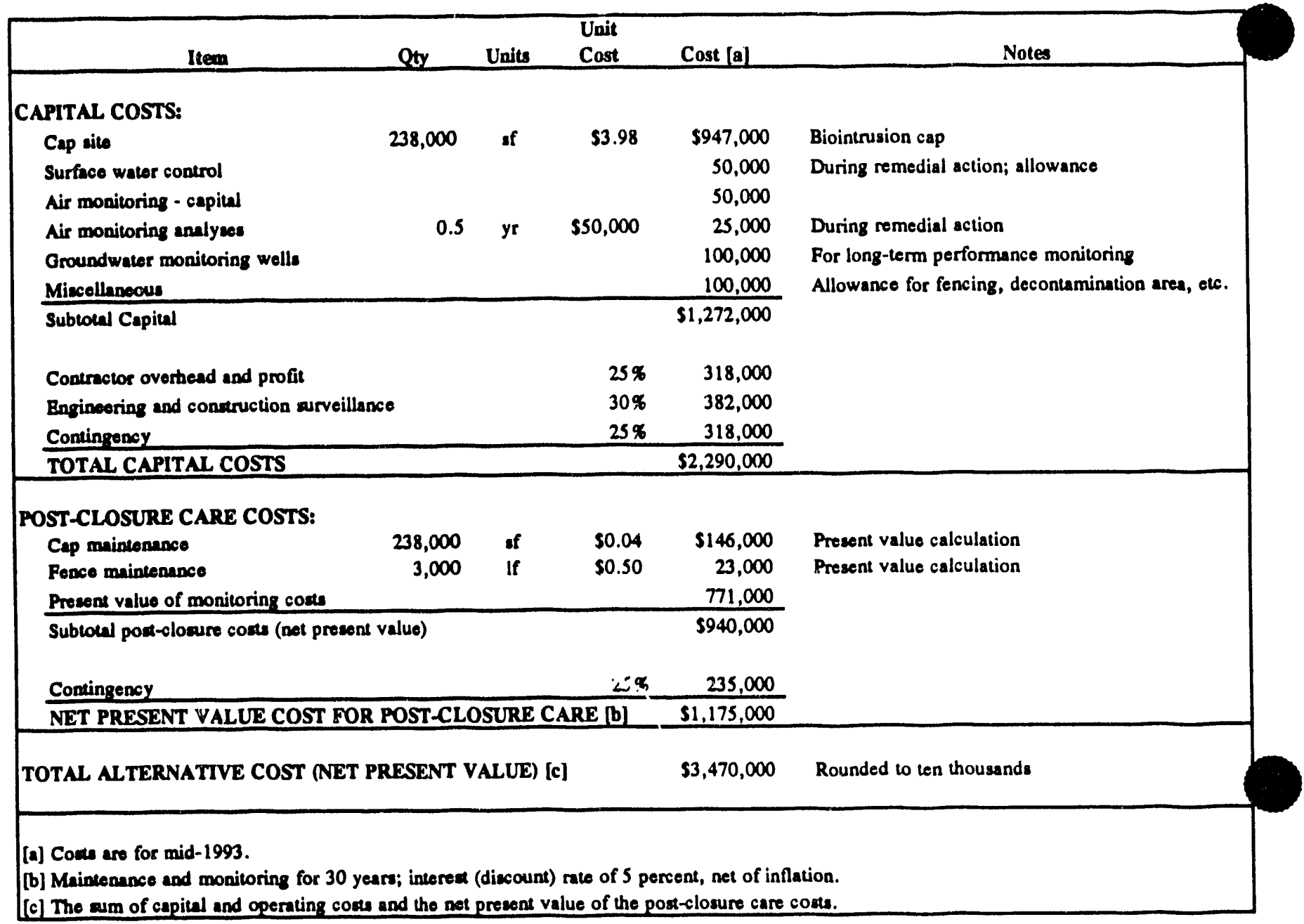


DOE/RL-93-35, Rev. 0

TABLE A-5. Cost Estimate for Alternative D - Modified RCRA Barrier.

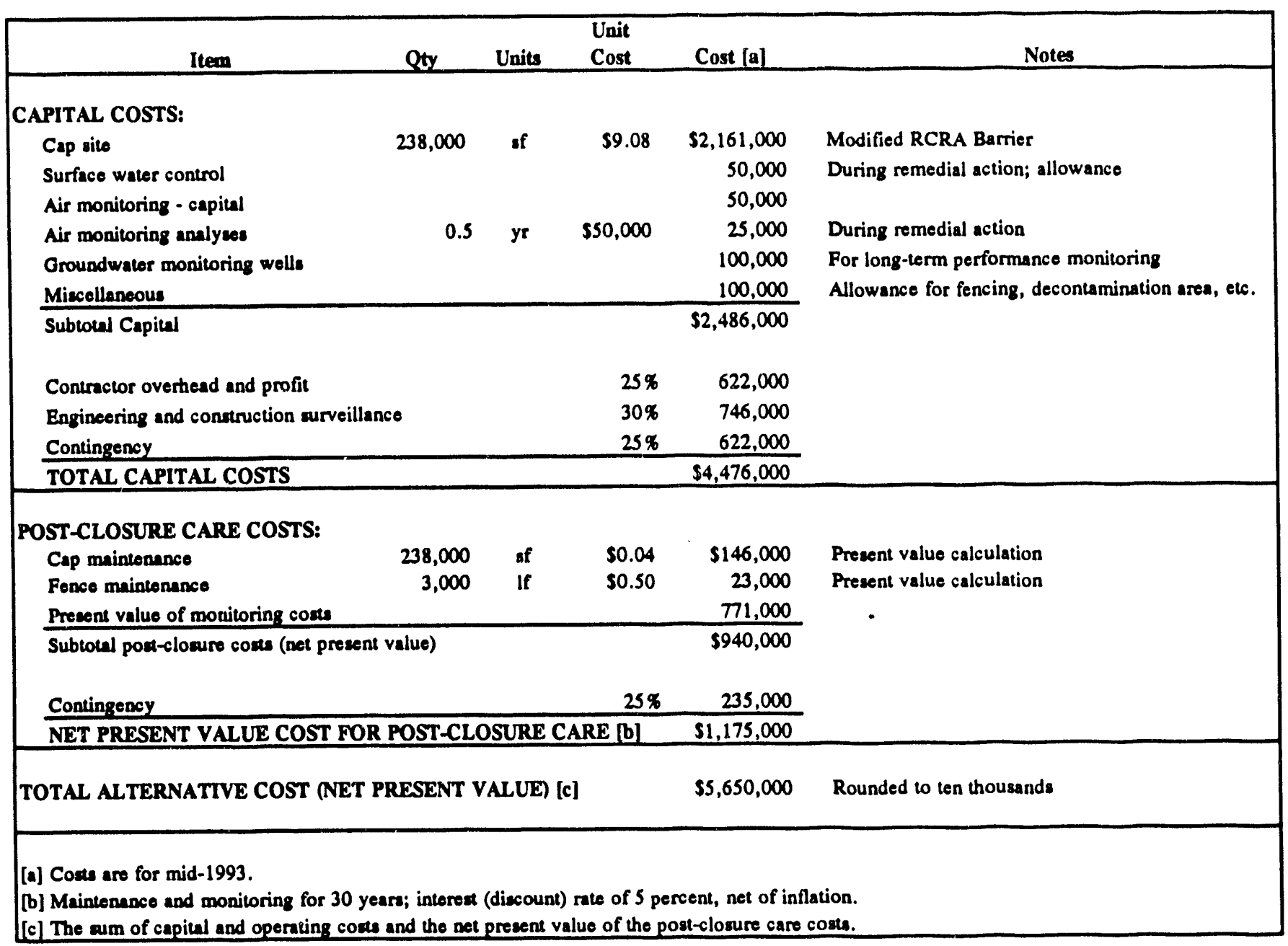


DOE/RL-93-35, Rev. 0

TABLE A-6. Cost Estimate for Alternative E - Hanford Barrier.

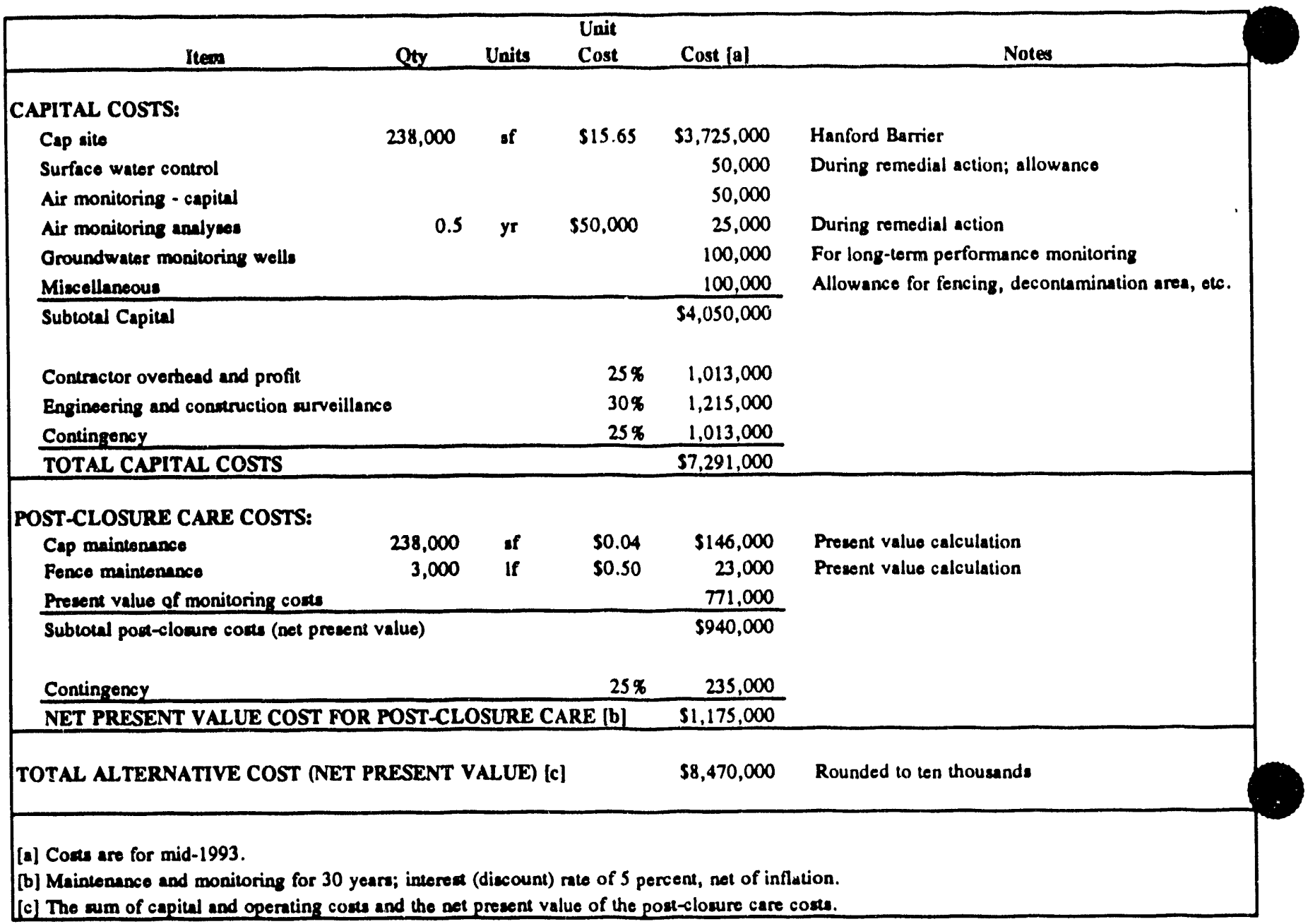


DOE/RL-93-35, Rev. 0

TABLE A-7. Cost Estimate for Alternative F - Excavation and Soil Washing.

\begin{tabular}{|c|c|c|c|c|c|}
\hline Item & Qty & Units & $\begin{array}{l}\text { Unit } \\
\text { Cost } \\
\end{array}$ & Cost [a] & Notes \\
\hline \multicolumn{6}{|l|}{ CAPITAI COSTS: } \\
\hline Excavacion & 472,000 & cy & $\$ 30$ & $\$ 14,160,000$ & \multirow{3}{*}{$\begin{array}{l}\text { See Table B-9 } \\
\text { See Table B- }-1\end{array}$} \\
\hline Sril waching & 312,000 & cy & $\$ 58$ & $18,096,000$ & \\
\hline Backfill over-excavated clean soil & 160,000 & cy & $\$ 3.50$ & 560,000 & \\
\hline Beckfill treated soil & 265,176 & cy & $\$ 3.50$ & 928,000 & \multirow{2}{*}{$\begin{array}{l}\text { Soil meeting cleanup targets } \\
\text { Cap completes backfill }\end{array}$} \\
\hline Backfill from offaite & 0 & cy & $\$ 5.00$ & 0 & \\
\hline Cap sile & 238,000 & sf & $\$ 9.08$ & $\$ 2,161,000$ & Modified RCRA Barrier \\
\hline Solidify dewrlered fines & 133,000 & cy & $\$ 40$ & $5,320,000$ & \multirow{5}{*}{$\begin{array}{l}\text { Dewatered fines ( } 50 \% \text { moisture) } \\
\text { Solidified (25\% vol. increase); bulk transport } \\
\text { Solidified (25\% vol. increase); containerized } \\
\text { Dewatered fines; } 50 \% \text { solids; assume } 1 \text { ton/cy } \\
\text { During remedial action; bee Table B-8 }\end{array}$} \\
\hline Transport low activity fines to ERSDF & 49,875 & cy & 57 & 349.000 & \\
\hline Transpor high activity fines to ERSDF & 116,375 & cy & $\$ 370$ & $43,059,000$ & \\
\hline ERSDF disposal & 166,250 & cy & $\$ 83$ & $13,799,000$ & \\
\hline Warewater treatmem - capital & & & & 533,000 & \\
\hline Wastewaler treatment - operating & 5 & yr & $\$ 105,000$ & 455,000 & \multirow[t]{2}{*}{ Present value calculation } \\
\hline Air monitoring - capital & & & & 50,000 & \\
\hline Air monitoring analyess & 5 & yr & $\$ 50,000$ & 216,000 & \multirow{4}{*}{$\begin{array}{l}\text { Present value calculation } \\
\text { For long-lerm performance monitoring } \\
\text { Allowance for fencing, decontamination area, etc. }\end{array}$} \\
\hline Groundwater monitoring wells & & & & 100,000 & \\
\hline Miscellaneous & & & & 100,000 & \\
\hline Subtotal Capital & & & & $\$ 99,886,000$ & \\
\hline Contractor overhead and pi, fit & & & $25 \%$ & $24,972,00 n$ & \\
\hline Engineering and construction surveillanc & & & $30 \%$ & $29,966,000$ & \\
\hline Contingency & & & $25 \%$ & $24,972,000$ & \\
\hline QNQC laboratory costs & 5 & yr & 300,000 & $1,299,000$ & \multirow[t]{2}{*}{ Hanford laboratory; present value calculation } \\
\hline TOTAL CAPITAL COSTS & & & & $\$ 181,095,000$ & \\
\hline \multicolumn{6}{|l|}{ BOST-CLOSURE CARE COSTS: } \\
\hline Cap maintenance & 238,000 & sf & SO.04 & $\$ 146,000$ & \multirow{6}{*}{$\begin{array}{l}\text { Present value calculation } \\
\text { Present value calculation }\end{array}$} \\
\hline Fence maintenance & $j, 000$ & If & \$o.so & 23,000 & \\
\hline Present value of monitoring costs & & & & 771,000 & \\
\hline Sublotal poutclosure costs (net present v & (alue) & & & $\$ 940,000$ & \\
\hline Centingency & & & $25 \%$ & 235,000 & \\
\hline \multicolumn{4}{|c|}{ NET PRESENT VALUE COST FOR POST-CLOSURE CARE [b] } & $\$ 1,175,000$ & \\
\hline \multicolumn{4}{|c|}{ TOTAL ALTERNATIVE COST (NET PRESENT VALUE) [C] } & $\$ 182,000,000$ & Rounded to millions \\
\hline
\end{tabular}


TABLE A-8. Cost Estimate for Alternative G - Excavation and Soil Washing with Vitrification.

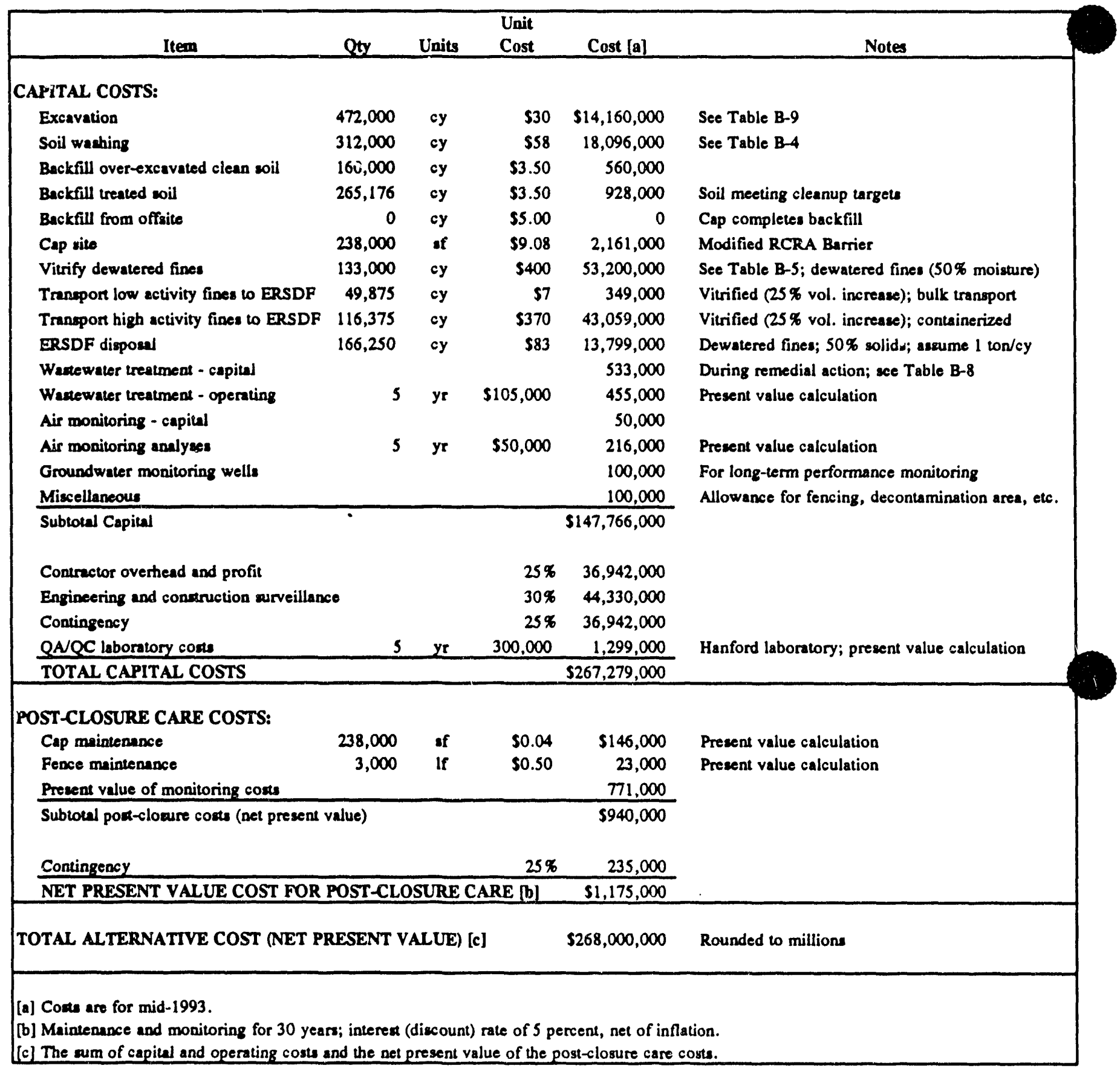


TABLE A-9. Cost Estimate for Alternative H - Excavation and Fixation.

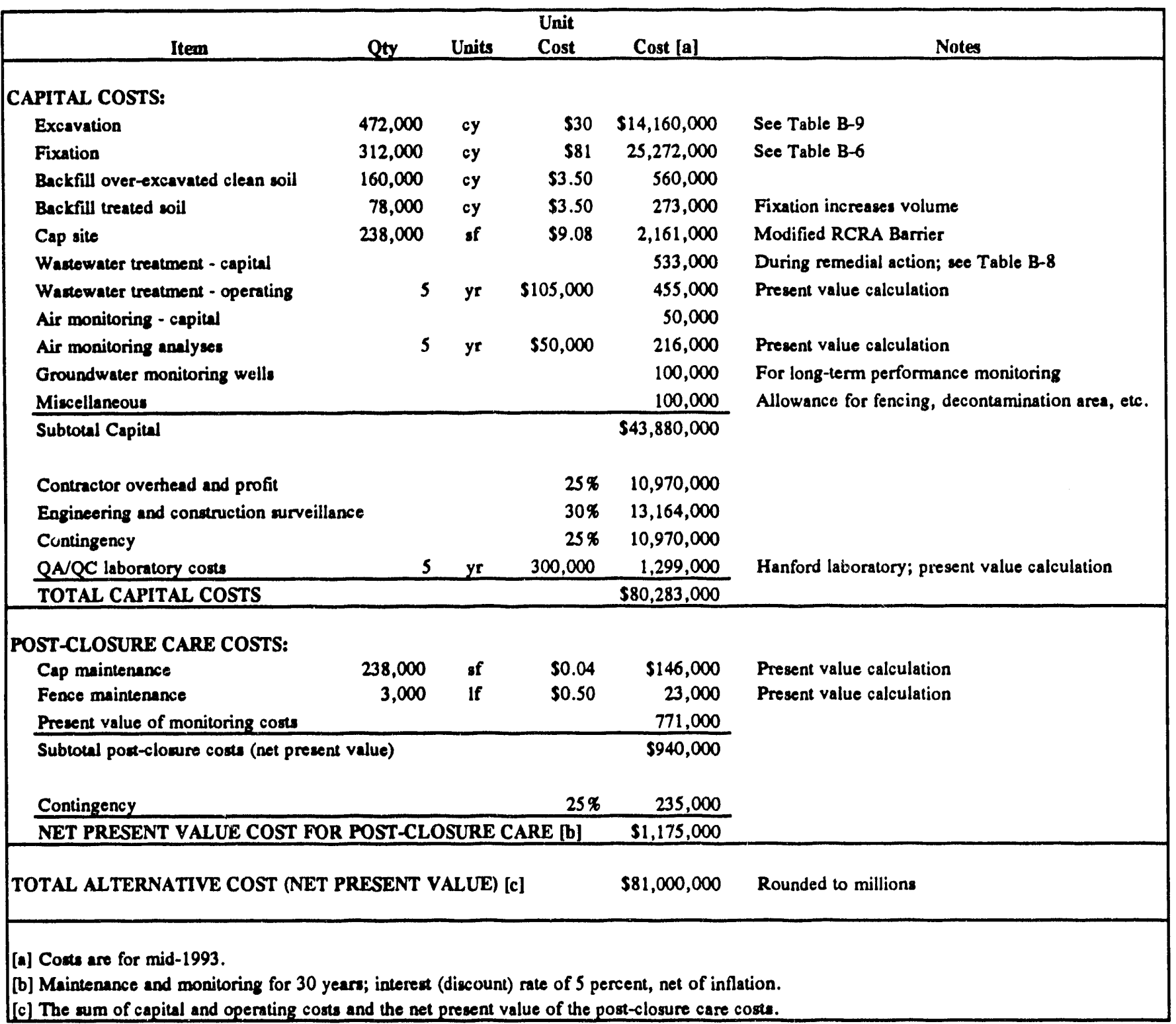


TABLE A-10. Cost Estimate for Alternative I - Excavation and ERSDF Disposal.

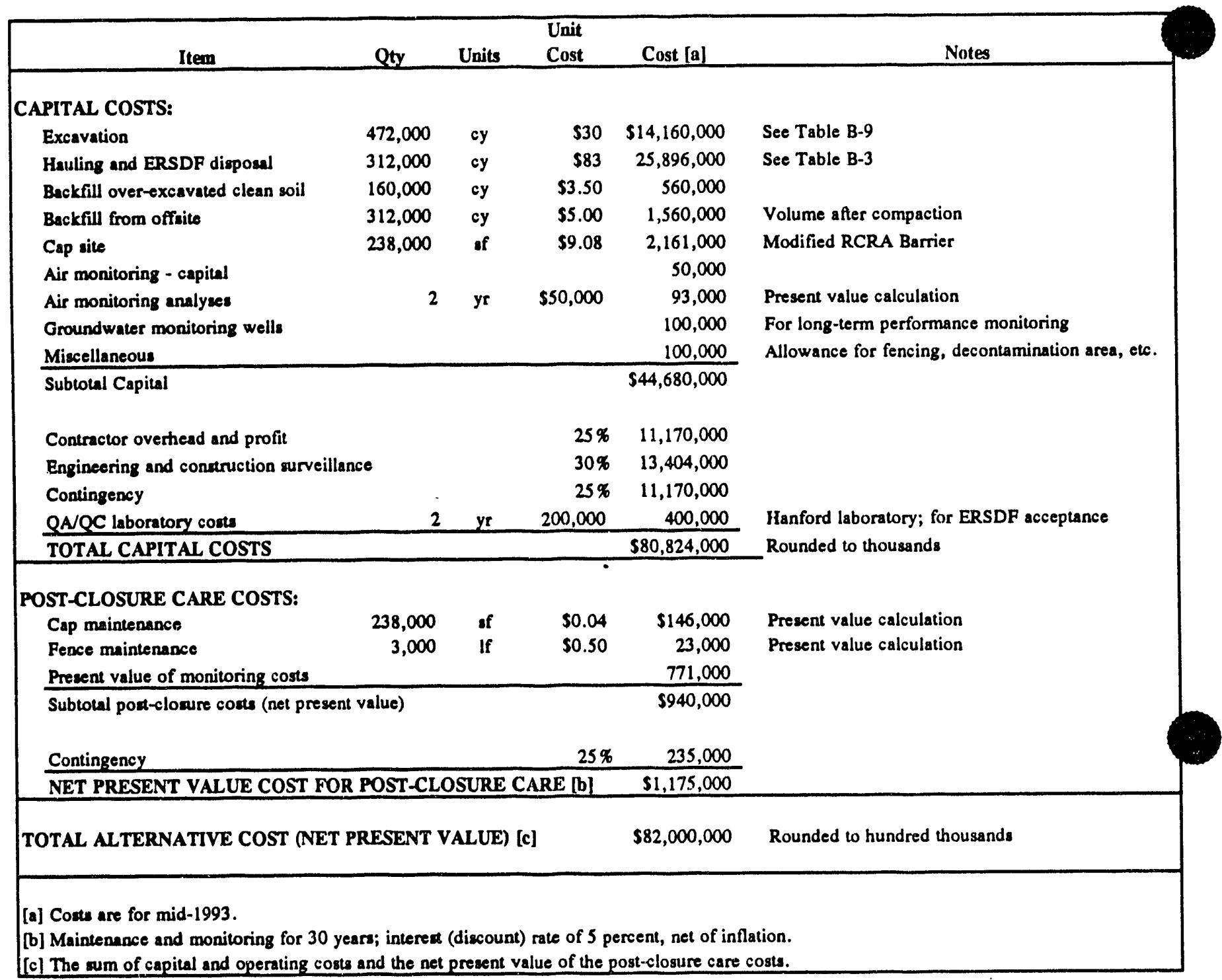


TABLE A-11. Cost Estimate for Alternative J - In-Situ Fixation.

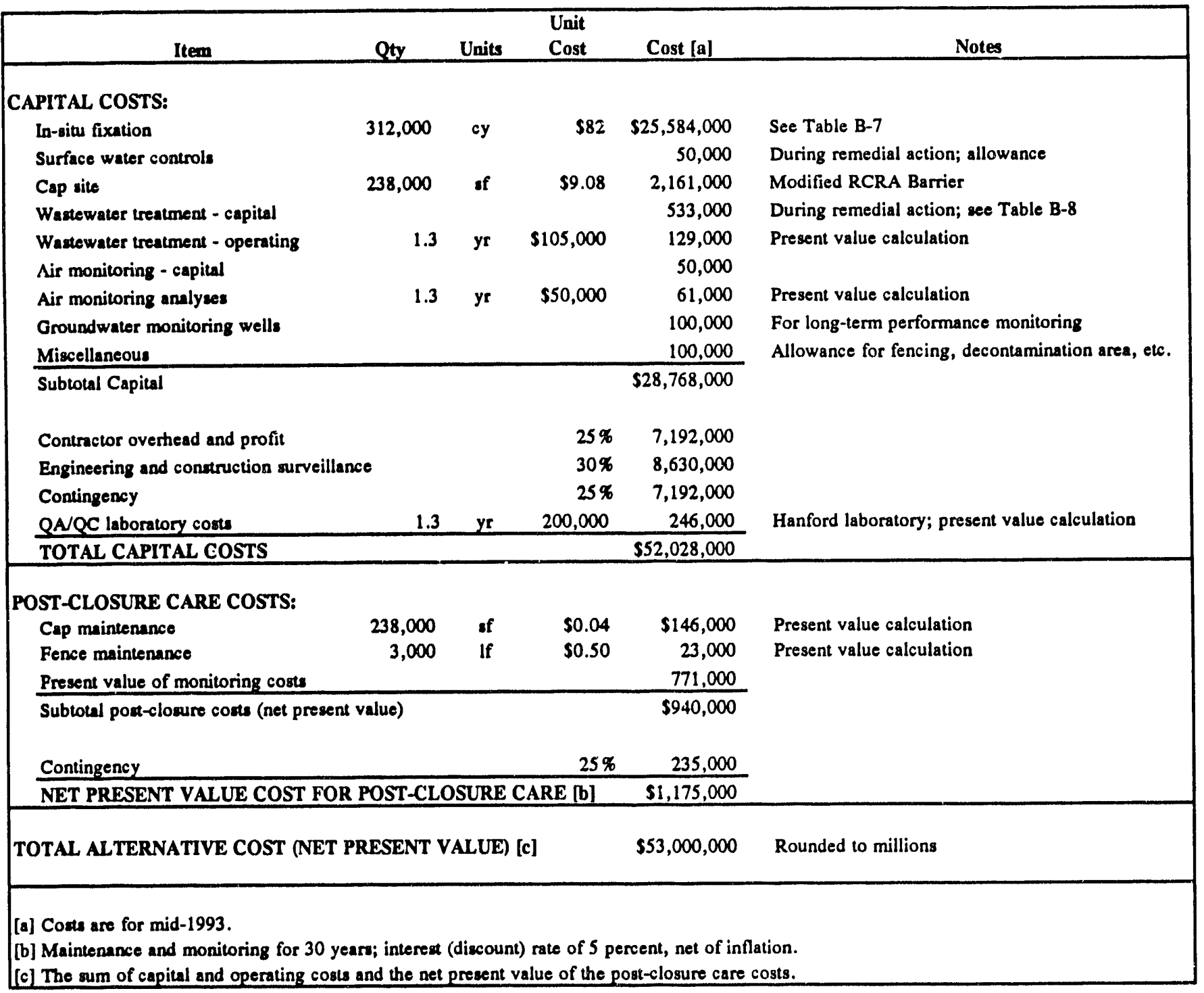


DOE/RL-93-35, Rev. 0

APPENDIX B

UNIT COSTS DERIVATIONS FOR REMEDIATION 
DOE/RL-93-35, Rev. 0

CONTENTS

\section{TABLES:}

B-1 Common Factors, Areas and Volumes $\ldots \ldots \ldots \ldots \ldots \ldots \ldots \ldots \ldots \ldots$

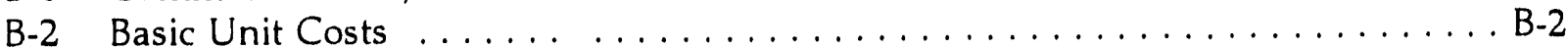

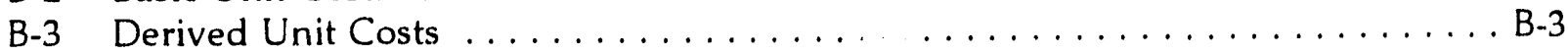

B-4 Estimated Costs for Soil Washing $\ldots \ldots \ldots \ldots \ldots \ldots \ldots \ldots \ldots \ldots \ldots \ldots$

B-5 Estimated Costs for Vitrification of Fines $\ldots \ldots \ldots \ldots \ldots \ldots \ldots \ldots \ldots \ldots \ldots$

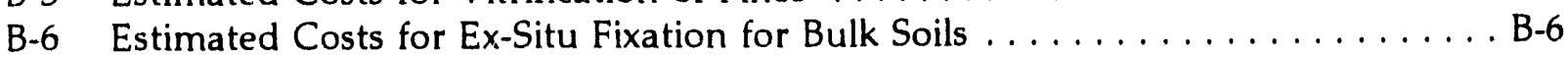

B-7 Estimated Costs for In-Situ Fixation $\ldots \ldots \ldots \ldots \ldots \ldots \ldots \ldots \ldots \ldots \ldots$

B-8 Estimated Costs for Wastewater Treatment $\ldots \ldots \ldots \ldots \ldots \ldots \ldots \ldots \ldots \ldots$ B-8

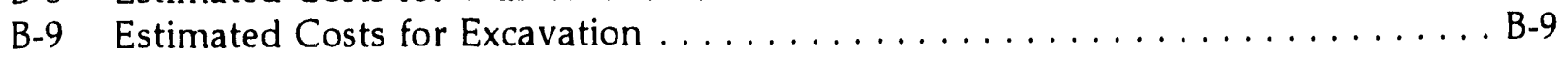


DOE\RL-93-35, Rev. 0

TABLE B-1. Common Factors, Areas and Volumes.

\begin{tabular}{|c|c|c|c|}
\hline Item & $\begin{array}{l}\text { Unit } \\
\text { Cost } \\
\end{array}$ & Units & Source/Comments \\
\hline Interest rate (net of inflation) & $5 \%$ & & EPA value; for present value calculations \\
\hline Post-closure care period & 30 & $\mathrm{yr}$ & \\
\hline Present value factor using above & 15.372451 & & Calculated \\
\hline Contractor overhead \& profit factor & $25 \%$ & & Extra for radioactive site \\
\hline Engineering \& construction surveillance & $30 \%$ & & Per Westinghouse (29\% rounded) \\
\hline Contingency & $25 \%$ & & Appropriate for FS \\
\hline Fence length & 3,000 & If & \\
\hline Retaining wall length & 800 & If & \\
\hline Cap area & 238,000 & sf & \\
\hline Total excavation volume & 472,000 & $\overline{c y}$ & \\
\hline Contaminated soil volume & 312,000 & cy & \\
\hline Soil density & 1.42 & ton/cy & \\
\hline Contaminated soil weight & 443,000 & ton & \\
\hline Fines fraction in place & $6 \%$ & & \\
\hline Contaminated fines after washing & $15 \%$ & & Effective separation \\
\hline Fines weight & 66,450 & dry ton & Assume negligible moisture \\
\hline Clean soil weight & 376,550 & & Treated soil for site backfill \\
\hline Clean soil volume & 265,176 & & Assume in-place density \\
\hline Solids content in dewatered fines & $50 \%$ & & \\
\hline Dewatered fines weight/vol & 133,000 & wet ton $=c y$ & \\
\hline Weight/volume increase due to solidification & $25 \%$ & & Applies to fixation and vitrification \\
\hline Fraction of low-activity contaminated fines & $30 \%$ & & \\
\hline Solidified fines weight/vol - total & 166,250 & wet ton $=c y$ & Bulk disposal \\
\hline Solidified fines weight/vol - low activity & 49,875 & wet ton $=c y$ & Containerized disposal \\
\hline Solidified fines weight/vol - high activity & 116,375 & wet ton $=\mathrm{cy}$ & \\
\hline
\end{tabular}


DOE/RL-93-35, Rev, 0

TABLE B-2. Basic Unit Costs.

\begin{tabular}{|c|c|c|c|}
\hline Item & $\begin{array}{l}\text { Unit } \\
\text { Cost } \\
\end{array}$ & Units & $\begin{array}{c}\text { Source/Comments } \\
\end{array}$ \\
\hline SITE WORK (abor, materials and equipment): & & & Not including contractor overhead \& profit \\
\hline \multicolumn{4}{|l|}{ Excavation/Placement: } \\
\hline Soil placement (incl. normal compaction) & $\$ 3.50$ & cy & Estimate from sile experience \\
\hline Revegetation & So.08 & sf & Hydromulching \\
\hline \multicolumn{4}{|l|}{ Waste treatment/disposal: } \\
\hline Solidification & $\$ 40$ & cy & Estimate based on past vendor quotes \\
\hline Haul low-activity soil/wante to ERSDF & $\$ 7$ & cy & Bulk \\
\hline Haul high-activity soil/waste to ERSDF & $\$ 370$ & cy & $1.5 \times$ bulk haul +90 cf container $\$ \$ 1200$ \\
\hline \multicolumn{4}{|l|}{ Maintenance: } \\
\hline Fence maintenance & \$0.50 & If-yr & Allowance \\
\hline Waste site cap maintenance & So.04 & sf-yr & Allowance, including construction surveillance \\
\hline \multicolumn{4}{|l|}{ Materials (in place, including normal compaction): } \\
\hline Silty soil & $\$ 10$ & cy & McGee ranch; Westinghouse estimate (rounded) \\
\hline Silty soil with gravel admix & $\$ 12$ & cy & Westinghouse estimate (rounded) \\
\hline Sand, filter & $\$ 14$ & cy & Westinghouse estimate (rounded) \\
\hline Gravel, filter & $\$ 10$ & cy & Westinghouse estimate (rounded) \\
\hline Gravel, drainage & $\$ 10$ & cy & Westinghouse estimate (rounded) \\
\hline Gravel, rand & $\$ 10$ & cy & Westinghouse estimate (rounded) \\
\hline Basalt, crushed & $\$ 21$ & cy & Westinghouse estimate (rounded) \\
\hline Asphaltic concrete & $\$ 80$ & cy & Westinghoure estimate (rounded) \\
\hline Aephalt conting & $\$ 3$ & sf & Westinghouse estimate (rounded) \\
\hline Asphalt tisse & $\$ 16$ & cy & Westinghouse estimate (rounded) \\
\hline Gravel, pea & $\$ 15$ & cy & Golder estimate \\
\hline Clean fill & $\$ 5$ & cy & Golder estimate \\
\hline Clay, low permeability & $\$ 15$ & cy & Golder estimate \\
\hline Geotextile & \$0.30 & sf & Golder estimate \\
\hline Geonet drainage layer & $\$ 0.50$ & sf & Golder estimate \\
\hline HDPE liner, $60 \mathrm{mil}$ & $\$ 0.85$ & sf & Golder estimate \\
\hline Fencing & $\$ 12.70$ & If & Means 1991; 6-ft fence w/ 3-strand barbed wire \\
\hline Retaining wall for excavation & $\$ 48$ & sf & Golder estimate \\
\hline \multicolumn{4}{|l|}{ General construction: } \\
\hline Shielded concrete building & $\$ 375$ & of & \\
\hline Office building & $\$ 85$ & sf & \\
\hline Temporary structure cover & $\$ 20$ & sf & Estimate from vendor quotes \\
\hline \multicolumn{4}{|c|}{$\begin{array}{l}\text { TREATMENT PLANT LABOR, EQUIPMENT AND MATERIALS: } \\
\text { Labor: }\end{array}$} \\
\hline Plant manager & $\$ 80$ & hr & Estimate \\
\hline Supervisor & $\$ 60$ & hr & Estimate \\
\hline Operator (plant or equipment) & $\$ 40$ & hr & Estimate \\
\hline Laborer/operator helper & $\$ 30$ & hr & Estimate \\
\hline Clerical & $\$ 35$ & hr & Estimate \\
\hline \multicolumn{4}{|l|}{ Equipment: } \\
\hline Backhoe/loader & $\$ 150,000$ & each & \\
\hline \multicolumn{4}{|l|}{ Utilities and Chemicals: } \\
\hline Electricity & \$0.06 & kwh & Typical for northwest region \\
\hline Soda ash & $\$ 180$ & ton & Estimate (\$200/metric ton) \\
\hline Cement & $\$ 80$ & ton & Estimate (\$88/metric ton) \\
\hline Fly ash & $\$ 35$ & ton & Estimate ( $\$ 39 /$ metric ton) \\
\hline \multicolumn{4}{|l|}{ OTHER: } \\
\hline Air monitoring capital costs & $\$ 50,000$ & LS & Sampling station \\
\hline Annual air monitoring costs & $\$ 50,000$ & yr & During remedial action; allowance \\
\hline Mircellaneous remedial action costs & $\$ 100,000$ & LS & Allowance for fencing, decontamination area, lighting, etc. \\
\hline Groundwater monitoring wells & $\$ 100,000$ & LS & Installation of 4 for long-term monitoring \\
\hline Annual monitoring costs - initial & $\$ 50,000$ & yr & Allowance \\
\hline Annual monitoring couts - after 5 years & $\$ 25,000$ & $\mathbf{y r}$ & Allowance \\
\hline Performance review (every 5 years) & $\$ 100,000$ & each & Allowance \\
\hline Present value of long-term monitoring costs & $\$ 771,000$ & LS & Assuming 30 years @ 5\% net interest; includes 5-yr reviews \\
\hline
\end{tabular}


TABLE B-3. Derived Unit Costs.

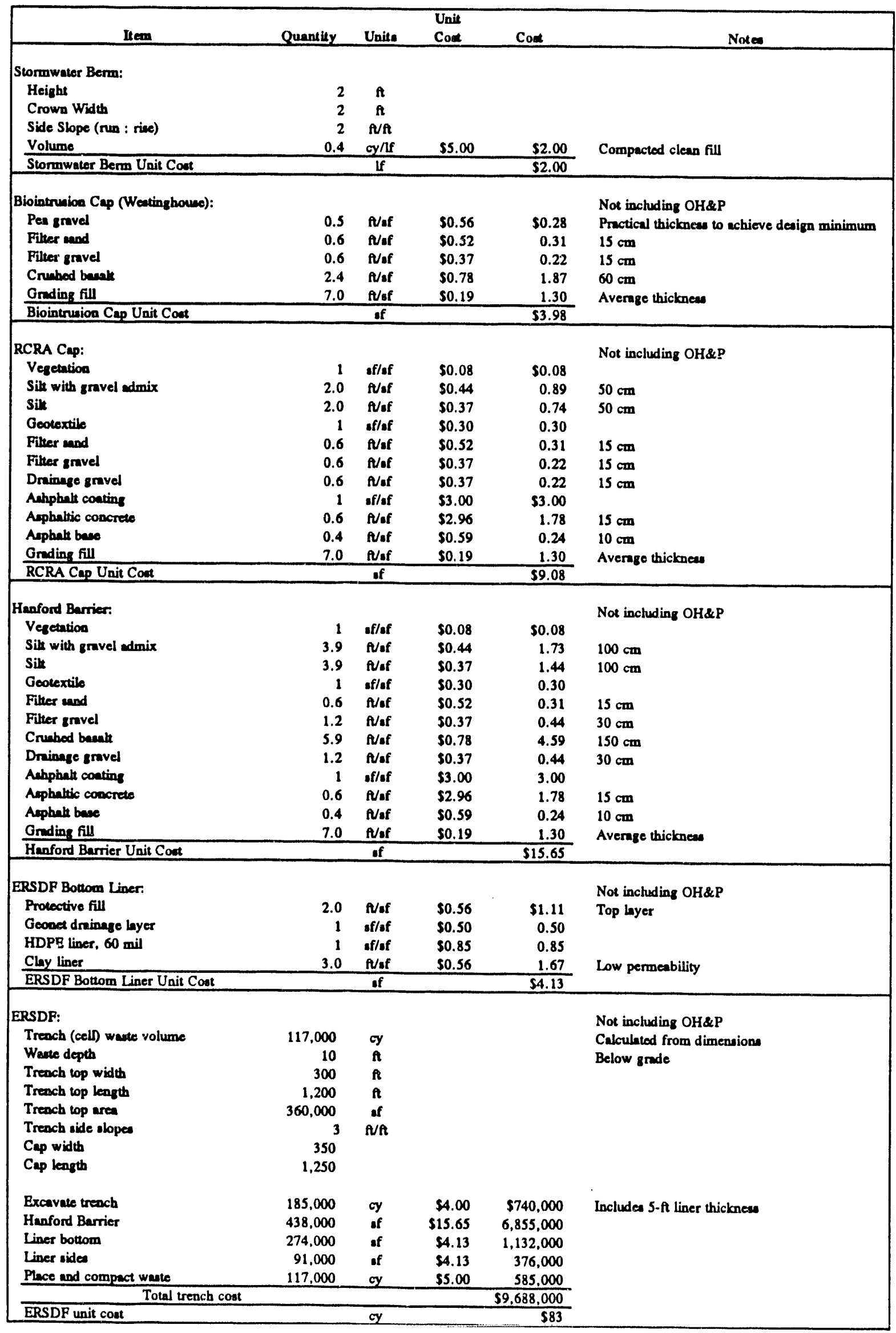


DOE/RL-93-35, Rev. 0

TABLE B-4. Estimated Costs for Soil Washing.

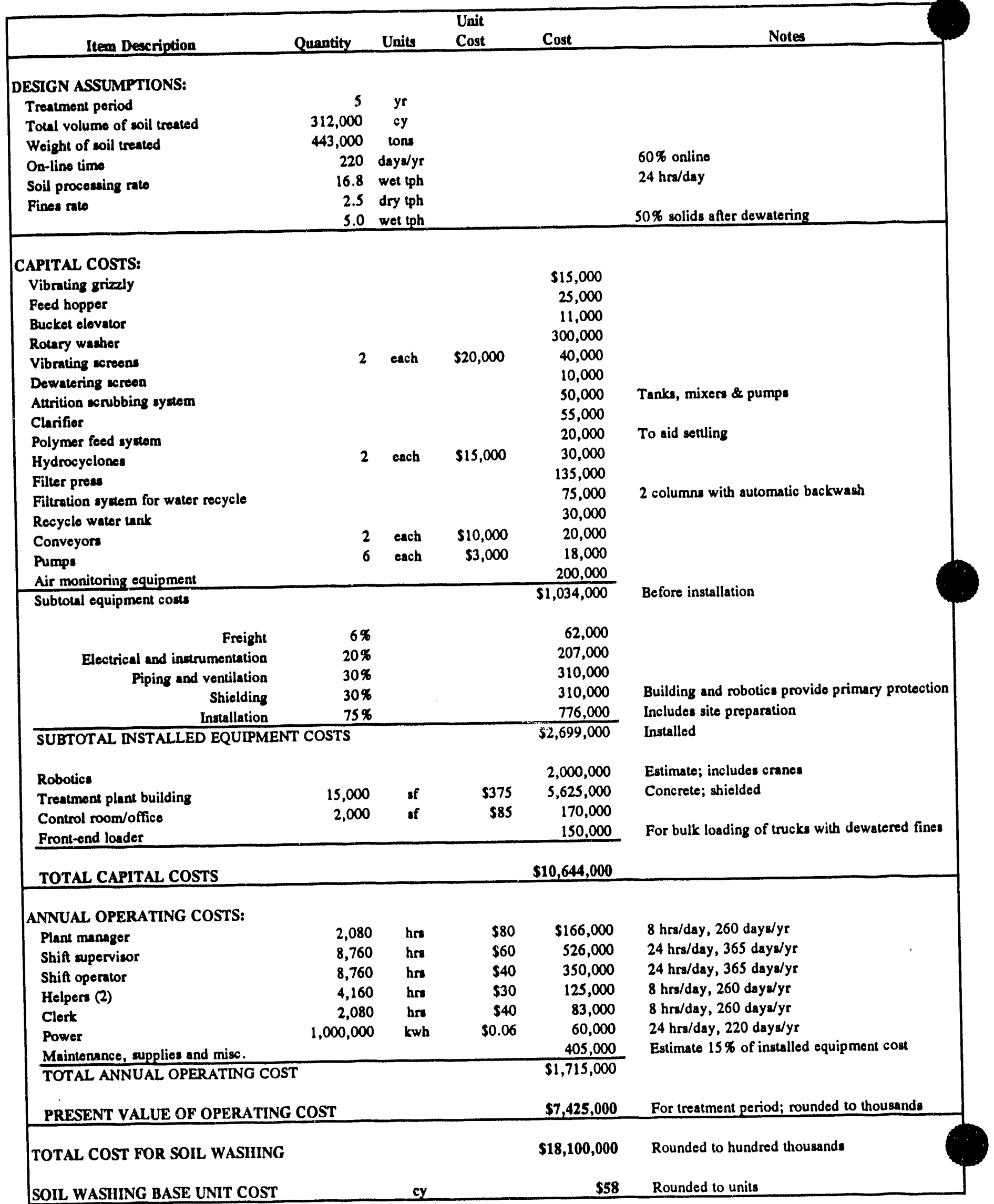


TABLE B-5. Estimated Costs for Vitrification of Fines

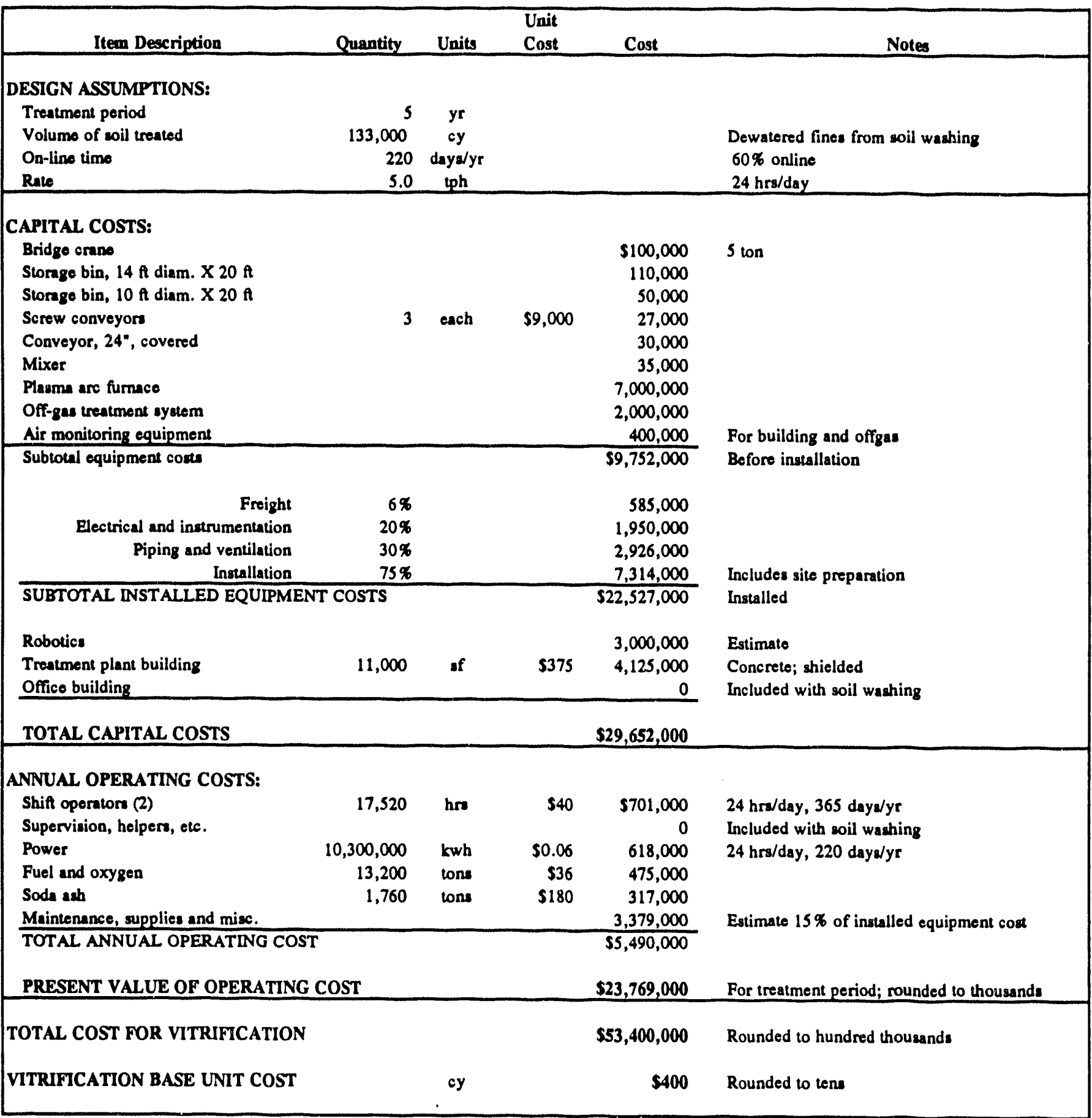


TABLE B-6. Estimated Costs for Ex-Situ Fixation of Bulk Soils

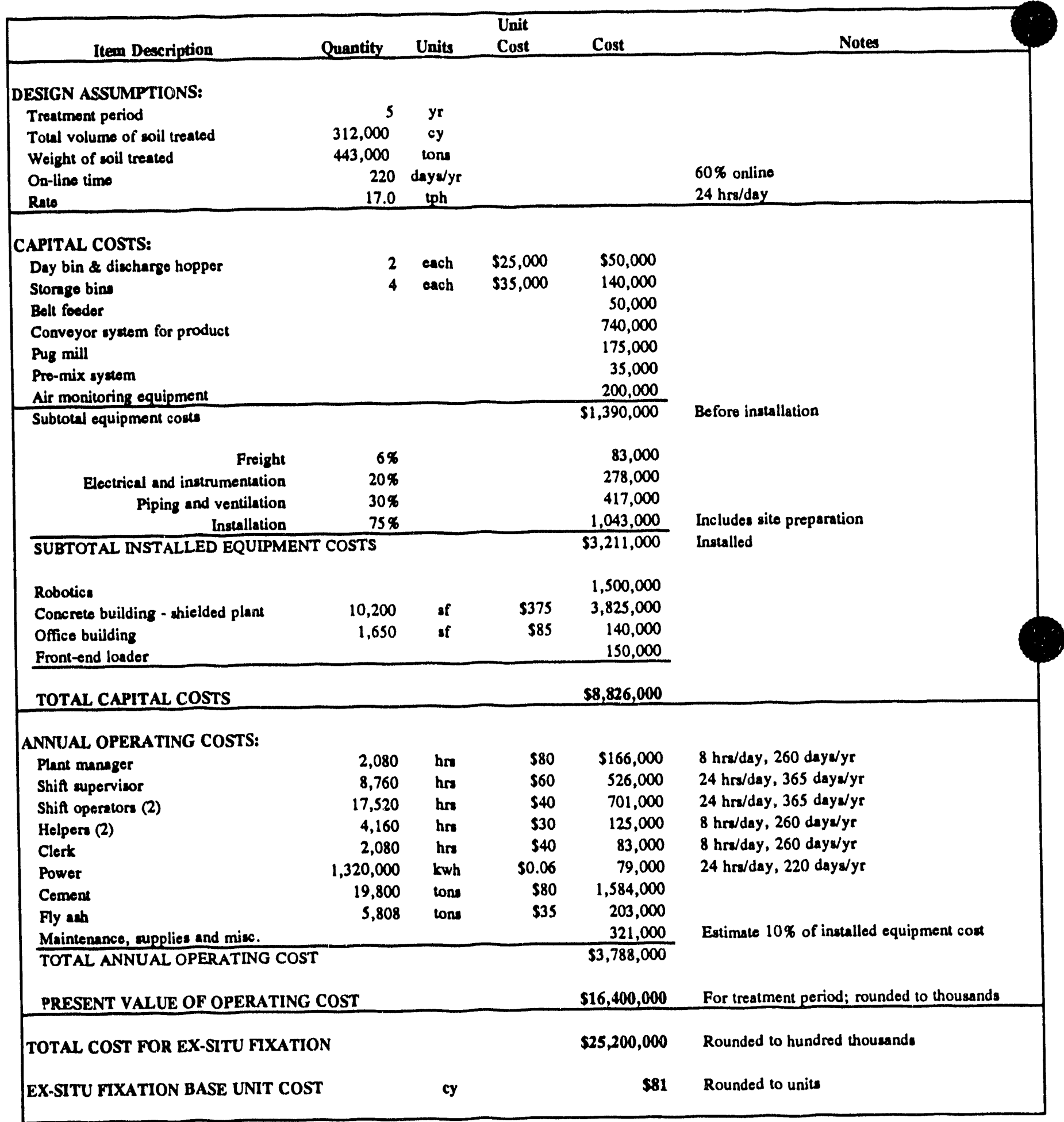


DOE/RL-93-35, Rev. 0

TABLE B-7. Estimated Costs for In-Situ Fixation

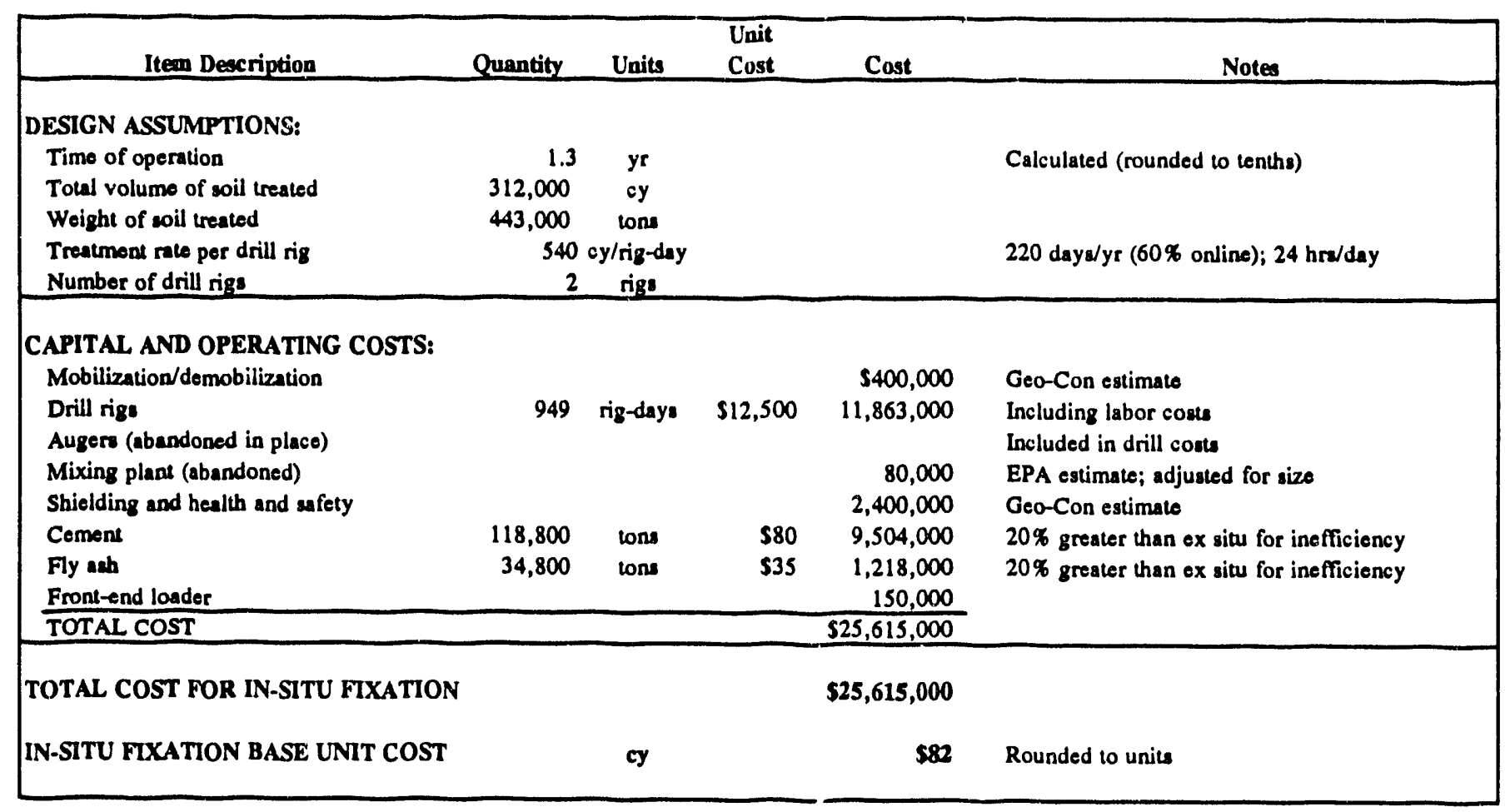


DOF/RL-93-35, Rev. 0

TABLE B-8. Estimated Costs for Wastewater Treatment

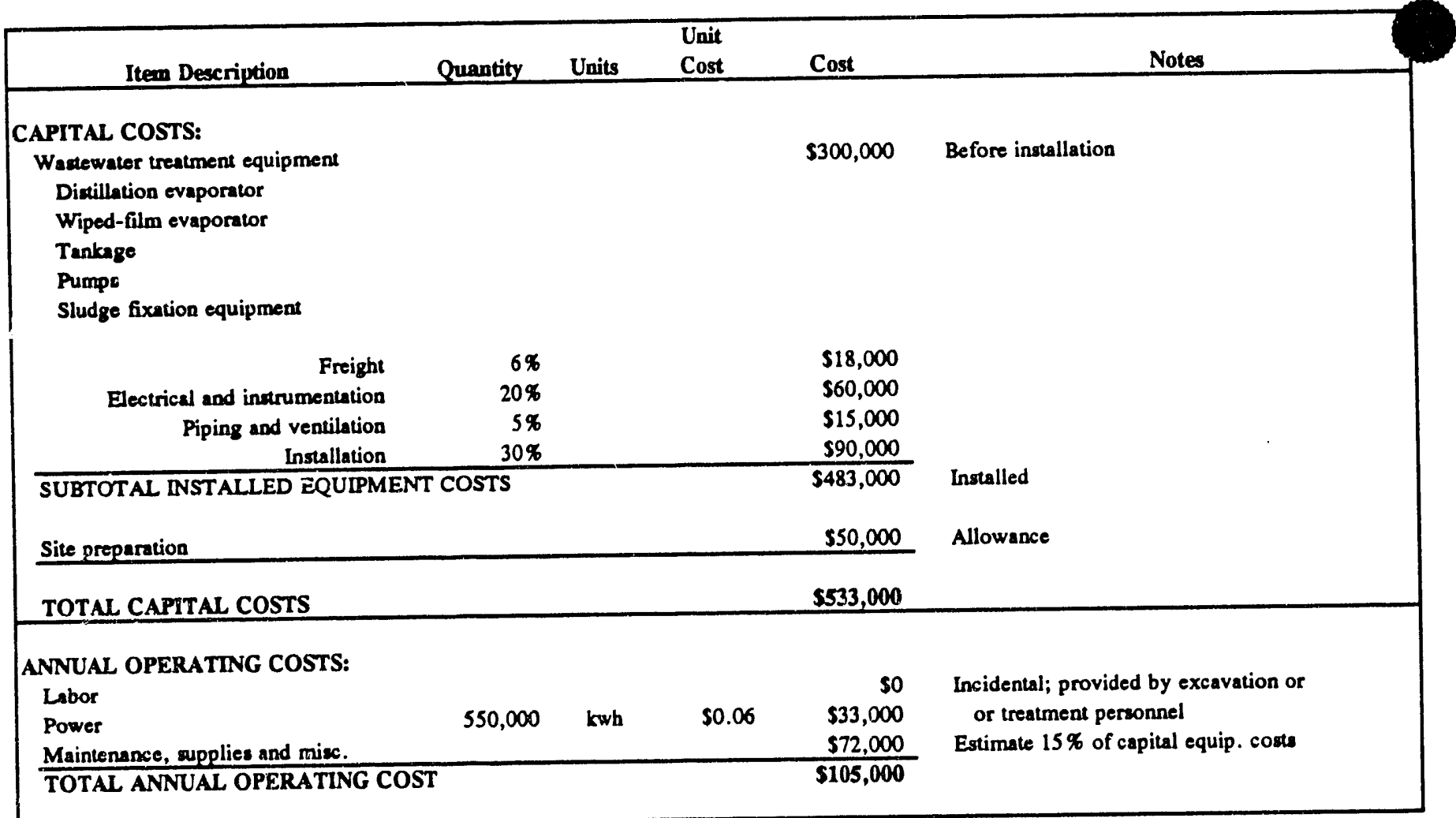


DOE/RL-93-35, Rev. 0

TABLE B-9. Estimated Costs for Excavation

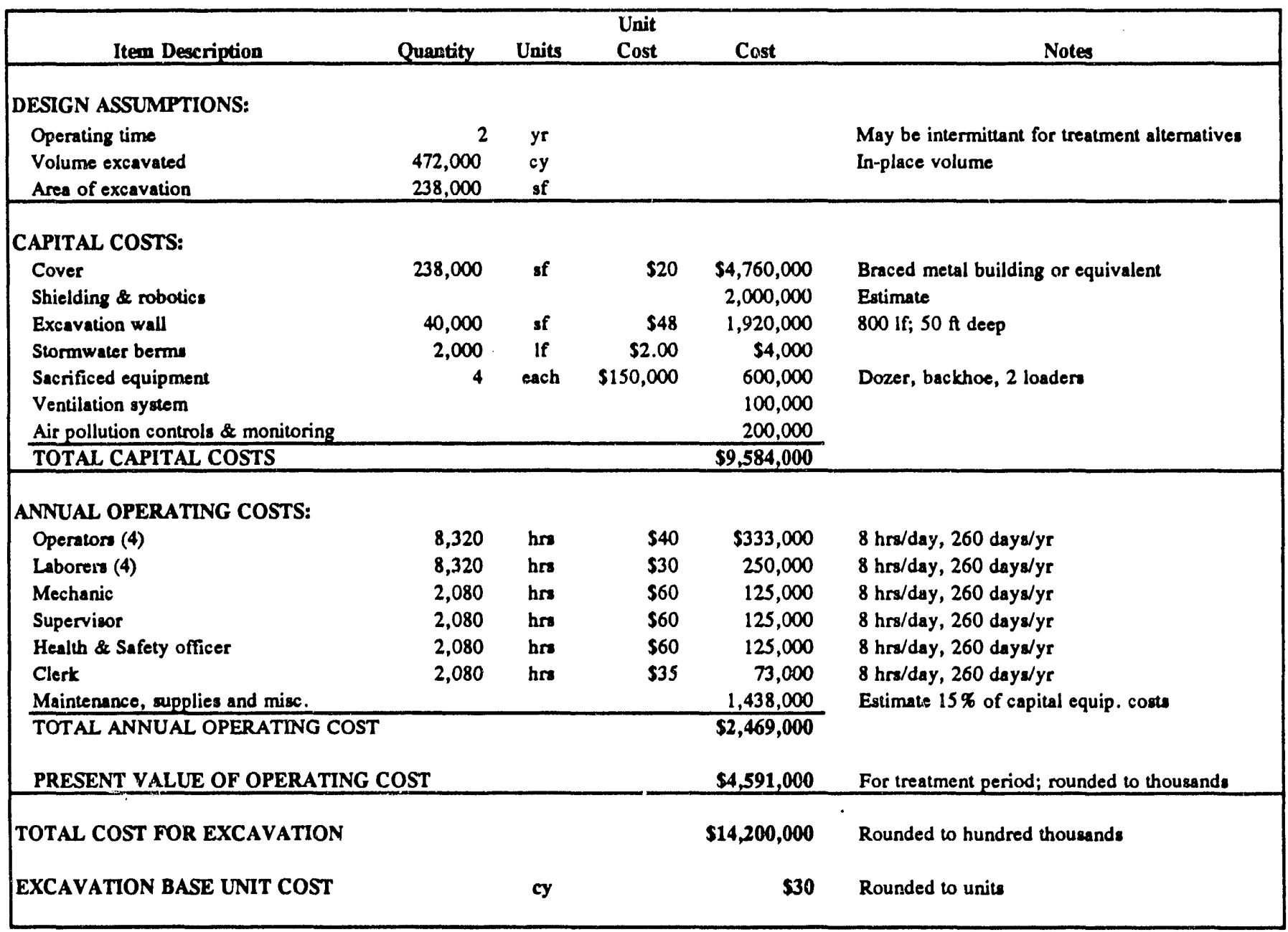


DOE/RL-93-35, Rev. 0

\section{DISTRIBUTION}

Number of Copies

Onsite

31

1

48
U.S. Department of Energy. Richland Field Office

J. K. Erickson (30)

A5-19

Public Reading Room

A $1-65$

Pacific Northwest Laboratory

Hanford Technical Library

P8-55

Westinghouse Hanford Company

L. D. Arnold

B2-35

M. A. Buckmaster

EDMC (7)

ERC (G. Fitzgibbon)

ERE (F. Stone) (2)

ERE Project File

ER Program Office (2)

IRA (3)

Resource Center
H6-03

H6-08

H6-07

H6-01

H6-03

H6-27

H4-17

N3-05 

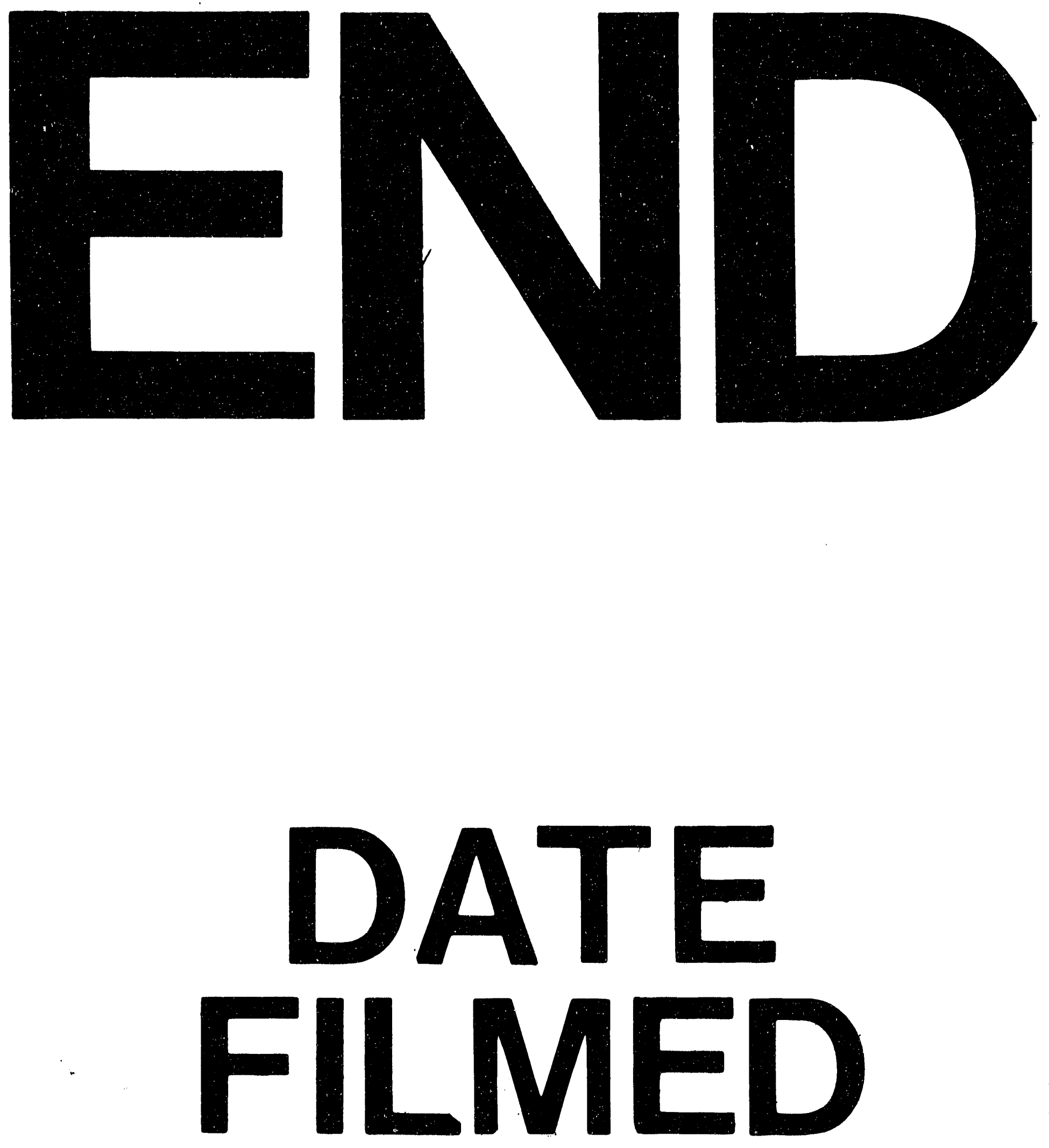

1

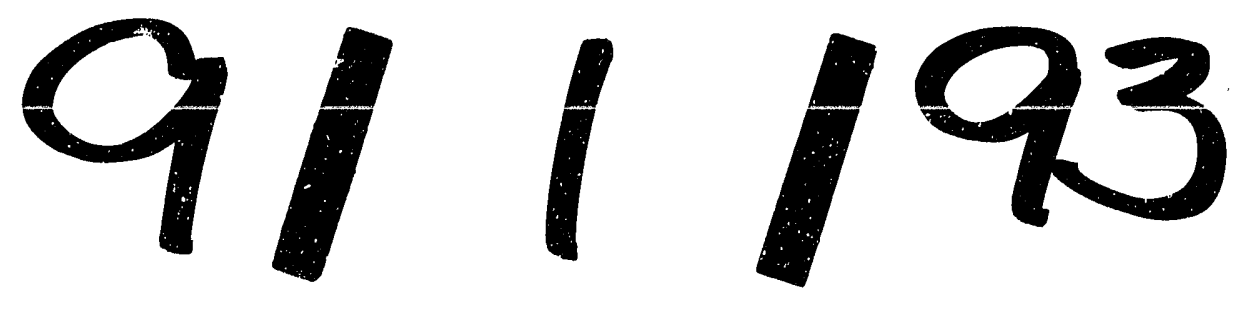


4 